\title{
Neuroaxonale Schädigung in experimentellen Modellen der multiplen Sklerose
}

\author{
DISSERTATION \\ zur Erlangung des mathematisch-naturwissenschaftlichen Doktorgrades \\ „Doctor rerum naturalium“ \\ der Georg-August-Universität Göttingen
}

vorgelegt von

Angelika Escher

aus

Augsburg

Göttingen 2008 
D 7

Referent:

Professor Dr. Detlef Doenecke

Korreferent:

Professor Dr. Tomas Pieler

Tag der mündlichen Prüfung:

26.06.2008 


\section{Inhaltsverzeichnis}

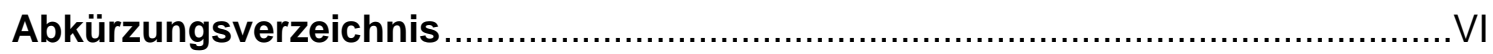

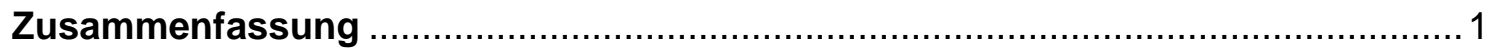

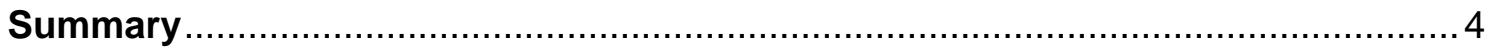

\section{Einleitung}

$1.1 \quad$ Epidemiologie und Verlaufsformen der multiplen Sklerose .................... 6

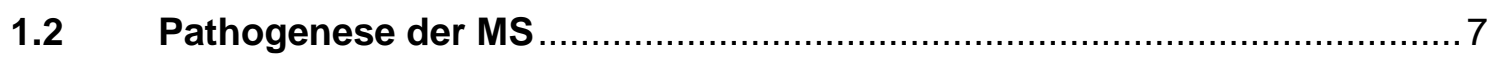

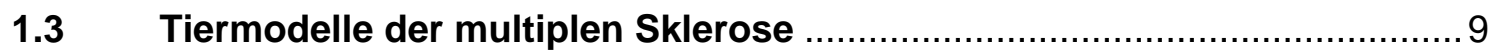

1.3.1 Experimentelle autoimmune Enzephalomyelitis.......................................... 9

1.3.2 Toxin-induzierte Entmarkung durch Cuprizon ........................................ 11

1.4 Aktivierung von Makrophagen und Mikrogliazellen ................................ 13

1.4.1 Allgemeines zur Makrophagen/Mikrogliaaktivierung ................................... 13

1.4.2 Expression aktivierungsabhängig regulierter Gene .................................. 14

1.4.2.1 S100A9/MRP14 - ein damage-associated molecular pattern Protein .............. 15

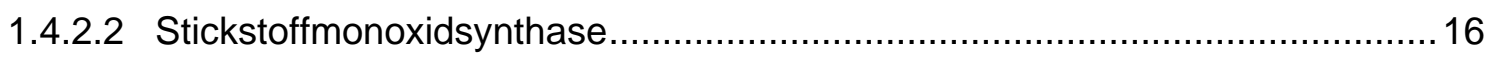

1.4.2.3 CD163 - ein makrophagenspezifisches Protein .......................................... 17

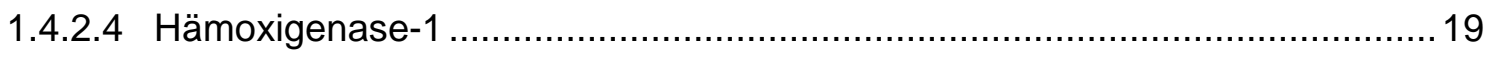

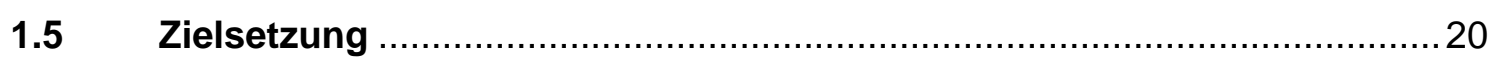

\section{Material und Methoden}

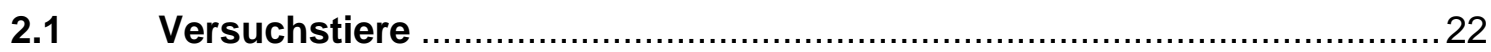

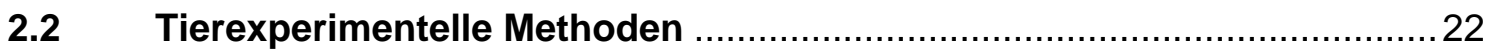

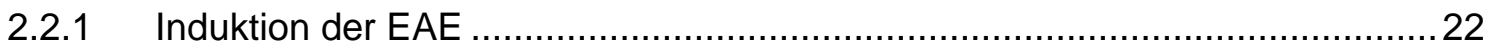

2.2.1.1 Herstellung der $\mathrm{MOG}_{35-55}$-Emulsion und Induktion der EAE in Mäusen..........22

2.2.1.2 Herstellung der $\beta$-Synuklein ${ }_{93-111}$-Emulsion, Induktion der EAE und der Transfer von Antikörpern .................................................... 23

2.2.1.3 Klinische Beurteilung der EAE bei Mäusen und Ratten .................................. 24

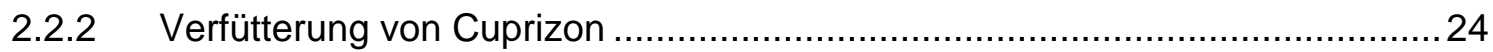

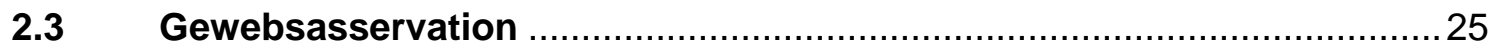


2.3.1 Transkardiale Perfusion mit Paraformaldehyd (PFA) und die Einbettung

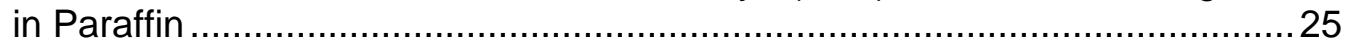

2.3.2 HOPE-Fixierung und Einbettung in Paraffin........................................... 25

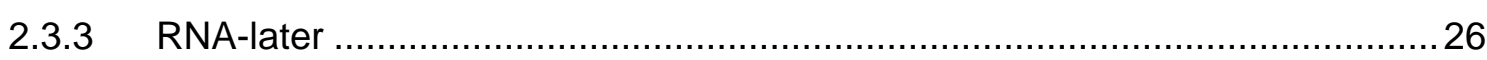

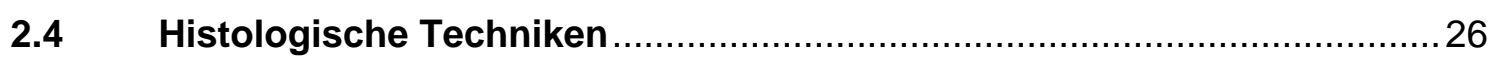

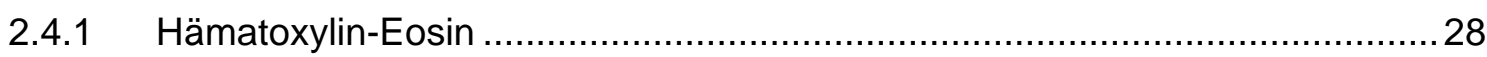

2.4.2 Luxol-fast-blue / Perjodsäure-Schiff'sche Reagenz (LFB/PAS) Färbung .......29

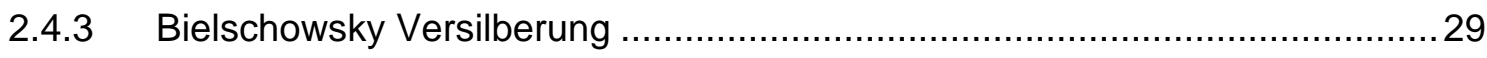

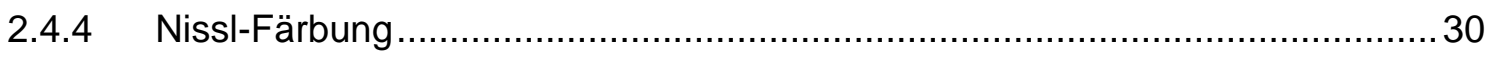

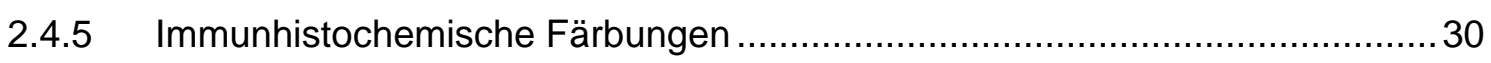

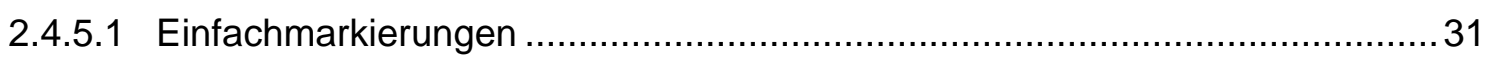

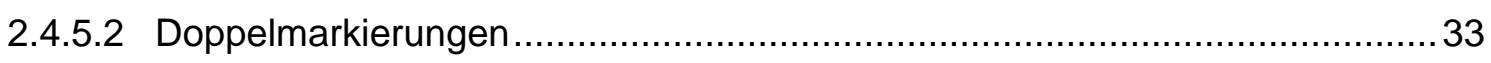

2.4.5.2.1 Doppelmarkierungen, mit zwei Primärantikörpern aus unterschiedlichen

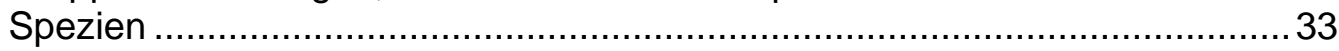

2.4.5.2.2 Doppelmarkierungen, mit zwei Primärantikörpern aus der gleichen Spezie.. 33

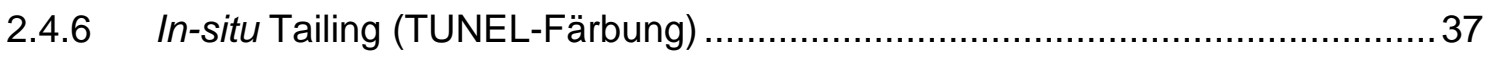

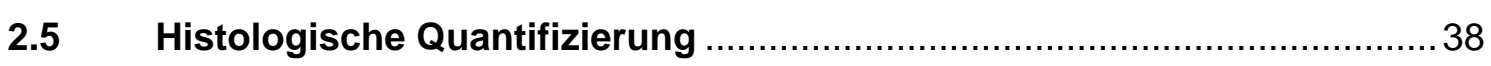

2.5.1 Quantifizierung der Infiltrate in den Rückenmarksquerschnitte der

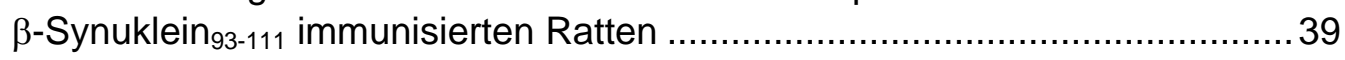

2.5.2 Quantifizierung der Infiltrate im Gehirn von Cuprizon-EAE-Mäusen ................ 39

2.6 Enzyme-linked immunosorbent assay (ELISA) ................................. 40

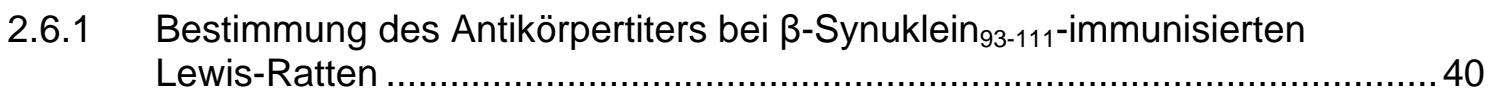

2.6.2 Bestimmung des Antikörperkonzentration des aufgereinigten anti-MOG

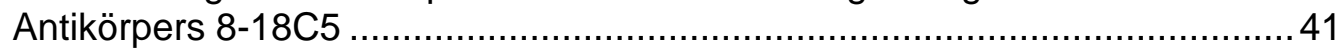

2.7 Isolierung und Stimulation von T-Lymphozyten aus Lymphknoten ........ 41

2.8 Produktion und Aufreinigung des anti-MOG-Antikörpers 8-18C5 ........... 42

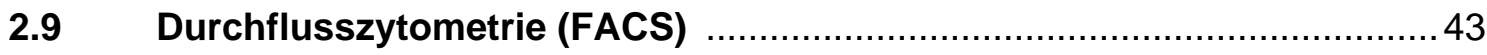

2.9.1 Isolierung der Zellen aus dem Gewebe ................................................. 43

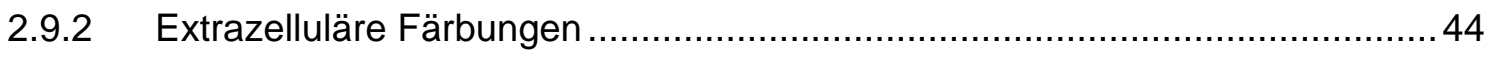

2.10 Molekulargenetische Methoden ................................................... 45

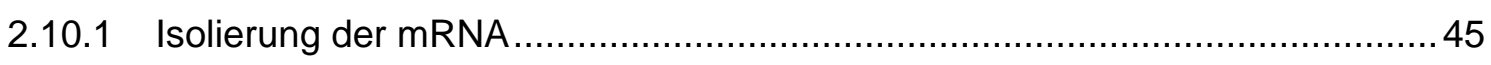

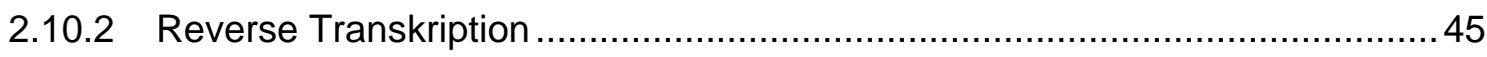

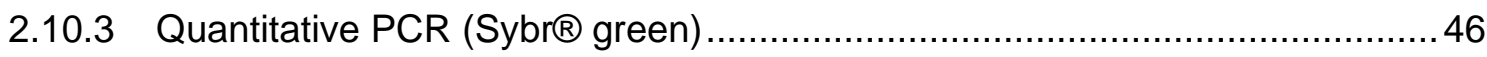

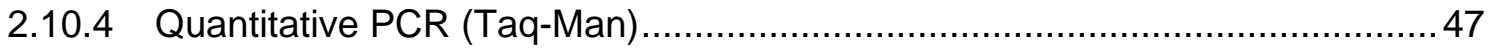

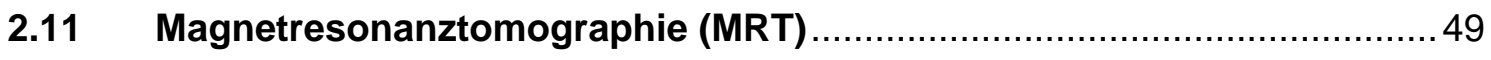

2.11.1 Vorbereitung für die Messungen ..................................................... 49

2.11.2 Messung der Blut-Hirn-Schranken-Permeabiltät....................................... 49 


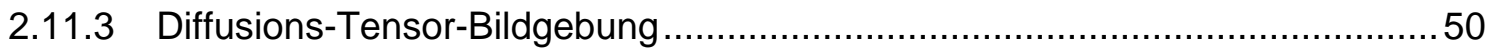

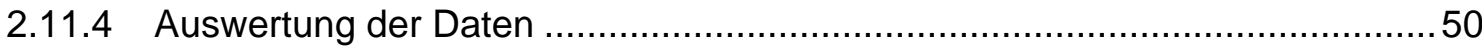

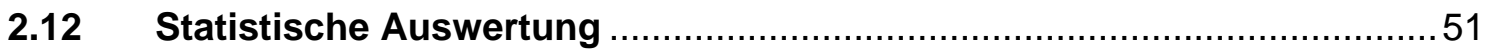

\section{Ergebnisteil I}

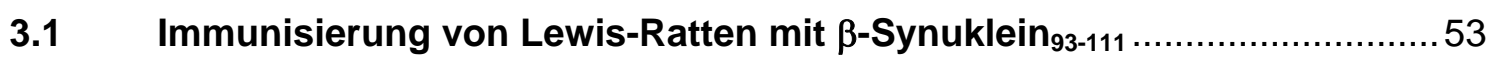

3.1.1 Immunisierung mit $\beta$-Synuklein ${ }_{93-111}$ führte zu einer selektiven Entzündung in der grauen Substanz

3.2 Der Transfer des anti-MOG Antikörpers 8-18C5 induzierte entmarkte Läsionen in der grauen Substanz ....................................................... 55

3.2.1 Histologische Auswertung der entzündlichen Infiltrate .................................56

3.2.1.1 Infiltration von T-Zellen und Makrophagen/Mikroglia in die graue Substanz ..56

3.2.1.2 Ein Fehlen CD8-positiver Zellen hatte keinen Einfluss auf den Krankheitsverlauf der $\beta$-Synuklein-EAE 58

3.3 Eine Schädigung der Axone erfolgte hauptsächlich in entmarkten

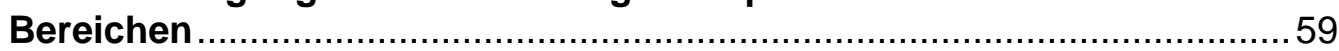

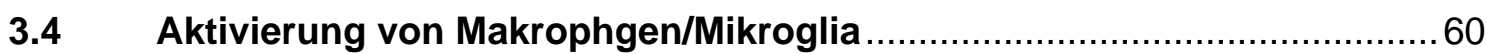

3.4.1 Mehr iNOS-exprimierende Makrophagen/Mikroglia in Ratten mit Entmarkung 60

3.4.2 Makrophagen/Mikroglia in rein entzündlicher Umgebung exprimierte mehr CD163

3.4.3 Hämoxigenase-1 wurde in Ratten ohne Entmarkung vermehrt exprimiert

3.5 Auswirkungen der Entzündung auf die Nervenzellen

3.5.1 Entzündung und Entmarkung führten zu einer vermehrten Transkription von cJun.

3.5.2 Entzündung und Entmarkung in der grauen Substanz führten nicht zum neuronalen Zelltod 65

3.6 Infiltration von Makrophagen/Mikroglia führte zur Reduktion Synaptophysin-positiver Strukturen 68

\section{Ergebnisteil II}

4.1 Entwicklung eines Mausmodells mit MS-ähnlichen Läsionen im Gehirn

4.2 Optimaler Immunisierungszeitpunkt von Cuprizon-behandelten Mäusen 
4.2.1 Cuprizon- induzierte Genexpression. 70

4.2.2 Immunisierung von Mäusen nach unterschiedlich langer Cuprizon-Behandlung

4.3 Charakterisierung der entzündlichen Infiltrate in Balken und Kortex......75

4.3.1 Infiltration von T-Zellen in das Corpus callosum und den Kortex nach

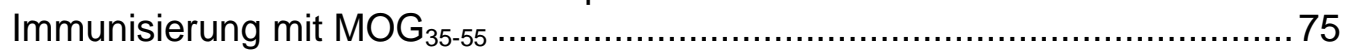

4.3.2 Verstärkte Aktivierung von Makrophagen/Mikroglia bei Entzündung ..............78

4.4 Axonschaden nach der Infiltration von T-Zellen und Makrophagen .........82

4.5 Vergleichbare Effizienz der Remyelinisierung in Tieren mit und ohne Entzündung .....

4.5.1 Histologische Quantifizierung der Remyelinisierung ....................................84

4.5.2 Expressionsanalyse von oligodendrogliaspezifischen Genen .......................86

4.6 Magnetresonanztomographische Analyse von Entzündung und Entmarkung im Modell der Cuprizon-EAE

4.6.1 Verminderte Integrität der Blut-Hirn-Schranke nach Immunisierung..... 90

4.6.2 Nachweis der axonalen Schädigung durch die Diffusions-

Tensor-Bildgebung....

\section{Diskussion}

5.1 Pathogenese von Läsionen in der grauen Substanz

5.1.1 Läsionen in der grauen Substanz des Rückenmarks und des Gehirns nach Immunisierung mit $\beta$-Synuklein ${ }_{93-111}$

5.1.2 Entmarkte Läsionen in der grauen Substanz nach anti-MOG-Antikörpertransfer

5.1.3 Histologische Unterschiede zwischen der rein entzündlichen und der entzündlich-entmarkenden $\beta$-Synuklein-EAE .

5.1.3.1 Vermehrte Aktivierung der Makrophagen/Mikroglia in demyelinisierten Läsionen

5.1.4 CD8-defiziente Ratten zeigten nach Immunisierung mit ß-Synunklein ${ }_{93-111}$ einen vergleichbaren Krankheitsverlauf .................................................. 101

5.1.5 Vermehrter axonaler Schaden durch Demyelinisierung............................... 102

5.1.6 Neuronale cJun-Expression in der akuten Phase der $\beta$-Synuklein-EAE .....103

5.1.7 Kein Nervenzellverlust durch Entzündung in der grauen Substanz .............. 104

5.1.8 Verlust Synaptophysin-positiver Strukturen ............................................. 107

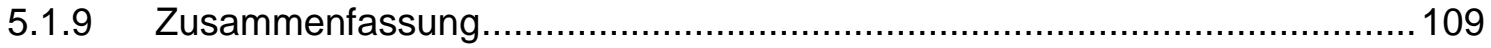


5.2 Cuprizon-EAE, ein neues Modell mit MS-ähnlichen Läsionen im Mausgehirn.

5.2.1 Infiltration von Entzündungszellen in vorgeschädigtes Gehirngewebe durch myelinspezifische T-Zellen

5.2.2 Infiltration von Entzündungszellen in das Mausgehirn über eine geöffnete Blut-Hirn-Schranke

5.2.3 Axonale Schädigung im Mausgehirn nach T-Zell- und Makrophageninfiltration

5.2.4 Expression von iNOS und S100A9 in monozytären Zellen nach Immunisierung mit $\mathrm{MOG}_{35-55}$

5.2.5 Proinflammatorische Zytokine hemmen die Expression von HO-1 und CD163

5.2.6 Entzündung hat keinen Einfluß auf Geschwindigkeit und Ausmaß der Remyelinisierung

5.2.7 Entzündung und Entmarkung verändern die Anisotropie bei der Diffusions-Tensor-Bildgebung

5.2.8 Zusammenfassung. 125

\section{Literaturverzeichnis}

\section{Anhang}

7.1 Danksagung . 158

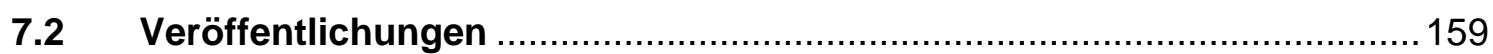

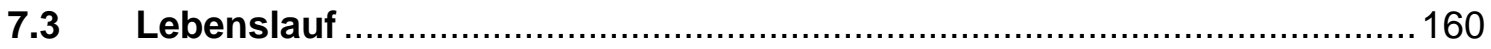




\section{Abkürzungsverzeichnis}

\begin{tabular}{|c|c|}
\hline$\beta-\mathrm{A} 4$ & amyloid-beta A4 precursor protein \\
\hline$\mu \mathrm{g}$ & Mikrogramm \\
\hline Abb. & Abbildung \\
\hline$A D$ & Axiale Diffusivität \\
\hline ADC & Apparent diffusion coefficient (scheinbare Diffusionskoeffizent) \\
\hline AP-1 & activator protein 1 \\
\hline APC & antigen presenting cell (Antigenpräsentierende Zellen) \\
\hline APP & amyloid precursor protein (Amyloidvorläuferprotein) \\
\hline Aqua bidest. & zweifach destilliertes Wasser \\
\hline $\mathrm{BCIP}$ & 5-Brom-4-chlor-3-indolylphosphat \\
\hline BDNF & brain-derived neurotrophic factor \\
\hline $\mathrm{BHS}$ & Blut-Hirn-Schranke \\
\hline BSA & bovine serum albumin \\
\hline C/EBP & CCAAT/enhancer binding protein \\
\hline CAMP & 3'-5'-cyclic Adenosinmonophosphat \\
\hline cDNA & komplementäre Desoxyribonukleinsäure \\
\hline CFA & complete freund's adjuvant (komplettes Freundsches Adjuvant) \\
\hline cJun & jun oncogene \\
\hline $\mathrm{CO}$ & Kohlenmonoxid \\
\hline ConA & Concanavalin A \\
\hline Cup/MOG & Cuprizon-behandelt mit $\mathrm{MOG}_{35-55}$ immunisiert \\
\hline Cup/Ova & Cuprizon-behandelt mit Ovalbumin immunisiert \\
\hline Cuprizon & bis-cyclohexanon-Oxaldihydrozon \\
\hline DAB & 3-3'-Diaminobenzidin-Tetrahydrochlorid \\
\hline Dig & Digoxigenin \\
\hline DMFA & $N^{\prime} N^{\prime}$-Dimethylformamid \\
\hline DNA & Desoxyribonukleinsäure \\
\hline DNase & Desoxyribonuklease \\
\hline dNTP & Desoxyribonukleosidtriphosphate \\
\hline dpi & days post immunization \\
\hline $\mathrm{EtBr}$ & Ethidiumbromid \\
\hline DT & Diffusions Tensor \\
\hline DTT & Dithiothreitol \\
\hline
\end{tabular}




\begin{tabular}{|c|c|}
\hline EAE & experimentelle autoimmune Enzephalomyelitis \\
\hline EDTA & Ethylendiamintetraessigsäure \\
\hline ELISA & enzyme-linked immunosorbent assay \\
\hline FA & fractional anisotropy \\
\hline FACS & fluorescence-activated cell sorter \\
\hline Fas & CD95 \\
\hline FCS & fetal calf serum \\
\hline FGF & fibroblast growth factor \\
\hline FITC & Fluoreszeinisothiocyanat \\
\hline FLASH & fast low angle shot \\
\hline GAP-43 & growth associated protein 43 \\
\hline Gd-DATP & Diethylentriaminpentaessigsäure \\
\hline GFAP & saures gliales Faserprotein \\
\hline $\mathrm{H}_{2} \mathrm{O}_{2}$ & Wasserstoffperoxid \\
\hline $\mathrm{HCl}$ & Salzsäure \\
\hline $\mathrm{Hb}-\mathrm{Hp}$ & Hämoglobin-Haptoglobin \\
\hline $\mathrm{HE}$ & Hämatoxylin-Eosin \\
\hline $\mathrm{HO}$ & Hämoxigenase \\
\hline HRP & horseradish peroxidase \\
\hline ICAM-1 & intracellular adhesion molecule 1 \\
\hline IFN- $\gamma$ & Interferon- $\gamma$ \\
\hline IGF-1 & insulin-like growth factor \\
\hline $\lg G$ & Immunglobulin \\
\hline IL & Interleukin \\
\hline iNOS & induzierbare Stickstoffmonoxid-Synthase \\
\hline $\mathrm{kDa}$ & kiloDalton \\
\hline LFB/PAS & Luxol-fast-blue / Perjodsäure-Schiffsche Reagenz \\
\hline LPS & Lipopolysaccharid \\
\hline LysM & Lysozym M \\
\hline MBP & Myelin-basisches Protein \\
\hline MCP-1 & monocyte chemoattractant protein 1 \\
\hline $\mathrm{mg}$ & Milligramm \\
\hline $\mathrm{MHC}$ & major histocompability complex \\
\hline $\min$ & Minute \\
\hline
\end{tabular}




\begin{tabular}{|c|c|}
\hline MIP-1 $\alpha$ & Makrophagen-Entzündungsprotein-1 \\
\hline $\mathrm{ml}$ & Milliliter \\
\hline $\mathrm{mM}$ & Millimolar \\
\hline MOG & Myelin-Oligodendroglia-Glykoprotein \\
\hline mRNA & messenger-Ribonukleinsäure \\
\hline MRP 14 & myelin-related protein 14 \\
\hline MRT & Magnetresonanttomographie \\
\hline MS & Multiple Sklerose \\
\hline NBT & 4-NitroblauTetrazoliumchlorid \\
\hline NeuN & neuronal nuclei \\
\hline NF-кB & nuclear factor $\kappa$ B \\
\hline NGF & nerve growth factor \\
\hline $\mathrm{nm}$ & Nanometer \\
\hline NO & Stickstoffmonoxid \\
\hline NT-3 & neurotrophin-3 \\
\hline OD & optische Dichte \\
\hline $\mathrm{bHLH}$ & basic helix-loop-helix transcription factor \\
\hline Olig1 & oligodendrocyte transcription factor 1 \\
\hline Olig2 & oligodendrocyte transcription factor 2 \\
\hline OPC & oligodendrocyte precursor cell (Oligodendrozytenvorläuferzelle) \\
\hline Ova & Ovalbumin \\
\hline PBS & phosphate buffered saline (Phosphat gepufferte Salzlösung) \\
\hline PDGF- $\alpha$ & platelet-derived growth factor- $\alpha$ \\
\hline PDGF-R $\alpha$ & platelet-derived growth factor- $\alpha$ receptor \\
\hline PE & Phycoerythrin \\
\hline PerCP & Peridinin-chlorophyll-protein complex \\
\hline PFA & Paraformaldehyd \\
\hline PLP & Proteolipidprotein \\
\hline PTX & Pertussis Toxin \\
\hline RD & Radiale Diffusität \\
\hline RNA & Ribonukleinsäure \\
\hline ROI & region of interest (ausgewertete Region) \\
\hline ROS & reactiv oxygen species \\
\hline rpm & rounds per minute (Umdrehungen pro Minute) \\
\hline
\end{tabular}




\begin{tabular}{ll}
\hline \hline RPMI & Rosewell Park Memorial Institute \\
\hline RT & Raumtemperatur \\
\hline sek. & Sekunde \\
\hline SMI & Sternberger Monoclonals Incorporated \\
\hline Sox & SRY-box containing gene \\
\hline STEAM & stimulated echo acquisition modes \\
\hline TBS & tris buffered saline (Tris-gepufferte Salzlösung) \\
\hline TGF- $\beta$ & transforming growth factor- $\beta$ \\
\hline Th & T-Helfer Zelle \\
\hline TNF & Tumornekrosefaktor \\
\hline TRIS & Tris(hydroxymethyl)-aminomethan \\
\hline UV & ultraviolettes Licht \\
\hline VCAM-1 & vascular cell adhesion molecule 1 \\
\hline WT & Wildtyp \\
\hline ZNS & zentrales Nervensystem \\
\hline \hline
\end{tabular}




\section{Zusammenfassung}

Multiple Sklerose (MS) ist die häufigste neurologische Erkrankung des jungen Erwachsenenalters mit bleibender Behinderung. Sie wird als Autoimmunerkrankung erachtet. Krankheitstypisch sind fokale demyelinisierte Läsionen mit infiltrierten T-Zellen und Makrophagen/Mikroglia in der weißen Substanz des Gehirns und Rückenmarks. Entmarkungsherde im Bereich des Kortex wurden kürzlich als wesentliche Aspekte der MS-Pathologie identifiziert. Obwohl der Verlust von Myelin eine Beeinträchtigung der Nervenleitung verursacht, korrelieren vor allem axonale Schädigung und axonaler Verlust mit dem Ausmaß der bleibenden neurologischen Behinderung.

Die klassische experimentelle autoimmune Enzephalomyelitis (EAE), das am häufigsten verwendete Modell der Erkrankung, führt zu einem nahezu ausschließlichen Befall der weißen Substanz des Rückenmarks. Aus diesem Grund war das Ziel der vorliegenden Arbeit, neue experimentelle Modelle der MS zu entwickeln, welche eine gezielte Untersuchung der Mechanismen axonaler und neuronaler Schädigung in der grauen Substanz und im Gehirn erlauben. Hierzu wurden die folgenden beiden Ansätze gewählt:

1) B-Synuklein-EAE als experimentelles Modell für pathologische Veränderungen in der grauen Substanz bei multipler Sklerose

Durch den selektiven Befall der grauen Substanz nach Immunisierung von Ratten mit dem neuronalen Antigen $\beta$-Synuklein ${ }_{93-111}$ konnte die schädigende Wirkung von T-Zellinfiltration und Makrophagen/Mikrogliaaktivierung auf Nervenzellen und Axone unabhängig von einem Befall der weißen Substanz untersucht werden. Durch die zusätzliche intravenöse Gabe des entmarkenden anti-MOG-Antikörpers 8-18C5 konnte Demyelinisierung induziert werden. Somit wurde eine bessere Übereinstimmung mit der Pathologie der MS erzielt. Hierdurch konnten die pathologischen Auswirkungen einer rein entzündlichen mit einer entzündlich-entmarkenden Enzephalomyelitis in der grauen Substanz verglichen werden.

Anhand einer vermehrten neuronalen cJun- und verminderten NeuN-Expression wurde gezeigt, dass die unmittelbare Nähe der Entzündungszellen zu Neuronen Zellstress verursacht. Dabei scheint Myelinverlust ein zusätzlicher Stressfaktor zu sein, da diese Tiere deutlich mehr cJun-positive Neurone in den Rückenmarksquerschnitten aufwiesen als jene ohne Entmarkung. Die Dichte der Nervenzellen war im akuten Entzündungsstadium deutlich reduziert. Dies konnte jedoch auf die verminderte 
NeuN-Expression und das akute, entzündlich-bedingte Ödem zurückgeführt werden. Die neuronale Stressantwort führte also nicht zum Zelltod. Des Weiteren konnte gezeigt werden, dass iNOS-positive Makrophagen/Mikroglia und transportgestörte, APPpositive Axone vorwiegend in den entmarkten Läsionen vorhanden waren. Die Expression der beiden antiinflammatorischen Proteine CD163 und Hämoxigenase-1 (HO-1) wurde in den Rückenmarksquerschnitten beider Versuchsgruppen nachgewiesen.

Eine akute Entzündungsreaktion in der grauen Substanz führt demzufolge nicht zwangsläufig zum neuronalen Untergang, sondern zu einer transienten neuronalen Stressreaktion. Axonale Schädigung nach Entmarkung trägt wesentlich zu dieser neuronalen Stressreaktion bei.

\section{Cuprizon-EAE, ein neues Modell mit MS-ähnlichen Läsionen im Mausgehirn}

Die toxisch induzierte Entmarkung durch Cuprizon, einem Kupferchelator, verursacht - bei geschlossener Blut-Hirn-Schranke - eine selektive Oligodendrozytenapoptose mit nachfolgender Entmarkung und geringfügiger axonaler Schädigung im Corpus callosum von Mäusen. Durch zusätzliche Immunisierung mit $\mathrm{MOG}_{35-55}$ wurde eine Entzündungsantwort im vorgeschädigten Gehirnparenchym ausgelöst. Anhand des gewählten Versuchsansatzes konnte untersucht werden, inwieweit aus dem Blut rekrutierte Makrophagen und T-Zellen zu einer Verstärkung der axonalen Schädigung führen und welche Mediatoren an diesen Prozessen beteiligt sind.

Durch den gewählten Versuchsansatz konnten reproduzierbare, MS-ähnliche Entzündungsherde im Balken und Kortex erzeugt werden. Im Gegensatz zur Cuprizoninduzierten Entmarkung hatte die Infiltration von Entzündungszellen - über eine geöffnete Blut-Hirn-Schranke - zahlreiche APP-positive geschädigte Axone zur Folge. Des Weiteren exprimierten Makrophagen/Mikroglia in immunisierten Tieren die proinflammatorischen Proteine iNOS und S100A9/MRP14 sowie das antiinflammatorische Protein HO-1. Nach Beenden der Cuprizon-Diät erfolgte in Tieren mit und ohne Entzündungsreaktion eine Neubildung des Myelins mit vergleichbarer Effizienz. Aufgrund der Lokalisation der Läsionen im Balken eignet sich dieses Modell besonders für bildgebende Analysen. Mittels der Diffusions-Tensor-Technik, die vor allem zur Untersuchung der Integrität von Myelin und Axonen dient, soll durch Bildgebung eine Unterscheidung zwischen Axonschaden und Myelinverlust möglich werden. Axonschaden konnte durch eine geringere axiale Diffusivität nachgewiesen werden. Allerdings war die radiale Diffusivität bei Tieren mit Entzündung - im Vergleich zu Kontrollmäusen unverändert, obwohl der Verlust von Myelin diese normalerweise erhöht. Dies weist 
darauf hin, dass zelluläre Infiltrate die freie Diffusion der Wassermoleküle quer zu den Axonen in einem vergleichbaren Maße beeinflussen wie Myelin selbst. Eine Unterscheidung zwischen Axonschaden und Myelinverlust war bei Entmarkung mit Entzündung mit dieser Technik daher nicht eindeutig möglich.

Mithilfe des Modells der Cuprizon-EAE konnte gezeigt werden, dass Entzündung die Remyelinisierung nicht fördert und Axonschaden hauptsächlich durch Komponenten der erworbenen Immunantwort verursacht wird. 


\section{Summary}

Multiple sclerosis (MS) is the commonest non-traumatic neurological disease leading to permanent disability in young adults and is considered to be autoimmune in nature. The hallmarks of MS are focal demyelinated lesions with infiltrating macrophages/microglia and T cells in the spinal cord and brain white matter. In the last few years, demyelinated lesions of the cortex and the spinal cord grey matter have become the focus of attention. Although demyelination itself leads to disturbed conduction velocities the loss of axons correlates much better with the degree of neurological disability.

Classical experimental autoimmune encephalomyelitis (EAE) is the most commonly used animal model of MS. There, inflammation is predominantly located in the spinal cord white matter. Based on recent findings in MS tissue, the aim of the present work was to establish experimental models with predominant involvement of the brain and spinal cord grey matter. Two different approaches were used:

\section{1) B-synuclein induced EAE, as a model for pathological changes in the grey matter in}

$\underline{\mathrm{MS}}$

Immunization of Lewis rats with the neuronal antigen $\beta$-synuclein ${ }_{93-111}$ leads to a selective inflammation of the spinal cord grey matter. Therefore, the effects of $T$ cell infiltration and macrophage/microglia activation on neurons and axons could be investigated independent of inflammation in the white matter. To mimic the inflammatory-demyelinating pathology found in MS more closely, demyelinating

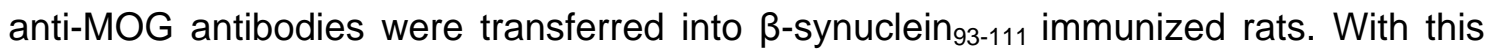
approach, the pathological effects of inflammation alone and inflammatorydemyelinating encephalomyelitis could be compared.

Inflammation in the grey matter led to a neuronal stress response verified by increased cJun and reduced NeuN expression. Demyelination served as an additional stress factor demonstrated by an additional increase of cJun-positive neurons. Neuronal density was reduced because of inflammatory oedema. However, the neuronal stress response did not lead to neuronal cell death. Furthermore, it was found that iNOSpositive macrophages/microglia and APP-positive axons were predominantly located in demyelinated as compared to purely inflammatory lesions. The antiinflammatory proteins CD163 and Hemeoxygenase-1 were expressed irrespective of demyelination. 
In summary, acute inflammation in spinal cord grey matter did not lead to neuronal cell death in the model used, but it did induce a neuronal stress response which was further increased by demyelination and axonal damage.

\section{Cuprizone-EAE, a new model with MS-like lesions in the mouse brain}

Toxin-induced demyelination by the copper chelator cuprizone induces selective apoptosis of oligodendrocytes with only little axonal damage in the mouse corpus callosum. The integrity of the blood-brain-barrier (BBB) is not affected. In contrast, immunization with $\mathrm{MOG}_{35-55}$ leads to a massive infiltration of immune cells into the spinal cord via an open BBB. The combination of toxin-induced demyelination and immunization with $\mathrm{MOG}_{35-55}$ led to reproducible, MS-like lesions in the corpus callosum and cortex of mice. This approach made it possible to investigate the presumably harmful effects of infiltrating blood-borne macrophages and $T$ cells on axons and to see if inflammatory mediators contribute further to this damage.

In contrast to cuprizone-induced demyelination alone, the additional infiltration of inflammatory cells via an open BBB increased the number of APP-positive axons. In these immunized animals, macrophages/microglia expressed the proinflammatory proteins S100A9 and iNOS, and also the anti-inflammatory protein HO-1. Withdrawing cuprizone from the diet resulted in rapid remyelination, which proved comparable in mice with and without inflammation. The lesion location in the corpus callosum made this model a valuable tool for diffusion tensor imaging, a technique that allows the assessment of white matter microstructure. This method has been reported to differentiate between myelin loss and axonal damage. In the current study, axonal damage could be demonstrated by reduced axial diffusion. Radial diffusion was unchanged compared to naïve animals, although myelin loss was expected to lead to an increased radial diffusion. This result suggests that the cellular infiltrates affect the water diffusion similar to myelin itself. In the presence of inflammation, it was not possible to differentiate between axonal damage and demyelination the model used.

In summary, in the present study, the newly developed cuprizone-EAE model served to demonstrate that adaptive inflammation does not affect the extent and velocity of remyelination and that axonal damage is markedly aggravated by components of the acquired immune system. 


\section{Einleitung}

\subsection{Epidemiologie und Verlaufsformen der multiplen Sklerose}

Multiple Sklerose (MS), zum ersten Mal 1868 von Jean Martin Charcot beschrieben, ist die häufigste neurologische Erkrankung junger Erwachsener mit bleibender Behinderung (Sanders und De Keyser 2007). Pathogenetisch geht man davon aus, dass es sich dabei um eine Autoimmunerkrankung handelt (Sospedra und Martin 2005; Gold et al. 2006). Das Risiko an MS zu erkranken, ist in der nordamerikanischen und europäischen Bevölkerung erhöht. Der Anteil der Betroffenen wird mit 60-200 pro 100000 Menschen angegeben, wobei ungefähr doppelt so viele Frauen wie Männer an MS leiden (Sospedra und Martin 2005). Bislang konnten die genauen Krankheitsursachen noch nicht geklärt werden. So diskutiert man neben einer genetischen Prädisposition (Träger der MHC II Haplotypen HLA-DR und QR haben eine höhere Wahrscheinlichkeit, an MS zu erkranken), Umwelteinflüsse (Menge des UV-Lichts), Hormonveränderungen, Krankheitserreger und die Folgen des gestiegenen ökonomischen Status als mögliche Ursachen (Sospedra and Martin 2005). Der Krankheitsverlauf und morphologische Veränderungen, nachgewiesen durch Magnetresonanztomographie (MRT) und Histologie, sind bei den einzelnen Patienten äußerst heterogen und können bislang nicht vorhergesagt werden (Lassmann et al. 2001; Huizinga et al. 2008). Generell werden vier Verlaufsformen unterschieden (Lublin und Reingold 1996).

- Die schubförmige MS ist nach einem Krankheitsschub durch Phasen der Erholung gekennzeichnet und tritt bei $80-85 \%$ aller MS-Patienten auf. Für gewöhnlich geht diese Variante in die sekundär progrediente Form, mit ständig zunehmender Behinderung, über.

- Bei der primär progredienten MS gibt es von Krankheitsbeginn an keine Phasen der Besserung. Sie ist gekennzeichnet durch eine kontinuierliche, schleichende Verschlechterung.

- Das Kennzeichen der progredient-schubförmigen MS ist ein von Beginn an chronisches Fortschreiten mit zusätzlichen Krankheitsschüben und partiellen Besserungen. 


\subsection{Pathogenese der MS}

Im Allgemeinen wird davon ausgegangen, dass autoreaktive T-Zellen und aktivierte Makrophagen/Mikroglia die Markscheiden schädigen und dadurch die Nervenleitung beeinträchtigen (Friese und Fugger 2005). Ursprünglich wurde angenommen, dass dabei in erster Linie CD4-T-Helfer Zellen, welche die proinflammatorischen Zytokine IL-2, IFN- $\gamma$ und TNF- $\alpha$ sezernieren, eine zentrale Rolle spielen. Hinweise dafür sind zahlreiche CD4-positive Zellen in den Läsionen und im Liquor von MS-Patienten. Des Weiteren sind die bekannten genetischen Risikofaktoren die MHC II kodierenden Gene HLA-DR und HLA-DQ (Fogdell et al. 1995) und fast alle derzeit verfügbaren Tiermodelle beruhen auf einem CD4 vermittelten Mechanismus (Sospedra und Martin 2005).

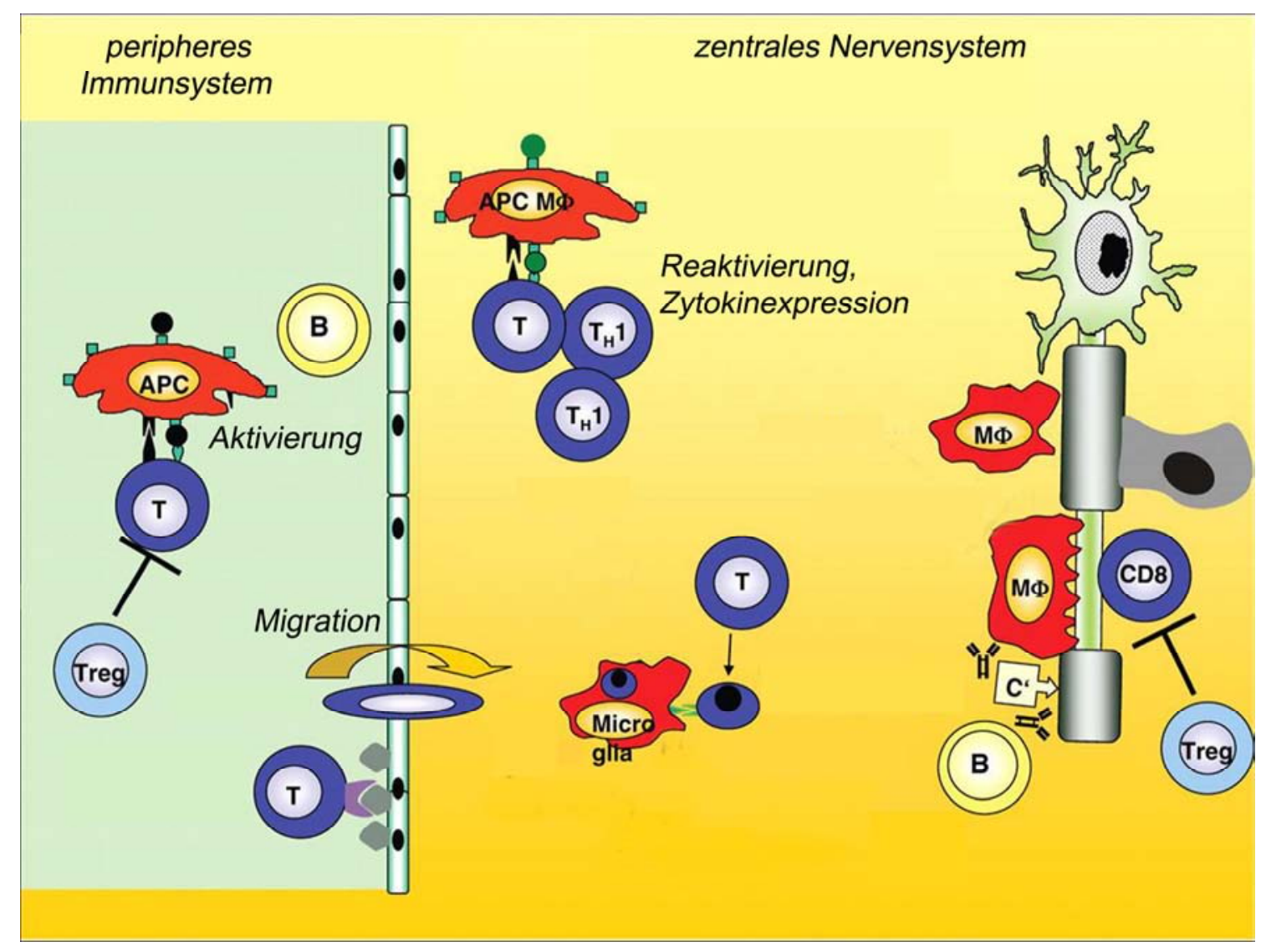

Abb. 1-1: Pathogenese der multiplen Sklerose und der experimentellen autoimmunen Enzephalomyelitis. Die Aktivierung enzephalitogener T-Zellen erfolgt in der Peripherie. Diese aktivierten T-Zellen wandern in das ZNS ein und lösen nach dortiger Antigenerkennung eine lokale Entzündungsreaktion aus, die die Öffnung der Blut-Hirn-Schranke zur Folge hat. Es kommt zur Rekrutierung von zahlreichen Entzündungszellen und folglich zur Schädigung des Myelins und der Axone. APC: Antigenpräsentierende Zelle, MФ: Makrophage, T: T-Zelle, B: B-Zelle, C: Komplement (modifiziert nach Gold et. al. 2006) 
Mittlerweile wird jedoch eine Beteiligung der zytotoxischen CD8-T-Zellen am Krankheitsprozess für wahrscheinlich gehalten. Untermauert wird diese Annahme durch folgende Befunde aus der humanen Erkrankung: Erstens findet eine klonale Vermehrung von CD8-positiven Zellen in den ZNS-Läsionen statt (Babbe et al. 2000; Skulina et al. 2004), zweitens haben Träger des MHC I Hapolotyps HLA-A3 ein erhöhtes Erkrankungsrisiko (Naito et al. 1972) und drittens korreliert die Anzahl CD8positiver T-Zellen mit dem Ausmaß an axonalem Schaden (Bitsch et al. 2000). Unterstützend konnten mittlerweile EAE-Modelle etabliert werden, die auf einem rein CD8vermittelten Mechanismus beruhen (Sun et al. 2001; Huseby et al. 2001; Ford und Evavold 2005). Dabei entspricht die Pathologie dieser Modelle, mit einer überwiegenden Beteiligung des Gehirns und großflächig entmarkten Läsionen mehr der humanen Erkrankung als die meisten CD4-vermittelten EAE-Modelle (Friese und Fugger 2005).

Darüber hinaus tragen, wie bereits erwähnt, professionell antigenpräsentierende Zellen (Gold et al. 2006) und aktivierte Makrophagen/Mikroglia (Heppner et al. 2005) zur Aktivierung von T- und B-Lymphozyten bei. Ein Einwandern von Immunzellen in das ZNS wird durch eine geöffnete Blut-Hirn-Schranke (BHS) möglich (Minagar und Alexander 2003; Lassmann et al. 2007).

Typische Kennzeichen der MS sind fokale Entzündungsherde in der weißen Substanz des Gehirns und Rückenmarks (Kidd et al. 1999). Charakteristische Merkmale dieser Läsionen sind neben infiltrierenden T-Zellen, Monozyten und vereinzelten Granulozyten, der Verlust der Markscheiden und axonaler Schaden (Lassmann et al. 2007). MRT-spektroskopische Arbeiten konnten jedoch zeigen, dass vor allem die Schädigung und der Verlust von Axonen mit dem Ausmaß der bleibenden neurologischen Behinderung korrelieren (Kornek et al. 2000; Lovas et al. 2000; Hendriks et al. 2005).

In den letzten Jahren konnte, durch verbesserte pathologische Untersuchungen und Bildgebungsverfahren, das Vorhandensein von Läsionen in der grauen Substanz des Kortex und des Rückenmarks nachgewiesen werden (Kidd et al. 1999; Bozzali et al. 2002; Bo et al. 2003b). Bemerkenswert an kortikalen MS-Läsionen sind eine im Vergleich zur weißen Substanz geringere Anzahl an Entzündungszellen (Peterson et al. 2001; Bo et al. 2003a) und das Fehlen von Komplement- und Immunglobulinablagerungen (Bo et al. 2003a; Brink et al. 2005). Zudem konnte im Modell der fokalen experimentellen autoimmunen Enzephalomyelitis gezeigt werden, dass entzündliche Läsionen im Kortex sich schnell auflösen und eine vollständige Remyelinisierung innerhalb kurzer Zeit erfolgt (Merkler et al. 2006b). Aufgrund dieser Beobachtungen werden un- 
terschiedliche Mechanismen vermutet, die zur Entstehung von Läsionen in der grauen und weißen Substanz führen (Bo et al. 2003a; Merkler et al. 2006a) .

Neben den bereits beschriebenen Krankheitsmerkmalen haben bei MS ein Verlust von Neuronen und eine Atrophie des Gehirns in den letzten Jahren vermehrt Beachtung gefunden (Peterson et al. 2001; Kutzelnigg und Lassmann 2005; Vercellino et al. 2007). Als mögliche Ursachen des neuronalen Schadens werden eine retrograde Degeneration als Folge axonaler Schädigung (Bozzali et al. 2002), eine direkte Schädigung durch Antikörper und Entzündungszellen und eine Schädigung durch Entzündungsmediatoren diskutiert.

\subsection{Tiermodelle der multiplen Sklerose}

Aufgrund der Komplexität der Erkrankung kann die MS in verschiedenen Tiermodellen jeweils nur partiell abgebildet werden. Die typischen Modelle hierzu sind: die experimentelle autoimmune Enzephalomyelitis (EAE), das Cuprizon-Modell und die Infektion durch das Theiler-Virus. Das EAE- und Cuprizon-Modell wurde in der vorliegenden Arbeit angewandt und sind nachfolgend beschrieben. Das Theiler-Modell beruht auf der Hypothese, dass MS durch eine Virusinfektion ausgelöst wird und wird in Mäusen durch das Theiler's Maus Enzephalomyelitis Virus induziert (Oleszak et al. 2004).

\subsubsection{Experimentelle autoimmune Enzephalomyelitis}

EAE ist das am häufigsten verwendete Tiermodell im Bereich der MS-Forschung. Die Ursprünge der induzierten Enzephalomyelitis reichen bis in das Jahr 1885 zurück, als die von Louis Pasteur entwickelte Tollwutimpfung Lähmungserscheinungen bei geimpften Menschen verursachte. In den 30er Jahren untersuchte Thomas River den Mechanismus dieser unerwünschten Begleiterscheinung durch die Immunisierung von Rhesusaffen mit ZNS-Homogenat in komplettem Freund'schen Adjuvans (Baxter 2007).

Seit diesen anfänglichen Studien von River wurde EAE in einer Vielzahl von Arten, wie Maus, Ratte, Hamster, Schaf, Ziege, Schwein, Marmoset und Huhn, etabliert. Mittlerweile werden für die sogenannte aktive Immunisierung häufig Myelin-Peptide verwendet, deren Sequenz über die MHC II Moleküle der jeweiligen Spezies präsentiert werden können. Eine weitere Möglichkeit EAE auszulösen ist die passive Immunisierung. Dabei werden autoreaktive, myelinspezifische T-Zellen in naive Mäuse oder Ratten transferiert (Ben Nun et al. 1981). Sie gilt als Beweis dafür, dass EAE eine Autoim- 
munerkrankung ist und weist darauf hin, dass Autoimmunität bei MS ebenfalls eine Rolle spielen könnte (Gold et al. 2006)

Durch die Verwendung von unterschiedlichen Antigenen und Tierarten lassen sich spezifische Aspekte der MS darstellen. In Tabelle 1-1 sind einige der wichtigsten EAEModelle aufgeführt (Gold et al. 2006). Ihre Gemeinsamkeit und zugleich ihr größter Unterschied zur MS ist, dass die Krankheit durch Immunisierung induziert werden muss und nicht wie MS spontan auftritt (Gold et al. 2006).

Tabelle 1-1: Häufig verwendete EAE-Modelle und ihre jeweiligen Ähnlichkeiten / Unterschiede zur MS (Gold et al. 2006). MOG=Myelin/Oligodendrozyten-Glykoprotein, MBP=Myelin-basisches-Protein, PLP=Proteolipid-Protein

\begin{tabular}{llll}
\hline \hline Modell & Ähnlichkeit zur MS & Unterschied zur MS & Vorteil/Nachteil \\
\hline \hline Lewis-Ratte & & & \\
\hline \hline MBP-, PLP- & T-Zellbeteiligung & $\begin{array}{l}\text { monophasisch, keine } \\
\text { Entmarkung }\end{array}$ & $\begin{array}{l}\text { kaum genetisch ver- } \\
\text { änderte Ratten }\end{array}$ \\
\hline rektid & & primäre Entmarkung \\
MOG-Protein & perbeteiligung, Ent- & & \\
& markung, optischer & & \\
& Nerv ist häufig betrof- & & \\
& fen & & \\
\hline Adoptiver & perivaskuläre T-Zell- & monophasischer Ver- \\
Transfer von & und Makrophagenin- & lauf & \\
T-Zellen & filtrate, ADEM (akute & & \\
& disseminierte En- & & \\
& zephalomyelitis) & & \\
\hline \hline
\end{tabular}




\begin{tabular}{llll}
\hline \hline Modell & Ähnlichkeit zur MS & Unterschied zur MS & Vorteil/Nachteil \\
\hline \hline Maus & & & \\
\hline \hline C57BL/6 & primär progredient, & keine Antikörperbe- & viele genetisch ver- \\
MOG $_{35-55)}$ & Axonschaden, & $\begin{array}{l}\text { teiligung, hauptsäch- } \\
\text { änderte Stämme }\end{array}$ & \\
& T-Zellen und & lich sek. Myelinver- & \\
& Makrophagen medi- & lust, da sehr destruk- & \\
& ierte Entmarkung & tiv & \\
\hline Biozzi ABH, & schubförmiger Ver- & & \\
(MOG/ ZNS- & lauf & & \\
Homogenat) & & & \\
\hline SJL (PLP- & schubförmiger Ver- & keine Antikörperbe- & \\
Peptid) & lauf & teiligung & ethische Bedenken, \\
PL/J (MBP) & & & primär progredient \\
\hline \hline Marmoset & & & \\
\hline \hline rekombinantes & primär progredient, & & \\
MOG Protein & kortikale Läsionen & & \\
\hline \hline
\end{tabular}

Außerdem ist die EAE in Nagern im Gegensatz zur MS überwiegende eine Erkrankung der weißen Substanz des Rückenmarks. Da sich jedoch die Zusammensetzung der Läsionen in der grauen und weißen Substanz unterscheidet, sollte in der vorliegenden Arbeit ein Modell etabliert werden, durch welches die pathologischen Vorgänge in der grauen Substanz untersucht werden können. Des Weiteren war von Interesse, ein Mausmodell der MS mit einer reproduzierbaren Beteiligung des Gehirns zu etablieren.

\subsubsection{Toxin-induzierte Entmarkung durch Cuprizon}

Mit dem Modell der EAE können entzündlich bedingte Schädigungsmechanismen, die ebenfalls bei der MS eine Rolle spielen, untersucht werden.

Im Gegensatz hierzu steht die toxisch-induzierte Entmarkung durch Cuprizon (bis-Cyclohexanon-Oxaldihydrozon), welche ohne die Beteiligung von T-Zellen und bei geschlossener Blut-Hirn-Schranke stattfindet (Bakker und Ludwin 1987; Kondo et al. 1987). Wird Cuprizon über einen Zeitraum von sechs Wochen dem Futter beigemengt, so zeigt sich bei jungen Mäusen ein nahezu vollständiger Verlust der Markscheiden im Corpus callosum und im Pedunculus cerebellaris superior (Suzuki und Kikkawa 1969; Hiremath et al. 1998; Morell et al. 1998). Nach Beendigung der Cuprizon-Gabe erfolgt 
die Neubildung des Myelins, ein Prozess, welcher nach einem Zeitraum von 6 Wochen nahezu abgeschlossen ist (Hiremath et al. 1998; Morell et al. 1998). Aufgrund des reversiblen Effekts und des geringen axonalen Verlusts, wird das Cuprizon-Modell für Untersuchungen von De- und Remyelinisierungsvorgängen verwendet. Dieses Modell ermöglicht, die einzelnen Schritte der Remyelinisierung besser zu verstehen und therapeutische Ansätze für die teilweise unvollständige Neubildung der Markscheiden in MS-Läsionen zu entwickeln.

Der molekulare Mechanismus des selektiven Oligodendrozytentodes mit nachfolgender Entmarkung wird durch die Kupfer-bindende Eigenschaft des Cuprizons erklärt. Der daraus resultierende Kupfermangel führt vor allem in Oligodendrozyten, welche physiologisch einen hohen Kupfergehalt aufweisen (Hiremath et al. 1998; Morell et al. 1998), zur Unterbrechung der Elektronentransportkette, zur Bildung von reaktiven Sauerstoffmolekülen und somit zum Zelltod (Murphy et al. 1999). Bereits nach einer Woche Cuprizon-Gabe finden sich zahlreiche apoptotische Oligodendrozyten und eine verminderte Expression von Myelinproteinen, wenn histologisch noch kein Myelinverlust nachgewiesen werden kann (Mason et al. 2000). Die Cuprizon-bedingte Entmarkung verläuft, ohne die Beteiligung von T-Zellen, führt jedoch zur Aktivierung der Mikroglia und zur Astrogliose (Hiremath et al. 1998). Die Mikrogliazllen produzieren nach der Phagozytose von Myelin trophische Stoffe wie z. B. FGF, PDGF, NT-3, NGF und IGF-1, welche eine Neubildung der Markscheiden fördern (Matsushima und Morell 2001).

Nach sechswöchiger Cuprizon-Diät lassen sich kaum mehr reife Oligodendrozyten nachweisen. Aus diesem Grund wird angenommen, dass eine Neubildung des Myelins durch Proliferation und Differenzierung von Oligodendrozytenvorläuferzellen (OPC) in reife Oligodendrozyten erfolgt (Mason et al. 2000; Zhao et al. 2005). Molekulare Hinweise für den postulierten Mechanismus sind die Expression der Transkriptionsfaktoren Nkx2.2 und Olig2 (oligodendrocyte transcription factor 2), welche hauptsächlich von aktivierten OPC gebildet werden und im adulten ZNS-Gewebe nur in sehr geringen Mengen vorkommen. Des Weiteren werden Olig1 und PDGF-R $\alpha$ in entmarkten Bereichen verstärkt exprimiert (Fancy et al. 2004; Zhao et al. 2005). 


\subsection{Aktivierung von Makrophagen und Mikrogliazellen}

\subsubsection{Allgemeines zur Makrophagen/Mikrogliaaktivierung}

Makrophagen/Mikroglia sind zahlenmäßig die dominierende Zellpopulation in frischen MS-Herden und EAE-Läsionen und spielen bei der Pathogenese eine wichtige Rolle (Bauer et al. 2001). Obwohl Makrophagen/Mikroglia trophische Stoffe bilden, wird insbesondere die Schädigung von Axonen und Entmarkung als Folge von aktivierten Makrophagen/Mikroglia angesehen. Die genauen Schädigungsmechanismen sind jedoch bislang unklar (Hendriks et al. 2005).

Mikrogliazellen, die ortständigen „Gehirnmakrophagen“, sind hämatopoetischen Ursprungs und wandern während der Embryonalentwicklung bzw. unmittelbar nach der Geburt in das ZNS ein (Barron 1995). Unter physiologischen Bedingungen und somit im ruhenden Zustand weisen sie eine verzweigte Morphologie auf, welche innen erlaubt, ihre Umgebung nach Pathogenen „abzusuchen“ (Nimmerjahn et al. 2005). Aufgrund der Aktivierung durch endogene oder exogene Signale nehmen sie ein rundes Aussehen an (Sanders und De Keyser 2007). Dabei vergrößert sich ihr Soma (Brown 2007).

Makrophagen entwickeln sich ebenfalls aus Knochenmarksvorläuferzellen. Zusammen mit den Mikrogliazellen übernehmen sie durch Phagozytose, der Präsentation von Antigenen über den MHC-Komplex und der Produktion von Zyto- und Chemokinen eine wichtige Funktion bei der Immunantwort. Eine Unterscheidung zwischen Makrophagen und aktivierten Mikrogliazellen ist aufgrund gleicher Morphologie und gleichem Proteinexpressionsmuster histologisch nicht möglich.

Makrophagen sind eine heterogene Zellpopulation, welche durch die Aktivierungswege und die Expression von bestimmten Oberflächenrezeptoren unterschieden werden. Nach Gordon erfolgt eine Unterteilung in fünf Subpopulationen (Gordon 2003).

- Die angeborene Aktivierung, durch mikrobielle Stimuli, erfolgt durch Mustererkennungs-Rezeptoren (Toll, CD14/LPS-binde-Protein) und führt zur Bildung von proinflammatorischen Zytokinen, reaktiven Sauerstoffmolekülen und Stickstoffmonoxid (NO).

- Die humorale Aktivierung und Phagozytose wird durch Fc- und Komplementrezeptoren vermittelt. 
- Die klassische Aktivierung erfolgt durch LPS oder IFN- $\gamma$ und führt neben der Produktion von proinflammatorischen Zytokinen zur Bildung von toxischen Entzündungsmediatoren wie NO und IL-12.

- Neben den antiinflammatorischen Zytokinen IL-4 und IL-13 führen Glukokortikoide zur alternativen Aktivierung von Makrophagen. Diese sind hauptsächlich bei Allergien, humoraler Immunantwort und parasitären Erkrankungen vorzufinden.

- Die Deaktivierung von Makrophagen kann durch Mechanismen der angeborenen und erworbenen Immunität erfolgen. Eine antiinflammatorische Immunantwort wird durch die Phagozytose apoptotischer Zellen bewirkt. Des Weiteren modulieren Zytokine und der Kontakt von Makrophagen zu T-Zellen und Fibroblasten die Aktivität von Makrophagen.

Im ZNS wurden bisher noch keine, den oben beschriebenen Aktivierungsmustern, vergleichbare Makrophagenpopulation beschrieben, jedoch weisen Makrophagen/Mikroglia in MS- und EAE-Läsionen Merkmale von Makrophagen auf, welche über den klassischen Weg aktiviert wurden. Diese bilden, zumindest für eine begrenzte Zeit, proinflammatorische Zytokine, iNOS und S100A9 (Hendriks et al. 2005). Weitere Merkmale dieser Makrophagen/Mikroglia in MS- und EAE- Entzündungsherden sind die erhöhte Expression von MHC II, CD45, CD40, CD86, CD80, CD11C, Komponenten der Komplementkaskade, Zytokinen, Chemokinen, Proteasen und Neurotrophinen (Raivich und Banati 2004).

\subsubsection{Expression aktivierungsabhängig regulierter Gene}

Über die Art der Aktivierung von Makrophagen/Mikroglia im ZNS ist wenig bekannt, und eine Einteilung in unterschiedlich aktivierte Makrophagen/Mikrogliapopulationen derzeit noch nicht möglich. Grundsätzlich stellt sich die Frage, ob phagozytierende Makrophagen lediglich Myelinbruchstücke und geschädigte Zellen abräumen, oder ob durch Phagozytose schädliche Mediatoren gebildet werden, die zu weiterem Gewebeschaden führen. Im Nachfolgenden werden Proteine beschrieben, die mit der Aktivierung von Makrophagen/Mikroglia in Verbindung gebracht werden und anhand deren Expression Phagozyten in verschiedene Gruppen eingeteilt werden können. 


\subsubsection{S100A9/MRP14 - ein damage-associated molecular pattern Protein}

S100A9/MRP14 (myelin related protein 14), ein Kalzium-bindendes Protein, gehört zur Familie der S100-Proteine und bildet zusammen mit S100A8 ein funktionelles Heterodimer (Foell et al. 2007). Promotoranalysen zeigten Bindungsstellen für die Transkriptionsfaktoren AP-1, NF-кB und C/EBP (Gebhardt et al. 2006). Eine gesteigerte Expression kann deshalb durch proinflammatorische Zytokine wie TNF- $\alpha$ und IL-1 induziert werden. Da S100A9 in myeloiden Zellen, Granulozyten, Monozyten und Makrophagen in frühen Differenzierungsstadien gebildet wird, wird von einer Funktion bei der angeborenen Immunantwort ausgegangen (Foell et al. 2007). S100A9/A8 überexprimierende Phagozyten produzieren zudem TNF- $\alpha$ und IL-1 und sind nur in akuten und nicht in chronischen Entzündungsstadien vorzufinden. Aus diesem Grund werden sie als Marker für aktivierte und / oder neu rekrutierte Phagozyten verwendet (Kerkhoff et al. 1999). Neben S100A9-positiven Monozyten lässt sich eine erhöhte Serumkonzentration von S100A9 bei diversen entzündlichen Erkrankungen wie z.B. der chronischen Bronchitis, der zystischen Fibrose, der rheumatoiden Arthritis, der Lupus und der MS nachweisen (Kerkhoff et al. 1999). Dabei korreliert die Menge im Serum mit der Aktivität der Krankheit (Foell et al. 2007).

Funktionell wird der S100A9/A8-Komplex der Gruppe der „damage-associated molecular pattern proteins“ zugeordnet. Diese Proteine sind durch unterschiedliche Funktionen intra- und extrazellulär gekennzeichnet (Foell et al. 2007). So beeinflusst der zytoplasmatisch vorliegende S100A9/A8-Komplex die Migration von Phagozyten durch die Modulation des Tubulin-abhängigen Zytoskeletts. Hinweis dafür ist die verminderte Rekrutierung von Granulozyten im Granulationsgewebe bei der Wundheilung von S100A9-defizienten Mäusen (Vogl et al. 2004).

Die Sezernierung des S100A9/A8-Komplexes erfolgt über die Bindung an die Mikrotubuli. Für diesen sogenannten alternativen Sekretionsweg gibt es zwei Voraussetzungen: Erstens die Aktivierung der Proteinkinase $C$ muss durch Entzündung erfolgen und zweitens wird ein erhöhter intrazellulärer Kalziumspiegel benötigt, welcher nach Kontakt von Phagozyten an TNF- $\alpha$ stimulierten Endothelzellen ansteigt. Der genaue Mechanismus dieses Transportwegs ist allerdings bislang unbekannt (Roth et al. 2003). Der Kontakt von Phagozyten mit nicht aktivierten Endothelzellen hingegen hemmt die Sezernierung des Komplexes. Dadurch lässt sich erklären, warum die S100A9/A8Konzentration im Serum mit der Krankheitsaktivität bei entzündlichen Erkrankungen korreliert (Frosch et al. 2000). 
Extrazellulär wird dieser Komplex zu einem „Gefahrensignal“. Er bindet über Heparansulfatproteoglykane und carboxylierte Glykane an Endothelzellen, was nach bisherigen Erkenntnissen folgende entzündungsfördernden Auswirkungen hat:

- Es entsteht eine verstärkte Adhäsion des Integrinrezeptors CD11b-CD18 auf Leukozyten zum ICAM-1 der Endothelzellen, was wichtige Voraussetzung für das Einwandern von Leukozyten aus dem Blutstrom in das Gewebe ist.

- Ebenso kommt es zu einer erhöhte Transkription von proinflammatorischen Zytokinen (IL-8), Adhäsionsmolekülen (ICAM-1 und VCAM-1) und Enzymen des mitochondrialen Superoxidmetabolismus.

- Eine erhöhte Permeabilität der Gefäßwände, durch verminderten Zell-ZellKontakt und eine verminderte Expression von Zellverbindungsproteinen, zählen ebenfalls zu den Folgen.

Die Expression von S100A9 in Monozyten bei MS wird als ein Kriterium zur Beurteilung des Alters der MS-Läsionen verwendet. Da davon ausgegangen wird, dass neben Granulozyten nur akut aus dem Blutstrom eingewanderte Monozyten in MSEntzündungsherden S100A9 exprimieren, wird die Expression von S100A9 in Monozyten als ein Kennzeichen früh aktiver Läsionen gewertet (Bruck et al. 1995).

\subsubsection{Stickstoffmonoxidsynthase}

Das freie Radikal NO wird bei der Umwandlung von L-Arginin zu L-Zitrullin durch die Stickstoffmonoxidsynthase gebildet (MacMicking et al. 1997; van der Veen 2001). Geringe NO-Mengen, welche von der endothelialen und neuronalen Stickstoffmonoxidsynthase konstitutiv gebildet werden, spielen eine wichtige Rolle bei intrazellulären Signalwegen, wie der Neurotransmission und Vasoregulation (Linares et al. 2006; Sanders und De Keyser 2007). Die dritte Form, die induzierbare Stickstoffmonoxidsynthase (iNOS), wird mit erhöhten Stickstoffmonoxidkonzentrationen im ZNS in Verbindung gebracht. Deren Expression ist ein Kennzeichen entzündlicher und neurodegenerativer ZNS-Erkrankungen (Smith und Lassmann 2002; Linares et al. 2006). Unter physiologischen Bedingungen kann keine Expression von iNOS im ZNS nachgewiesen werden (Koprowski et al. 1993; Van Dam et al. 1995).

Die Produktion von iNOS erfolgt hauptsächlich durch Makrophagen/Mikroglia, aber auch Astrozyten, Oligodendrozyten und Endothelzellen können iNOS exprimieren 
(Hewett et al. 1993; Merrill et al. 1997). Die Regulation der Expression erfolgt auf transkriptionaler Ebene über den NF-кB-Signalweg. Somit kann die Transkription von iNOS durch die Zytokine TNF- $\alpha$, IFN- $\gamma$ und IL-1, durch Prostaglandin 2 und CAMP induziert werden. IFN- $\gamma$ scheint hierbei eine besondere Rolle zu spielen, da IFN- $\gamma$ defiziente-Mäuse kein iNOS in entzündlichen Läsionen bilden (van der Veen 2001). Der bekannteste Inhibitor der iNOS Expression ist TGF- $\beta$. Durch die Destabilisierung der mRNA wird die Translation verzögert bzw. gehemmt und ihr Abbau beschleunigt (Vodovotz und Bogdan 1994). Des Weiteren wirken IL-4, IL-10, und Glukokortikoide inhibierend (Bogdan et al. 1991; Bogdan et al. 1994; Kunz et al. 1996). NO selbst hemmt die NF-кB-Aktivierung in Gliazellen und bildet auf diesem Weg eine negativen Regulationsmechanismus (Griscavage et al. 1993).

Bei MS-Patienten lassen sich neben iNOS-positiven Makrophagen/Mikroglia in aktiven Läsionen NO-Produkte im Serum, Liquor und Urin nachweisen (Giovannoni et al. 1997; Giovannoni 1998; Giovannoni et al. 1999). Die iNOS-Expression und die Menge von NO-Produktion korreliert mit der Krankheitsaktivität, sowie dem Myelin- und Axonschaden, bei der EAE (van der Veen et al. 1997; Touil et al. 2001). Allerdings werden die Auswirkungen von NO und NO-Produkten (Nitroxyl, Salpetrige Säure, Stickstoffdioxid, Nitrat und Salpetersäure) bei MS und EAE kontrovers diskutiert (Sanders und De Keyser 2007). So werden neben einer Schädigung des Gewebes durch oxidativen Stress, Hemmung der mitochondrialen Atmungskette, Erhöhung der Blut-HirnSchranken Permeabilität und Schädigung der DNA, Axone und Oligodendrozyten auch protektive Eigenschaften beschrieben. Hierzu zählen die Hemmung der T-Zellproliferation und der Antigenpräsentation, eine verminderte Adhäsion und Migration von Leukozyten durch das Endothel und eine NO-induzierte Apoptose von T-Zellen (Albina und Henry, Jr. 1991; Kubes et al. 1991; Sicher et al. 1994).

\subsubsection{CD163 - ein makrophagenspezifisches Protein}

CD163 wurde bislang bei Menschen, Marmosets, bei Schweinen und Nagern beschrieben (Zwadlo-Klarwasser et al. 1992; Law et al. 1993; Schaer et al. 2001; Polfliet et al. 2006). Das humane CD163 ist ein $130 \mathrm{kDa}$ großes Glykoprotein mit einer Transmembrandomäne, wobei ein geringer Teil des Proteins zytoplasmatisch und der Großteil extrazellulär vorliegt (Law et al. 1993; Hogger et al. 1998). Es gehört zur Familie der cysteinreichen Scavengerrezeptoren Gruppe B und wird bei Menschen in Makrophagen und Monozyten gebildet (Graversen et al. 2002). Dabei exprimieren humane Gewebsmakrophagen mehr CD163, wie z. B. die Kupferzellen in der Leber, 
Makrophagen der roten Pulpa der Milz und der Thymusrinde, Knochenmarksmakrophagen und meningeale Makrophagen im ZNS, als Monozyten (Ritter et al. 1999). Im gesunden ZNS-Gewebe sind verzweigte Mikrogliazellen negative für CD163 (Fabriek et al. 2005b). Bei der Ratte hingegen wird CD163 nur von reifen Gewebsmakrophagen gebildet (Polfliet et al. 2006).

Typischerweise werden bei der Heilungsphase von akuten, aber auch bei chronischen Entzündungen CD163-positive Makrophagen beschrieben (Moestrup und Moller 2004). Verschiedene antiinflammatorische Faktoren wie Glukokortikoide, IL-10 und IL-6 induzieren die Expression von CD163 (Van Den Heuvel et al. 1999; Buechler et al. 2000). Umgekehrt hemmen proinflammatorische Mediatoren wie LPS, IFN- $\gamma$ und TNF- $\alpha$ die Expression von CD163 (Buechler et al. 2000) und induzieren die Abspaltung von der Zelloberfläche (Hintz et al. 2002; Weaver et al. 2006). Dies führt zu einer verminderten CD163-Menge in der Zelle und folglich zu einer erhöhten Konzentration im Serum (Hintz et al. 2002; Fabriek et al. 2007). Diese proteolytische Spaltung erfolgt durch Metalloproteinasen und der Proteinkinase C (Droste et al. 1999; Hintz et al. 2002; Matsushita et al. 2002).

Es wird angenommen, dass CD163 eine Rolle bei der Immunsuppression und Heilung spielt. Allerdings ist die bislang am besten charakterisierte Funktion des membranständigen CD163 die Bindung des Hämoglobin-Haptoglobin-Komplexes ( $\mathrm{Hb}-\mathrm{Hp})$, der anschließend durch Endozytose von Makrophagen aufgenommen wird. Auf diese Weise wird die im Plasma zirkulierende Menge an freiem Hämoglobin reduziert und beugt somit dessen toxischer Wirkung vor (Kristiansen et al. 2001; Graversen et al. 2002). In Makrophagen erfolgt anschließend der Abbau des Häms durch die Hämoxigenase-1. Neben dem Schutz vor Gewebeschaden scheint die Hämendozytose ein wichtiger Weg zur Eisenaufnahme von Makrophagen zu sein (Kristiansen et al. 2001; Fabriek et al. 2005a). Die Bindung von Hb-Hp an CD163 hat zusätzlich die Synthese von Zytokinen, darunter IL-10, zur Folge. Da IL-10 wiederum die Expression von CD163 und Hämoxigenase-1 induzieren kann, stellt dies womöglich einen positiven Feed-back Mechanismus dar. Der Signalweg, über welchen CD163 die Zytokinproduktion reguliert, ist noch nicht erforscht (Philippidis et al. 2004).

Über die Funktion des löslichen CD163 (sCD163) ist bislang wenig bekannt. Da durch inflammatorische Stimuli die Abspaltung induziert wird, wird von einer immunmodulatorischen Funktion ausgegangen (Droste et al. 1999).

In MS-Läsionen können CD163-positive, schaumzellige Makrophagen nachgewiesen werden (Fabriek et al. 2005b). Ebenso wurde über erhöhte Mengen im Serum berichtet 
(Fabriek et al. 2007). Allerdings ist die Rolle von CD163 bei EAE und MS bislang unklar.

\subsubsection{Hämoxigenase-1}

Die Hämoxigenase (HO), ein Hitzeschockprotein, wird bei zahlreichen ZNSErkrankungen vermehrt gebildet. Hämolyse und oxidativer Stress führen zu einer Freisetzung von Häm (Ryter et al. 2007), welches aufgrund der Bildung von freien Radikalen und Lipidperoxidation toxisch für Zellen ist (Dong et al. 2000). Ein Abbau von Häm, welches zuvor über den $\mathrm{Hb}-\mathrm{Hp}-K o m p l e x$ in die Zelle aufgenommen wurde, erfolgt über HO durch die Spaltung des Tetrapyrrolrings. Dabei werden zweiwertiges Eisen, Kohlenmonoxid ( $\mathrm{CO}$ ) und Biliverdin, das durch die Biliverdinreduktase weiter in Bilirubin umgewandelt wird, freigesetzt (Tenhunen et al. 1969).

Beim Menschen sind bislang zwei Isoformen bekannt: die konstitutiv und ubiquitär exprimierte Form HO-2 und die induzierbare Form HO-1 (Maines 1988). Obwohl beide Enzyme die gleiche Reaktion katalysieren, schützen sie wahrscheinlich auf unterschiedliche Weise das Gewebe vor Schädigungen (Mancuso 2004). In der Ratte wird zudem eine dritte Form beschrieben, welche ebenfalls konstitutiv exprimiert wird (Scapagnini et al. 2002). Unter physiologischen Bedingungen erfolgt die Expression von HO-1 in geringen Mengen in vereinzelten Neuronen und in glialen Zellen (Baranano und Snyder 2001). Erst durch oxidativen und nitrosativen Stress, Ischämie, Hitzeschock, LPS, Hämin, $\mathrm{H}_{2} \mathrm{O}_{2}, \beta$-Amyloid, Dopamin, $\mathrm{T}_{\mathrm{H}} 1$-Zytokine, Prostaglandine, UV-Licht oder andere prooxidative und inflammatorische Stimuli erfolgt eine vermehrte Expression von HO-1 (Schipper 2004).

Die Rolle von HO-1 erscheint kontrovers, wobei HO-1 je nach exprimierter Menge protektiv oder schädlich wirken kann. Eine geringe bis mäßige Überexpression von HO-1 (bis fünffach über Grundniveau) gilt als antiinflammatorisch und schützt die Zellen unter anderem durch die antioxidative Wirkung von Bilirubin und Biliverdin. Hingegen führen hohe Mengen (ab 15fach) an HO-1 durch eine übermäßige Freisetzung von Eisen zu Eisenablagerungen in den Zellen und zur Bildung von reaktiven Sauerstoffmolekülen (Zhang und Piantadosi 1992; Suttner und Dennery 1999; Frankel et al. 2000). Ebenso führt übermäßig freigesetztes CO zur Weitung von Gefäßen und Ischämie und zudem sind erhöht Mengen an Bilirubin toxisch für Zellen (Stocker et al. 1987).

Bei MS und EAE wird die Expression von HO-1 beschrieben, die Rolle ist allerdings bisher unklar. Es kann einerseits ein milderer EAE-Verlauf durch die pharmakologische Hemmung von HO-1 erzielt werden (Chakrabarty et al. 2003), andererseits wird bei 
EAE-Versuchen mit HO-1 defizienten Mäusen vermehrt Entzündung und eine höhere Mortalitätsrate beschrieben (Kapturczak et al. 2004; Chora et al. 2007).

\subsection{Zielsetzung}

Ziel der vorliegenden Arbeit ist es, experimentelle Modelle der multiplen Sklerose (MS) zu entwickeln, mit deren Hilfe die pathologischen Schädigungsmechanismen bei entzündlicher Entmarkung speziell in der grauen Substanz des Rückenmarks und im Gehirn untersucht werden können. Hierzu wurden die folgenden beiden Ansätze gewählt:

1) Die Immunisierung von Lewis-Ratten mit dem neuronalen Antigen $\beta$-Synuklein ${ }_{93-111}$ führt zu einem selektiven Befall der grauen Substanz des Rückenmarks (Mor et al. 2003). Der zusätzliche Transfer des entmarkenden anti-MOG-Antikörpers 8-18C5 erhöht die Ähnlichkeit der rein entzündlichen $\beta$-Synuklein ${ }_{93-111}$-induzierten EAE zur entzündlich-entmarkenden Pathologie der MS. In diesem Modell sollte untersucht werden, welche Auswirkungen entzündliche Entmarkung in der grauen Substanz - bei weitgehendem Fehlen eines Befalls der weißen Substanz - auf die Funktion und das Überleben von Nervenzellen hat. Des Weiteren sollte das Ausmaß der Makrophagenund Mikrogliaaktivierung bei der rein entzündlichen $\beta$-Synuklein-EAE mit der entzündlich-entmarkenden $\beta$-Synuklein-EAE nach anti-MOG-Antikörpertransfer vergleichend untersucht werden.

2) Die Cuprizon-induzierte Entmarkung führt zu einem Verlust der Oligodendrozyten und Markscheiden mit nur geringfügiger axonaler Schädigung im Corpus callosum von Mäusen bei intakter Blut-Hirn-Schranke (BHS). Die Immunisierung von Mäusen mit $\mathrm{MOG}_{35-55}$ hingegen hat die massive Infiltration von Entzündungszellen in das Rückenmark über eine offene BHS zur Folge. Im zweiten Teil dieser Arbeit sollten durch die Kombination der Toxin-induzierten Entmarkung durch Cuprizon und der Immunisierung mit $\mathrm{MOG}_{35-55}$ reproduzierbare $M S$-ähnliche Läsionen im Mausgehirn induziert werden. Anhand des neu etablierten Modells sollte untersucht werden, inwieweit eine adaptive Immunantwort mit Infiltration von Entzündungszellen aus dem Blut und die dadurch vermehrte Freisetzung entzündlicher Mediatoren zum Axonschaden beitragen. Ein weiterer Aspekt dieser Arbeit war es zu untersuchen, inwieweit sich aktivierte Mikroglia im Cuprizon-Modell von aktivierten Makrophagen/Mikroglia nach aktiver Immunisierung unterscheiden. 
Das Beenden der Cuprizon-Diät hat die rasche Neubildung der Markscheiden zu Folge. Ein Vergleich der Remyelinisierungseffizienz nach ausschließlicher Cuprizon-Gabe und Cuprizon-Gabe mit zusätzlicher Immunisierung sollte Aufschluss darüber geben, ob Entzündung die Neubildung der Myelinscheiden beeinflusst.

Aufgrund der Läsionslokalisation im Mausgehirn eignet sich das Modell der CuprizonEAE besonders für bildgebende Analysen. Bei der Cuprizon-induzierten Entmarkung kann mittels der Diffusions-Tensor-Bildgebung zwischen Axonschaden und Myelinverlust unterschieden werden (Sun et al. 2006). Da bei diesem nicht-entzündlichen Modell der Einfluss von Entzündungszellen auf die Anisotropie der Wassermoleküle nicht untersucht werden konnte, sollte anhand des hier neu entwickelten Modells untersucht werden, welchen Einfluss entzündliche Infiltrate auf die Diffusion der Wassermoleküle haben. 


\section{Material und Methoden}

\subsection{Versuchstiere}

Für die Versuche wurden weibliche Mäuse (C57BL/6) im Alter von sechs bis acht Wochen verwendet und wurden von der Firma Charles River, Sulzfeld, Deutschland bezogen.

Darüber hinaus wurden folgende Ratten verwendet:

- Lewis-Ratten (weiblich, 160-180 g) der Firma Harlan-Winkelmann (Borchen, Deutschland), sowie

- CD8-defiziente Ratten (männlich und weiblich, 10 Wochen) aus der Zucht von Prof. Dr. H. Reichardt. Bei diesen Tieren dienten die jeweiligen Wurfgeschwister als Kontrollen.

Die Haltung der Tiere sowie Durchführung aller Versuche erfolgten nach den Richtlinien der Tierexperimentellen Einrichtung der Universität Göttingen bei einem regelmäßigen Tag-Nacht-Zyklus von je 12 Std.. Die dafür benötigten Genehmigungen erteilte die Bezirksregierung in Braunschweig.

\subsection{Tierexperimentelle Methoden}

\subsubsection{Induktion der EAE}

\subsubsection{Herstellung der $\mathrm{MOG}_{35-55}$-Emulsion und Induktion der EAE in Mäusen}

Pro Maus wurden $200 \mu \mathrm{l}$ Emulsion verwendet. Diese bestand aus $100 \mu \mathrm{l}$ kompletten Freund'schen Adjuvans (CFA; inkomplettes Freund'sches Adjuvans, Sigma-Aldrich Chemie $\mathrm{GmbH}$, Steinheim, Deutschland mit $10 \mathrm{mg} / \mathrm{ml}$ Mycobacterium tuberculosis H37Ra, Difco Laboratories, Augsburg, Deutschland) sowie $300 \mu \mathrm{g} \mathrm{MOG}_{35-55}$-Peptid (Institut für Medizinische Immunologie, Universitätsklinikum Charité, Berlin, Deutschland) in $100 \mu \mathrm{l}$ PBS. Durch wiederholtes Sonifizieren (Sonopuls ${ }^{\circledR}$ Ultraschallgerät, Bandelin electronic, Berlin, Deutschland, 20 sec., cycle 5, 45-50\%) auf Eis wurde eine cremige Emulsion hergestellt.

Die Emulsion für die Immunisierung mit dem ZNS-unspezifischen Antigen Ovalbumin wurde analog dem Protokoll der $\mathrm{MOG}_{35-55}$-Emulsion hergestellt, jedoch wurde anstelle des MOG-Peptids $100 \mu \mathrm{g}$ Ovalbuminprotein (Sigma-Aldrich Chemie GmbH, Steinheim, Deutschland) verwendet. 
Unter Äthernarkose (Diethylether, Sigma-Aldrich Chemie GmbH, Steinheim, Deutschland) wurden an den Abgängen der Vorder- und Hinterbeine jeweils $50 \mu \mathrm{l}$ Emulsion subkutan injiziert. Am Tag der Injektion und zwei und neun Tage danach erhielten die Mäuse durch intraperitoneale Injektion zusätzlich 300 ng Pertussis Toxin (PTX) (List Biological Laboratories, London, UK), welches in $300 \mu$ I PBS gelöst war. In den unter 4.2.2 beschriebenen Versuchen erhielten die Mäuse nur am Tag der Injektion und zwei Tage danach jeweils 300 ng PTX.

\subsubsection{Herstellung der $\beta$-Synuklein ${ }_{93-111}$-Emulsion, Induktion der EAE und der Trans- fer von Antikörpern}

Zunächst wurde das $\beta$-Synuklein ${ }_{93-111}$-Peptid (Institut für Medizinische Immunologie, Universitätsklinikum Charité, Berlin, Deutschland) nach den Angaben von Mor (Mor et al. 2003) gelöst und auf eine Konzentration von $4 \mu \mathrm{g} / \mu \mathrm{l}$ mit PBS verdünnt. Die anschließend hergestellte Emulsion enthielt für jede Ratte $200 \mu \mathrm{g}$ M. tuberculosis H37Ra in $50 \mu \mathrm{l}$ inkomplettem Freund'schen Adjuvans (CFA) und $100 \mu \mathrm{g} \beta$-Synuklein ${ }_{93-111}$ in $50 \mu \mathrm{l}$ PBS. Durch wiederholtes Sonifizieren (20 sec., cycle 5, 45-50\%) auf Eis wurde eine cremige Emulsion hergestellt. Die subkutane Injektion erfolgte unter Isofluorannarkose (Isoflouran, Abbott, Wiesbaden, Deutschland) an der Schwanzbasis. Diese Emulsion erhielten alle Ratten, abgesehen von den Kontrolltieren. Bei diesen bestand die Emulsion aus $50 \mu \mathrm{l}$ CFA und $50 \mu \mathrm{l}$ PBS.

Den Lewis-Ratten wurde zusätzlich 2 mg Antikörper in $500 \mu \mathrm{l}$ PBS (anti-MOG 8-18C5 (Linnington et al. 1984) oder IgG1-Isotypkontrollantikörper; BioExpress Inc., West Lebanon, USA) unter Isofluorannarkose in den retroorbitalen Venenplexus bei beginnender Krankheit injiziert. Die Anzahl aller hierbei verwendeten Tiere sowie das Versuchsende ist der Tabelle 2-1 zu entnehmen.

Tabelle 2-1: Gesamtzahl der verwendeten Ratten, der Zeitpunkt der Tötung und der verwendete Antikörper.

\begin{tabular}{llll}
\hline \hline $\begin{array}{l}\text { Versuchsende } \\
\text { nach Transfer }\end{array}$ & $\mathbf{3 0}$ Stunden & 4 Tage & 20 Tage \\
\hline \hline Kontrollen (CFA) & 5 & & \\
\hline$\beta$-Synuklein & & \\
& $8(8-1111$ & $3(8-18 C 5)$ & $5(8-18 C 5)$ \\
& $6(\operatorname{lgG})$ & & $5(\operatorname{lgG})$ \\
\hline \hline
\end{tabular}

Bei dem zusätzlichen Versuch mit CD8-defizienten Ratten wurden die Tiere mit

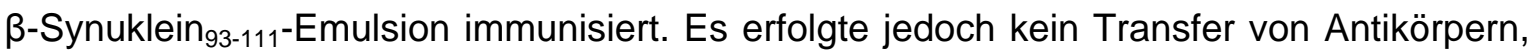


wie dies bei den zuvor beschriebenen Versuchen vorgenommen wurde. Die weiblichen Tiere (3 $\mathrm{CD}^{-{ }_{-}}$und 3 WT) wurden in der akuten Krankheitsphase getötet, die männlichen (3 $\mathrm{CD}^{-/-}$und $2 \mathrm{WT}$ ) hingegen erst nach vollständiger Erholung.

\subsubsection{Klinische Beurteilung der EAE bei Mäusen und Ratten}

Bis zum Krankheitsbeginn wurde, angefangen mit dem Tag der Immunisierung, das Gewicht jeden zweiten Tag bestimmt. Nach Einsetzen der ersten klinischen Symptome wurden die Tiere täglich gewogen und der Krankheitsgrad anhand des nachfolgenden EAEScores bestimmt (Tab. 2-2).

Tabelle 2-2: Verwendeter EAE-Score

\begin{tabular}{ll}
\hline \hline EAE-Score & Klinische Symptome \\
\hline \hline 0 & keine \\
\hline 0,5 & Schwanzspitzenparese \\
\hline 1 & komplette Schwanzparese \\
\hline 1,5 & komplette Schwanzlähmung und leichte Parese der Hinterbeine \\
\hline 2 & komplette Schwanzlähmung, deutliche Parese der Hinterbeine \\
\hline 2,5 & starke Parese der Hinterbeine, mindestens ein Bein wird nachgezogen \\
\hline 3 & Paralyse beider Hinterbeine \\
\hline 3,5 & Paralyse der Hinterbeine und leichte Parese der Vorderbeine \\
\hline 4 & Paralyse der Hinter- und Vorderbeine \\
\hline 4,5 & schwere Tetraparese, moribund \\
\hline 5 & tot \\
\hline \hline
\end{tabular}

Tiere mit einem Gewichtsverlust von mehr als 25\% und / oder einem Score von mindestens 3,5 wurden aus dem Versuch genommen.

\subsubsection{Verfütterung von Cuprizon}

Cuprizon (Sigma-Aldrich Chemie $\mathrm{GmbH}$, Steinheim) wurde geriebenem Normalfutter beigemengt und an die Versuchstiere verfüttert. Die nicht-behandelten Kontrolltiere erhielten über den gleichen Zeitraum ausschließlich Normalfutter. Die Tiere in den unter 4.2 beschriebenen Versuchen erhielten während der gesamten Versuchsdauer 0,2\% Cuprizon dem Futter beigemengt. Der Versuchsaufbau und die verwendeten Cuprizonmengen aller 
nachfolgenden Versuche (ab. 4.3) sind im Ergebnisteil II (Abschnitt. 4.1.2) aufgeführt. Die Ergebnisse aller durchgeführten Versuche wurden durch Wiederholung bestätigt.

\subsection{Gewebsasservation}

Bei Versuchsende wurden Mäuse mit $300 \mu \mathrm{l}$ und Ratten mit 1 ml 14\%-iger Chloralhydratlösung (Merck KGaA, Darmstadt, Deutschland) anästhesiert. Sobald die Tiere keinerlei Schmerzreflexe mehr zeigten, wurde das Gewebe durch Perfusion fixiert oder nativ entnommen.

\subsubsection{Transkardiale Perfusion mit Paraformaldehyd (PFA) und die Einbettung in Paraffin}

Bei der transkardialen Perfusion wurde den Tieren zunächst das Blut mit PBS aus dem Körper gespült und anschließend das Gewebe mit 4\%-iger PFA-Lösung fixiert. Das so asservierte Gehirn und Rückenmark wurde aus der knöchernen Hülle auspräpariert, in 3 bis $4 \mathrm{~mm}$ dicke Scheiben geschnitten und anschließend in einer aufsteigenden Alkoholreihe dehydriert und in Paraffin (Paraplast Plus, Tyco Healthcare $\mathrm{GmbH}$, Neustadt a.d. Donau, Deutschland) ausgegossen.

\section{4\% PFA}

40 g PFA (Merck KGaA, Darmstadt, Deutschland)

in $500 \mathrm{ml}$ Aqua bidest. unter Rühren auf $60-65^{\circ} \mathrm{C}$ erhitzen

$1 \mathrm{M} \mathrm{NaOH}$ zugeben, bis die Lösung klar wird

$100 \mathrm{ml}$ PBS (10fach konzentriert)

ad. $1000 \mathrm{ml}$ Aqua bidest. pH 7,3

\subsubsection{HOPE-Fixierung und Einbettung in Paraffin}

Von einem Teil der Tiere wurde das ZNS mit HOPE-Lösung (DCS, Innovative DiagnostikSystem, Hamburg, Deutschland) fixiert. Zu diesem Zweck wurde das nativ entnommene Gehirn in 3 bis $4 \mathrm{~mm}$ dicke Scheiben geschnitten und über Nacht in HOPE-1 Lösung inkubiert. Am folgenden Tag wurde diese für 2 Std. durch die HOPE-2 Lösung (1:1000 in Aceton) ersetzt. Anschließend erfolgte die Entwässerung des Gewebes durch Aceton (Merck KGaA, Darmstadt, Deutschland) für 2 Std. Dieser Schritt wurde insgesamt dreimal durchgeführt. Alle Arbeitsschritte erfolgten auf Eis und mit vorgekühlten Lösungen. Abschließend wurde das Gewebe über Nacht mit $60^{\circ} \mathrm{C}$ warmen Low Melting-Paraffin (DCS, 
Innovative Diagnostik-System, Hamburg, Deutschland) durchtränkt und am nächsten Tag in Paraffin ausgegossen und bei $4^{\circ} \mathrm{C}$ aufbewahrt.

\subsubsection{RNAlater}

Für die Isolierung von mRNA wurde zunächst der Balken aus nativen Gehirnen ausgeschnitten und bis zur Weiterverarbeitung in $1 \mathrm{ml}$ RNAlater pro $50 \mu \mathrm{g}$ Gewebe (Qiagen, Hilden, Deutschland) konserviert.

\subsection{Histologische Techniken}

Von den zuvor angefertigten Paraffinblöcken wurden für die nachfolgenden histologischen Färbungen $1 \mu \mathrm{m}$ dicke, serielle Schnitte mit einem Mikrotom (Leica, Wetzlar, Deutschland) angefertigt und auf Objektträger (Menzel-Gläser, Braunschweig, Deutschland) aufgezogen.

Das Gewebe wurde vor sämtlichen beschriebenen histologischen Techniken zunächst entparaffiniert (dreimal 3 min Xylol, 3 min Isoxylol) und in einer absteigenden Alkoholreihe rehydriert (jeweils 3 min in Ethanol 100\% $\rightarrow$ 100\% $\rightarrow$ 90\% $\rightarrow 70 \% \rightarrow 50 \% \rightarrow$ Aqua bidest.).

Nach Abschluss der jeweils angewandten Färbemethode wurde das Gewebe zur abschließenden Konservierung, soweit nicht anders angegeben, in der aufsteigenden Alkoholreihe dehydriert (jeweils 3 min Aqua bidest. $\rightarrow 50 \% \rightarrow 70 \% \rightarrow 90 \% \rightarrow 100 \%$ $100 \%$ Ethanol $\rightarrow$ Xylol) und mit DePeX mounting medium eingedeckelt.

Tabelle 2-3: Verwendete Substanzen für die histologischen Techniken

\begin{tabular}{ll}
\hline \hline Substanz & Bezugsquelle \\
\hline \hline $\begin{array}{l}\text { 3-3'-Diaminobenzidin-Tetrahydrochlorid } \\
\text { (DAB) }\end{array}$ & Sigma-Aldrich \\
\hline 3-Amino-9 Ethylcarbazol & Merck \\
\hline 4-NitroblauTetrazoliumchlorid (NBT) & Roche \\
\hline 5-bromo-4 chlor-3-indolyl-phospat (BCIP) & Roche \\
\hline Ammoniak & Merck \\
\hline anti-Digoxigenin-AP Antikörper & Roche \\
\hline Aviden-Biotin-Block & DAKO \\
\hline BSA Fraktion V & Serva \\
\hline
\end{tabular}




\begin{tabular}{|c|c|}
\hline Substanz & Bezugsquelle \\
\hline Kakodylsäure & Sigma-Aldrich \\
\hline I-Block (Casein) & Tropix \\
\hline CytomaFluorescent mounting Medium & DAKO \\
\hline DePeX mounting medium & VWR International \\
\hline DigDNA & Roche \\
\hline Eisessig & Merck \\
\hline Eosin-G Certistain $^{\circledR}$ & Merck \\
\hline Essigsäure (100 \%) & Merck \\
\hline Ethanol & Merck \\
\hline ExtraAvidin & Sigma-Aldrich \\
\hline fetales Kälberserum (FCS) & Biochrom \\
\hline Formalin (37 \%) & Merck \\
\hline Hämalaun-Lösung nach Meyer & Merck \\
\hline Immu-Mount & Thermo Shandon \\
\hline Isopropylalkohol & Merck \\
\hline Kalziumchlorid $(\mathrm{CaCl})$ & Merck \\
\hline Kobaltchlorid (CoCl) & Merck \\
\hline Kresylviolett (N) & Merck \\
\hline Lithiumcarbonat & Merck \\
\hline Luxol-fast-blue & $\mathrm{BDH}$ \\
\hline Magnesiumchlorid (MgCl) & Merck \\
\hline N’N - Dimethylformamid & Merck \\
\hline Natriumacetat-Trihydrat & Merck \\
\hline Natriumchlorid $(\mathrm{NaCl})$ & Merck \\
\hline Natriumthiosulfatlösung & Merck \\
\hline $\begin{array}{l}\text { PBS DULBECCO Instamed 9,55g/l w/o } \\
\mathrm{Ca}^{2+}, \mathrm{Mg}^{2+}\end{array}$ & Biochrom AG \\
\hline Perjodsäure & Merck \\
\hline Proteinase $\mathrm{K}$ & Roche \\
\hline Proteinase Typ XXIV & Sigma-Aldrich \\
\hline Salpetersäure (65 \%) & Merck \\
\hline Salzsäure & Merck \\
\hline Schiff's Reagenz & Merck \\
\hline Sibernitrat & Roth \\
\hline
\end{tabular}




\begin{tabular}{ll}
\hline \hline Substanz & Bezugsquelle \\
\hline \hline Terminale Transferase & Roche \\
\hline Tris & Sigma-Aldrich \\
\hline Wasserstoffperoxid $\left(\mathrm{H}_{2} \mathrm{O}_{2} 30 \%\right)$ & Merck \\
\hline Xylol & Merck \\
\hline Zitronensäure-Monohydrat & Merck \\
\hline \hline
\end{tabular}

Roche Applied Science, Mannheim, Deutschland; Sigma-Aldrich Chemie GmbH, Steinheim, Deutschland; Merck KGaA, Darmstadt, Deutschland; Roth, Karlsruhe, Deutschland; Biochrom AG, Berlin, Deutschland; DAKO, Glostrup, Dänemark; Thermo Shandon, Pittsburgh, PA, USA; VWR International Ltd., Poole, UK; (BDH Laboratory Supplies); SERVA Electrophoresis GmbH, Heidelberg, Tropix, Bedford,USA

Tabelle 2-4: Allgemein verwendete Lösungen

\begin{tabular}{ll}
\hline \hline Lösung & Zusammensetztung \\
\hline \hline HCl-Alkohol & $1750 \mathrm{ml}$ Iso-Alkohol \\
& $750 \mathrm{ml}$ Wasser \\
& $25 \mathrm{ml}$ Salzsäure $(20 \%)$ \\
\multirow{2}{*}{ Iso-Xylol } & Ethanol und Xylol zu gleichen Teilen \\
\hline \hline
\end{tabular}

\subsubsection{Hämatoxylin-Eosin}

Bei dieser Färbetechnik werden das Chromatin und Ribsomen-haltige Strukturen blau angefärbt, das Parenchym rosa.

Nach der Entparaffinierung und Rehydrierung in der absteigenden Alkoholreihe erfolgte die Färbung der Zellkerne in der Hämalaun-Lösung nach Meyer (8 min). Vor dem Bläuen der Schnitte unter fließendem Leitungswasser wurden diese zunächst in $\mathrm{HCl}$-Alkohol differenziert. Für die Färbung des Parenchyms wurden die Schnitte 5 min in der Eosinlösung inkubiert. Um ein zu starkes Auswaschen des Eosins bei der Rehydrierung zu verhindern, wurden die Schnitte in der aufsteigenden Alkoholreihe bis zum reinen Ethanol jeweils nur kurz eingetaucht. Alle weiteren Schritte konnten wie zuvor beschrieben durchgeführt werden.

\section{Eosin-Stammlösung 1\%}

2 g Eosin-G Certistain ${ }^{\circledR}$

$40 \mathrm{ml}$ Aqua bidest.

$160 \mathrm{ml}$ Ethanol 95\% 


\subsubsection{Luxol-fast-blue I Perjodsäure-Schiff'sche Reagenz-(LFB/PAS) Färbung}

Bei der LFB/PAS-Färbung erfolgt eine Blaufärbung des Myelins mittels Luxol-fast-blue, das Parenchym und die entmarkten Bereiche werden durch die Inkubation im Schiff'schen Reagenz rosa gefärbt.

Nach der Entparaffinierung und Rehydierung bis zum 90\%-igen Ethanol wurden die Schnitte über Nacht bei $60^{\circ} \mathrm{C}$ in der Luxol-fast-blue-Lösung inkubiert. Am nächsten Tag wurden diese zunächst erneut in die 90\%-ige Ethanollösung überführt. Zur anschließenden Differenzierung wurden die Schnitte in 0,05\% Lithiumcarbonat in Aqua bidest., 70\%-igen Ethanol und destilliertes Wasser getaucht, bis die überschüssige Färbelösung ausgewaschen und nur noch das Myelin blau gefärbt war. Im nächsten Arbeitsschritt wurden die Schnitte für 5 min in 1\%-iger Perjodsäure in Aqua bidest. inkubiert und anschließend unter fließendem Leitungswasser und Aqua bidest. gespült. Durch die Inkubation im Schiff's Reagenz (30 min) und erneutem Spülen mit Leitungswasser (5 min) und Aqua bidest. erfolgte die Färbung des Parenchyms. Die Kerne wurden mit Hämalaun-Lösung nach Meyer (2 min), kurzem Differenzieren in HCl-Alkohol und Bläuen unter fließendem Leitungswasser (5-10 min) gegengefärbt. Abschließend erfolgte die Entwässerung des Gewebes in der aufsteigenden Alkoholreihe.

\section{Luxol-fast-blue-Lösung (LFB-Lösung)}

$1 \mathrm{~g}$ Luxol-fast-blue

$1000 \mathrm{ml}$ Ethanol 95\%

$5 \mathrm{ml}$ Essigsäure 10\%

\subsubsection{Bielschowsky-Versilberung}

Bei der Versilberung nach Bielschowsky färben sich die Axone schwarz / tiefbraun an. Das restliche Gewebe erscheint hellbraun.

Nach der Entparaffinierung und Rehydrierung in der absteigenden Alkoholreihe wurden die Schnitte zunächst in eine 20\%-ige Silbernitratlösung für 20 min gestellt und anschließend mit Aqua bidest. gespült. Der zuvor verwendeten Silbernitrat-Lösung wurde - bis sich der entstandene Niederschlag klärte - tropfenweise Ammoniak (32\%) zugegeben. Die Schnitte wurden daraufhin für 15 min im Dunkeln in der zuvor hergestellten Silbernitrat-Ammoniak-Lösung inkubiert und anschließend in mit einigen Tropfen Ammoniak versetztem Wasser gespült. Zur Silbernitrat-Ammoniak-Lösung wurden 10 Tropfen Entwicklerlösung zugegeben und die Schnitte in der Lösung belassen, bis sich die Nervenfasern schwarz und das Parenchym braun färbten. Die Objekträger wurden erneut mit Aqua bi- 
dest. gespült sowie für 2 min in 2\%-iger Natriumthiosulfatlösung inkubiert. Abschließend erfolgte die Rehydrierung in einer aufsteigenden Alkoholreihe, wobei die verwendeten Objektträger zuvor mit Leitungswasser gespült wurden.

$\begin{array}{ll}\text { Entwicklerlösung } & \\ 20 \mathrm{ml} & \text { Formalin (37\%) } \\ 100 \mathrm{ml} & \text { Aqua bidest. } \\ 0,5 \mathrm{~g} & \text { Zitronensäure } \\ 2 \text { Tropfen } & \text { Salpetersäure (65\%) }\end{array}$

\subsubsection{Nissl-Färbung}

Neurone können durch die sogenannte Nissl-Färbung sichtbar gemacht werden. Bei dieser Technik färben sich die Nissl-Schollen und die Zellkerne blau-violett.

Nach der Entparaffinierung und Rehydrierung in der absteigenden Alkoholreihe erfolgte die Inkubation der Schnitte in 1\%-iger Kresylviolett (N)-Lösung für 30 min bei Raumtemperatur. Anschließend wurden diese in Aqua bidest. gespült und überschüssiger Farbstoff in 1\%-iger Essigsäure ausgewaschen. Vor der Rehydrierung der Schnitte in der aufsteigenden Alkohlreihe erfolgte eine zweimalige Inkubation in reinem Isopropylalkohol für jeweils 3 Minuten.

\subsubsection{Immunhistochemische Färbungen}

Alle immunhistochemischen Färbungen wurden in einer feuchten Kammer durchgeführt. Um ein Ausbleichen der Chromogene bei Fluoreszenzfärbungen zu vermeiden, waren diese lichtundurchlässig. Bei den Färbungen wurde der Sekundärantikörper jeweils so gewählt, dass dieser gegen die Spezies gerichtet war, in welcher der Primärantikörper erzeugt worden war. Sind keine anderslautenden Angaben gemacht, wurde pro Objekträger $50 \mu \mathrm{l}$ der jeweiligen Lösung verwendet. Des Weiteren wurden alle Inkubationsschritte über Nacht bei $4^{\circ} \mathrm{C}$ durchgeführt und das Gewebe mit Deckgläsern abgedeckt. Kürzere Inkubationszeiten wurden für gewöhnlich bei Raumtemperatur (RT) durchgeführt oder bei den entsprechenden angegebenen Temperaturen. 


\subsubsection{Einfachmarkierungen}

Alle immunhistochemischen Färbungen wurden nach folgendem Protokoll durchgeführt, soweit nachfolgend keine abweichenden Angaben aufgeführt sind.

Nachdem das Gewebe entparaffiniert und rehydriert wurde, erfolgte die Demaskierung (Vorbehandlung) der Antigene durch Kochen in Citratpuffer oder Inkubation in Proteinase. Bei Antikörpern ohne Vorbehandlung entfiel dieser Schritt. Nach jedem der nachfolgenden Arbeitsschritte erfolgte mehrmaliges Waschen der Objektträger mittels PBS.

Anschließend wurde die endogene Peroxidase des Gewebes in $50 \mathrm{ml}$ 3,33\%-igem $\mathrm{H}_{2} \mathrm{O}_{2}$ in PBS (10 min bei $4^{\circ} \mathrm{C}$ ) blockiert und unspezifische Bindungsstellen mit einer $10 \%$-igen FCS/PBS-Lösung abgesättigt. Der Primärantikörper wurde - wie in den Tabellen 2-6, 2-7 oder 2-8 angegeben - in 10\%-iger FCS/PBS-Lösung verdünnt, auf die Objekträger getropft und über Nacht inkubiert. Am folgenden Tag wurde die Sekundärantikörperverdünnung (10\% FCS/PBS) auf die Schnitte aufgetragen. Die jeweilige Verdünnung der Antikörper ist der Tabelle 2-9 zu entnehmen. Nachfolgend wurden die Schnitte für $1 \mathrm{Std}$. mit Peroxidase konjugiertem Streptavidin (1:1000) inkubiert. Die Sichtbarmachung der gebundenen Antikörper erfolgte mit DAB als Chromogen. Zu diesem Zweck wurden die Schnitte in der DAB-Lösung inkubiert, bis sich eine ausreichende Braunfärbung der markierten Zellen zeigte. Für die Gegenfärbung der Zellkerne wurden diese mit Hämalaun behandelt. Hierfür wurden die Schnitte für 10 sek. in die Hämalaunlösung nach Meyer getaucht, in $\mathrm{HCl}$-Alkohol differenziert und zum Bläuen unter fließendes Leitungswasser gestellt. Abschließend erfolgte die Dehydrierung des Gewebes in der aufsteigenden Alkoholreihe.

\section{Vorbehandlung mit Citratpuffer}

Die Schnitte wurden in einer Küvette fünfmal für jeweils $3 \mathrm{~min}$ in $50 \mathrm{ml}$ Citratpuffer in einer Mikrowelle (800 Watt) gekocht. Nach jedem Kochschritt wurde die Küvette abwechselnd mit Aqua bidest. oder Citratpuffer aufgefüllt. Abschließend kühlte der Puffer für 30 min bei Raumtemperatur ab und dann wurden die Schnitte mit Leitungswasser gespült.

\section{Vorbehandlung mit Proteinase}

Bei dieser Vorbehandlungsmethode wurde das Gewebe in $37^{\circ} \mathrm{C}$ warmer Proteinaselösung für 10 min behandelt. Anschließend wurden die Objekträger in Ethanol kurz geschwenkt und bei Raumtemperatur getrocknet. 
Tabelle 2-5: Verwendete Lösungen bei Einfach- und Doppelmarkierungen

\begin{tabular}{|c|c|}
\hline Lösung & Zusammensetzung \\
\hline Citrat-Puffer & $\begin{array}{l}\text { 2,1014 g Zitronensäure-Monohydrat } \\
\text { ad. } 1 \text { I Aqua bidest., pH } 6\end{array}$ \\
\hline Proteinase-Lösung & $\begin{array}{l}25 \mathrm{mg} \text { Proteinase } \\
\text { ad. } 60 \mathrm{ml} \text { Wasser }\end{array}$ \\
\hline AEC-Stammlösung & $\begin{array}{l}\text { 12,5 g 3-Amino-9 Ethylcarbazol } \\
250 \mathrm{ml} \text { Dimethylformamid }\end{array}$ \\
\hline Acetat-Stammlösung (0,1 M; pH 5,2) & $\begin{array}{l}\text { 1,73 ml Eisessig } \\
\text { 4,025 g Natriumacetat-Trihydrat } \\
\text { ad. } 1 \text { I Aqua bidest., } \mathrm{pH} \mathrm{5,2}\end{array}$ \\
\hline AEC-Entwicklungschromogen & $\begin{array}{l}4 \mathrm{ml} \text { AEC-Stammlösung } \\
56 \mathrm{ml} \text { Acetatpuffer }(0,1 \mathrm{M} ; \mathrm{pH} 5,2) \text {, filtrieren } \\
20 \mu \mathrm{l} \text { Wasserstoffperoxid }(30 \%)\end{array}$ \\
\hline NBT & 100 mg/ml 70\% Dimethylformamid \\
\hline $\mathrm{BCIP}$ & 50 mg/ml 100\% Dimethylformamid \\
\hline NBT-BCIP & $\begin{array}{l}100 \mathrm{mM} \text { Tris } \\
100 \mathrm{mM} \mathrm{NaCl} \\
50 \mathrm{mM} \mathrm{MgCl}{ }_{2} \text { ad. } 50 \mathrm{ml} \text { Aqua bidest. } \\
225 \mu \mathrm{l} \mathrm{NBT} \\
175 \mu \mathrm{l} \mathrm{BCIP}\end{array}$ \\
\hline DAB-Lösung & $\begin{array}{l}25 \mathrm{mg} \mathrm{DAB} \\
18 \mu \mathrm{H} \mathrm{H}_{2} \mathrm{O}_{2} \\
\text { ad. } 50 \mathrm{ml} \text { PBS }\end{array}$ \\
\hline TBS & $\begin{array}{l}9 \mathrm{~g} \mathrm{NaCl} \\
50 \mathrm{ml} \text { Tris/HCl }(1 \mathrm{M} ; \mathrm{pH} 7,5) \\
\text { ad. } 1 \text { I Aqua bidest. }\end{array}$ \\
\hline
\end{tabular}




\subsubsection{Doppelmarkierungen}

Durch Doppelmarkierungen kann die Expression von zwei unterschiedlichen Proteinen gleichzeitig nachgewiesen werden.

\subsection{Doppelmarkierungen, mit zwei Primärantikörpern aus unterschiedlichen Spezien}

Olig2 wird von Oligodendrogliazellen gebildet und NogoA von unreifen und reifen Oligodendrozyten (Kuhlmann et al. 2007).

Die ersten Schritte dieser Doppelmarkierung - bis zur Blockierung der endogenen Peroxidase - sind dem Protokoll für die Einzelfärbung (Abschnitt 2.4.5.1) zu entnehmen. Im nächsten Arbeitsschritt erfolgte die Absättigung unspezifischer Bindungsstellen mit einer 0,2\%-igen Caseinlösung, welche für 15 min auf den Schnitten belassen wurde. Anschließend wurden die Objektträger mit PBS gespült. Der erste Primärantikörper Olig2 wurde in TBS verdünnt (1:300) auf das Gewebe aufgetragen und über Nacht inkubiert. Am nächsten Tag wurden die Schnitte erneut mit PBS gewaschen. Die Inkubationszeit des in TBS verdünnten Sekundärantikörpers (Ziege-anti-Kaninchen AP-konjungiert) betrug $2 \mathrm{Std}$. Im Anschluss wurden die Schnitte mit Tris-Puffer gespült. Der gebundene Antikörper wurde mit NBT/BCIP als Chromogen sichtbar gemacht. Unspezifische Bindungsstellen wurden nun erneut blockiert (10\% FCS in PBS; 20 min). An dieser Stelle und nach jedem weiteren Arbeitsschritt wurden die Schnitte mit PBS gespült. Der Inkubation des zweiten Primärantikörpers in 10\% FCS in PBS (NogoA 1:15 000) folgte die Inkubation des Sekundärantikörpers (biotinyliert anti-Maus 1:200, 10\% FCS in PBS) für 1 Std.. Abschließend wurde für 1 Std. Peroxidase-konjungiertes Streptavidin (1:1000 in PBS) aufgetragen und die gebundenen Antikörper mit AEC als Chromogen sichtbar gemacht. Zur Konservierung wurden die Schnitte mit Immu-Mount eingedeckelt.

\subsection{Doppelmarkierungen, mit zwei Primärantikörpern aus der gleichen Spezies}

Für die Doppelmarkierung mit den Antikörpern CD8 und ED1 wurde das Prinzip der Tyramidamplifikation angewand (Kim et al. 2003), da es sich jeweils um monoklonale antiMaus Antikörper handelte. Hierzu wurde der Tyramide Signal Amplification Kit (Alexa 555, Molecluar Probes ${ }^{\mathrm{TM}}$, Eugene, USA) verwendet. In diesem Kit waren das Blocking Reagent, das Merrettichperoxidase-konjungierte (HRP) Strepdavidin, der Alexa 555 gekoppelte Antikörper und der Amplifikationspuffer enthalten. Für jeden Objektträger wurden 
$50 \mu \mathrm{l}$ der jeweiligen Lösung verwendet, soweit keine andersweitigen Angaben gemacht wurden.

Nach der Entparaffinierung und Rehydrierung des Gewebes erfolgte die Demaskierung der Antigene durch Kochen in Citratpuffer. Nach jedem nachfolgenden Arbeitsschritt wurden die Objektträger mit PBS gewaschen.

Zunächst erfolgte der sogenannte Avidin-Biotin-Block. Hierzu wurde das Gewebe mit einem Tropfen der im Kit enthaltenen Lösung A für 10 min inkubiert. Überschüssige Lösung wurde abgetropft. Anschließend wurde die Lösung B (1 Tropfen) auf dem Schnitt aufgetragen und ebenfalls für 10 min inkubiert. Unspezifische Bindungsstellen wurden bei dieser Methode mit 1\%-iger Blocking Reagent-Lösung abgesättigt (1 Std. RT). Die Bindung des anti-CD-8-Antikörpers (1:10 000 in 1\% Blocking Reagent) erfolgte über Nacht bei $4^{\circ} \mathrm{C}$. Am folgenden Tag wurde zunächst biotinylierter anti-Maus-Antikörper auf den Objektträger aufgetragen (1 Std. RT), welcher an den Primärantikörper bindet. Im folgenden Schritt wurde ein mit HRP-konjungierter anti-Strepdavidin-Antikörper auf das Gewebe aufgetragen (1:100 in 1\%-igem Blocking Reagent; 1Std. RT) und anschließend die gebunden Antikörper mit dem Fluorochrom Alexa 555 gekoppelten Antikörper sichtbar gemacht (1:500 in 0,0015\% $\mathrm{H}_{2} \mathrm{O}_{2}$ in Amplifikationspuffer; 5 min RT). Die Schnitte wurden nun erneut für 20 min bei Raumtemperatur mit 1\%-iger Blocking Reagent-Lösung inkubiert.

Im nächsten Arbeitsschritt wurde der zweite Primärantikörper (ED1 1:500 in 1\%-iger Blocking Reagent-Lösung; $4^{\circ} \mathrm{C}$ ) über Nacht auf den Objektträger aufgetragen, bei dem anti-Maus Cy2 als Sekundärantikörper zum Einsatz kam (1:100 in 1\% Blocking Reagent). Letzterer wurde 1 Stunde bei Raumtemperatur am folgenden Tag auf die Schnitte aufgetragen. Die Färbung der Zellkerne erfolgte mit DAPI (1:10 000; 15 min RT). Abschließend wurden die Objekträger mit Aqua bidest. gespült und mit CytomaFluorescent mounting Medium eingedeckelt. 
Tabelle 2-6: Für Mausgewebe verwendete Antikörper

\begin{tabular}{lllll}
\hline \hline & Antigen/KIon & Spezies & Verdünnung & Bezugsquelle \\
\hline \hline T-Zellen & CD3/CD3-12 & rmk & $1: 100^{1}$ & Serotec \\
\hline Makrophagen & Mac3/M3/84 & $\mathrm{mmk}$ & $1: 200^{1}$ & BD Bioscience \\
\hline Oligodendrozyten & NogoA/11C7 & $\mathrm{mmk}$ & $1: 10000^{1}$ & $\begin{array}{l}\text { (Oertle et al. } \\
\text { 2003) }\end{array}$ \\
\hline iNOS & & & & assay desings \\
\hline Oligodendroglia & iNOS $^{\mathrm{a}}$ & $\mathrm{rpk}$ & $1: 500^{1}$ & IBL \\
\hline Adhäsionsmolekül & VCAM2 $^{4}$ & $\mathrm{rpk}$ & $1: 200^{1}$ & BD \\
\hline Adhäsionsmolekül & ICAM/KAT-1 $^{4}$ & $\mathrm{rmk}$ & $1: 25$ & BD \\
\hline Serumkomponente & Fibrinogen & rpk & $1: 25$ & DAKO \\
\hline & IgG-Vector & sek. & $1: 200^{2}$ & Vector \\
\hline \hline
\end{tabular}

a) TBS anstelle von PBS verwendet und mit Eselserum blockiert; 1) Mikrowelle Citrat; 2) ohne Vorbehandlung; 4) Verwendung von HOPE-fixiertem Gewebe; DAKO, Glostrup, Dänemark;Serotec Ltd., Kidlington, Oxford, UK; Biosciences Clontech, Heidelberg, Deutschland, assay desings, Michigan, USA; IBL, Gunma, Japan, BioLegend, San Diego, USA; Vector laboratories Peterborough, England; BD Biosciences, Heidelberg, Deutschland mmk=Maus monoklonaler; rmk=Ratten monoklonaler, rpk=Kaninchen polyklonaler

Tabelle 2-7: Für Rattengewebe verwendete Antikörper

\begin{tabular}{lllll}
\hline \hline & Antigen/KIon & Spezies & Verdünnung & Bezugsquelle \\
\hline \hline T-Zellen, Granulozyten & CD43/W3/13 & $\mathrm{mmk}$ & $1: 200^{1}$ & Serotec \\
\hline zytotoxische T-Zellen & CD8/MRC & $\mathrm{mmk}$ & $1: 500^{1}$ & Linaris \\
& Ox-8 & & & \\
\hline Makrophagen & ED1 & $\mathrm{mmk}$ & $1: 500^{1}$ & Serotec \\
\hline Makrophagen & ED2/CD163 & $\mathrm{mmk}$ & $1: 50^{3}$ & Serotec \\
\hline iNOS & iNOS/C-11 & $\mathrm{rpk}$ & $1: 1000^{1}$ & Santa Cruz \\
\hline Apoptosemarker & Caspa- & $\mathrm{rpk}$ & $1: 500^{1}$ & Chemicon \\
& se3/CM1 & & & \\
\hline neuronales Protein & $\beta-S y n u k l e i n$ & $\mathrm{rpk}$ & $1: 25^{2}$ & oncogene \\
\hline \hline
\end{tabular}




\begin{tabular}{lllll}
\hline \hline & Antigen/KIon & Spezies & Verdünnung & Bezugsquelle \\
\hline \hline $\begin{array}{l}\text { hypophosphoryliertes } \\
\text { Neurofilament }\end{array}$ & SMI35 & $\mathrm{mmk}$ & $1: 10000^{2}$ & $\begin{array}{l}\text { Sternberger } \\
\text { Monoclonals }\end{array}$ \\
\hline $\begin{array}{l}\text { phosphoryliertes Neuro- } \\
\text { filament }\end{array}$ & SMI 31 & $\mathrm{mmk}$ & $1: 10000^{1}$ & $\begin{array}{l}\text { Sternberger } \\
\text { Monoclonals }\end{array}$ \\
\hline Neurone & & & & Chemicon \\
\hline regenerierende Axone & GAP43/ & $\mathrm{mmk}$ & $1: 5000^{1}$ & Chemicon \\
& $9-1 \mathrm{E} 12$ & & & \\
\hline Synapsen & Synaptophysin & $\mathrm{rpk}$ & $1: 25^{1}$ & DAKO \\
\hline Transkriptionsfaktor & cJun/H-79 & $\mathrm{rpk}$ & $1: 200^{2}$ & Santa Cruz \\
\hline \hline
\end{tabular}

1) Mikrowelle Citrat; 2) ohne Vorbehandlung; Serotec Ltd., Kidlington, Oxford, UK; Sternberger Monoclonals Inc., Lutherville, MD, USA, DakoCytomation, Glostrup, Dänemark, Santa Curz, CA, USA; oncogen = chalbiochem, Gibbstown, USA; Linaris, Wertheim-Bettingen, Deutschland; mmk=Maus monoklonaler, rpk=Kaninchen polyklonal

Tabelle 2-8: Für Maus- und Rattengewebe verwendete Antikörper

\begin{tabular}{lllll}
\hline \hline & Antigen/KIon & Spezies & Verdünnung & Bezugsquelle \\
\hline \hline$\beta$-Amyloid & APP/A4 & mmk & $1: 3000^{1}$ & Chemicon \\
\hline Hämoxigenase-1 & $\begin{array}{l}\text { HO-1/SPA- } \\
\text { 896 }\end{array}$ & rpk & $1: 3000^{2}$ & Stressgen \\
\hline saures Gliafaserprotein & GFAP & rpk & $1: 1000^{2}$ & DAKO \\
\hline $\begin{array}{l}\text { Myelin-basisches } \\
\text { Protein }\end{array}$ & MBP & rpk & $1: 200^{2}$ & DAKO \\
\hline $\begin{array}{l}\text { Monozyten und Granu- } \\
\text { lozyten }\end{array}$ & S100A9 & rpk & $1: 2000^{1}$ & (Nacken et al. \\
\hline nichtphosphoryliertes & SMI 32 & mmk & $1: 1000^{1}$ & 2000) \\
Neurofilament & & & & Sternberger \\
\hline
\end{tabular}

1) Mikrowelle Citrat; 2) ohne Vorbehandlung; Stressgen, Michigan, USA; Kanada; Sternberger Monoclonals Inc., Lutherville, MD, USA; DakoCytomation, Glostrup, Dänemark; mmk=Maus monoklonal; rpk=Kaninchen polyklonal 
Tabelle 2-9: Verwendete Sekundärsysteme

\begin{tabular}{llll}
\hline \hline Chromogen & Antigen & Verdünnung & Bezugsquelle \\
\hline \hline Cy2 & anti-Maus & $1: 200$ & Jackson \\
\hline Biotin & Schaf-anti-Maus & $1: 200$ & Amersham \\
\hline Biotin & Esel-anti-Kaninchen & $1: 200$ & Amersham \\
\hline Biotin & Ziege-anti-Ratte & $1: 200$ & Amersham \\
\hline alkalische & Ziege-anti-Kaninchen & $1: 50$ & DAKO \\
Phosphatase & & & \\
\hline & ExtrAvidin & \\
& DAB & $1: 1000$ & Sigma \\
\hline \hline
\end{tabular}

Amersham Pharmacia Biotech Europe GmbH, Freiburg; Molecular Probes Inc., Eugene, OR, USA; Jackson ImmunoResearch Laboratories Inc., West Grove, PA, USA, DakoCytomation, Glostrup, Dänemark

\subsubsection{In-situ Tailing (TUNEL-Färbung)}

Beim apoptotischen Zelltod kommt es zur Fragmentierung der DNA durch internucleosomale DNA-Spaltung, wobei zahlreiche freie 3'-DNA-Enden entstehen. Diese werden beim in-situ Tailing sichtbar gemacht.

Nach Entparaffinierung und Rehydrierung des Gewebes wurden die Schnitte zweifach mit TBS gespült und anschließend mit Proteinase K-Lösung für 15 min bei $37^{\circ} \mathrm{C}$ inkubiert. Im folgenden Schritt erfolgte eine dreimalige Spülung der Objektträger mit TBS (RT). Anschließend wurden diese für 5 min in eisgekühltem TBS inkubiert. Nachfolgend wurde der „Tailing-Mix“ aufgetragen und für $1 \mathrm{Std}$. bei $37^{\circ} \mathrm{C}$ inkubiert. Hieran anschließend wurden die Schnitte fünfmalig mit TBS gespült und mit 10\% FCS in TBS inkubiert (15 min RT). Im nächsten Arbeitsschritt wurde der anti-Digoxigenin-AP Antikörper (1:250 in 10\% FCS/TBS; 1 Std. RT) auf die Schnitte aufgetragen und diese anschließend erneut vierfach mit TBS gespült. Die abschließende Farbreaktion erfolgte mit NBT-BCIP im Dunkeln und wurde mit Aqua bidest. abgestoppt. Zur Konservierung wurden die Schnitte mit Immu-Mount eingedeckelt. 
Tabelle 2-10: Verwendete Lösungen bei der TUNEL-Reaktion

\begin{tabular}{|c|c|}
\hline Lösung & Zusammensetzung \\
\hline$\overline{T \text { TBS }}$ & $\begin{array}{l}17 \mathrm{~g} \mathrm{NaCl} \\
12,5 \mathrm{~g} \text { Tris } \\
\text { ad. } 2 \text { Liter mit } \mathrm{H}_{2} \mathrm{O} \mathrm{pH} 7,4-7,5\end{array}$ \\
\hline $\begin{array}{l}\text { 5\% Proteinase } \mathrm{K} \\
(150 \mu \mathrm{l} / \text { Objekträger) }\end{array}$ & $\begin{array}{l}0,05 \mathrm{mg} \text { Proteinase } \mathrm{K} \\
2 \mathrm{mM} \mathrm{CaCl} \\
\text { ad. } 5 \mathrm{ml} \mathrm{TBS}\end{array}$ \\
\hline Tailing-Puffer & $\begin{array}{l}\text { 1,38 g Kakodylsäure } \\
0,1514 \mathrm{~g} \text { Tris } \\
\text { 12,5 mg BSA } \\
\text { ad. } 10 \mathrm{ml} \mathrm{H}_{2} \mathrm{O}_{\text {dd }} ; \mathrm{pH} 6,6(\mathrm{KOH})\end{array}$ \\
\hline Tailing-Mix (1 Schnitt) & $\begin{array}{l}10 \mu \mathrm{l} \text { Tailing-Puffer } \\
2 \mu \mathrm{l} \mathrm{CoCl}_{2} \\
1 \mu \mathrm{l} \text { DigDNA } \\
0,5 \mu \mathrm{l} \text { Terminale Transferase } \\
\text { ad. } 50 \mu \mathrm{l} \text { Aqua bidest. }\end{array}$ \\
\hline NBT-BCIP & $\begin{array}{l}100 \mathrm{mM} \text { Tris } \\
100 \mathrm{mM} \mathrm{NaCl} \\
50 \mathrm{mM} \mathrm{MgCl} \\
\text { ad. } 50 \mathrm{ml} \text { Wasser; pH 9,5 } \\
\text { dann } 225 \mathrm{ml} \text { NBT + } 175 \mu \mathrm{l} \mathrm{BCIP} \mathrm{zugeben} \\
\text { (lichtempfindlich) }\end{array}$ \\
\hline NBT-Stammlösung: & $100 \mathrm{mg} / \mathrm{ml}$ in $70 \%$ DMFA \\
\hline BCIP-Stammlösung & $50 \mathrm{mg} / \mathrm{ml}$ in $100 \%$ DMFA \\
\hline
\end{tabular}

\subsection{Histologische Quantifizierung}

Die histologische Auswertung erfolgte am Mikroskop vom Typ BX 41 der Firma Olympus Deutschland $\mathrm{GmbH}$, Hamburg. Das hierbei verwendete Okular (10fache Vergrößerung) mit standardisiertem Zellzählgitter wurde ebenfalls von Olympus bezogen.

Die Fotodokumentation erfolgte mit einer 12,5 Megapixel-Kamera (Typ DP/71) von Olympus und der Bildanalysesoftware „analySIS“ bzw. der Nachfolgeversion „cell“ der Firma Soft Imaging System GmbH, Münster. 


\subsubsection{Quantifizierung der Infiltrate in den Rückenmarksquerschnitten der} $\beta-$ Synuklein $_{93-111}$ immunisierten Ratten

Die Auswertungen erfolgten an den drei am stärksten betroffenen lumbalen Rückenmarksquerschnitten. ED1-positive Makrophagen/Mikroglia und W3/13-positive T-Zellen wurden bei 400 facher Vergrößerung in sechs definierten Gesichtsfeldern in der grauen Substanz (Vorderhorn, Hinterhorn, seitlich des Zentralkanals) quantitativ bestimmt.

Die Zahl der iNOS-, HO-1-positiven Makrophagen/Mikroglia und CD8-positiven Zellen wurde in der gesamten grauen Substanz bei 200facher Vergrößerung quantifiziert. CD163-positive Makrophagen/Mikroglia wurden bei 400facher Vergrößerung in der gesamten grauen Substanz ermittelt.

Die Zahl der NeuN- und Nissl-positiven Neurone wurde im ventralen Bereich der Rückenmarksquerschnitte bei 200facher Vergrößerung bestimmt.

\subsubsection{Quantifizierung der Infiltrate im Gehirn von Cuprizon-EAE-Mäusen}

Die Quantifizierung der CD3-positiven T-Zellen, Mac3-positiven Makrophagen/Mikroglia, APP-positiven Axone, iNOS-, HO-1-, und S100A9-positiven Makrophagen/Mikroglia erfolgte in der Abbildung 2-1 B aufgezeigten Ebene bei 400facher Vergrößerung. Hierbei wurde das Gesichtsfeld in der Gehirnmitte am unteren Bereich des Balkens angelegt. Insgesamt wurden je 8 Gesichtsfelder nach beiden Seiten ausgewertet.
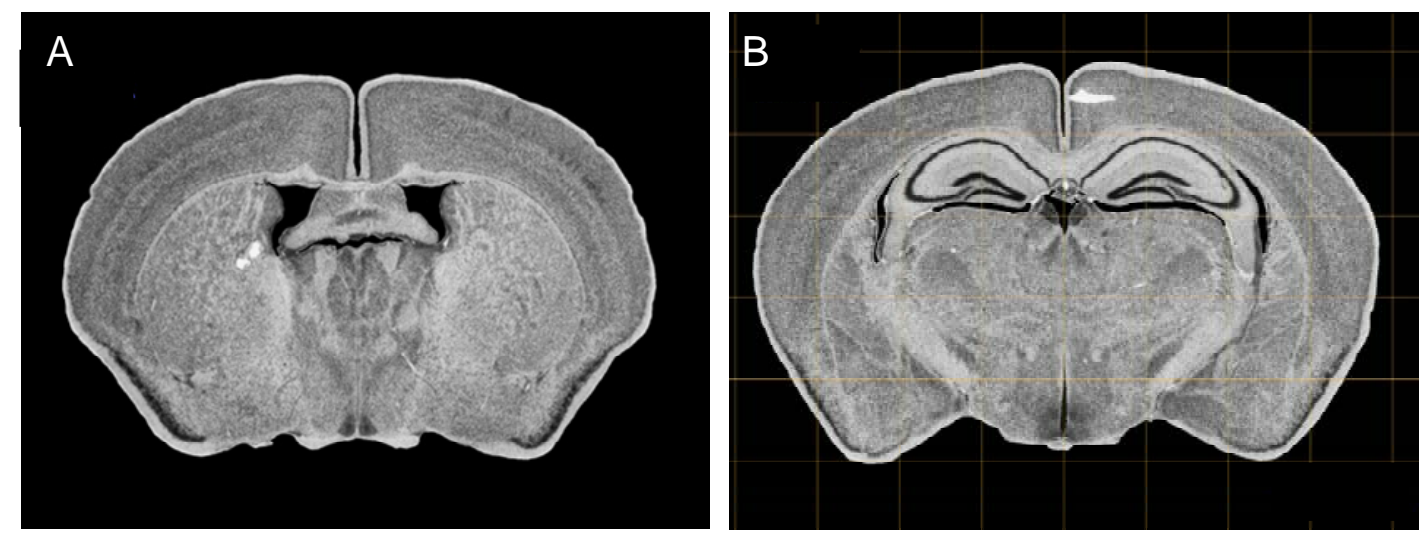

Abb. 2-1: Ebene für die histologische Quantifizierung. (A) Abgebildet ist die Ebene, in welcher die Entmarkung anhand der LFB/PAS-Färbung bestimmt wurde. (B) Abgebildet ist die Ebene, in welcher die CD3-, APP-, iNOS-, HO-1- und S100A9-positiven Zellen ausgewertet wurden. 
Die Bestimmung der entmarkten Fläche erfolgte in der in Abb. 2-1 A aufgezeigten Ebene anhand des in Tabelle 2-10 aufgeführten semiquantitativen Scores (Hiremath et al. 1998).

Tabelle 2-11: Semiquantitativer Score zur Bestimmung des Myelinverlusts.

\begin{tabular}{ll}
\hline \hline Score & Ausmaß des Myelinverlusts \\
\hline \hline 0 & kein Myelinverlust \\
\hline 1 & weniger als 1/3 des Balkens ohne Myelin \\
\hline 2 & $1 / 3-2 / 3$ des Balkens ohne Myelin \\
\hline 3 & mehr als 2/3 des Balkens ohne Myelin \\
\hline \hline
\end{tabular}

\subsection{Enzyme-linked immunosorbent assay (ELISA)}

\subsubsection{Bestimmung des Antikörpertiters bei $\beta$-Synuklein ${ }_{93-111}$-immunisierten Lewis-} Ratten

Der Nachweis von synukleinspezifischen Antikörpern im Serum von $\beta$-Synuklein ${ }_{93-111^{-}}$ immunisierten Ratten erfolgte durch ELISA. In einem ersten Arbeitsschritt wurde zur Gewinnung des primären Antikörpers aus der Zungenvene Blut entnommen und abzentrifugiert (Epperndorf 5415R, Eppendorf, Hamburg, Deutschland; 15 min, 15000 rpm, $4^{\circ} \mathrm{C}$ ).

Zunächst wurde jede Vertiefung einer 96-Well-Platte (R\&D Systems; WiesbadenNordenstadt, Deutschland) mit 0,4 $\mu \mathrm{g} \beta$-Synuklein $_{93-111}$ in $50 \mu \mathrm{l}$ PBS über Nacht beschichtet und nicht gebundenes Peptid durch dreimaliges Waschen mit PBS entfernt. Vorhandene unspezifische Bindungsstellen wurden für 4 Std. mit $5 \%$ BSA/PBS (200 $\mu \mathrm{l} /$ Vertiefung) abgesättigt und anschließend wurde jede Vertiefung dreifach mit 0,05\% Tween/PBS gewaschen (Tween: Carl-Roth GmbH \& Co., Karlsruhe, Deutschland).

Für die Ermittlung der Antikörperkonzentration wurde das gewonnene Serum in $100 \mu \mathrm{l}$ 0,05\% Tween/3\% BSA/PBS 1:40 verdünnt und hierauf aufbauend eine Verdünnungsreihe (1:3) angefertigt (BSA: SERVA Electrophoresis $\mathrm{GmbH}$, Heidelberg). Von jeder Verdünnung wurden $100 \mu \mathrm{l}$ in die zuvor beschichtete 96-Well-Platte pipettiert und über Nacht bei $4^{\circ} \mathrm{C}$ inkubiert. Nachfolgend wurde die Platte wiederum mit 0,05\% Tween/PBS gewaschen.

Die Menge des im Serum enthaltenen Antikörpers wurde durch die Umsetzung des PODSubstrates bestimmt. Hierfür wurde ein HRP-gekoppelter Sekundärantikörper verwendet. Jeweils $100 \mu \mathrm{l}$ der Antikörperverdünnung (Ziege anti-Ratte IgG (Fc) HRP-konjungiert; pb perbio, Rockford, USA 1:10 000 in 0,1\% BSA/0,05\% Tween/PBS) wurde in jede Vertie- 
fung pipettiert, für 2 Std. bei Raumtemperatur inkubiert und die Platte erneut gewaschen. Für den abschließenden Arbeitsschritt wurden $100 \mu \mathrm{l}$ POD-Substrat (BM blue, POD substrate; Roche applied Science, Mannheim, Deutschland) in jede Vertiefung pipettiert und bis zu einer ausreichenden Blaufärbung im Dunkeln inkubiert. Die Reaktion wurde mit $50 \mu \mathrm{l}$ 0,9 M Schwefelsäure/Vertiefung abgestoppt und die Absorption bei $450 \mathrm{~nm}$ im Plattenreader (Modell 680, Biorad, München, Deutschland) gemessen. Der Antikörpertiter wurde als die Serumverdünnung bei halbmaximalem Signal angegeben.

\subsubsection{Bestimmung der Antikörperkonzentration des aufgereinigten anti-MOG Anti- körpers 8-18C5}

Die Bestimmung der Konzentration wurde analog dem Protokoll der Antikörpertiterbestimmung durchgeführt (Abschnitt 2.6.1). Hierbei wurden folgende Abänderungen vorgenommen:

Die Beschichtung der Platte erfolgte mit rekombinant hergestelltem MOG-Protein (Adelmann et al. 1995). Als Primärantikörper wurde der aufgereinigte Antikörper (Verdünnung 1:500) verwendet. Der Sekundärantikörper war ein HRP-konjungierter anti-MausIgG Antikörper (1:20 000 Amersham, Biosciences, Freiburg, Deutschland). Die Antikörperkonzentration wurde über eine Verdünnungsreihe von 8-18C5 mit bekannter Konzentration bestimmt.

\subsection{Isolierung und Stimulation von Lymphozyten aus Lymphknoten}

Die antigenspezifische Immunantwort wurde mittels eines sogenannten ProliferationsAssays bestimmt. Alle Ansätze wurden in einer Dreifachbestimmung gemessen. Hierzu wurden die axillären und inguinalen Lymphknoten von immunisierten Mäusen (kein PTX, 11 Tage nach Immunisierung) präpariert und vorsichtig mit Hilfe eines Spritzenstempels durch ein Zellsieb (70 $\mu \mathrm{m}$ Porengröße, BD Biosciences, Heidelberg, Deutschland) gedrückt und so in Einzelzellsuspension überführt. Die Lymphknotenzellen wurden in kaltem PBS aufgenommen, abzentrifugiert (1200 rpm, $4^{\circ} \mathrm{C}, 6 \mathrm{~min}$ ) und die Zellzahl mit Hilfe einer Neubauerzählkammer bestimmt. Die Zellsuspension wurde anschließend in eine 96-iger Rundbodenwellplatte (Greiner bio-one, Frickenhausen, Deutschland) ausgesät (150 000 Zellen in $110 \mu \mathrm{l}$ Medium). Die Kultivierung der Zellen erfolgte $48 \mathrm{Std}$. bei $37^{\circ} \mathrm{C}$, $5 \% \mathrm{CO}_{2}$ wie folgt: 
- $20 \mu \mathrm{g} \mathrm{MOG}_{35-55} / \mathrm{ml}$ Medium

- $20 \mu \mathrm{g}$ Ovalbumin/ml Medium

- $1,25 \mu \mathrm{g} / \mathrm{ml}$ ConA/Medium (Sigma-Aldrich Chemie $\mathrm{GmbH}$, Steinheim, Deutschland)

Die Teilungsrate der Zellen wurde über den Einbau von ${ }^{3} \mathrm{H}$-Thymidin $(0,5 \mu \mathrm{Ci} /$ Vertierfung $)$ in die DNA über einen Zeitraum von 24 Stunden bestimmt. Hierfür wurde abschließend die Menge an eingebautem ${ }^{3} \mathrm{H}$-Thymidin bestimmt (Zellerntegerät: FilteMate und Counter 1450 LCS \& Luminescence Counter Micro Beta Tri Lux; Perkin elmer, RodgauJügesheim, Deutschland).

\author{
$\underline{\text { Medium }}$ \\ $500 \mathrm{ml}$ RPMI \\ $50 \mathrm{ml}$ FCS \\ $5 \mathrm{ml}$ Penicillin/Streptomycin (PAA, Pasching, Österreich)
}

\title{
2.8 Produktion und Aufreinigung des anti-MOG-Antikörpers 8-18C5
}

Zur Antikörpergewinnung wurden zunächst Hybridomazellen (Linnington et al. 1984) bei $37^{\circ} \mathrm{C}, 5 \% \mathrm{CO}_{2}$ in Medium in Zellkulturflaschen (Greiner bio-one, Frickenhausen, Deutschland) vermehrt. Vor dem letzten Umsetzungsschritt wurde das im Medium enthaltene FCS durch 5\% Ultra-low-IgG-FCS (Gibco, Karlsruhe, Deutschland) ersetzt und die Zellen in insgesamt 5 Liter Medium ausgesät. Nach sechs bis acht Tagen wurden die Zellen pelletiert und die Antikörper aus dem Überstand mit Ammoniumsulfat $\left(\left(\mathrm{NH}_{4}\right)_{2} \mathrm{SO}_{4}\right)$ ausgefällt. Hierzu wurden $313 \mathrm{~g}\left(\mathrm{NH}_{4}\right)_{2} \mathrm{SO}_{4}$ (Fluka, Steinheim, Deutschland) pro Liter Überstand langsam eingerührt und über Nacht bei $4^{\circ} \mathrm{C}$ unter langsamem Rühren präzipitiert. Die gebundenen Antikörper wurden abzentrifugiert (Beckman, Modell J2-HS; 35 min, $1000 \mathrm{rpm}, 4^{\circ} \mathrm{C}$ ), das Pellet in $200 \mathrm{ml} 10$ fach konzentriertem PBS (pH 8,2) gelöst, ungelöste Bestandteile erneut abzentrifugiert und der daraus erhaltene Überstand steril filtriert (Porengröße erst 0,45 $\mu \mathrm{m}$, dann 0,2 $\mu \mathrm{m}$ ). Die Aufreinigung des Antikörperkonzentrates erfolgte über eine Protein-G-Sepharose-4-Fast-Flow-Säule (Amersham Biosciences, Freiburg, Deutschland) mit steril filtrierten Lösungen. Mit Hilfe einer Pumpe (Fließgeschwindigkeit $1,4 \mathrm{ml} / \mathrm{min}$ ) wurde das Säulenmaterial zunächst mit 10fach konzentriertem PBS ( $\mathrm{pH} 8,2$ ) äquilibriert, anschließend das Antikörperkonzentrat aufgetragen und Verunreinigungen mit 10fach PBS $(\mathrm{pH} \mathrm{8,2)}$ ausgewaschen. Der Antikörper wurde mit 0,1 M Gylcin- $\mathrm{HCl}$ pH 2,7 eluiert und der pH-Wert des Eluats mit $100 \mu 1 \mathrm{M}$ TRIS-Lösung 
(pH 8-9) neutralisiert. Zuletzt wurde der Antikörper gegen PBS pH 7,4 über Nacht bei $4^{\circ} \mathrm{C}$ dialysiert (PIERCE Silde-A-Lyzer ${ }^{\circledR}$ Dialyse Kassette, 3500 MWCO; PIERCE, Rockford, USA), steril filtriert und bei $4^{\circ} \mathrm{C}$ aufbewahrt. Die Konzentrationsbestimmung erfolgte mittels ELISA (entsprechend Abschnitt 2.6.2). Vor der Aufbewahrung bei $4^{\circ} \mathrm{C}$ wurde das Säulenmaterial mit Boratpuffer (0,1 M Borat, $2 \mathrm{M} \mathrm{NaCl}$; $\mathrm{pH}$ 8) gespült.

\author{
Medium \\ $10 \%$ FCS, \\ 2 mM Glutamin \\ 1fach Penicillin/Streptomycin (100x; PAA, Pasching, Österreich)
}

\title{
2.9 Durchflusszytometrie (FACS)
}

Durchflusszytometrische Analysen beruhen auf der Detektion der optischen Signale von an Zellen gebundenen fluoreszenzgekopplten Antikörpern, wenn diese den Laserstrahl bei der Messung passieren. Alle FACS-Messungen wurden in Kooperation mit Dr. Fred Lühder, IMSF Göttingen, am FACS-Calibur der Firma BD durchgeführt (BD, Bioscience, Heidelberg, Deutschland). Es wurden jeweils die isolierten Zellen aus sieben Mausgehirnen pro Gruppe vereiniget. Die im Ergebnisteil angegebenen Prozentwerte entspechen dem prozentualen Anteil der positiven Zellen an allen gemessen, lebenden Zellen.

\subsubsection{Isolierung der Zellen aus dem Gewebe}

Die Entzündungszellen wurden durch Dichtegradientenzentrifugation aus dem Rückenmark isoliert. Hierzu wurde das Mausgehirn nach der transkardialen Perfusion (ca. 100 ml PBS) herauspräpariert und mit dem Rücken eines Spritzenstempels in einer Petrischale zerkleinert. Das Homogenat wurde in Resuspensionspuffer aufgenommen, abzentrifugiert (10 min, $1600 \mathrm{rpm}, 4^{\circ} \mathrm{C}$ ) und das Pellet in $6 \mathrm{ml}$ 30\%-iger Percolllösung resuspendiert.

Für die Herstellung des Percoll-Gradienten (Percoll, GE Healthcare, Uppsala, Schweden) wurden $4 \mathrm{ml}$ 45\%-ige Percollösung in einem $15 \mathrm{ml}$ Falcon-Röhrchen mit $2 \mathrm{ml}$ 70\%-iger Percolllösung unterschichtet. Die im ersten Arbeitsschritt hergestellte Zellsuspension wurde anschließend als oberste Schicht auf den Gradienten aufgetragen.

Durch die Zentrifugation (Eppendorf, 5810 R, $2300 \mathrm{rpm}, 20 \mathrm{~min}, 4^{\circ} \mathrm{C}$, ohne Beschleunigung und Bremse) sammelten sich die Leukozyten, Monozyten und Granulozyten in den beiden Interphasen an und konnten von dort mit einer $5 \mathrm{ml}$ Spritze abgenommen werden. 
Diese Zellen wurden über ein Zellsieb (Porengröße $40 \mu \mathrm{m}$, BD, Bioscience, Heidelberg, Deutschland) in ein $50 \mathrm{ml}$ Falcon-Röhrchen überführt, welches mit FACS-Puffer auf $50 \mathrm{ml}$ aufgefüllt und anschließend zentrifugiert wurde. Das Zellpellet wurde in $1 \mathrm{ml}$ FACS-Puffer aufgenommen und die Zellzahl mit einer Neubauerzählkammer bestimmt. Für jede FACSFärbung wurden $3 \times 10^{4}-5 \times 10^{4}$ Zellen in ein FACS-Röhrchen (BD, Bioscience, Heidelberg, Deutschland) überführt.

Tabelle 2-12: Verwendete Lösungen bei der FACS-Analyse (Mengenangaben für jeweils ein Tier)

\begin{tabular}{ll}
\hline \hline Lösung & Zusammensetzung \\
\hline \hline FACS-Puffer & $0,1 \mathrm{~g} \quad \mathrm{BSA}$ \\
& $0,1 \% \quad$ Natriumazid (Sigma-Aldrich Chemie \\
& $\mathrm{GmbH}$, Steinheim, Deutschland) \\
& ad $100 \mathrm{ml}$ PBS \\
\hline Percoll-Lösungen & $6 \mathrm{ml} \quad 30 \%$ Percoll \\
(mit Percoll-Verdünnungspuffer verdünnt) & $4 \mathrm{ml} \quad 45 \%$ Percoll \\
& $2 \mathrm{ml} \quad 70 \%$ Percoll \\
\hline Percoll-Verdünnungspuffer & $0,04 \mathrm{~g}$ BSA \\
& $0,4 \mathrm{~g} \quad$ D(+)-Glucose-Monohydrat $\quad$ (Merck \\
& $\mathrm{KGaA}$, Darmstadt, Deutschland) \\
& ad. $20 \mathrm{ml}$ PBS \\
\hline Resuspensionspuffer & $20 \mathrm{ml}$ Verdünnungspuffer \\
& $200 \mu \mathrm{ll}$ DNase (10 mg/ml; Roche Applied \\
& Bioscience, Penzberg, Deutschland) \\
\hline \hline
\end{tabular}

\subsubsection{Extrazelluläre Färbungen}

In diesem Schritt wurden die Oberflächenantigene markiert. Hierzu wurden die Zellen zunächst mit $3 \mathrm{ml} \mathrm{FACS-Puffer} \mathrm{gewaschen} \mathrm{und} \mathrm{abzentrifugiert} \mathrm{(5min} \mathrm{1200rpm,} 4^{\circ} \mathrm{C}$ ). Die entsprechenden fluoreszenzgekoppelten Antikörper wurde in $100 \mu$ FACS-Puffer zu den Zellen gegeben, gut gemischt und für $15 \mathrm{~min}$ im Dunkeln bei $4^{\circ} \mathrm{C}$ inkubiert. Anschließend wurden die Zellen erneut mit $3 \mathrm{ml}$ FACS-Puffer gewaschen und abzentrifugiert, so dass die abschließende Messung erfolgen konnte. 
Tabelle 2-13: Verwendete Antikörper bei der Durchflusszytometrie. Alle verwendeten Antikörper wurden von der Firma BD Bioscience, Heidelberg, Deutschland bezogen.

\begin{tabular}{llllll}
\hline \hline Antikörper & Klon & Fluorochrom & Spezies & Isotyp & \\
\hline \hline CD11b & M1/70 & FITC/APC & Ratte & IgG2b & kappa \\
\hline CD4 & RM4-5 & PerCP/PE & Ratte & IgG2a & kappa \\
\hline CD45 & $30-F 11$ & PerCP & Ratte & IgG2b & kappa \\
\hline CD8a & $53-6.7$ & APC & Ratte & IgG2a & kappa \\
\hline MHCII & $2 G 9$ & PE & Ratte & IgG2a & kappa \\
\hline TcR & H57-597 & FITC & Hamster & IgG2 & lamda1 \\
\hline \hline
\end{tabular}

\subsection{Molekulargenetische Methoden}

\subsubsection{Isolierung der mRNA}

Die Isolierung der mRNA erfolgte mit Hilfe des RNeasy® Mini-Kit von Qiagen. Zu diesem Zweck wurde das Gewebe (max. $30 \mathrm{mg}$ ) in flüssigem Stickstoff eingefroren und mit Hilfe eines Mörsers zu einem feinen Pulver verrieben und anschließend in $600 \mu$ RLT-Puffer (+ $6 \mu \mathrm{l} \beta$-Mercaptoethanol), welcher im Kit enthalten war, aufgenommen. Im nächsten Schritt wurde das aufgenommene Gewebe auf eine QIAShredder-Säule aufgetragen und diese anschließend zentrifugiert (2 min, $1600 \mathrm{rpm}, \mathrm{RT}$ ). Der so entstandene Durchfluss wurde mit 70\%-igem Ethanol gemischt. Die weiteren Schritte erfolgten nach den Angaben des Herstellers. Nach Abschluss der Arbeiten wurde die mRNA in $30 \mu \mathrm{l}$ Wasser eluiert und die Konzentration (RNA $\mathrm{ng} / \mathrm{ml}=\mathrm{OD}_{260} \times$ Verdünnung $\times$ 40) und die Reinheit $\left(\mathrm{OD}_{260} / \mathrm{OD}_{280}\right)$ photometrisch bestimmt (Bio-photometer, Eppendorf, Hamburg). Die mRNA wurde bis zur Verwendung bei $-80^{\circ} \mathrm{C}$ gelagert.

\subsubsection{Reverse Transkription}

Die nachfolgend angeführte Methode wurde für die Analyse der Cuprizon-induzierten Genexpression herangezogen (4.2.1).

In einem ersten Arbeitsschritt wurde die chromosomale DNA für 30 min bei $30^{\circ} \mathrm{C}$ in folgedem Ansatz verdaut. 


\section{Ansatz}

$1 \mu g$ RNA,

$1 \mu \mathrm{l}$ RNasin (Promega, Madison, USA)

0,5 $\mu \mathrm{g}$ DNase (Roche Applied Bioscience, Penzberg, Deutschland)

Im Anschluss hieran erfolgte die Inaktivierung der DNase bei $70^{\circ} \mathrm{C}$ für 10 min. Für die reverse Transkription wurde folgender Ansatz zur mRNA gegeben und die RNA für $1 \mathrm{Std}$. bei $37^{\circ} \mathrm{C}$ umgeschrieben.

\section{Ansatz}

$8 \mu \mathrm{ldt15}$ Primer (Roche Applied Bioscience, Penzberg, Deutschland)

$4 \mu \mathrm{d}$ dNTPs (10 mM, Fermentas, St. Leon-Roth, Deutschland)

$8 \mu \mathrm{l} 5 \mathrm{x}$ RT-Puffer

$4 \mu \mathrm{l} 0,1 \mathrm{M}$ DTT

$1 \mu$ l Superscript ${ }^{\mathrm{TM}}$ RTase (Invitrogen, Karlsruhe, Deutschland)

Die Reaktion wurde durch erneute Hitzeinaktiverung beendet. Vor der Lagerung bei $-20^{\circ} \mathrm{C}$ wurde die cDNA mit $40 \mu \mathrm{l}$ Aqua bidest. verdünnt.

\subsubsection{Quantitative PCR (Sybr® green)}

Die Menge der exprimierten mRNA wurde mittels quantitativer Realtime-PCR bestimmt, die den Einbau des Fluoreszenzfarbstoffes Sybr®green, (ABgene House, Surrey, UK) misst. Die Genexpression wurde nach der Methode von Pfaffl (Pfaffl 2001) bestimmt. Alle PCR-Ansätze wurden als Triplikate, von drei repräsentativen Mäusen pro untersuchten Zeitpunkt, gemessen.

Das verwendete PCR-Programm ist in der Tabelle 2-14 aufgeführt. Die jeweils verwendete Annealingtemperatur ist der Tabelle 2-15 zu entnehmen. Angegeben ist die relative Expressionsmenge im Vergleich zum Kontrollgen ADP-ribosylation factor related protein 1 (ARP) angegeben.

\begin{tabular}{ll} 
PCR-Ansatz: & \\
\hline Sybr® green & $12,5 \mu \mathrm{l}$ \\
Primer $1(10 \mathrm{pmol} / \mu \mathrm{l})$ & $5 \mu \mathrm{l}$ \\
Primer $2(10 \mathrm{pmol} / \mu \mathrm{l})$ & $5 \mu \mathrm{l}$ \\
CDNA & $2,5 \mu \mathrm{l}$
\end{tabular}


Tabelle 2-14: Verwendetes PCR-Programm. Angegeben sind die einzelnen Schritte, die jeweilige Temperatur und Dauer.

\begin{tabular}{llll}
\hline \hline Zyklus & Anzahl der Zyklen & Dauer & Temperatur \\
\hline \hline 1 & 1 & $15 \mathrm{~min}$ & $94^{\circ} \mathrm{C}$ \\
\hline 2 & 50 & $30 \mathrm{sec}$. & $94^{\circ} \mathrm{C}$ \\
\hline & & $45 \mathrm{sec}$. & Annealingtemperatur \\
\hline 3 & $30 \mathrm{sec}$. & $72^{\circ} \mathrm{C}$ \\
\hline 4 & $20 \mathrm{sec}$. & $78^{\circ} \mathrm{C}$ \\
\hline 5 & 80 & $30 \mathrm{sec}$. & $94^{\circ} \mathrm{C}$ \\
\hline \hline
\end{tabular}

Tabelle 2-15: Verwendete Oligonukleotide (MWG, Ebersberg, Deutschland)

\begin{tabular}{lll}
\hline \hline Gen & Sequenz & Annealing Temperatur $\left({ }^{\circ} \mathrm{C}\right)$ \\
\hline \hline ARP & 5- CGA CCT GGA AGT CCA ACT AC & $58^{\circ} \mathrm{C}$ \\
& 3- ATC TGC TGC ATC TGC TTG & \\
\hline ICAM-1 & 5- GAG ACG CAG AGG ACC TTA ACA & $55^{\circ} \mathrm{C}$ \\
& 3-TTG GCT CCC TTC CGA GAC & \\
\hline VCAM-1 & 5- CCG TCA TTG AGG ATA TTG GA & $52^{\circ} \mathrm{C}$ \\
& 3- TCG CTG GAA CAG GTC ATT GT & \\
\hline iNOS & 5- TTG CCA CGG ACG AGA CGG ATA & $57^{\circ} \mathrm{C}$ \\
& 3- TCA AGA TAG GGA GCT GCG ACA & \\
\hline LysM & 5- ATT TCA GAT CAA TAG CCG ATA & $54^{\circ} \mathrm{C}$ \\
& 3- GCC ACC CAT GCT CGA ATG C & \\
\hline MCP-1 & 5- AGA TGA TCC CAA TGA GTA GGC & $52^{\circ} \mathrm{C}$ \\
& 3- TCT CAT TTG GTT CCG ATC & \\
\hline MIP-1 $\alpha$ & 5- TTG CCA CGG ACG AGA CGG ATA & $52^{\circ} \mathrm{C}$ \\
& 3- TCA AGA TAG GGA GCT GCG ACA & \\
\hline \hline
\end{tabular}

\subsubsection{Quantitative PCR (Taq-Man)}

Die im Folgenden beschrieben Taq-Man-PCR wurde für die unter 4.5.2 angegebenen Ergebnisse angewandt und wurde in Kooperation mit Dr. Patrick Vollmar und Prof. Dr. Bernhard Hemmer, Neurologische Kopf- und Poliklinik, Klinikum rechts der Isar, TU München, durchgeführt.

Die Isolation der mRNA erfolgte ebenfalls mit Hilfe des RNeasy® Mini-Kit von Qiagen nach den Angaben des Herstellers. Die mRNA wurde mit Hilfe des High-capacity RT Kit ${ }$ (Applied Biosytems) nach den Angaben des Herstellers in komplementär DNA (cDNA) 
umgeschrieben. Die Analyse der exprimierten mRNA-Menge der Zielgene und des internen Kontrollgens Glycerinaldehyd-3-phosphat-Dehydrogenase (GAPDH) erfolgte mittels Taq-Man PCR (7500 Fast Real-Time PCR System, Applied Biosystems) mit Sonden (250 nM, Applied Biosystems, USA), welche am 5-Ende mit dem Farbstoff 6-carboxyfluorescein phosphoramidite (FAM-Farbstoff) markiert waren. Die jeweiligen PCR-Ansätze enthielten eine Primerkonzentration von 900 nM. Alle PCR-Ansätze wurden als Duplikate gemessen. Jede Versuchsgruppe enthielt drei repräsentative Mäuse und die gemessene mRNA-Menge ist als die xfache Menge im Vergleich zu nicht-behandelten Kontrollmäusen angegeben.

Tabelle 2-16: Assay ID Nummer der Firma Applied Biosystems

\begin{tabular}{|c|c|}
\hline Gen & Assay ID der Firma Applied Biosystems \\
\hline CD4 & Mm00442754_m1 \\
\hline GAPDH & Mm99999915_g1 \\
\hline IFN- $\gamma$ & Mm00801778_m1 \\
\hline iNOS & Mm00440485_m1 \\
\hline MBP & Mm00521979_m1 \\
\hline MHC II & Mm00439216_m1 \\
\hline Olig1 & Mm00497537_s1 \\
\hline Olig2 & Mm01210556_m \\
\hline PLP & Mm00456892_m1 \\
\hline Sox2 & Mm00488369_s1 \\
\hline
\end{tabular}

PCR-Ansatz pro Vertiefung:

$8 \mu \mathrm{HPLC}-\mathrm{H} 2 \mathrm{O}$

$10 \mu \mathrm{l}$ TaqMan FAST Universal Master Mix

$1 \mu \mathrm{l} 20 x$ Gene Expession Assay Mix

$1 \mu \mathrm{lCDNA}$
Thermocycler Programm:

$95^{\circ} \mathrm{C} 20$ sek. Halten

$95^{\circ} \mathrm{C} 3$ sek. Zyklus

$60^{\circ} \mathrm{C} 30$ sek.

Anzahl der Zyklen: 40 


\subsection{Magnetresonanztomographie (MRT)}

\subsubsection{Vorbereitung für die Messungen}

Alle MRT-Messungen und die Auswertung der Daten erfolgte in Kooperation mit Dr. Susann Boretius und Prof. Dr. Jens Frahm, Biomedizinische MNR Forschung GmbH am Max-Plank-Institut für biophysikalische Chemie in Göttingen.

Die Messungen erfolgten an nicht-behandelten Mäusen, Cuprizon-behandelten oder Cuprizon-behandelten / $\mathrm{MOG}_{35-55}$-immunisierten Mäusen. Die Messungen fanden 14-21 Tage nach Immunisierung statt. Für sämtliche MRT-Messungen wurden die Mäuse initial in einer Narkosebox mit Isofluoran tief narkotisiert und anschließend mit einem Endotrachealschlauch aus Polyethylen intubiert und auf einer MR-tauglichen Halterung fixiert. Die Narkose wurde durch ein 1-1,5\% Isofluoran-Sauerstoff-Gemisch aufrechterhalten und die künstliche Beatmung über einen selbstgebauten Drucksensor überwacht, welcher außen am Brustkorb der Mäuse fixiert war. Während der gesamten Messung wurde die Rektaltemperatur $\left(36 \pm 1^{\circ} \mathrm{C}\right)$ über beheizbare, mit Wasser gefüllte Kissen konstant gehalten. In der Tabelle 2-17 sind alle gemessenen Tiere aufgeführt.

Nach der jeweiligen Messung wurden die Tiere mit 4\% PFA perfundiert und das Gewebe für eine histologische Auswertung aufgearbeitet (2.3.1).

Tabelle 2-17: Durchgeführte MRT-Messungen und die jeweils verwendete Anzahl der Tiere.

\begin{tabular}{lccc}
\hline \hline & Kontrollen & Cuprizon & Cuprizon/MOG \\
\hline \hline Blut-Hirn-Schranken & & 3 & 7 \\
Permeabilität (Gd) & & & \\
\hline Axondiffusionswert & 5 & 5 & 5 \\
\hline \hline
\end{tabular}

\subsubsection{Messung der Blut-Hirn-Schranken-Permeabilität}

Die Messungen der Blut-Hirn-Schranken-Permeabilität mittels GadoliniumDiethylentriaminpentaAcetat (Gd-DTPA) und die Bestimmung des Diffusionstensors (DTI) erfolgten an einem 9.4 T MR - Tomographen (Bruker Biospin, Deutschland). Als Anregungsspule diente ein Birdcage-Resonator und zum Signalempfang eine sattelförmige Oberflächenspule (beide Bruker Biospin, Deutschland)

Zur Bestimmung der Blut-Hirn-Schranken-Störung wurden T1-gewichtete Datensätze (3D FLASH, Echozeit $=4,2 \mathrm{~ms}$, Repetitionszeit $=17 \mathrm{~ms}$, Kippwinkel $=25 \mathrm{Grad}$ ) vor und nach der i.v. Gabe von 0,5 mmol/kg Körpergewicht Gd-DTPA (MagnevistTM, Schering AG, Berlin, Deutschland) mit einer isotropen Auflösung von $100 \mu \mathrm{m}$ aufgenommen. Das 
die T1 Relaxationszeit verkürzende Gd-DTPA führt an Stellen einer gestörten Blut-HirnSchranke zu einer Signalverstärkung im umliegenden Hirngewebe. Bei intakter Blut-HirnSchranke zeigten sich nur die blutführenden Gefäße signalverstärkt.

\subsubsection{Diffusions-Tensor-Bildgebung}

Der Diffusions-Tensor wurde mittels Half-Fourier diffusion weighted turbo-STEAM mit einer räumlichen Auflösung von $125 \times 125 \times 500 \mu \mathrm{m}$ bestimmt. Es wurden neben Referenzbildern $\left(b=0 \mathrm{~s} \mathrm{~mm}^{-2}\right)$, diffusiongewichtete Datensätze $\left(b=1000 \mathrm{~s} \mathrm{~mm}^{-2}\right)$ durch die Schaltung von Diffusionsgradienten in 12 unterschiedlichen Richtungen aufgenommen. Aus den Eigenwerten des Diffusionstensors $\left(\lambda_{1}, \lambda_{2}, \lambda_{3}\right)$ wurden pixelweise die folgenden Parameterkarten berechnet:

Axiale Diffusivität $=\lambda_{1}$ (Größter Eigenwert)

Radiale Diffusivität $=\left(\lambda_{2}+\lambda_{3}\right) / 2$ (Mittelwert der beiden Eigenwerte, die senkrecht zu $\lambda_{1}$ stehen)

scheinbare Diffusionskoeffizient (ADC):

$\mathrm{ADC}=\left(\lambda_{1}+\lambda_{2}+\lambda_{3}\right) / 3$

Fraktionale Anisotropie (FA):

$F A=\sqrt{\frac{3}{2}} \frac{\sqrt{\left(\lambda_{1}-\lambda_{M}\right)^{2}+\left(\lambda_{2}-\lambda_{M}\right)^{2}+\left(\lambda_{3}-\lambda_{M}\right)^{2}}}{\sqrt{\lambda_{1}^{2}+\lambda_{2}^{2}+\lambda_{3}^{2}}}$

mit $\lambda_{M}$ für die mittlere Diffusivität (entspricht dem ADC)

\subsubsection{Auswertung der Daten}

Die ausgewertete Region (ROI) in der entspechenden Schicht war der mittlere Balken bis zur lateralen Ventrikelkante. 


\subsection{Statistische Auswertung}

Die statistische Analyse der Daten erfolgte mit Hilfe der Software GraphPad $^{\mathrm{TM}}$ Prism 4 (Graph Pad Software, Inc., San Diego, CA, USA). Alle Daten sind als Mittelwerte mit Standardfehler angegeben. Soweit Unterschiede zwischen zwei Gruppen ermittelt werden konnten, wurde bei einer nichtparametrischen Verteilung der Daten der "Mann-Whitney U“-Test verwendet bzw. bei einer parametrischen Verteiung der ungepaarte Student's T-Test. Für Vergleiche zwischen mehreren unabhängigen Gruppen wurde die Varianzanalyse (ANOVA) mit anschließendem „Tukey's“ Post-Test herangezogen, im Ergebnisteil mit „ANOVA“ bezeichnet. Die verwendete Testmethode ist im Ergebnisteil jeweils in Klammer angegeben. 


\section{Ergebnisteil I}

\section{$\beta$-Synuklein-EAE als experimentelles Modell für pathologische Veränderungen in der grauen Substanz bei multipler Sklerose}




\subsection{Immunisierung von Lewis-Ratten mit $\beta$-Synuklein $93-111$}

Ein charakteristisches Krankheitsmerkmal der MS ist das Auftreten von fokalen, demyelinisierten Läsionen mit infiltrierenden Makrophagen und T-Zellen in der weißen Substanz des Gehirns und Rückenmarks (Lassmann et al. 2007). Entmarkungsherde im Bereich der Hirnrinde und der grauen Substanz des Rückenmarks sind erst kürzlich als wesentliche Aspekte der MS-Pathologie identifiziert worden (Kidd et al. 1999; Gilmore et al. 2006).

Die Immunisierung mit dem neuronalen Antigen $\beta$-Synuklein ${ }_{93-111}$ führte zu entzündlichen Läsionen in der grauen Substanz des Rückenmarks (Mor et al. 2003). Sie steht somit im Gegensatz zu den bislang verwendeten EAE-Modellen, welche zu einem überwiegenden Befall der weißen Substanz des Rückenmarks führen. Durch die $\beta$-Synuklein-EAE kann erstmals die schädigende Wirkung der T-Zellinfiltration und Makrophagen/Mikrogliaaktivierung auf Nervenzellen und Axone unabhängig von einem Befall der weißen Substanz untersucht werden.

$\beta$-Synuklein wird in weiten Bereichen des ZNS gebildet (Li et al. 2002). Es gehört zu einer Familie von hoch konservierten, zytoplasmatischen Proteinen, die hauptsächlich von Neuronen exprimiert werden (Giasson et al. 2001; Mori et al. 2002). Neben der präsynaptischen Lokalisation konnte es ebenfalls im Soma von Neuronen nachgewiesen werden (Maroteaux et al. 1988; Jensen et al. 1999; Mori et al. 2002). Die Funktion des Proteins ist bislang unklar.

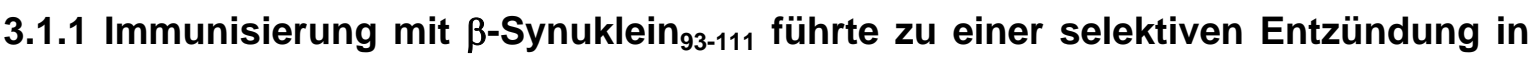 der grauen Substanz}

In der vorliegenden Arbeit zeigten Lewis-Ratten neun bis zehn Tage nach Immunisierung mit $\beta$-Synuklein ${ }_{93-111}$ erste Krankheitssymptome wie Gewichtsverlust und ungeputztes, struppiges Fell. Ein Grossteil der Tiere entwickelte anschließend die für EAE charakteristischen Lähmungserscheinungen, welche an der Schwanzspitze begannen und später auch Hinter- und Vorderbeine betrafen. Einige Tiere jedoch zeigten einen atypischen Krankheitsverlauf mit ausschließlicher Lähmung der Vorderbeine, der Zunge oder keiner Lähmung. Die maximale Krankheitsschwere wurde meistens drei bis vier Tage nach Beginn erreicht. Ihr folgte eine schnelle und vollständige Erholung. Weitere Krankheitsschübe traten bis 32 Tage nach Immunisierung nicht auf (Abb. 3-1 A). Die $\beta$-Synuklein-EAE ist daher eine monophasische Erkrankung. Im Serum von immunisierten Ratten konnten $\beta$-Synuklein-spezifische Antikörper nachgewiesen werden (Daten nicht gezeigt). 

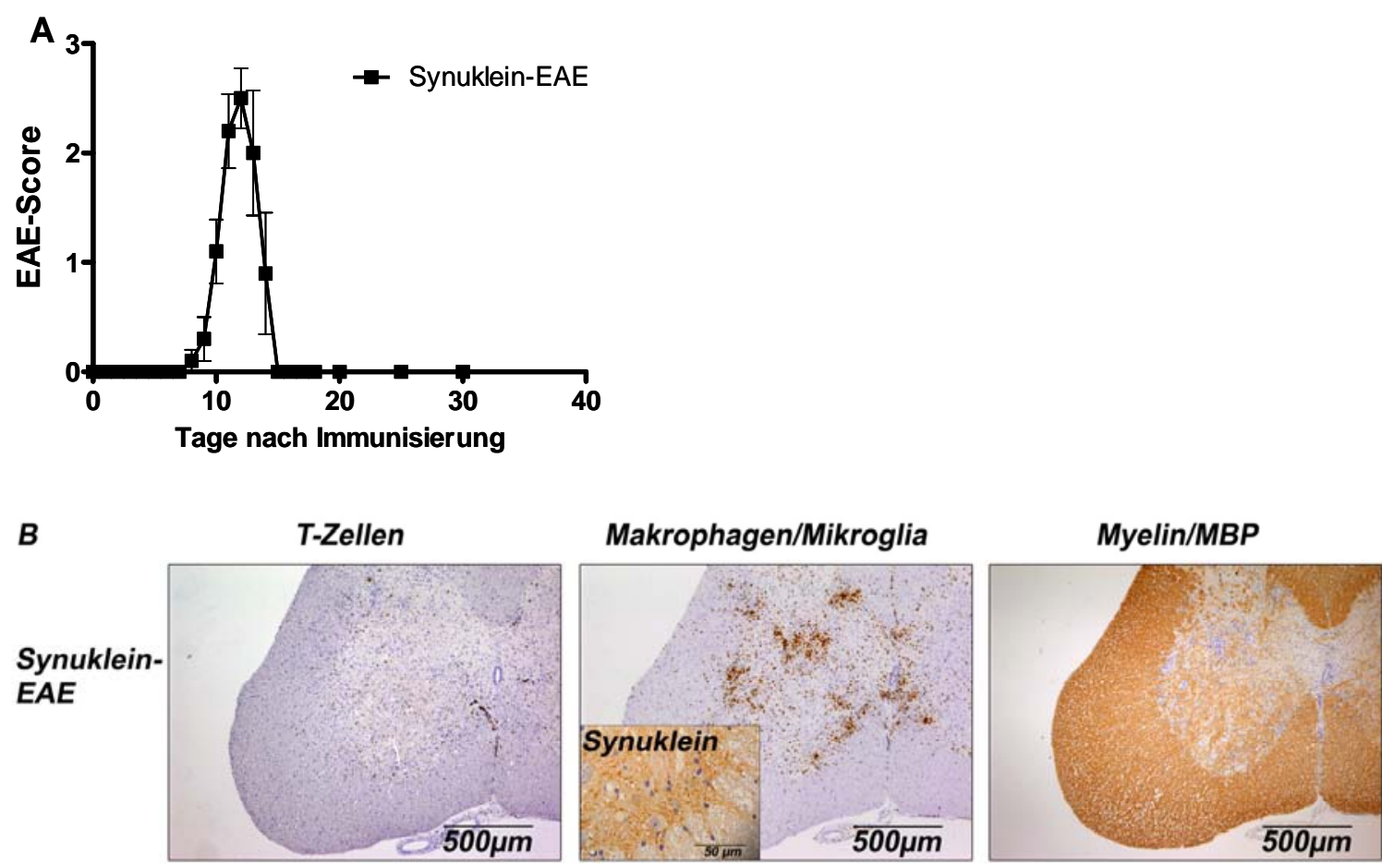

Abb. 3-1: Krankheitsverlauf und Befall der grauen Substanz nach Immunisierung mit $\beta$-Synuklein ${ }_{93-111 .}$

(A) Lewis-Ratten entwickelten neun bis zehn Tage nach Immunisierung die ersten Krankheitssymptome, welche sich nach drei bis vier Tagen vollständig zurückbildeten. Weitere Krankheitsschübe traten bis 32 Tage nach Immunisierung nicht auf. (B) Färbungen mit W3/13 (T-Zellen und Granulozyten) und dem Makrophagenmarker ED1 verdeutlichten, dass nahezu alle Entzündungszellen in der grauen Substanz lokalisiert waren. Die Lokalisation dieser Zellen entsprach dem Expressionsmuster des $\beta$-Synukleinproteins. Ein Myelinverlust konnte in der Färbung mit dem Antikörper gegen das Myelin-basische Protein (MBP) nicht nachgewiesen werden.

Die histologische Auswertung des zentralnervösen Gewebes von $\beta$-Synuklein ${ }_{93-111^{-}}$ immunisierten Ratten zeigte einen vorwiegenden Befall der grauen Substanz, insbesondere des Rückenmarks. In anderen Regionen, wie z.B. Pons, Hirnstamm und Kortex stellten sich in der grauen Substanz ebenfalls entzündliche Infiltrate dar. Insgesamt war auffallend, dass der Großteil der Entzündungszellen in der grauen Substanz lokalisiert war (perivaskuläre und diffuse Verteilung) und somit mit dem $\beta$-SynukleinproteinExpressionsmuster übereinstimmte (Abb. 3-1 B). Obwohl $\beta$-Synuklein im peripheren Nervensystem exprimiert wird (Giasson et al. 2001), konnten keine entzündlichen Infiltrate in den Hinterwurzelganglien und dem Ischiasnerv, welche exemplarisch für das PNS untersucht wurden, nachgewiesen werden (Daten nicht gezeigt). In der Myelinfärbung mit einem Antikörper gegen MBP und LFB/PAS zeigten sich keine Bereiche mit Myelinverlust (Abb. 3-1 B) 


\subsection{Der Transfer des anti-MOG Antikörpers 8-18C5 induzierte entmarkte Läsionen in der grauen Substanz}

Um in diesem Tiermodell eine bessere Übereinstimmung mit der entmarkenden Pathologie der MS zu erzielen, wurden zusätzlich demyelinisierende Herde durch den Transfer des anti-MOG Antikörpers 8-18C5 induziert (Linington et al. 1988).

In der vorliegenden Arbeit erfolgte die intravenöse Injektion von 2 mg 8-18C5 oder der gleichen Menge an Isotypkontrollantikörper (IgG1) bei beginnender Krankheit (Score 1-1,5). Für die histologische Auswertung wurde das ZNS 30 Stunden, vier Tage oder 20 Tage nach Transfer entnommen. Die Auswertung erfolgte an den jeweils drei am stärksten betroffenen lumbalen Rückenmarksquerschnitten.
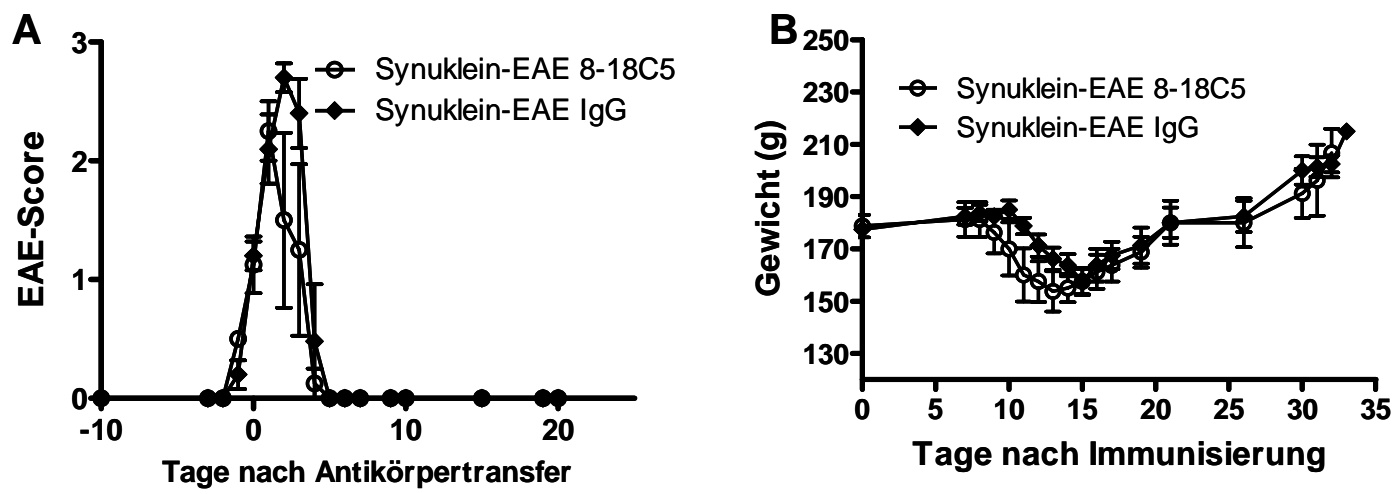

\section{C \\ Synuklein-
EAE mit \\ Synuklein- $\lg G$ \\ Synuklein- EAE mit 8-18C5} LFB/PAS MBP
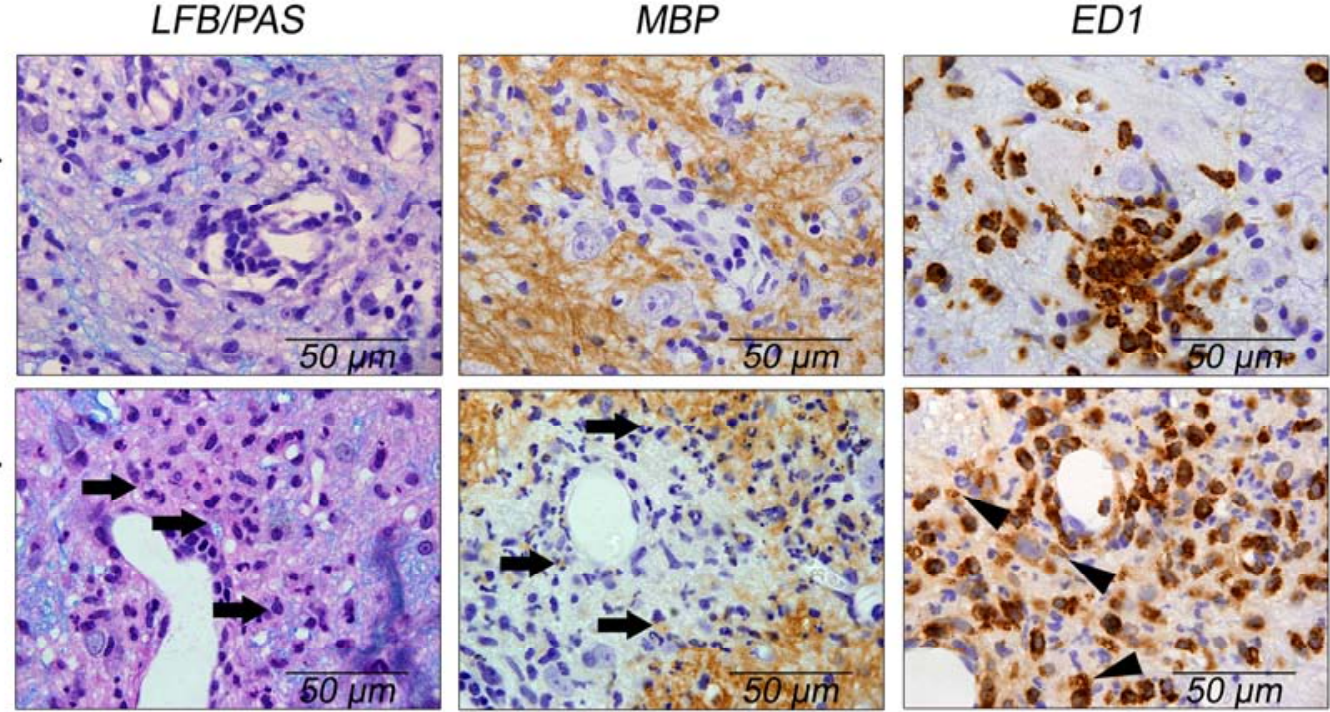

Abb. 3-2: Der Transfer des anti-MOG Antikörpers 8-18C5 führte zu entmarkten Läsionen in der grauen Substanz bei der $\beta$-Synuklein-EAE. (A) Der Myelinverlust führte zu keiner Verstärkung der Krankheitssymptome, (B) jedoch zu einem geringfügig stärkeren Gewichtsverlust. (C) In den Myelinfärbungen mit LFB/PAS und MBP wurden perivaskuläre Läsionen ohne (IgG) und mit (8-18C5) Myelinverlust nachgewiesen. In der ED1-Färbung waren Myelin-phagozytierende (Pfeil), schaumzellige Makrophagen (Pfeilspitze), ein typisches Kennzeichen entmarkender Läsionen, zu erkennen. 
Die zusätzliche Gabe der entmarkenden Antikörper (8-18C5) führte zu keiner offensichtlichen Verstärkung der Krankheitssymptome, jedoch verloren diese Ratten im akuten Krankheitsstadium (9-14 dpi) im Vergleich zu Isotyp-transferierten Tieren stärker an Gewicht (Abb. 3-2 A+B). 8-18C5-behandelte Tiere zeigten zahlreiche perivaskuläre entmarkte Läsionen in der grauen Substanz. Entmarkungsherde, die am Übergang zwischen grauer und weißer Substanz lokalisiert waren, endeten häufig an der Grenze zur weißen Substanz. Der Verlust der Myelinscheiden war ausschließlich bei den Tieren nachweisbar, die 30 Stunden oder vier Tage nach Antikörpertransfer getötet wurden. Hingegen zeigten Ratten, die 20 Tage nach dem Transfer geopfert wurden, keine Hinweise für demyelinisierte Läsionen mehr. 30 Std. nach Antikörpertransfer konnten am Rand der entmarkten Bereiche zahlreiche schaumzellige, MBP-positive Makrophagen/Mikroglia nachgewiesen werden (Abb. 3-2 C).

\subsubsection{Histologische Auswertung der entzündlichen Infiltrate}

\subsubsection{Infiltration von T-Zellen und Makrophagen/Mikroglia in die graue Substanz}

Die Dichte der Makrophagen in der grauen Substanz war am größten in den Tieren mit entmarkenden Läsionen 30 Stunden nach dem Antikörpertransfer (30 Std. IgG1: $501 \pm 271$ Zellen/mm²; 30 Std. 8-18C5: $955 \pm 660$ Zellen/mm²; ungepaarter T-Test 30 Std. IgG vs. 30 Std. 8-18C5 $\mathrm{P}=0,181$ ). Selbst vier Tage nach Transfer gab es in Tieren mit Myelinverlust noch eine deutliche Makrophagen/Mikroglia Population (588 \pm 168 ED1-positive Zellen $/ \mathrm{mm}^{2}$ ). Obwohl die Ratten 20 Tage nach Transfer bereits seit durchschnittlich zwei Wochen keine Krankheitssymptome mehr zeigten, lag bei beiden Gruppen die Zahl an ED1-positiven Makrophagen/Mikroglia deutlich über dem Wert von CFAimmunisierten Kontrolltieren (CFA: $4 \pm 1$ Zellen/mm²; 20d IgG1: $135 \pm 56$ Zellen/mm²; 20d 8-18C5: $179 \pm 76$ Zellen/mm²; ANOVA CFA vs. 20d IgG1 P>0,05; 30 Std. IgG1 vs. 20d IgG1 P<0,01; CFA vs. 20d 8-18C5 P>0,05; 30 Std. 8-18C5 vs. 20d 8-18C5 P<0,05). Ein signifikanter Unterschied hinsichtlich der Makrophagen-/Mikrogliadichte war zwischen anti-MOG- und isotyptransferierten Tieren 20 Tage nach Transfer nicht vorhanden (ungepaarter T-Test $P=0,413$ ) (Abb. 3-3 A).

Die Analyse der 30 Stunden nach Antikörpertransfer geopferten Tiere zeigte, dass die Anzahl der W3/13-positiven T-Zellen zwischen Tieren mit und ohne Entmarkung statistisch nicht signifikant unterschiedlich war. Im Vergleich hierzu waren die Dichte der T-Zellen in den CFA-immunisierten Kontrollen deutlich niedriger (CFA: $0 \pm 0$ Zellen/mm; 30 Std. IgG1: $115 \pm 50$ Zellen/mm²; 39 Std. 8-18C5: $77 \pm 40$ Zellen/mm²). In der Auswer- 
tung der vier Tage nach Transfer getöteten Ratten ließ sich ein rascher Rückgang der T-Zelldichte nachweisen. Nur noch wenige T-Zellen konnten angefärbt werden (9 \pm 6 Zellen/mm²; ANOVA 30 Std. 8-18C5 vs. 4d 8-18C5 $\mathrm{P}<0,01) .20$ Tage nach Transfer wiesen die meisten Rückenmarksquerschnitte keine T-Zellen mehr auf (IgG1: $4 \pm 8$ Zellen/mm²; 8-18C5: $0 \pm 0$ Zellen/mm²; ANOVA 30 Std IgG. vs. 20d IgG1 $P<0,001 ; 30$ Std. 8-18C5 vs. 20d 8-18C5 $P<0,01$ ) (Abb. 3-3 B). Eine Ausnahme bildete hier allerdings eine Ratte, deren Rückenmark noch ein einzelnes entzündliches Infiltrat zeigte.
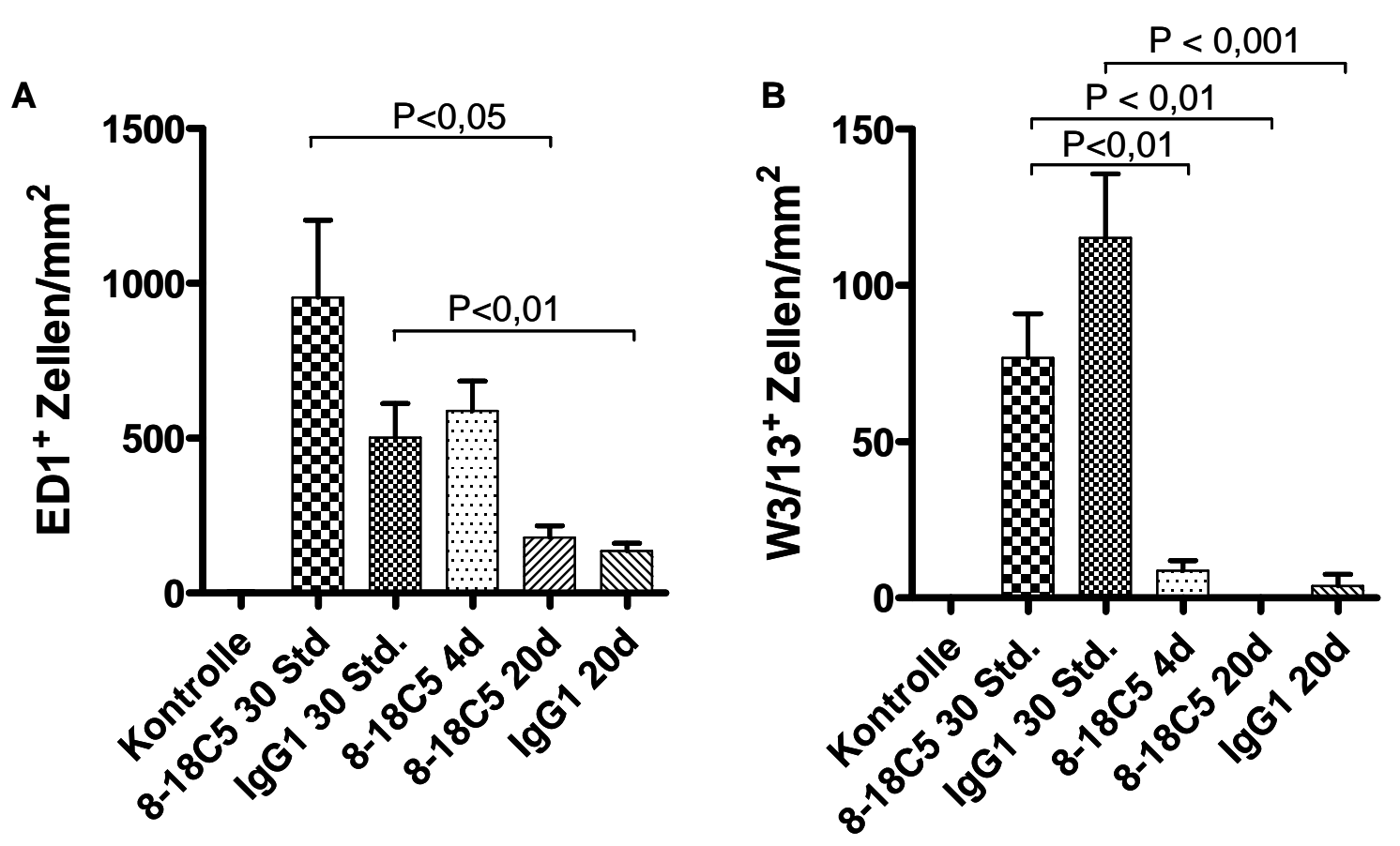

Abb. 3-3: Die Immunisierung mit $\beta$-Synuklein ${ }_{93-111}$ sowie der zusätzliche Antikörpertransfer führten zur Infiltration von Makrophagen/Mikroglia (ED1) und T-Zellen (W3/13) in die graue Substanz des Rückenmarks von Lewis-Ratten. Gezählt wurden ED1- und W3/13-positive Zellen in je sechs definierten Gesichtsfeldern in der grauen Substanz. (A) Dabei zeigte sich, dass in Tieren mit Entmarkung die Dichte der Makrophagen/Mikroglia $30 \mathrm{Std}$. nach Antikörpertransfer am höchsten war (IgG1: $501 \pm 271$ Zellen/mm²; 8-18C5: $955 \pm 660$ Zellen $/ \mathrm{mm}^{2}$; ungepaarter T-Test $\left.\mathrm{P}=0,181\right)$. Obwohl die Tiere 20 Tage nach Antikörpertransfer keine Krankheitssymptome mehr zeigten, war die Dichte der Makrophagen/Mikroglia im Vergleich zu Kontrolltieren deutlich erhöht (CFA: $4 \pm 1$ Zellen/mm²; 20d IgG1: $135 \pm 56$ Zellen/mm²; 20d 8-18C5: $179 \pm 76$ Zellen/mm²; ANOVA CFA vs. $20 \mathrm{~d}$ IgG1 P>0,05, $30 \mathrm{Std}$. IgG1 vs. $20 \mathrm{~d}$ IgG1 $\mathrm{P}<0,01$; CFA vs. 20d 8-18C5 P>0,05; 30 Std. 8-18C5 vs. 20d 8-18C5 P<0,05). (B) Die Dichte der eingewanderten T-Zellen war $30 \mathrm{Std}$. nach Transfer am höchsten (CFA: $0 \pm 0$ Zellen/mm²; 30 Std. IgG1: $115 \pm 50$ Zellen/mm²; 30 Std. 8-18C5: $77 \pm 40$ Zellen/mm²; 4d 8-18C5 $9 \pm 6$ Zellen/mm²; 20d IgG; $4 \pm 8$ Zellen $/ \mathrm{mm}^{2} ; 20 \mathrm{~d}$ 8-18C5 $0 \pm 0$ Zellen/mm²). Lediglich ein Tier (IgG1) der 20 Tage-Gruppe zeigte noch eine Läsion mit T-Zellen. 


\subsubsection{Ein Fehlen CD8-positiver Zellen hatte keinen Einfluss auf den Krankheitsver-} lauf der $\beta$-Synuklein-EAE

In der Vergangenheit wurde angenommen, dass MS und EAE hauptsächlich durch autoreaktive CD4-positive T-Helfer Zellen vermittelt werden (Weiss et al. 2007). Mittlerweile wird jedoch über eine Beteiligung von CD8-positiven zytotoxischen T-Zellen diskutiert, unter anderem da bei MS-Patienten eine klonale Vermehrung von CD8-positiven Zellen im ZNS und Liquor festgestellt wurde (Sospedra und Martin 2005). Des Weiteren korreliert das Ausmaß an axonalem Schaden mit der Anzahl der CD8-positiven Zellen in MSLäsionen (Bitsch et al. 2000). Die genaue Funktion dieser Zellen ist jedoch noch nicht geklärt (Weiss et al. 2007). Aufgrund der wachsenden Bedeutung zytotoxischer T-Zellen bei MS und EAE, sollte auch im Modell der $\beta$-Synuklein-EAE der Anteil der CD8-positiven T-Zellen in den jeweils drei am stärksten betroffenen lumbalen Rückenmarksquerschnitten in der grauen Substanz ermittelt werden.
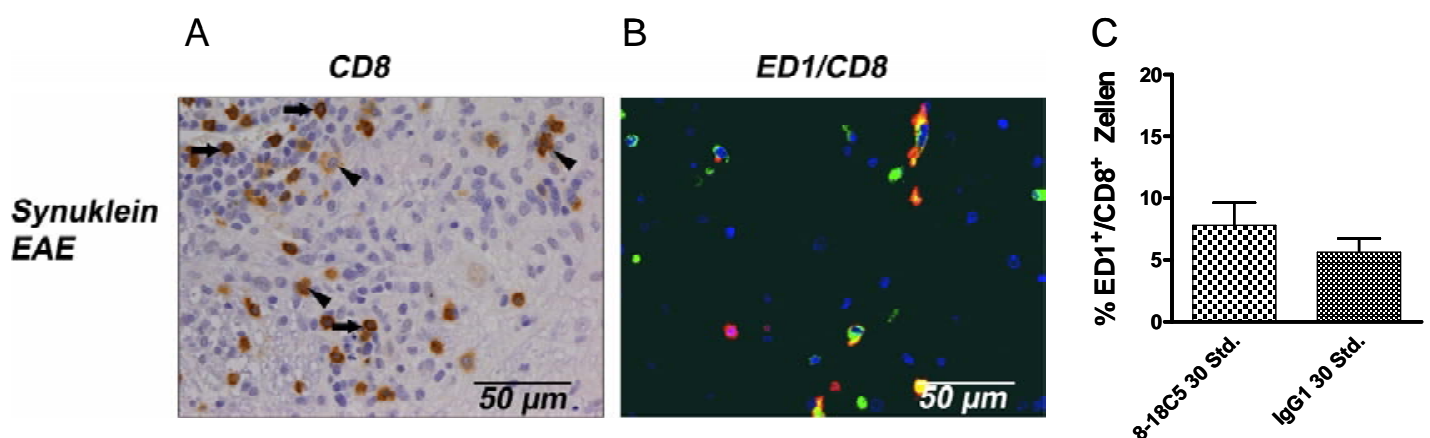

Abb. 3-4: Nicht nur zytotoxische T-Zellen exprimierten das Oberflächenmolekül CD8, sondern auch CD8-positive Makrophagen ließen sich im Rückenmark von immunisierten Ratten nachweisen. (A) CD8-positive Zellen wiesen sowohl die Morphologie von T-Zellen (Pfeil) als auch von Makrophagen/Mikroglia (Pfeilspitze) auf. (B) Durch die fluoreszenzmikroskopische Doppelmarkierung mit dem Makrophagen/Mikrogliamarker ED1 (rot) und CD8 (grün) konnte bestätigt werden, dass nicht nur zytotoxische T-Zellen CD8 exprimieren sondern auch Makrophagen/Mikroglia (ED1/CD8-doppletpositiv) (C) Der Anteil der CD8-positiven Makrophagen/Mikroglia lag ungefähr bei 10\% und war unabhängig von Entmarkung.

30 Stunden nach Antikörpertransfer waren in den Rückenmarksquerschnitten von $\beta$-Synuklein ${ }_{93-111}$-immunisierten Tieren zahlreiche CD8-positive Zellen vorhanden, unabhängig davon ob anti-MOG- oder Isotypkontrollantikörper transferiert wurden. Parallel zur T-Zell- und Makrophagen/Mikrogliadichte sank die Anzahl der CD8-positiven Zellen rasch nach Antikörpertransfer ab. Bei der histologischen Auswertung fiel auf, dass nicht nur CD8-positive Zellen mit T-Zellmorphologie vorhanden waren, sondern auch einige CD8positive Zellen einen Makrophagen/Mikroglia-Phänotyp aufwiesen. Die Doppelmarkierung 
mit dem Makrophagen/Mikrogliamarker ED1 und CD8 bestätigte, dass es sich bei ca. 10\% der CD8-positiven Zellen tatsächlich um Makrophagen/Mikroglia handelte (Abb. 3-4).

A

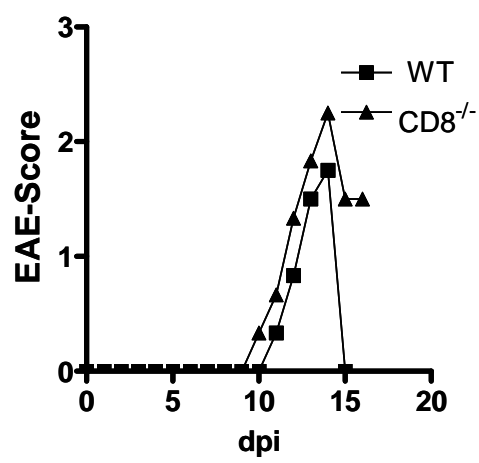

B

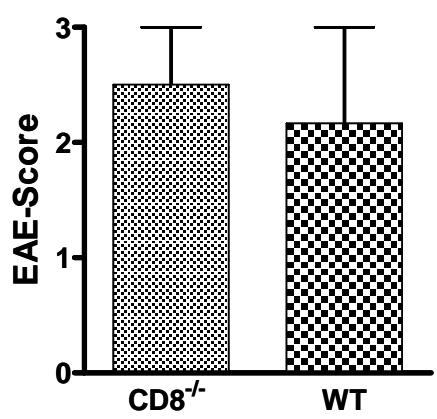

C Krankheitsbeginn

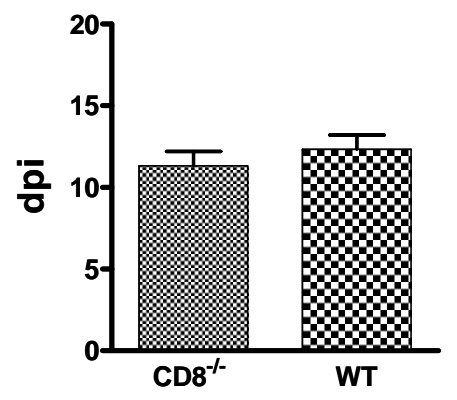

Abb. 3-5: Krankheitsverlauf von CD8-defizienten Lewis-Ratten nach Immunisierung mit $\beta$-Synuklein. Ein Vergleich zwischen WT und CD8-defizienten Ratten zeigte, dass weder (A) im Krankheitsverlauf noch beim (B) maximal erreichten Score (WT: 2,2 $\pm 1,4$; $^{-1} 8^{-1}: 2,5 \pm 0,9$; ungepaarter T-Test $P=0,749$ ), (C) noch im Tag des Krankheitsbeginns (WT: $12,3 \pm 1,5$ dpi; $\mathrm{CD}^{-1}: 11,3 \pm 1,5$; ungepaarter T-Test $\mathrm{P}=0,468$ ) ein Unterschied bestand. (dpi: Tage nach Immunisierung, $\mathrm{CD}^{-1}$ : CD8-defiziente Ratten, WT: Wildtyp Ratten)

Um zu untersuchen, ob die CD8-positiven Zellen eine Rolle im Krankheitsverlauf der $\beta$-Synuklein-EAE spielen, wurde die $\beta$-Synuklein-EAE in weiteren Versuchen in CD8defizienten Lewis-Ratten induziert. Ein Vergleich des Krankheitsverlaufs, der maximal erreichten Scores (WT: 2,2 und $\mathrm{CD}^{-{ }^{-}}$2,5) und der Tage des Krankheitsbeginns (WT: 12,3 dpi und CD8 ${ }^{-/}$11,3) zeigten jedoch keine signifikanten Unterschiede zwischen beiden Gruppen auf (Abb. 3-5 A - C).

\subsection{Eine Schädigung der Axone erfolgte hauptsächlich in entmarkten Bereichen}

Der Verlust der Myelinscheiden und die Freisetzung von entzündlichen Mediatoren wie z.B. NO aus Entzündungszellen tragen zur Schädigung der Axone bei (Smith und Lassmann 2002). Eine Transportstörung der Axone kann durch die Akkumulation des Amyloid-Vorläuferproteins (APP) nachgewiesen werden (Gentleman et al. 1993; Hendriks et al. 2005), da es dem schnellen axonalen Transport unterliegt (Koo et al. 1990).

In der vorliegenden Arbeit wurden APP-positive Axone nahezu ausschließlich in den entmarkten, perivaskulären Läsionen in der grauen Substanz gefunden. Entzündliche Infiltra- 
te ohne Entmarkung führten nur selten zu einer Transportstörung entlang der Nervenbahnen (Abb. 3-6).

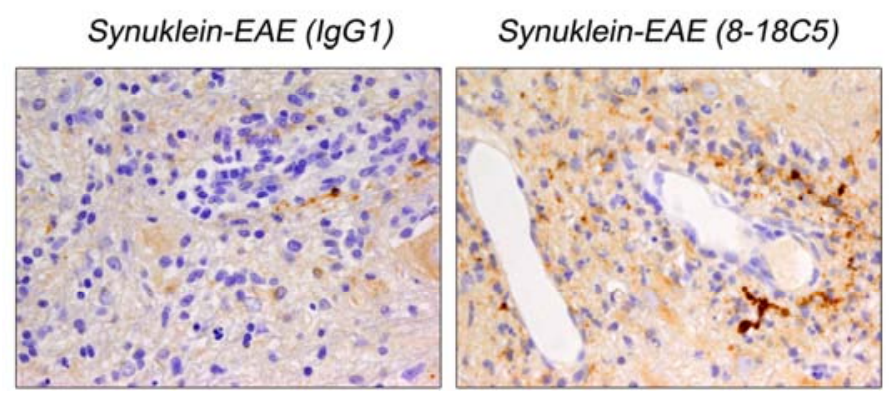

Abb. 3-6: Der Verlust der Myelinscheiden erleichterte axonalen Schaden. Eine Transportstörung entlang der Axone fand sich vor allem in demyelinisierten Arealen. Abgebildet ist die Akkumulation von APP 30 Stunden nach Antikörpertransfer in Tieren mit (8-18C5) und ohne (IgG1) Entmarkung.

\subsection{Aktivierung von Makrophagen/Mikroglia}

Aktivierte Makrophagen/Mikroglia sind bei weitem die häufigste Zellpopulation in entmarkten Läsionen. Ihre Funktion bei der MS-Pathologie wird kontrovers diskutiert. Zum einen spielen sie eine Rolle bei der Regeneration, da sie durch Phagozytose eine wichtige Voraussetzung für die Remyelinisierung schaffen. Zum anderen verursachen sie eine Schädigung der Axone und Oligodendrozyten durch toxische Mediatoren. Daher stellte sich die Frage, ob sich unterschiedliche Makrophagen-/Mikrogliapopulationen hinsichtlich der Expression verschiedener Markerproteine unterscheiden lassen: phagozytierende Makrophagen/Mikroglia und „nur“ entzündlich aktivierte Makrophagen/Mikroglia.

Dies wurde in der vorliegenden Arbeit durch die Analyse von verschiedenen Makrophagenaktivierungsmarkern bei der $\beta$-Synuklein-EAE mit und ohne Entmarkung untersucht. Die Auswertung erfolgte in der grauen Substanz an den jeweils drei am stärksten betroffenen lumbalen Rückenmarksquerschnitten.

\subsubsection{Mehr iNOS-exprimierende Makrophagen/Mikroglia in Ratten mit Entmarkung}

Erhöhte Mengen an NO, welche durch iNOS gebildet werden, sind ein typisches Kennzeichen von neurodegenerativen und entzündlichen ZNS-Erkrankungen (Smith und Lassmann 2002).

Im hier verwendeten Modell wurde die Expression von iNOS durch Entzündung alleine nur in sehr wenigen Zellen induziert (30 Std. IgG1: $7 \pm 8$ Zellen $/ \mathrm{mm}^{2}$ ). Erst nach dem Transfer des entmarkenden Antikörpers ließen sich deutlich mehr Zellen mit iNOSExpression nachweisen (30 Std. 8-18C5: $51 \pm 46$ Zellen/mm²; Mann-Whitney 30 Std. 
8-18C5 vs. 30 Std. IgG1 $\mathrm{P}=0,029)$. Allerdings kam nur im akuten Krankheitsstadium (30 Std. nach Transfer) eine deutliche Population an iNOS-exprimierenden Zellen zur Darstellung. Bereits vier Tage nach Transfer (8-18C5) konnten nur noch $8 \pm 12$ Zellen/mm $\mathrm{mm}^{2}$ angefärbt werden. In den Rückenmarksquerschnitten von CFA immunisierten Kontrollratten und Ratten, die 20 Tage nach Transfer getötet wurden, konnten keine iNOS-positiven Zellen nachgewiesen werden (Abb. 3-7 B).

\subsubsection{Makrophagen/Mikroglia in rein entzündlicher Umgebung exprimierten ver- mehrt CD163}

CD163 vermittelt die Bindung und Endozytose des Hämoglobin-Haptoglobin ( $\mathrm{Hb}-\mathrm{Hp})$ Komplexes durch Makrophagen (Schaer et al. 2007). Die Expression dieses Rezeptors wird mit antiinflammatorischen Bedingungen in Verbindung gebracht.

In der vorliegenden Arbeit wurden in den Rückenmarksquerschnitten von Tieren ohne Entmarkung mehr CD163-positive Zellen gezählt als in Tieren mit Entmarkung (30 Std. IgG1: $194 \pm 133$ Zellen/mm²; 30 Std. 8-18C5: $132 \pm 60$ Zellen/mm²). Der Unterschied zwischen diesen beiden Gruppen war jedoch nicht signifikant (ungepaarter T-Test $\mathrm{P}=0,358)$. Wie schon zuvor bei der iNOS-Expression waren CD163-positive Zellen hauptsächlich im akuten Krankheitsstadium vorzufinden (4d 8-18C5: $61 \pm 24$ Zellen $/ \mathrm{mm}^{2}$; ANOVA 30 Std. 8-18C5 vs. 4d 8-18C5 P>0,05) (Abb. 3-7 D).

\subsubsection{Hämoxigenase-1 wurde in Ratten ohne Entmarkung vermehrt exprimiert}

Es wird davon ausgegangen, dass HO-1 die Expression von iNOS und inflammatorischer Zytokine hemmt (Colville-Nash et al. 1998) und gilt daher als antiinflammatorisches Protein. In dieser Arbeit sollte anhand des Expressionsniveaus von HO-1 in Tieren mit und ohne Entmarkung untersucht werden, ob die Phagozytose von Myelin ein Stimulus für Makrophagen/Mikroglia ist, der zu HO-1-Expression führt.

HO-1 wurde nur von wenigen Zellen gebildet, und diese ließen sich morphologisch Makrophagen/Mikroglia zuordnen. Die Auszählung der HO-1-positiven Zellen in Tieren, die 30 Stunden nach Antikörpertransfer getötet wurden, ergab in Ratten ohne Entmarkung $33 \pm 27$ Zellen $/ \mathrm{mm}^{2}$. Die Dichte war somit doppelt so hoch wie in Tieren mit Entmarkung (30 Std. 8-18C5: $16 \pm 9$ Zellen/mm²). Aufgrund interindividueller Schwankungen zwischen einzelnen Tieren erreichte das Ergebnis keine statistische Signifikanz. In CFAimmunisierten Kontrollen fanden sich keine HO-1-exprimierenden Zellen (CFA: $0 \pm 0$ Zellen $/ \mathrm{mm}^{2}$ ). Vier Tage nach Antikörpertransfer waren noch $5 \pm 3$ Zellen/mm ${ }^{2}$ in den Rückenmarksquerschnitten nachweisbar (Abb. 3-7 C). 
A

iNOS

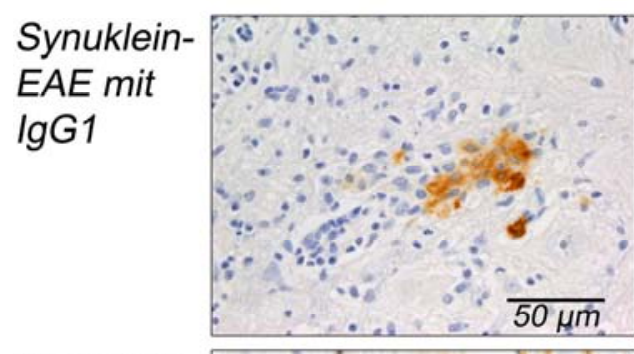

SynukleinEAE mit 8-18C5

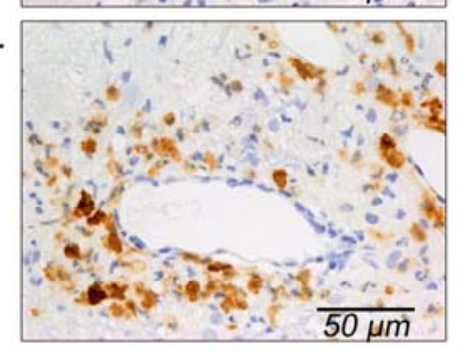

B

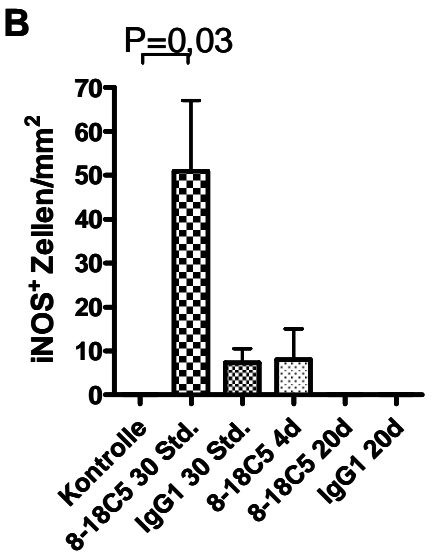

$\mathrm{HO}-1$
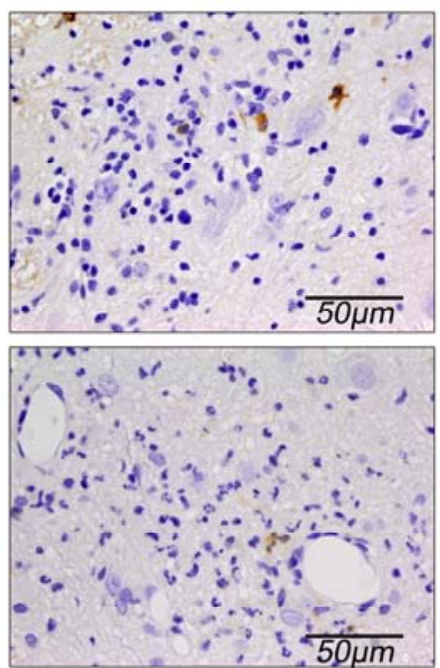

CD163
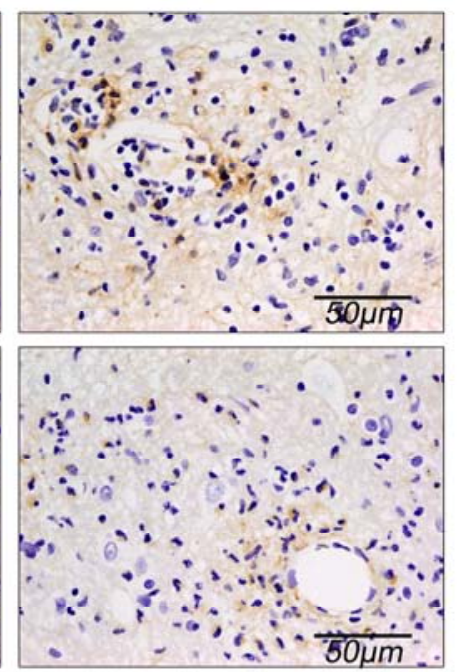

D

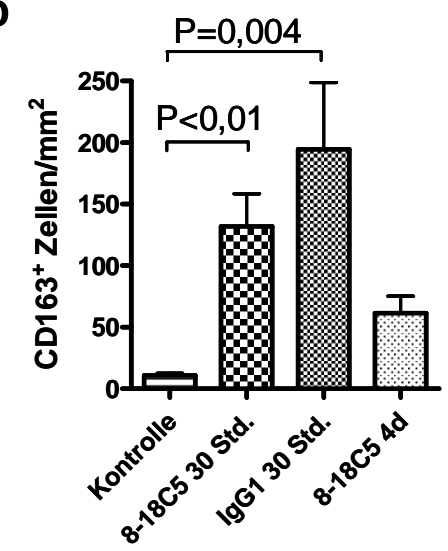

Abb. 3-7: Ein Vergleich der Makrophagen/Mikrogliaaktivierung unter rein entzündlichen Bedingungen und bei Entzündung mit Entmarkung. (A) Die Expression von iNOS, HO-1 und CD163 bei der $\beta$-SynukleinEAE in der grauen Substanz 30 Std. nach Antikörpertransfer. (B) Entzündung alleine induzierte nur in wenigen Zellen die Expression von iNOS (30 Std. IgG1: $7 \pm 8$ Zellen/ $/ \mathrm{mm}^{2}$ ). Erst entzündliche Entmarkung führte zu signifikant mehr iNOS-positiven Zellen in der grauen Substanz (30 Std. 8-18C5: $51 \pm 46$ Zellen/mm²; MannWhitney $30 \mathrm{Std}$. 8-18C5 vs. $30 \mathrm{Std}$. IgG1 P=0,03). Dabei war die Expression auf das akute Krankheitsstadium beschränkt. (C) Einige wenige Zellen exprimierten HO-1 (CFA: $0 \pm 0$ Zellen/mm²; 30 Std. 8-18C5: $16 \pm 9$ Zellen/mm²; 30 Std. IgG1: $33 \pm 27$ Zellen/mm²; ANOVA CFA vs. 30 Std. 8-18C5 P<0,05; Mann-Whitney Kontrolle vs. $30 \mathrm{Std}$. IgG1 $\mathrm{P}=0,004)$. Dabei war 30 Stunden nach Transfer der Unterschied zwischen Tieren mit und ohne Entmarkung nicht signifikant (Mann-Whitney 30 Std. 8-18C5 vs. 30 Std. IgG1 P=0,281). (D) Die Expression von CD163 war bei der $\beta$-Synuklein-EAE im Vergleich zu Kontroltieren ebenfalls erhöht. Dabei färbten sich 30 Stunden nach Transfer in Tieren ohne Entmarkung etwas mehr positive Zellen an (CFA: $11 \pm 4$ Zellen/mm²; 30 Std. 8-18C5: $132 \pm 60$ Zellen/mm²; 30 Std. IgG1:194 \pm 133 Zellen/mm²; ANOVA CFA vs. $30 \mathrm{Std}$. 8-18C5 $P<0,01$; Mann-Whitney Kontrolle vs. 30 Std. IgG1 $P=0,004$; ungepaarter T-Test $30 \mathrm{Std}$. 8-18C5 vs. 30 Std. $\lg \mathrm{G} 1 \mathrm{P}=0,358)$. 
Zusammenfassend lässt sich bemerken, dass durch Entmarkung zellschädigende Proteine wie iNOS vermehrt exprimiert werden. Hingegen werden in Tieren ohne Entmarkung in Makrophagen/Mikroglia tendenziell mehr Proteine gebildet, die als antiinflammatorisch gelten (CD163 und HO-1).

\subsection{Auswirkungen der Entzündung auf die Nervenzellen}

Im hier verwendeten Modell der $\beta$-Synuklein-EAE ließen sich entzündliche Infiltrate hauptsächlich in der grauen Substanz nachweisen. Die Zellen des Immunsystems befanden sich somit in unmittelbarer Nähe zu den Nervenzellen. Es stellte sich deshalb die Frage, in wieweit die infiltrierenden Zellen - unabhängig von einer Schädigung der weißen Substanz - eine Schädigung und / oder einen Verlust von Neuronen induzieren können.

\subsubsection{Entzündung und Entmarkung führten zu einer vermehrten Expression von cJun}

Die Expression des Transkriptionsfaktors cJun ist eines der ersten und zuverlässigsten Merkmale der neuronalen Stressantwort bei Axotomie und neurodegenerativen Erkrankungen. Dabei korreliert die Menge an cJun mit dem Stressausmaß (Herdegen et al. 1997).

Ein Vergleich der neuronalen cJun-Expression in den jeweils drei am stärksten betroffenen lumbalen Rückenmarksquerschnitten sollte klären, ob die unmittelbare Nähe von Immunzellen für eine Stressantwort in Neuronen ausreicht oder ob zusätzlich Entmarkung und axonale Schädigung als weiterer Stimulus nötig sind.

Die histologische Auswertung zeigte, dass entzündliche Infiltrate in der grauen Substanz die Expression von cJun in Neuronen induzieren (CFA: $3 \pm 1$ Neurone/Rückenmarksquerschnitt; 30 Std. IgG1: $15 \pm 7$ Neurone/Rückenmarksquerschnitt; ANOVA CFA vs. 30 Std. IgG1 $\mathrm{P}<0,01)$. In Tieren, die 30 Stunden nach 8-18C5-Transfer getötet wurden, waren im Vergleich zu Tieren ohne Entmarkung jedoch nahezu doppelt so viel Neurone pro Rückenmarksquerschnitt cJun-positiv (30 Std. 8-18C5: $25 \pm 12$ Neurone/Rückenmarks-querschnitt; ANOVA CFA vs. 30 Std. 8-18C5 $P<0,001 ;$ ungepaarter T-Test 30 Std. IgG1 vs. 30 Std. 8-18C5 P=0,084). Mit beginnender Besserung der Krankheit und damit verbundenem Rückgang der Entzündung nahm die Anzahl cJunexprimierender Neurone ab, lag aber immer noch deutlich über der Menge der konstitutiven cJun-Expression (4d 8-18C5: $11 \pm 3$ Neurone/Rückenmarksquerschnitt; ANOVA 30 Std. $8-18 C 5$ vs. 4d 8-18C5 P>0,05; CFA vs. 4d 8-18C5 P>0,05). Bei den Ratten, die 
20 Tage nach Antikörpertransfer getötet wurden (8-18C5: $3 \pm 2$ Neurone/Rückenmarksquerschnitt; IgG1: $4 \pm 2$ Neurone/Rückenmarksquerschnitt) war die Anzahl der cJunpositiven Neurone mit jener von Kontrollratten vergleichbar (3 \pm 1 Neurone/Rückenmarksquerschnitt; ANOVA CFA vs. 20d IgG1 P>0,05; CFA vs. 20d 8-18C5 P>0,05).
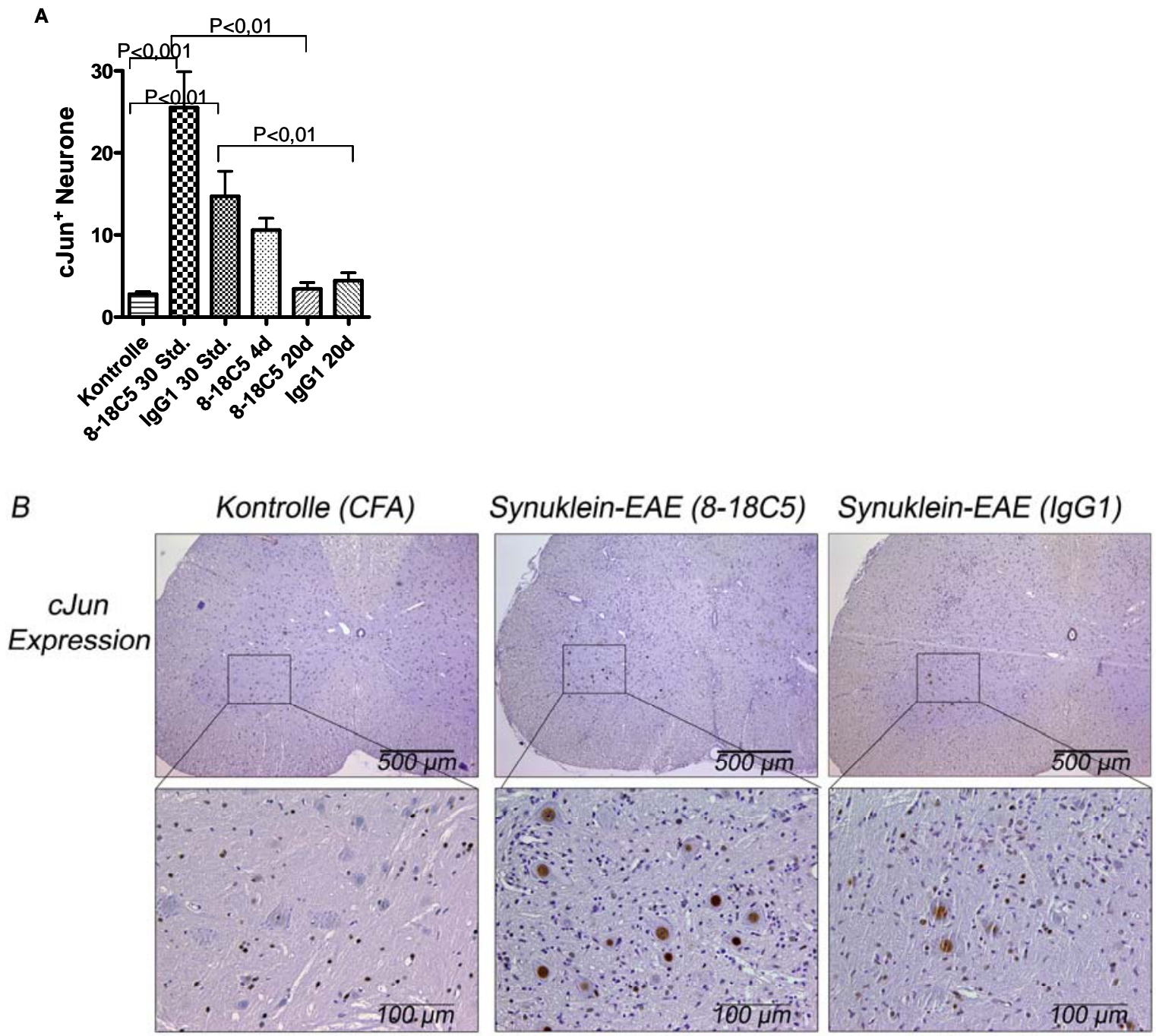

Abb. 3-8: Entzündung und Entmarkung führten zu vermehrter neuronalen cJun-Expression. (A) Aus diesen Abbildungen geht hervor, dass bereits Entzündung alleine eine vermehrte Expression von cJun induziert (CFA $3 \pm 1$ Neurone/Rückenmarksquerschnitt; 30 Std. IgG1: $15 \pm 7$ Neurone/Rückenmarksquerschnitt; ANOVA CFA vs. 30 Std. IgG1 P<0,01). Jedoch erhöhte sich die Zahl cJun-exprimierender Neurone durch zusätzliche Entmarkung (30 Std. 8-18C5: $25 \pm 12$ Neurone/Rückenmarksquerschnitt; ANOVA CFA vs. 30 Std. 8-18C5 P<0,001). Der Unterschied erreichte jedoch keine statistische Signifikanz (ungepaarter T-Test 30 Std. IgG1 vs. 30 Std. 8-18C5 P= 0,084). Nach dem Rückgang der Entzündung (Tiere der 20 Tage-Gruppe) war die cJun-Expression mit der von CFA-Kontrolltieren vergleichbar (8-18C5: $3 \pm 2$ Neurone/Rückenmarksquerschnitt; IgG1: $4 \pm 2$ Neurone/Rückenmarksquerschnitt). (B) In den Rückenmarksquerschnitten von CFAimmunisierten Kontrollen waren nur vereinzelte cJun-positive Neurone vorhanden. Die Immunisierung mit $\beta$-Synuklein ${ }_{93-111}$ hingegen führte zu einer vermehrten cJun-Expression in Tieren mit und ohne Entmarkung (30 Std. nach Transfer). 
Ein weiteres Stress- / Schädigungsmerkmal der Nervenzellen ist die Akkumulation von phosphoryliertem Neurofilament. Unter physiologischen Bedingungen liegen Neurofilamente im Soma unphosphoryliert vor, unter pathologischen Bedingungen hingenen und vor allem bei retrograder Chromatolyse sind diese häufig phosphoryliert (Sternberger und Sternberger 1983). Der hier verwendete Antikörper SMI35 erkennt sowohl schwach, als auch stark phosphoryliertes hochmolekulares Neurofilamentprotein und markiert u. a. Nervenzellen mit retrograder Chromatolyse als Zeichen einer somanahen Axondurchtrennung.

Die vorliegenden Experimente zeigten jedoch zu keinem der untersuchten Zeitpunkte SMI35-positive Neurone. Dieses Ergebnis war unabhängig von Entmarkung (Daten nicht gezeigt).

\subsubsection{Entzündung und Entmarkung in der grauen Substanz führten nicht zum neuronalen Zelltod}

Die Expression von cJun kann sowohl auf De- als auch auf Regenerationsprozesse hinweisen (Herdegen et al. 1997). Im nächsten Schritt sollte geklärt werden, ob die vermehrte cJun-Expression nur eine zeitlich begrenzte Stressantwort als Reaktion auf die pathologischen Veränderungen darstellt oder tatsächlich zum Zelltod führt. Da in der HEFärbung auf morphologischer Basis keine apoptotischen Neurone nachzuweisen waren, wurde zunächst die Anzahl der Nervenzellen gezählt.

NeuN (neuronal nuclei) wird ausschließlich von Nervenzellen gebildet und häufig als neuronaler Marker verwendet (Unal-Cevik et al. 2004; Lind et al. 2005; Portiansky et al. 2006). Um die Anzahl der Neurone zwischen den einzelnen experimentellen Gruppen vergleichen zu können, wurde die Nervenzelldichte im ventralen Bereich der drei am stärksten infiltrierten lumbalen Rückenmarksquerschnitte bestimmt.

Ein Vergleich der neuronalen Dichte von gesunden mit der von Ratten mit $\beta$-SynukleinEAE zeigte einen deutlichen Verlust von NeuN-positiven Nervenzellen in erkrankten Ratten. Dieser Verlust war bei Entmarkung nicht stärker ausgeprägt (CFA: $277 \pm 22$ Neurone/mm²; 30 Std. 8-18C5: $209 \pm 38$ Neurone/mm²; 30 Std. IgG1: $186 \pm 49$ Neurone/mm²; ANOVA CFA vs. 30 Std. IgG1 P<0,01; CFA vs. 30 Std. 8-18C5 $\mathrm{P}<0,01$; ungepaarter T-Test 30 Std. IgG1 vs. 30 Std. 8-18C5 P=0,356). Bemerkenswert war dabei, dass in Tieren, die vier oder 20 Tage nach Antikörpertransfer getötet wurden, die Zahl NeuNexprimierender Neurone wieder anstieg. So wurden bereits bei Ratten, die vier Tage nach Transfer getötet wurden $219 \pm 33$ Neurone $/ \mathrm{mm}^{2}$ gezählt. Bei den nach 20 Tagen getöteten Tieren war die Neuronendichte mit der von Kontrolltieren vergleichbar (IgG1: $283 \pm 35$ 
Neurone/mm²; 8-18C5: $277 \pm 22$ Neurone/mm²; ANOVA $30 \mathrm{Std}$. IgG1 vs. 20d IgG1 $\mathrm{P}<0,01$ und 30 Std. 8-18C5 vs. 20d 8-18C5 $\mathrm{P}<0,05)$ (Abb. 3-9).

A

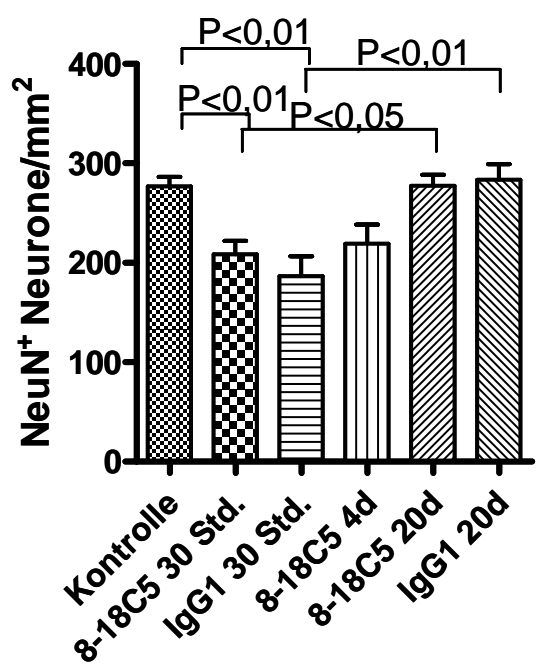

B
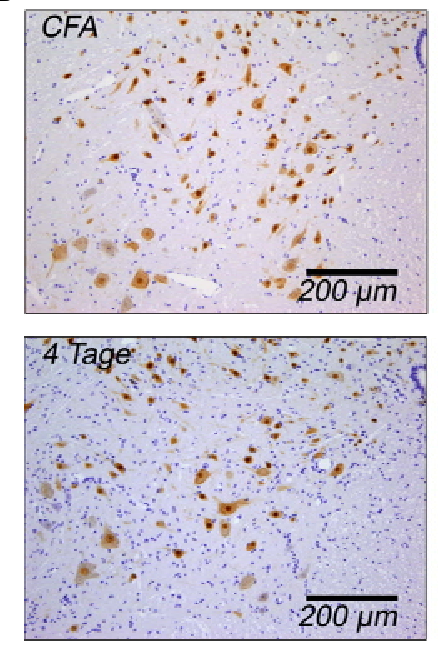
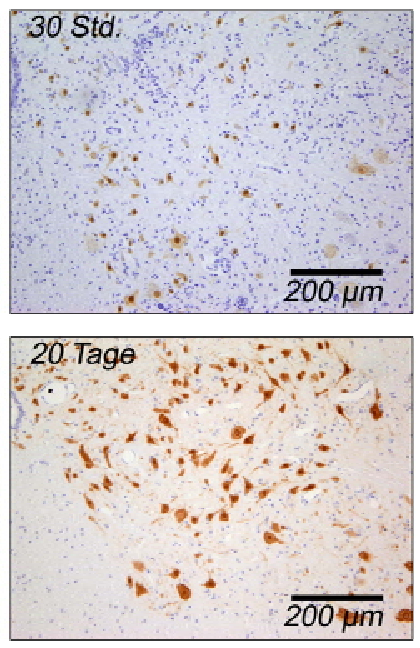

Abb. 3-9: Die Dichte NeuN-positiver Neurone. (A) Die Dichte NeuN-positiver Neurone nahm unter entzündlichen Bedingungen unabhängig von Entmarkung ab (CFA: $277 \pm 22$ Neurone/mm²; 30 Std. 8-18C5: $209 \pm 38$ Neurone/mm²; 30 Std. IgG1: $186 \pm 49$ Neurone/mm²; ANOVA CFA vs. 30 Std. IgG1 P<0,01; CFA vs. 30 Std. 8-18C5 $\mathrm{P}<0,01$; ungepaarter T-Test $30 \mathrm{Std}$. IgG1 vs. $30 \mathrm{Std}$. 8-18C5 $\mathrm{P}=0,356$ ). Jedoch nahm die Dichte der Nervenzellen nach dem Rückgang der Entzündung wieder zu und war 20 Tage nach Antikörpertransfer mit der von Kontroll-Ratten vergleichbar (4d 8-18C5: $219 \pm 33$ Neurone/mm²; 20d IgG1: $283 \pm 35$ Neurone/mm; 20d 8-18C5: $277 \pm 22$ Neurone/mm²; ANOVA 30 Std. IgG1 vs. 20d IgG1 $P<0,01,30$ Std. 8-18C5 vs. 20d 8-18C5 $P<0,05)$. (B) Die Färbung der Rückenmarksquerschnitte mit dem neuronalen Antigen NeuN von CFA-immunisierte Kontrollen und $\beta$-Synuklein ${ }_{93-111}$ immunisierten Ratten, die 30 Std., 4 oder 20 Tage nach 8-18C5 Transfer getötet werden.

Da sich auch NeuN-negative Neurone nachweisen ließen, wurde die Nervenzellzahl zusätzlich anhand der Nissl-Färbung bestimmt. Dadurch sollten NeuN-negative Neurone erfasst werden. Allerdings zeigte die Auswertung der Nissl-Färbung ebenfalls zunächst eine Abnahme der Neuronendichte bei Tieren im akuten Krankheitsstadium. Diese stieg allerdings über die Zeit, entsprechend den Daten der NeuN-Färbung, wieder an (Daten nicht gezeigt).

In apoptotischen Zellen kommt es zu einer Fragmentierung von chromosomaler DNA, welche durch In-situ Tailing (TUNEL-Reaktion) sichtbar gemacht werden kann. Ein weiterer Marker für den Zelltod ist die Expression aktivierter Caspase-3. Um auszuschließen, dass apoptotische Neurone in den Rückenmarksquerschnitten vorhanden waren, wurden 
diese beiden Färbetechniken angewandt. Mit beiden Methoden ließen sich keine apoptotischen Neurone identifizieren (Daten nicht gezeigt).
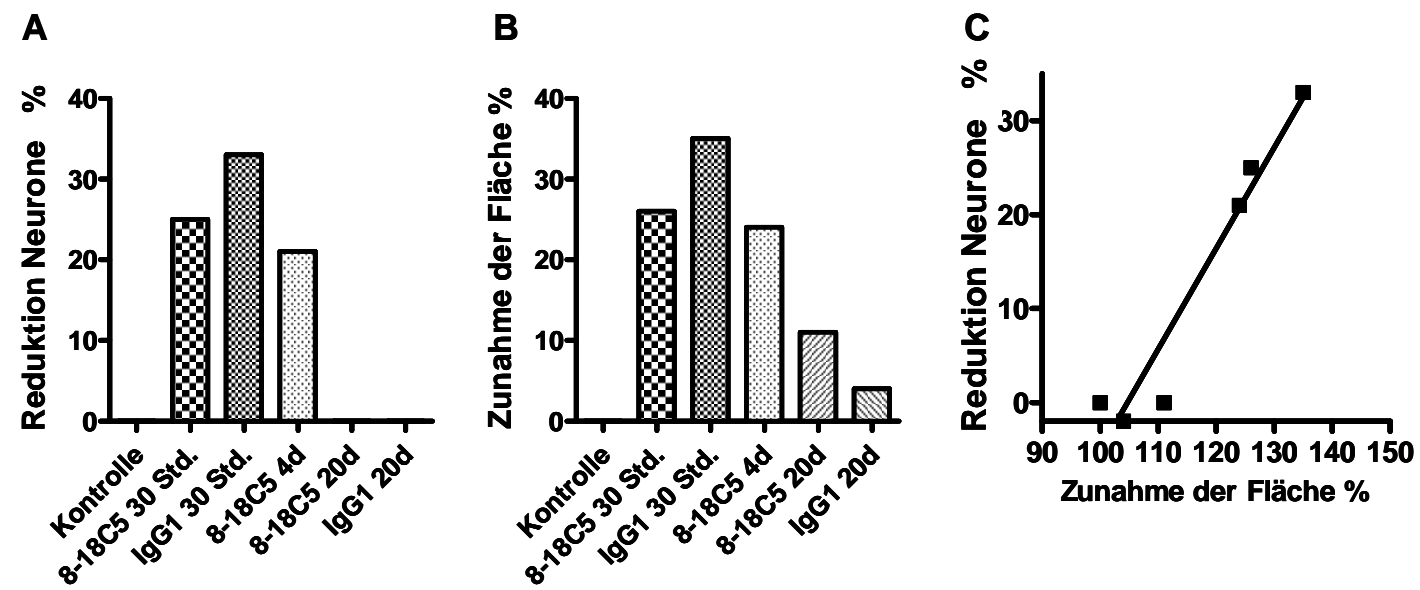

Abb. 3-10: Neuronaler Verlust bei akuter Entzündung. (A) Durch die Infiltration von Zellen des Immunsys-

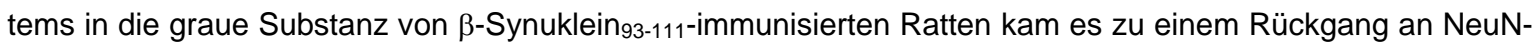
positiven Neuronen (30 Std. IgG1: 33\% Verlust). Diese Reduktion wurde durch zusätzliche Entmarkung nicht weiter verstärkt (30 Std. 8-18C5: 25\% Verlust). Mit dem Abklingen der Krankheitssymptome begann die Anzahl NeuN-positiver Neurone wieder anzusteigen (4d 8-18C5: 21\% Verlust) und war 20 Tage nach Antikörpertransfer mit den Werten CFA-immunisierter Kontrolltiere vergleichbar (20d IgG1 und 8-18C5: 0\% Verlust). (B) Das durch Entzündung bedingte Ödem führte zu einer Flächenvergrößerung der grauen Substanz (30 Std. 8-18C5: 26\% Zunahme; 30 Std. IgG1: 35\% Zunahme; 4d 8-18C5: 24\% Zunahme; 20d 8-18C5: 11\% Zunahme; 20d IgG1: 4\% Zunahme) (C) Die Zunahme der Fläche der grauen Substanz korrelierte $\left(P=0,0017 ; r^{2}=0,934\right)$ mit der Abnahme der Neuronendichte.

Entzündungsprozesse führen zur Ausbildung eines Ödems. So könnte dies eine Erklärung für die geringere Nervenzelldichte bei akuter $\beta$-Synuklein-EAE sein. Bei MSPatienten findet ebenfalls eine ödembedingte Volumenzunahme des ZNS durch Entzündung statt (Helms 2001),

Es zeigte sich, dass in den durchgeführten Experimenten die prozentuale Abnahme der Neuronendichte gut mit der prozentualen Zunahme der Fläche der grauen Substanz korrelierte $\left(\sim P=0,0017 ; r^{2}=0,934\right)$ (Abb. 3-10). 


\subsection{Infiltration von Makrophagen/Mikroglia führte zur Reduktion Synaptophysin-positiver Strukturen}

Neben Oligodendrozyten und Axonen sind ebenso Synapsen vulnerabel gegenüber zellulären Infiltraten und zytotoxischen Produkten, wie z.B. Entzündungsmediatoren und extrazellulärem Glutamat.

In der vorliegenden Arbeit konnten in der grauen Substanz keine Synaptophysin-positiven Strukturen in Phagozyten, als Zeichen einer Phagozytose von Synapsen, gefunden werden. Allerdings kam es in Regionen mit dichten zellulären Infiltraten zu einer Reduktion des immunhistochemischen Synaptophysinsignals. Diese Verminderung konnte in Tieren mit und ohne Entmarkung nachgewiesen werden (Abb. 3-11).

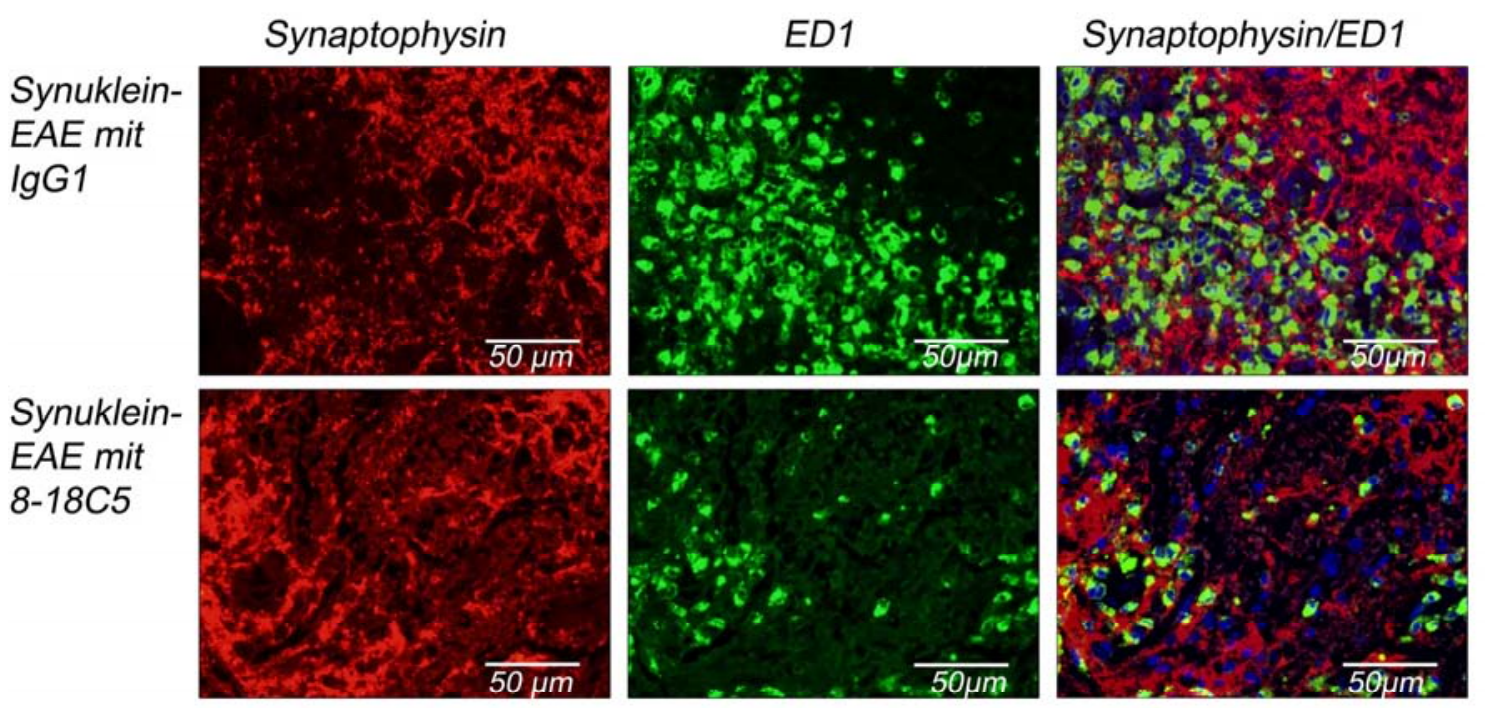

Abb. 3-11: Reduktion Synaptophysin-positiver Strukturen in den Rückenmarksquerschnitten

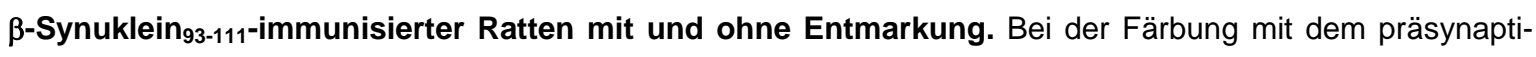
schen Marker Synaptophysin (rot) stellte sich in Bereichen mit dichter Makrophagen/Mikrogliainfiltration (grün) ein Verlust der Synaptophysinsignalintensität dar. Abgebildet sind Rückenmarksquerschnitte von Tieren, die 30 Std. nach Transfer getötet wurden. 


\section{Ergebnisteil II}

Cuprizon-EAE, ein neues Modell mit MS-ähnlichen Läsionen im Mausgehirn 


\subsection{Entwicklung eines Mausmodells mit MS-ähnlichen Läsionen im Gehirn}

Multiple Sklerose ist eine Erkrankung des Gehirns und des Rückenmarks. Bei Mäusen und Ratten hingegen finden die entzündlichen Prozesse der EAE nahezu ausschließlich in der weißen Substanz des Rückenmarks statt. In der vorliegenden Arbeit wurde ein Tiermodell mit MS-ähnlichen Gehirnläsionen etabliert, um die pathologischen Schädigungsmechanismen im Gehirn besser untersuchen zu können.

Hierzu wurden Cuprizon-behandelte Mäuse mit $\mathrm{MOG}_{35-55}$ immunisiert. Die Verfütterung von Cuprizon, einem Kupferchelator, führt vor allem im Balken zum selektiven Absterben von Oligodendrozyten und zur Aktivierung der Mikroglia, der ortsständigen Gehirnmakrophagen (Matsushima und Morell 2001). Der daraus resultierende Verlust der Markscheiden und die „Voraktivierung“ der Mikroglia sollten den Eintritt von aktivierten T-Zellen ins Gehirn begünstigen und auf diese Weise nach Immunisierung mit dem Myelinpeptid MOG $_{35-55}$ zu MS-ähnlichen Entzündungsherden im Gehirn führen.

\subsection{Optimaler Immunisierungszeitpunkt von Cuprizon-behandelten Mäusen}

\subsubsection{Cuprizon-induzierte Genexpression}

Kupfer ist an einer Reihe katalytischer und metabolischer Stoffwechselwege beteiligt, wie z. B. der Synthese von IL-2, einem wichtigen Aktivator der $T_{H} 1$ Immunantwort (Bala und Failla 1992). Auf Grund des Cuprizon-bedingten Kupfermangels wird neben der beabsichtigten Oligodendrozytenapoptose und Mikrogliaaktivierung zusätzlich eine abgeschwächte Immunantwort bei EAE-Versuchen beschrieben (Emerson et al. 2001). Deshalb wurde zunächst der geeignete Zeitpunkt für die Immunisierung von Cuprizon-behandelten Mäusen ermittelt (Emerson et al. 2001).

Im ersten Schritt wurde in der vorliegenden Arbeit der Zeitverlauf der Mikrogliaaktivierung näher untersucht. Dies erfolgte durch die Isolierung der mRNA aus dem Balken von Mäusen nach unterschiedlich langer Cuprizon-Gabe. Die Expressionsmengen der Adhäsionsmoleküle ICAM-1, VCAM-1, des Makrophagen/Mikrogliamarkers LysozymM (LysM), der Chemokine MIP-1 $\alpha$ und MCP-1 und der iNOS wurden mittels quantitativer RT-PCR gemessen. 
LysM

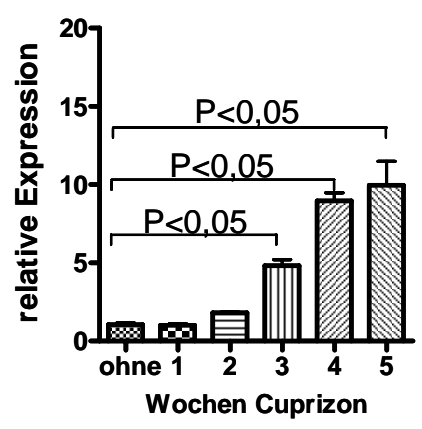

MCP-1

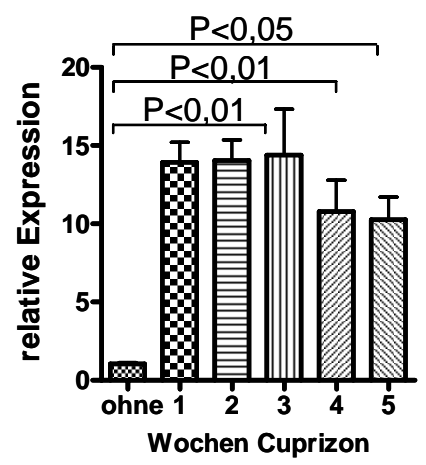

ICAM-1

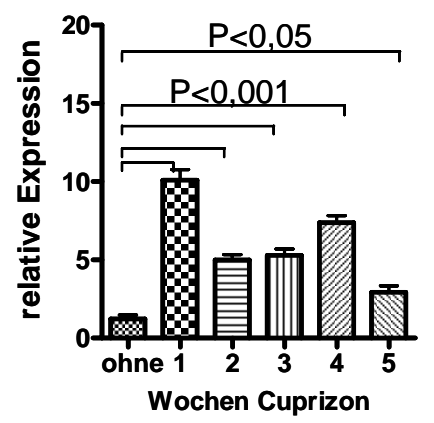

MIP-1 $\alpha$

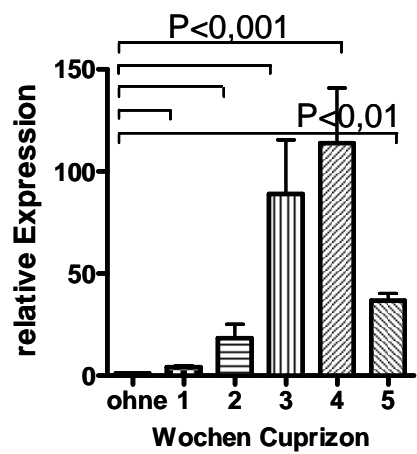

VCAM-1

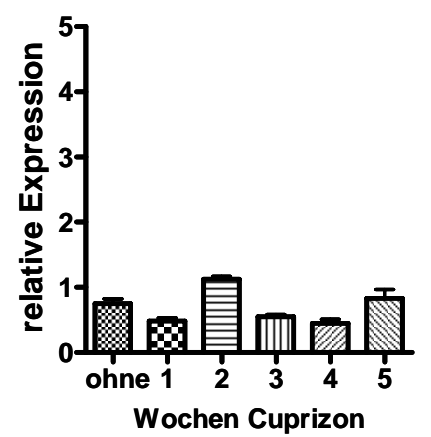

iNOS

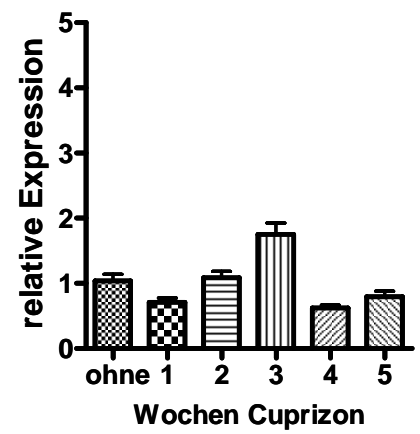

Abb. 4-1: Aktivierung der Mikrogliazellen durch Cuprizon. Mittels quantitativer RT-PCR konnte gezeigt werden, dass die Verfütterung von Cuprizon Mikrogliazellen im Balken aktiviert. Die höchste Expression des von Mikrogliazellen exprimierten Proteins LysozymM (LysM) wurde nach vier und fünf Wochen Cuprizon-Diät gemessen. Des Weiteren wurde das Adhäsionsmolekül ICAM-1 durch die Verfütterung von Cuprizon vermehrt exprimiert. Für VCAM-1 konnte dies nicht nachgewiesen werden. Zusätzlich wurden die Chemokine MIP-1 $\alpha$ und MCP-1 durch die Cuprizon-Gabe vermehrt gebildet. Für iNOS konnte keine erhöhte Transkription nachgewiesen werden. (ohne: nicht-behandelte Kontrollen)

Die durchgeführte quantitative RT-PCR (Abb. 4-1) zeigte eine Vervierfachung der LysM mRNA in Mäusen, welche über einen Zeitraum von drei Wochen mit Cuprizon behandelten wurden (ANOVA Kontrollen vs. 3 Wochen $P<0,05$ ). An den letzten beiden gemessenen Zeitpunkten (4 und 5 Wochen) konnte ein neun- bis zehnfacher Anstieg der LysM mRNA verzeichnet werden (ANOVA Kontrollen vs. 4 Wochen Cuprizon und Kontrollen vs. 5 Wochen Kontrollen $\mathrm{P}<0,05)$.

Eine vermehrte ICAM-1 Bildung wurde während des gesamten Versuchverlaufs festgestellt, wobei die maximal gemessene Expression nach einwöchiger Cuprizon-Gabe erreicht wurde (11fach; ANOVA Kontrollen vs. 1 Woche Cuprizon $P<0,001)$. In den Versuchswochen zwei bis vier erreichte die ICAM-1 mRNA Menge ungefähr ein fünffaches des Ausgangswerts (ANOVA Kontollen vs. Cuprizon für 2, 3, 4 Wochen $\mathrm{P}<0,001$ ). 
Eine veränderte Expression von VCAM-1 konnte über den gesamten untersuchten Zeitraum nicht nachgewiesen werden.

Das Chemokin MIP-1 $\alpha$ erreichte die maximale Expressionsmenge von 113fach über dem Wert nicht-behandelter Mäuse vier Wochen nach Versuchsbeginn (ANOVA Kontrollen vs. 4 Wochen Cuprizon $P<0,01)$. Die Expression war bei den Zeitpunkten drei und fünf Wochen ebenfalls deutlich erhöht (89fach und 37fach).

MCP-1 mRNA wurde bereits unmittelbar nach dem Beginn der Cuprizon-Gabe etwa um den Faktor 14 vermehrt gebildet, und dieser Wert wurde über den gesamten Versuchszeitraum weitgehend beibehalten (ANOVA Kontrollen vs. Cuprizon für 1, 2 ,3, 4, Wochen $\mathrm{P}<0,001$ und Kontrollen vs. 5 Wochen Cuprizon $\mathrm{P}<0,01)$.

Die induzierbare Stickstoffmonoxidsynthase wird von aktivierten Makrophagen/Mikroglia gebildet, jedoch konnte für iNOS nur eine unwesentlich vermehrte Bildung nach CuprizonGabe nachgewiesen werden (Abb.4-1).
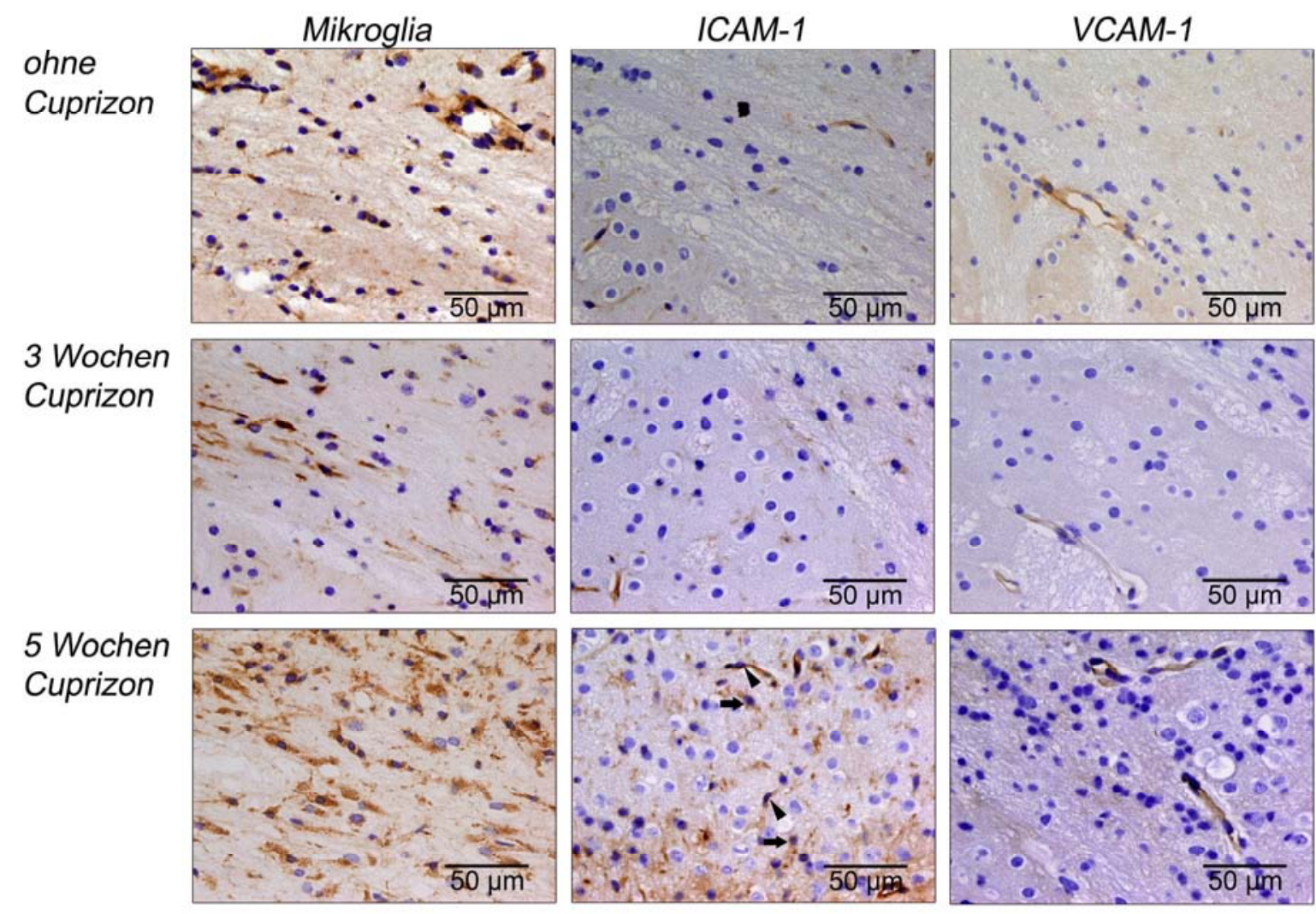

Abb. 4-2: Aktivierung von Mikrogliazellen und die Expression der Adhäsionsmoleküle ICAM-1 und VCAM-1. Auf histologischer Ebene konnten aktivierte Mikrogliazellen (Mac3) im Balken während der Cuprizon-Diät gezeigt werden. ICAM-1, ein Adhäsionsmolekül, wurde durch die Cuprizon-Gabe auf Mikroglia(Pfeil) und Endothelzellen (Pfeilspitze) vermehrt exprimiert. Eine erhöhte VCAM-1 Menge konnte hingegen nicht nachgewiesen werden. 
Die immunhistochemische Färbung mit dem Makrophagen/Mikrogliamarker CD107b/Mac3 zeigte, dass während der Cuprizon-Behandlung vor allem im Balken vermehrt aktivierte Mikrogliazellen vorhanden waren. Des Weiteren konnten vermehrt ICAM-1-positive Mikroglia- und Endothelzellen im Balken nachgewiesen werden. Wie zuvor auf mRNA-Ebene konnte auch auf Proteinebene keine erhöhte Expression von VCAM-1 nachgewiesen werden (Abb. 4-2).

\subsubsection{Immunisierung von Mäusen nach unterschiedlich langer Cuprizon- Behandlung}

Im nächsten Schritt wurden die Mäuse nach ein, zwei, drei, vier oder fünf Wochen Cuprizon-Gabe mit zweimal $300 \mu \mathrm{g} \mathrm{MOG}_{35-55}$ in CFA immunisiert. Als Maßstab für den optimalen Immunisierungszeitpunkt galten die Anzahl der erkrankten Mäuse, der Tag des Krankheitsbeginns und die maximal erreichte Krankheitsschwere (Score).

Tabelle 4-1: Effizienz der Immunisierung. Anhand der Anzahl der erkrankten Tiere ließ sich die Effizienz der Immunisierung ermitteln. In den ersten beiden Wochen war die immunsuppressive Wirkung von Cuprizon am stärksten. Allerdings wiesen nicht alle Tiere mit Infiltraten im Rückenmark auch Läsionen im Gehirn auf.

\begin{tabular}{lll}
\hline \hline Cuprizon-Gabe & $\begin{array}{l}\text { Mäuse mit } \\
\text { T-Zellinfiltraten im } \\
\text { Rückenmark }\end{array}$ & $\begin{array}{l}\text { Anzahl der Mäuse } \\
\text { mit T-Zellinfiltraten } \\
\text { im Gehirn }\end{array}$ \\
\hline \hline 1 Woche & $3 / 6$ & $2 / 6$ \\
2 Wochen & $3 / 5$ & $1 / 5$ \\
3 Wochen & $5 / 6$ & $3 / 6$ \\
4 Wochen & $4 / 4$ & $2 / 4$ \\
5 Wochen & $5 / 6$ & $2 / 6$ \\
\hline \hline
\end{tabular}

Die immunsuppressive Wirkung von Cuprizon war in den ersten beiden Behandlungswochen mit nur 50\% bzw. 60\% erkrankter Mäuse am deutlichsten. Wurde die EAE ab drei Wochen Cuprizon-Diät induziert, lag die Immunisierungseffizienz jeweils über $80 \%$ und war mit nicht Cuprizon-behandelten Mäusen nahezu vergleichbar (Daten nicht gezeigt und Tabelle 4-1). 

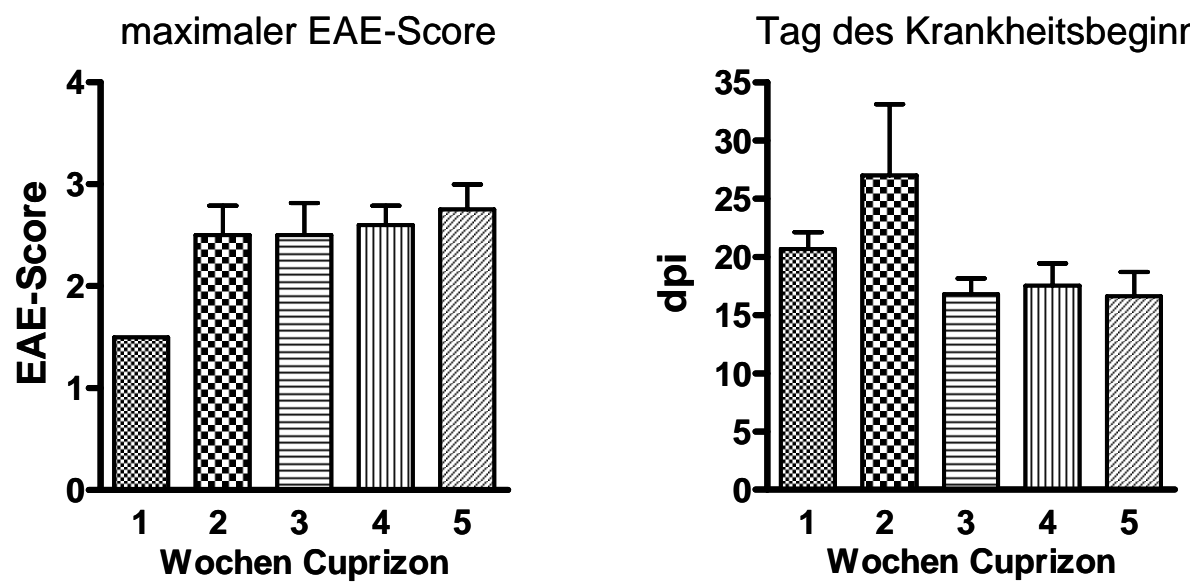

Abb. 4-3: Der optimale Immunisierungszeitpunkt. Die Mäuse wurden im wöchentlichen Abstand und somit nach unterschiedlich langer Cuprizon-Gabe mit MOG $_{35-55}$ immunisiert. Die maximal erreichte Krankheitsschwere nach Immunisierung war ausschließlich nach einer Woche Cuprizon-Diät vermindert. Der durchschnittliche Tag des Krankheitsbeginns zeigte, dass die Immunisierung nach 1-2 Wochen Cuprizon-Gabe zu einem leicht verzögerten Krankheitsbeginn führte. (dpi: Tage nach Immunisierung)

Ebenfalls spiegelte der Zeitpunkt des Krankheitsbeginns die über die Zeit abnehmende immunsuppressive Wirkung wider. Während der letzten drei Immunisierungszeitpunkte erkranken die Mäuse ungefähr zehn Tage früher als Mäuse, welche nach einer bzw. zwei Wochen Cuprizon-Diät immunisiert wurden (Abb. 4-3).

Die maximal erreichte Krankheitsschwere war nur bei den Tieren der ersten Gruppe (eine Woche Cuprizon) mit einem Mittelwert von 1,5 deutlich niedriger als bei später immunisierten Mäusen (EAE-Score ca. 2,5) (Abb. 4-3).

Diese Vorversuche ergaben des Weiteren, dass Mäuse mit messbarem EAE-Score, welcher das Ausmaß der Schädigung des Rückenmarks wider spiegelt, nicht immer T-Zellen im Balken aufwiesen. Andererseits enthielten z.T. die Gehirne von Tieren ohne Lähmung der Extremitäten entzündliche Infiltrate (Tabelle 4-1). Diese Mäuse waren durch Gewichtsverlust, ungeputztes, struppiges Fell und gekrümmten Rücken erkennbar.

Aufgrund der erhoben Daten wurde folgender Versuchsplan entworfen: Eine ausreichende Mikrogliaaktivierung sollte durch einen Cuprizongehalt von 0,25\% im Futter während der ersten beiden Wochen erzielt werden. Die immunsuppressive Wirkung der Substanz wurde durch anschließende Senkung der Dosis auf 0,15 \% Cuprizon im Futter vermindert. An Tag 17 nach Versuchsbeginn erfolgte die subkutane Injektion von $300 \mu \mathrm{g}$ MOG in CFA, welche zur Verstärkung der Immunantwort nach sieben Tagen wiederholt wurde. Die Mäuse erhielten als zusätzlichen Immunstimulus Pertussistoxin (PTX, 300 ng) durch intraperitoneale Injektion an den Tagen null, zwei und neun nach Immunisierung. Die Ver- 
suchsdauer betrug insgesamt 34 Tage. Der Versuchsaufbau aller nachfolgenden Versuche erfolgte, wenn keine abweichenden Angaben gemacht werden, nach dem folgenden Schema (Abb. 4-4).

\begin{tabular}{ccccccc}
0 & 14 & 17 & 19 & 24 & 26 & 34 Tage \\
$\downarrow$ & $\downarrow$ & $\downarrow$ & $\downarrow$ & $\downarrow$ & $\downarrow$ & $\downarrow$ \\
\hline $0,25 \%$ & $0,15 \%$ & MOG & PTX & MOG PTX & PTX & Versuchsende \\
Cuprizon & & PTX & & & &
\end{tabular}

Abb. 4-4: Der Versuchsaufbau bei der Cuprizon-EAE. Um eine ausreichende Mikrogliaaktivierung zu erzielen, erhielten die Mäuse für 14 Tage 0,25\% Cuprizon im Futter. Diese Dosis wurde anschließend bis zum Versuchsende auf 0,15\% Cuprizon im Futter gesenkt. Die Immunisierung mit $300 \mu \mathrm{g}$ MOG $_{35-55}$ erfolgte nach 17-tägiger Cuprizon-Diät und wurde nach 7 Tagen wiederholt, um die Immunantwort zu verstärken. Die dreimalige PTX Injektion (300 ng) wirkte zusätzlich immunstimulierend.

\subsection{Charakterisierung der entzündlichen Infiltrate in Balken und Kortex}

\subsubsection{Infiltration von T-Zellen in das Corpus callosum und den Kortex nach Immunisierung mit MOG $35-55$}

Die rein toxisch induzierte Entmarkung durch Cuprizon führt zur Aktivierung der Mikroglia bei geschlossener BHS (McMahon et al. 2002). Eine Immunisierung mit $\mathrm{MOG}_{35-55}$ hat im Gegensatz hierzu die Öffnung der BHS zur Folge, so dass Entzündungszellen aus dem Blut in das ZNS einwandern können.

Anhand des folgenden beschriebenen Versuchaufbaus wurde untersucht, ob ausschließlich aktivierte ZNS-spezifische oder auch ZNS-unspezifische T-Zellen eine Entzündungsreaktion in vorgeschädigtem Gehirngewebe auslösen können. Hierzu wurden Cuprizonbehandelte Mäuse mit $\mathrm{MOG}_{35-55}$ (Cup/MOG) oder mit Ovalbumin (Cup/Ova), einem Bestandteil des Hühnereiweißes, das nicht im Maus-ZNS exprimiert wird, immunisiert. 

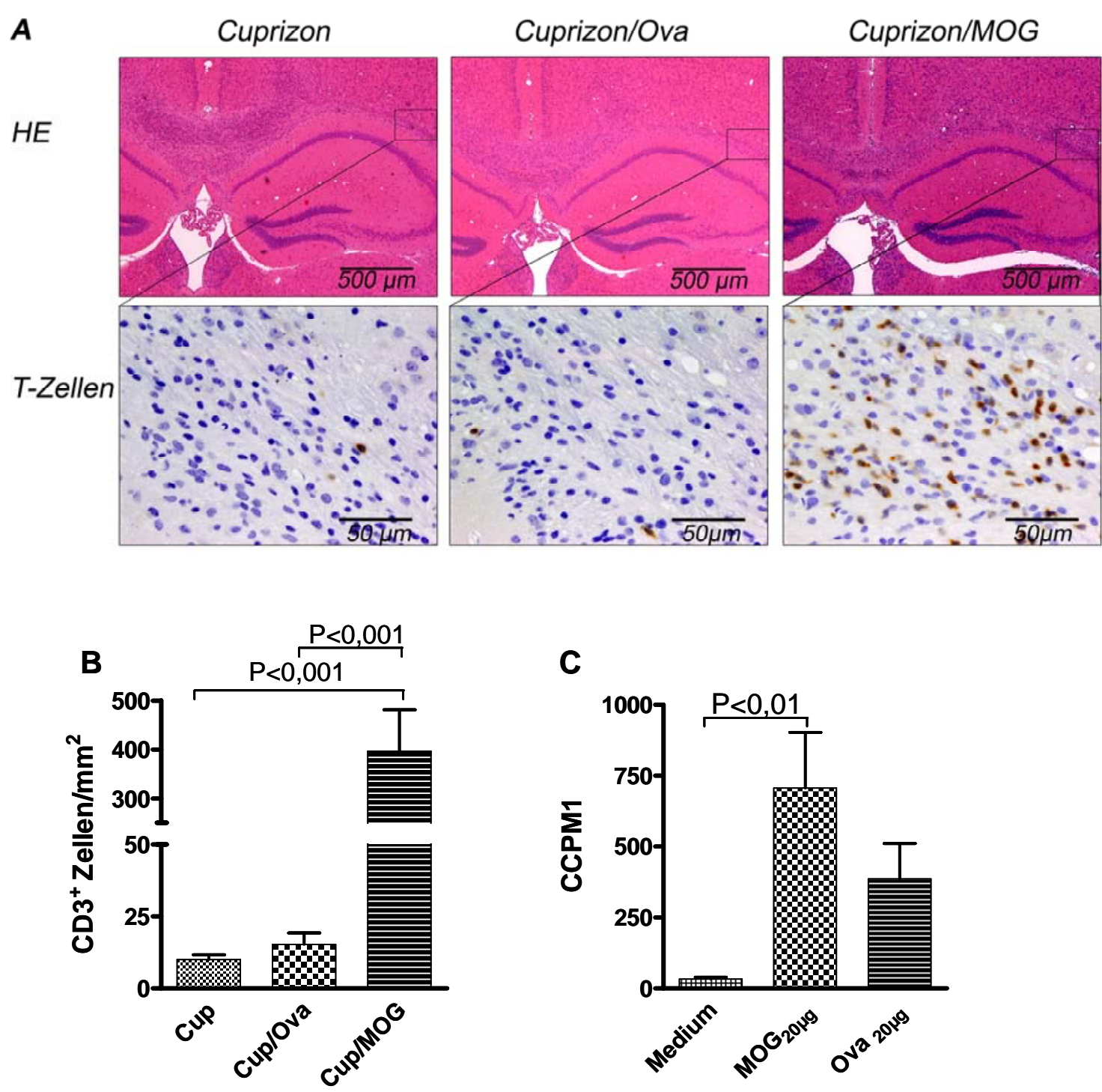

Abb. 4-5: Infiltration von T-Zellen in das Mausgehirn nach Immunisierung mit MOG $_{35-55}$ bzw. Ovalbumin. (A) In den Gehirnen, vor allem im Balken, von Cuprizon und Cup/Ova Mäusen waren vereinzelte T-Zellen (CD3) vorzufinden. Ausschließlich nach Immunisierung mit MOG $35-55$ wanderten zahlreiche CD3positive T-Zellen in die Gehirne von Cuprizon-behandelten Mäusen ein. (B) ZNS-unspezifische OvalbuminT-Zellen induzierten keine T-Zellinfiltration im ZNS. In diesen Tieren war die Dichte an T-Zellen mit nicht immunisierten Cuprizon-Mäusen vergleichbar (Cup: $10 \pm 4$ Zellen/mm²; Cup/Ova: $15 \pm 12$ Zellen/mm²; ANOVA Cup vs. Cup/Ova $P>0,05)$. Erst die Immunisierung von Cuprizon-behandelten Mäusen mit $\mathrm{MOG}_{35-55}$ verursachte die Infiltration von zahlreichen T-Zellen in das Mausgehirn (396 \pm 239 Zellen/mm²; ANOVA Cup vs. Cup/MOG $\mathrm{P}<0,001)$. (C) Durch die in vitro Stimulation mit dem jeweiligen Antigen wurde gezeigt, dass die Immunisierung mit Ova zur Bildung von antigen spezifischen T-Zellen führt. Der Unterschied zwischen der Proliferation von MOG- und Ova-spezifischen T-Zellen erreichte keine statistische Signifikanz (ANOVA $P>0,05$ ). (Cup: Cuprizon, Cup/Ova: Cuprizon-behandelt und mit Ovalbumin immunisiert; Cup/MOG: Cuprizonbehandelt und mit $\mathrm{MOG}_{35-55}$ immunisiert. 
In den Gehirnen von Cuprizon-behandelten Tieren ließen sich nur sehr wenige T-Zellen nachweisen (Cup: $10 \pm 4$ Zellen/ $\mathrm{mm}^{2}$ ). Nach Immunisierung mit dem ZNS-unspezifischen Antigen Ovalbumin wurden vergleichbar geringe Mengen von T-Zellen im Balken vorgefunden (15 \pm 12 Zellen/mm²; ANOVA Cup vs. Cup/Ova $P>0,05$ ). Ein vollkommen anderes Bild zeigte sich nach Immunisierung mit $\mathrm{MOG}_{35-55}$. Nach $\mathrm{MOG}_{35-55}$ Immunisierung wurden zahlreiche CD3-positive T-Zellen im Balken der Mäuse nachgewiesen (396 \pm 239 Zellen/mm²; ANOVA Cup vs. Cup/MOG und Cup/Ova vs. MOG $\mathrm{P}<0,001)$ (Abb.4-5B). Bemerkenswert war, dass die T-Zellen nicht wie in Rückenmarksläsionen ausschließlich in lokal begrenzten Entzündungsherden vorlagen, sondern häufig diffus im Balken verteilt waren. Zudem konnten bei zahlreichen Mäusen CD3-positive T-Zellen auch im Kortex, den Basalganglien und im Kleinhirn nachgewiesen werden (Abb. 4-5 A + B und Daten nicht gezeigt).

Um sicher zu stellen, dass die Immunisierung mit Ovalbumin ebenfalls zur Bildung von aktivierten T-Zellen führte, wurden Lymphozyten aus den Lymphknoten von immunisierten Mäusen ( $\mathrm{MOG}_{35-55} \mathrm{bzw}$. Ova) isoliert und in vitro durch das jeweils spezifische Antigen restimuliert. Der so genannte Proliferations-Assay ergab, dass nach Ova-Immunisierung durchaus antigenspezifische T-Zellen gebildet wurden, obwohl die Teilungsrate von MOGspezifischen T-Zellen mit $706 \pm 341$ CCPM1 über dem Wert der Ova-spezifischen T-Zellen (386 \pm 217 CCPM1) lag. Dieser Unterschied war statistisch allerdings nicht signifikant (Abb. 4-5 C).

Die durchflußzytometrische (FACS)-Analyse ist eine weitere Möglichkeit um die Zusammensetzung entzündlicher Infiltrate zu bestimmen. Wie zuvor durch histologische Quantifizierung, konnten mit dieser Methode nur wenige T-Zellen in den Gehirnen von Cuprizon(3,3\% TcR-positive Zellen) und Cuprizon/Ova-behandelten (1,9\% TcR-positive Zellen) Tieren nachgewiesen werden. Des Weiteren wurde bestätigt, dass im Gegensatz hierzu nach Immunisierung mit MOG $35-55$ zahlreiche T-Lymphozyten (10\% TcR-positive Zellen) in das Mausgehirn eingewandert waren (Daten nicht gezeigt).

T-Zellen können anhand der Oberflächenmoleküle CD4 und CD8 in T-Helfer und zytotoxische T-Zellen unterteilt werden. Die wenigen nachweisbaren T-Zellen aus Tieren der Cuprizon-Gruppe ließen sich überwiegend den zytotoxischen T-Zellen zuordnen (Verhältnis: $C D 4 / C D 8=0,64)$. Nach Immunisierung mit Ovalbumin war eine vergleichbare Anzahl an CD4- und CD8-positiven T-Zellen vorhanden. Hingegen führte die Immunisierung mit 
dem CD4-Epitop $\mathrm{MOG}_{35-55}$ zu einer deutlich verstärkten Infiltration von CD4-positiven T-Zellen (Verhältnis CD4/CD8 = 5,8) (Daten nicht gezeigt).

\subsubsection{Verstärkte Aktivierung von Makrophagen/Mikroglia bei Entzündung}

In den vorangegangenen Versuchen konnte gezeigt werden, dass es nur nach Immunisierung mit $\mathrm{MOG}_{35-55} \mathrm{Zu}$ einer wesentlichen Infiltration von T-Zellen in die durch Cuprizon entmarkten Hirnregionen kam. Ziel des nächsten Versuches war, den Aktivierungsstatus von Makrophagen/Mikroglia zu untersuchen. Hierbei wurde die Makrophagen/Mikrogliapopulation aus den Gehirnen von Cuprizon-behandelten Mäusen mit der aus zusätzlich mit Ova- bzw. MOG 35 -55-immunisierten Mäusen vergleichend untersucht.
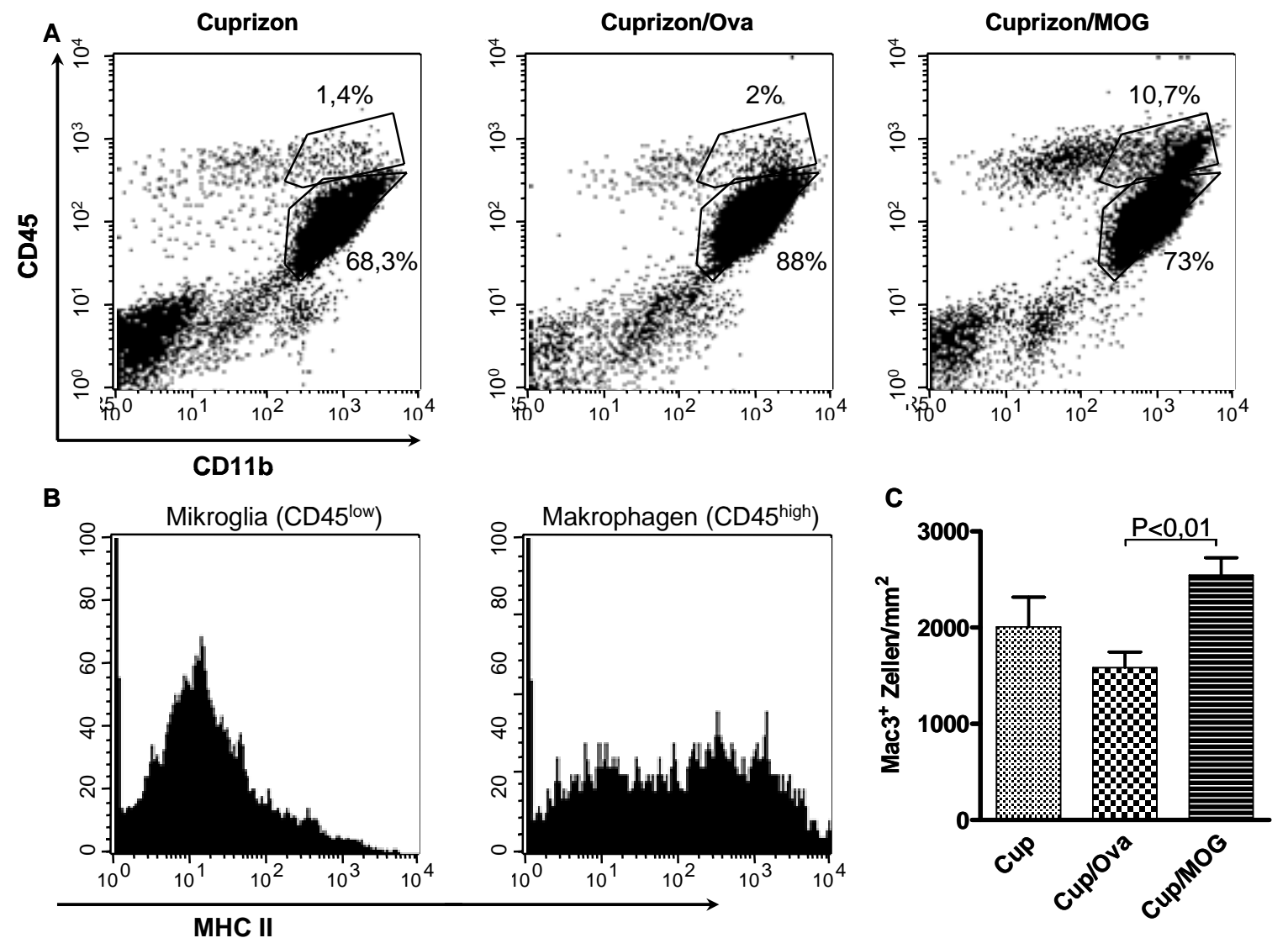

Abb. 4-6: Rekrutierung von Makrophagen und die Aktivierung von Makrophagen/Mikrogliazellen. (A) Erst nach Immunisierung mit MOG $_{35-55}$ wanderten zahlreiche Makrophagen (10,7\% CD45 ${ }^{\text {high }}$-positive Zellen) in das Gehirn von Cuprizon-behandelten Mäusen ein. In den beiden anderen Versuchsgruppen konnten kaum

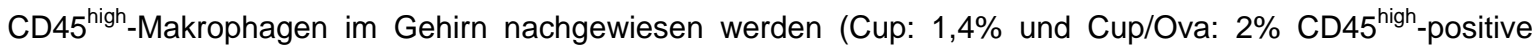
Zellen). (B) Es konnte gezeigt werden, dass CD45 ${ }^{\text {low }}$-Zellen weniger MHC II (Mittelwert: 55) exprimieren als CD45 ${ }^{\text {high }}$-Zellen (Mittelwert: 552). (C) Bei der histologischen Quantifizierung von Mac3-positiven Zellen im Balken zeigte sich, dass nach Immunisierung mit MOG $_{35-55}$ die meisten Makrophagen/Mikroglia vorhanden waren (Cup: $2007 \pm 458$ Zellen/mm²; Cup/Ova: $1585 \pm 758$ Zellen/mm²; Cup/MOG: $2545 \pm 524$ Zellen/mm²; ANOVA Cup/Ova vs. Cup/MOG $\mathrm{P}<0,01$ ). Angegeben ist der prozentuale Anteil an gemessenen, lebenden Zellen. 
Für die histologische Quantifizierung von Makrophagen/Mikroglia im Mausgewebe, wurde ein Antikörper gegen das lysosomale Membranprotein CD107b (Mac3) verwendet. Nach einem Versuchszeitraum von 34 Tagen und alleiniger Cuprizon-Diät wurden $2007 \pm 758$ Zellen/mm² und nach zusätzlicher Ova-Immunisierung (Cup/Ova): wurden $1585 \pm 458$ Zellen $/ \mathrm{mm}^{2}$ gezählt. Nach zusätzlicher Immunisierung mit MOG $35-55$ zeigte sich ein Trend zu einer höheren Dichte von Makrophagen/Mikroglia (Cup/MOG: $2500 \pm 514$ Zellen/mm², ANOVA Cup vs. Cup/Ova P>0,05; Cup vs. Cup/MOG P>0,05; Cup/Ova vs. Cup/MOG P<0,01) (Abb. 4-6 C).

Das in der FACS-Analyse nachgewiesene Antigen CD45 wird von allen hämatopoetischen Zellen gebildet. Da ein unterschiedliches Expressionsniveau von CD45 in Makrophagen (CD11 $\left.\mathrm{b}^{+} / \mathrm{CD} 45^{\text {high }}\right)$ und Mikrogliazellen (CD11 $\left.\mathrm{b}^{+} / \mathrm{CD} 45^{\text {low }}\right)$ besteht, wird dieser Marker zur Unterscheidung der beiden Zellpopulationen verwendet (Sedgwick et al. 1991; Ford et al. 1995).

Nach der Cuprizon-Diät ließen sich nahezu keine CD11b ${ }^{+} / C D 45^{\text {high }}$-positiven Zellen nachweisen $\left(1,4 \% \mathrm{CD}_{11} \mathrm{~b}^{+} / \mathrm{CD} 45^{\text {high }}\right.$-positive Zellen). Gleiches galt für zusätzlich Ovaimmunisierte Tiere (2\% CD $11 \mathrm{~b}^{+} / \mathrm{CD} 45^{\text {high }}$-positive Zellen). Im Gegensatz hierzu war nach zusätzlicher $\mathrm{MOG}_{35-55}$-Immunisierung eine $\mathrm{CD}_{11} \mathrm{~b}^{+} / \mathrm{CD} 45^{\text {high }}$-Zellpopulation eindeutig nachweisbar (10,7\% CD11 ${ }^{+} / C D 45^{\text {high }}$-positive Zellen) (Abb. 4-6 A).

Im nächsten Schritt wurde die Expression von MHC II analysiert, das von allen antigenpräsentierenden Zellen gebildet wird. Die Menge an MHC II-Molekülen auf $\mathrm{CD}_{11} \mathrm{~b}^{+} / \mathrm{CD} 45^{\text {high }}$ Zellen war mit einem Mittelwert von $558 \mathrm{im}$ Vergleich zu $\mathrm{CD} 11 \mathrm{~b}^{+} / \mathrm{CD} 45^{\text {low }}$ Zellen (Mittelwert 55) deutlich erhöht. Für die Antigene CD80 und CD86 zeigte sich in allen drei Versuchsgruppen keine Expression (Daten nicht gezeigt und Abb. 4-6 B)

Im Weiteren wurde das Aktivierungsstadium der Makrophagen/Mikroglia mit Hilfe der Expression der folgenden aktivierungsabhängig regulierten Gene histologisch untersucht:

S100A9, von neutrophilen Granulozyten und aktivierten Monozyten/Makrophagen in frühen Differenzierungsstadien gebildet (Foell et al. 2007), wird u. a. zur Beurteilung des Alters von MS-Läsionen verwendet. Es wird davon ausgegangen, dass nur akut aus dem Blut eingewanderte Makrophagen S100A9 exprimieren (Bruck et al. 1995; Foell et al. 2004). 
A
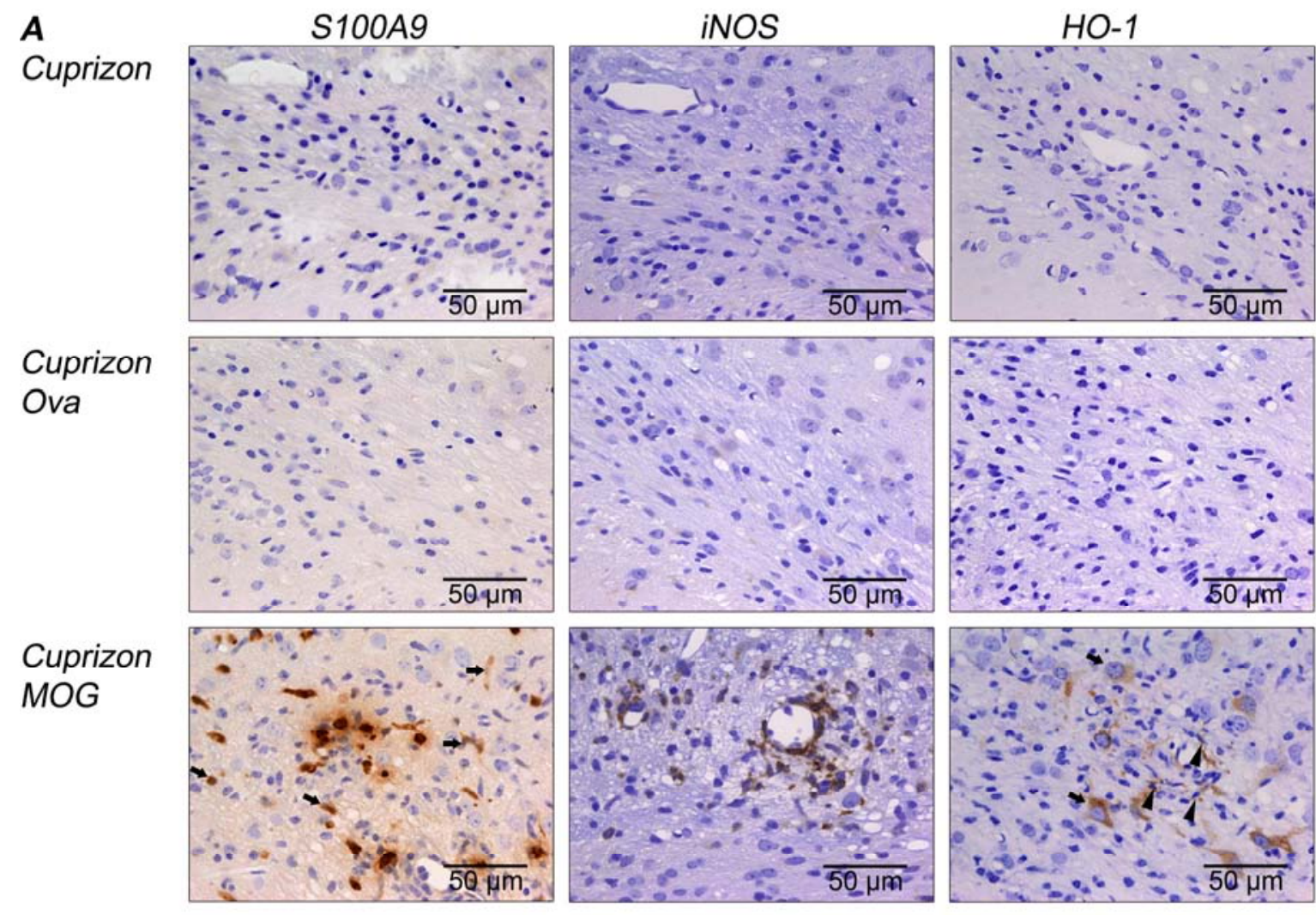

B
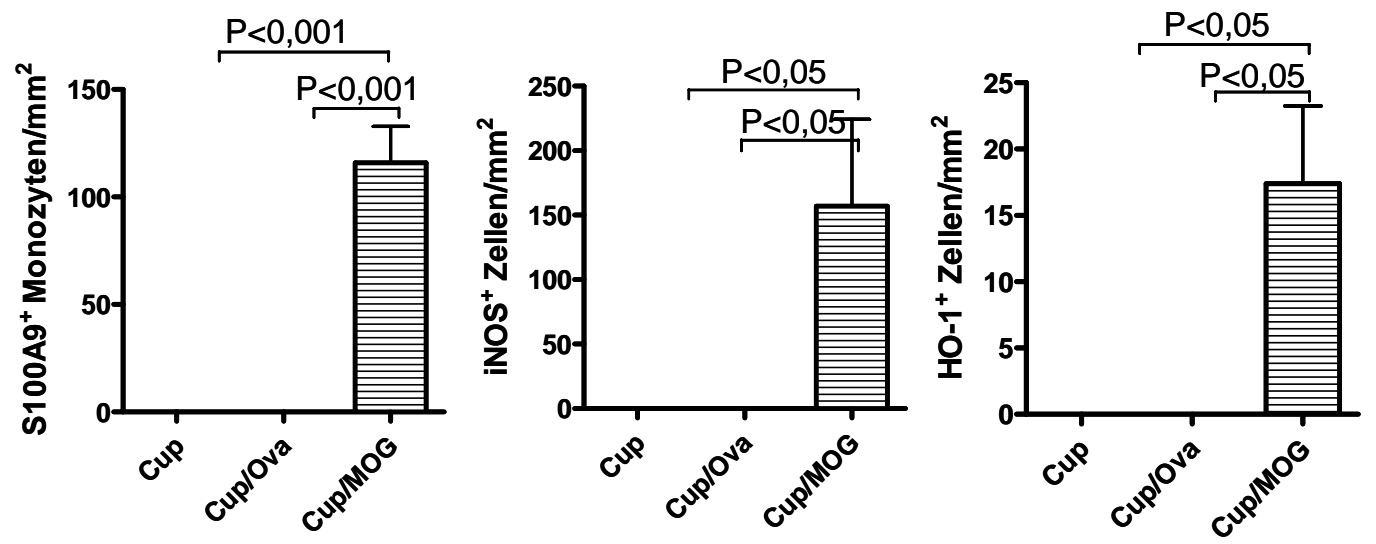

Abb. 4-7: Die Expression von S100A9, der Hämoxigenase-1 (HO-1) und der induzierbaren Stickstoff-

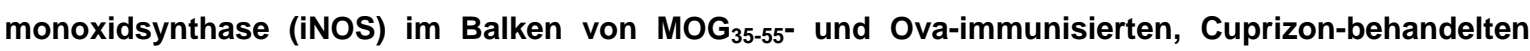
Mäusen. (A+B) Nur in MOG-immunisierten Mäusen konnten zahlreiche S100A9-positive Monozyten (Pfeil) nachgewiesen werden (Cup: $0 \pm 0$ Monozyten $/ \mathrm{mm}^{2}$; Cup/Ova: $0 \pm 0$ Monozyten/mm² Cup/MOG $116 \pm 48$ Monozyten/mm²; ANOVA Cup vs. Cup/MOG P<0,001 und Cup/Ova vs. Cup/MOG P<0,001). Die Expression von iNOS und HO-1 fand ebenfalls nur nach vermehrter Infiltration von T-Zellen statt (Cup: $0 \pm 0$ Zellen/mm²; Cup/Ova: $0 \pm 0$ Zellen/mm²). So konnten nach Immunisierung mit MOG $\mathrm{m}_{35-55} 157 \pm 190$ iNOS-positive Zellen/mm $\mathrm{mm}^{2}$ nachgewiesen werden (ANOVA Cup vs. Cup/MOG $\mathrm{P}<0,05$ und Cup/Ova vs. Cup/MOG $\mathrm{P}<0,05)$. Insgesamt konnten nur sehr wenige HO-1 exprimierende Zellen angefärbt werden, wobei hier nicht nur Makrophagen/Mikroglia (Pfeilspitze) sondern auch Astrozyten (Pfeil) HO-1 bildeten (Cup: $0 \pm 0$ Makrophagen/Mikroglia/mm²; Cup/Ova: $0 \pm 0$ Makrophagen/Mikroglia/mm²; Cup/MOG: $17 \pm 17$ Makrophagen/Mikroglia/mm²; ANOVA Cup vs. Cup/MOG $\mathrm{P}<0,05$ und Cup/Ova vs. MOG $P<0,05)$. 
In den eigenen Versuchen führte Cuprizon-induzierter Schaden weder zur Einwanderung von Granulozyten in den Balken noch zur Expression von S100A9 in Monozyten $\left(0 \pm 0\right.$ Monozyten $\left./ \mathrm{mm}^{2}\right)$. Ebenso konnten nach Immunisierung mit Ova keine S100A9positive Monozyten nachgewiesen werden $\left(0 \pm 0\right.$ Monozyten $/ \mathrm{mm}^{2}$; ANOVA Cup vs. Cup/Ova $P>0,05)$. Ein völlig anderes Bild zeigte sich hingegen nach Immunisierung mit $M_{35-55}$ und der Infiltration von T-Zellen. Dies führte zu einer signifikanten Zunahme an S100A9-exprimierenden Monozyten im Gehirn (116 \pm 48 Monozyten/mm²; ANOVA: Cup vs. Cup/MOG $\mathrm{P}<0,001$; Cup/Ova vs. Cup/MOG: $P<0,001)$. Darüber hinaus enthielten die Gehirne dieser Tiere S100A9-positive Granulozyten.

Erhöhte Mengen an NO im ZNS sind ein Kennzeichen von neurodegenerativen und entzündlich bedingten ZNS-Erkrankungen (Smith und Lassmann 2002). Histologisch lassen sich erhöhte NO-Werte indirekt durch die Expression von iNOS nachweisen.

Die histologische Auswertung der eigenen Experimente ergab, dass Mikrogliazellen während der Cuprizon-Diät keine iNOS exprimierten $\left(0 \pm 0\right.$ Zellen $\left./ \mathrm{mm}^{2}\right)$. Ebenso konnten nach Immunisierung mit Ovalbumin keine iNOS-positiven Zellen nachgewiesen werden $\left(0 \pm 0\right.$ Zellen/ $/ \mathrm{mm}^{2}$; ANOVA Cup vs. Cup/Ova P>0,05). Im Gegensatz hierzu hatte die Immunisierung mit $\mathrm{MOG}_{35.55}$ - mit Infiltration von zahlreichen T-Zellen - die Expression von iNOS in zahlreichen Makrophagen/Mikroglia zur Folge $(157 \pm 190$ Zellen/mm²; ANOVA Cup vs. Cup/MOG $\mathrm{P}<0,05$; Cup/Ova vs. Cup/MOG $\mathrm{P}<0,05)$.

HO-1 vermittelt den intrazellulären Abbau von Hämoglobin. Die Expression wird mit antiinflammatorischen Eigenschaften in Verbindung gebracht (Mancuso et al. 2006).

Die Analyse der histologischen Präparate ergab, dass HO-1 ausschließlich nach Immunisierung mit $\mathrm{MOG}_{35-55}$ von wenigen Makrophagen/Mikroglia gebildet wurde (Cup: $0 \pm 0$ Zellen/mm²; Cup/Ova: $0 \pm 0$ Zellen/mm²; Cup/MOG $17 \pm 17$ Zellen/mm²; ANOVA Cup vs. Cup/MOG $\mathrm{P}<0,05$; Cup/Ova vs. Cup/MOG $\mathrm{P}<0,05)$. Zusätzlich zu diesen wenigen Makrophagen/Mikroglia konnten HO-1-positive Astrozyten angefärbt werden. Diese waren sowohl in Cuprizon-behandelten Mäusen als auch in Tieren der Cup/OvaGruppe vorhanden (Abb. 4-7 A + B). 


\subsection{Axonschaden nach der Infiltration von T-Zellen und Makrophagen}

Neben der Beeinträchtigung der Nervenleitung durch den Verlust von Myelin tragen vor allem die Schädigung und der Verlust von Axonen zur neurologischen Behinderung bei MS-Patienten bei (Davie et al. 1995; De Stefano et al. 1998; De Stefano et al. 1999). Eine Unterscheidung zwischen rein entmarkungsbedingtem axonalen Schaden und axonaler Schädigung verursacht durch entzündliche Komponenten, wie ROS, Chemokine und Zytokine ist jedoch nicht möglich, da sowohl bei MS als auch im experimentellen Modell der EAE Entzündungszellen vorhanden sind. Zur Klärung dieser Fragestellung sollte der Axonschaden bei der toxisch induzierten Entmarkung durch Cuprizon mit der axonalen Schädigung im Modell der Cuprizon-EAE verglichen werden.

Eine Transportstörung innerhalb der Axone oder deren Durchtrennung lässt sich durch die Akkumulation des Amyloid-Vorläuferproteins (APP) nachweisen (Gentleman et al. 1993).

Anhand eigener Untersuchungen konnte eine Schädigung der Axone bereits nach Verlust der Markscheiden nachgewiesen werden (Cup: $169 \pm 95 \mathrm{APP}^{+} \mathrm{Axone} / \mathrm{mm}^{2}$ ). Dieser wurde durch die Immunisierung mit Ovalbumin nicht signifikant verstärkt $\left(257 \pm 93\right.$ APP $^{+}$Axone/mm²; ANOVA Cup vs. Cup/Ova P>0,05). Die Immunisierung mit $\mathrm{MOG}_{35-55}$ mit Infiltration von aktivierten T-Zellen und Makrophagen aus dem Blut führte jedoch zu einer erheblichen Zunahme der axonalen Schädigung. Ein signifikanter Anstieg an so genannten axonalen Sphäroiden konnte in diesen Tieren verzeichnet werden $\left(524 \pm 192 \mathrm{APP}^{+} \mathrm{Axo}-\right.$ ne/mm²; ANOVA Cup vs. Cup/MOG P<0,001; Cup/Ova vs. Cup/MOG P<0,01) (Abb. 4-8). Axone können durch die Versilberung nach Bielschowsky angefärbt werden. Durch den Vergleich der Axondichte mit gesunden Individuen kann ein Verlust der Nervenbahnen gemessen werden. In keinem der drei verwendeten Versuchsansätze zeigte sich eine wesentlich reduzierte Axondichte. 
$\boldsymbol{A}$

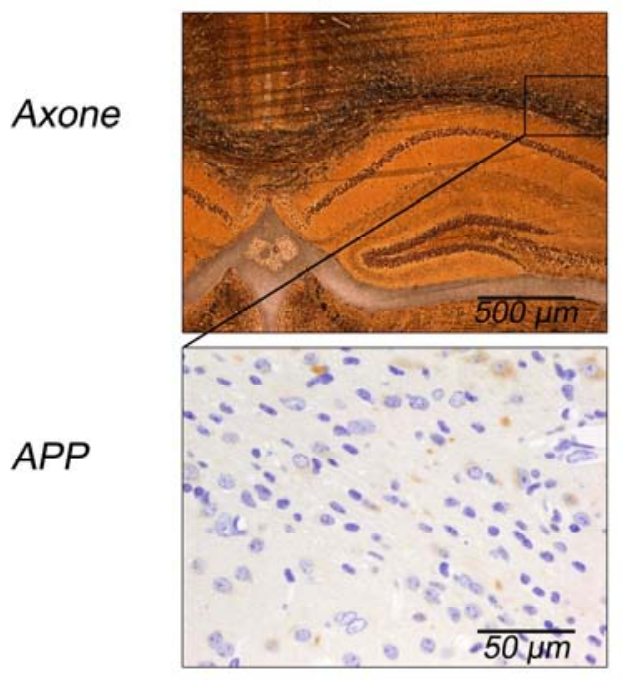

\section{Cuprizon/Ova}
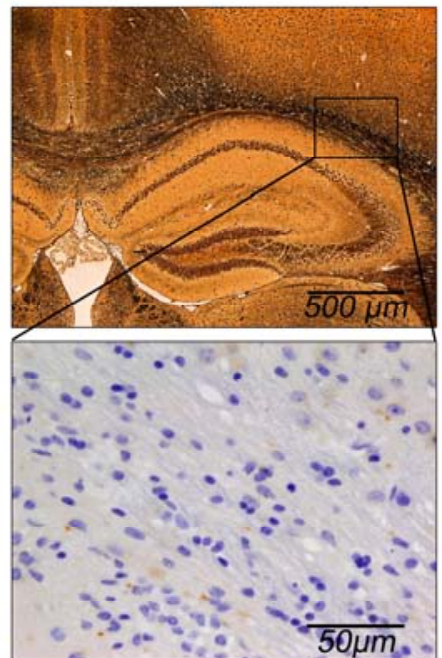

Cuprizon/MOG

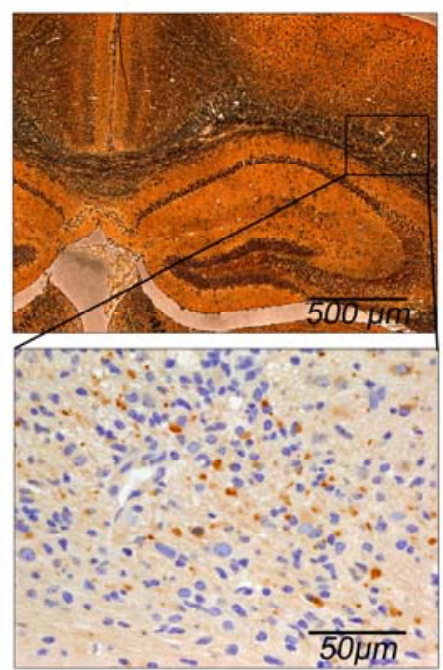

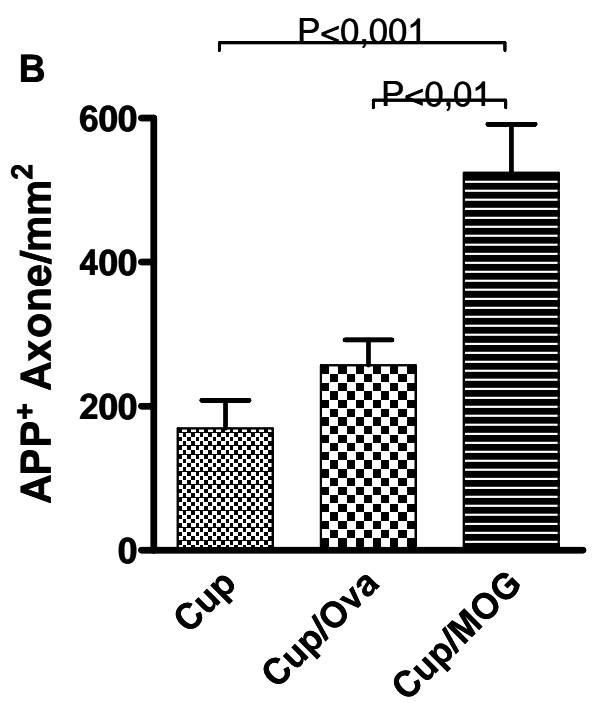

Abb. 4-8: Das Ausmaß der axonalen Schädigung nach Entmarkung und Entmarkung mit zusätzlicher Entzündung. (A) Erst Entzündung verursachte eine erhebliche Transportstörung innerhalb der Axone, was durch die Akkumulation von APP nachgewiesen werden konnte. Ein offensichtlicher Verlust von Axonen kam in der Versilberung nach Bielschowsky nicht zur Darstellung. B) Die Quantifizierung verdeutlichte, dass bereits der Verlust der Markscheiden zur axonalen Schädigung führte (Cup: $169 \pm 95 \mathrm{APP}^{+}$Axone $/ \mathrm{mm}^{2}$; Cup/Ova: $257 \pm 93 \mathrm{APP}^{+}$Axone/mm²; ANOVA Cup vs. Cup/Ova P>0,05). Erst die zusätzliche Entzündung verursachte eine signifikante Zunahme der axonalen Schädigung (Cup/MOG: $524 \pm 192 \mathrm{APP}^{+}$Axone $/ \mathrm{mm}^{2}$; ANOVA Cup vs. Cup/MOG P<0,001; Cup/Ova vs. Cup/MOG P<0,01). 


\subsection{Vergleichbare Effizienz der Remyelinisierung in Tieren mit und ohne Ent- zündung}

Die toxisch induzierte Entmarkung durch Cuprizon ist ein reversibler Prozess. Nach Beenden der Cuprizon-Diät differenzieren Oligodendrozytenvorläuferzellen in reife, myelinbildende Oligodendrozyten aus und führen zur raschen und annähernd vollständigen Remyelinisierung (Matsushima und Morell 2001).

T- und B-Zell-, sowie TNF- $\alpha$-defiziente Mäuse weisen gegenüber WT-Tieren eine verzögerte Remyelinisierung auf. Deshalb wird ein positiver Effekt von entzündlichen Prozessen auf die Neubildung der Markscheiden postuliert (Arnett et al. 2001; Arnett et al. 2003; Bieber et al. 2003; Boven et al. 2006). Des Weiteren laufen in MS-Läsionen Entzündung und Remyelinisierung häufig parallel ab (Prineas et al. 1993).

In den nachfolgend beschriebenen Versuchsansätzen zur Untersuchung der Remyelinisierungseffizienz erhielten immunisierte und nicht immunisierte Mäuse im Anschluss an die Cuprizon-Diät für zwei bzw. fünf Tage Normalfutter. Anhand dieser Versuche sollte untersucht werden, ob die spontane Remyelinisierung nach dem Ende der CuprizonVerfütterung durch Immunzellen und / oder deren Produkte beeinflusst wird.

\subsubsection{Histologische Quantifizierung der Remyelinisierung}

Anhand einer semiquantitativen Bewertungsskala (2.5.2 Tabelle 2-11) wurde das Ausmaß der Remyelinisierung nach fünftägiger Gabe von Normalfutter bestimmt. Zusätzlich wurde die Dichte der Oligodendrozytenvorläuferzellen (Olig2) und Oligodendrozyten (NogoA) quantifiziert.

Cuprizon-behandelte Tiere wiesen im Vergleich zu zusätzlich $\mathrm{MOG}_{35-55}$-immunisierten Tieren eine vergleichbare Dichte an NogoA-positiven Oligodendrozyten im Balken auf (Cup: $278 \pm 112$ Zellen/mm²; Cup/MOG: $262 \pm 122$ Zellen/mm²; T-Test P=0,75) (Abb. 4-9 A + B).

Die Dichte der Olig2-positiven und die der NogoA/Olig2-doppeltpositiven Oligodendroglia war ebenfalls ähnlich zwischen den beiden Gruppen (NogoA/Olig2: Cup: $7 \pm 17$ Zellen/mm²; Cup/MOG: $3 \pm 8$ Zellen $/ \mathrm{mm}^{2}$; Mann Whitney $\mathrm{P}=0,511$ und Olig2: Cup: $36 \pm 38$ Zellen/mm² Cup/MOG: $25 \pm 35$ Zellen $/ \mathrm{mm}^{2}$; Mann Whitney $\mathrm{P}=0,368$ ) (Abb. 4-9 A + C). 

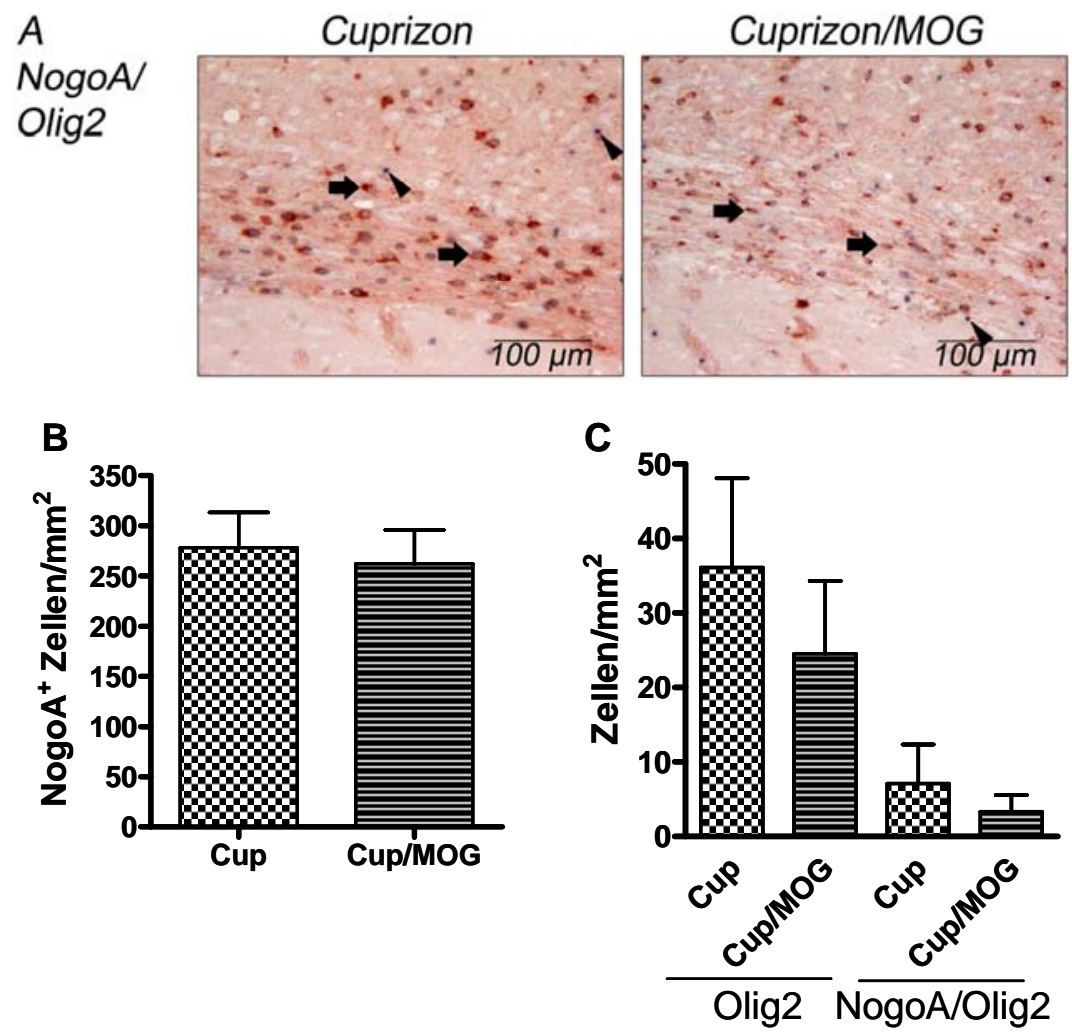

Abb. 4-9: Oligodendrozytendichte im Balken nach fünf Tagen Remyelinisierung (A) Nach Beenden der Cuprizon-Diät erfolgte die Proliferation von Oligodendrozytenvorläuferzellen im Balken. Aus diesen Vorläuferzellen entwickelten sich reife Oligodendrozyten (NogoA braun, Pfeil). Fünf Tage nach Beenden der CuprizonDiät waren mehr reife NogoA-positive Oligodendrozyten vorhanden als Olig2-positive Oligodendrozytenvorläuferzellen (blau, Pfeilspitze). (B) Die Dichte der NogoA-positiven Zellen war ebenfalls zwischen den beiden untersuchten Gruppen nicht unterschiedlich (Cup: $278 \pm 112$ Zellen/mm²; Cup/MOG: $262 \pm 122$ Zellen/mm²; Mann Whitney $P=0,75$ ). (C) Die Quantifizierung der Oligodendrogliazelldichte ergab keine Unterschiede zwischen entzündlichen und nicht entzündlichen Bedingungen (NogoA/Olig2: Cup: $7 \pm 17$ Zellen/mm²; Cup/MOG: $3 \pm 8$ Zellen $/ \mathrm{mm}^{2}$; Mann Whitney $\mathrm{P}=0,511$ und Olig2: Cup: $36 \pm 38$ Zellen/mm²; Cup/MOG: $25 \pm 35$ Zellen/mm²; Mann Whitney $\mathrm{P}=0,368)$.

Im nächsten Schritt wurde der Anteil der bemarkten Fläche in den einzelnen Tieren anhand eines semiquantitativen Myelinisierungsscores ausgewertet (Hiremath et al. 1998). Ein hoher Score-Wert entspricht dabei einem deutlichen Myelinverlust. Bereits fünf Tage nach dem Ende der Cuprizon-Diät waren Teile der Nervenfasern im Balken wieder von Myelin umgeben. Der Anteil der bemarkten Fläche war in der LFB/PAS-Färbung zwischen beiden Gruppen vergleichbar (LFB-Score: Cup: 1,8 \pm 0,9; Cup/MOG: 1,9 \pm 0,8; ungepaarter T-Test $\mathrm{P}=0,594)$. Durch die immunhistochemische Färbung mit dem anti-MBPAntikörper konnte dieses Ergebnis bestätigt werden (MBP-Score: Cup: 2,0 \pm 1; Cup/MOG: $2,5 \pm 1$; ungepaarter T-Test $P=0,351)(A b b .4-10 A+B)$. 
A

\section{Entmar- kung $4,5 \mathrm{~W}$}

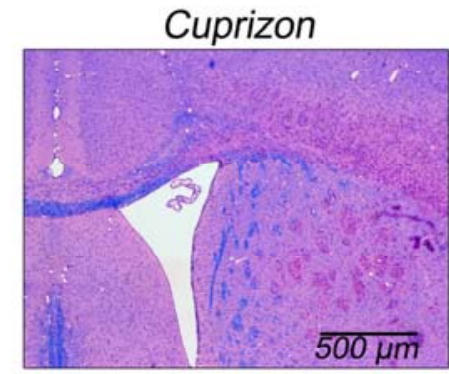

Remyelinisierung 5 Tage

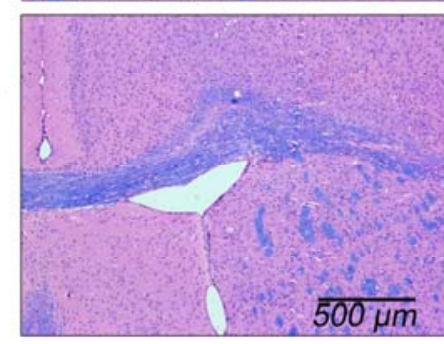

B

LFB/PAS
Cuprizon/MOG
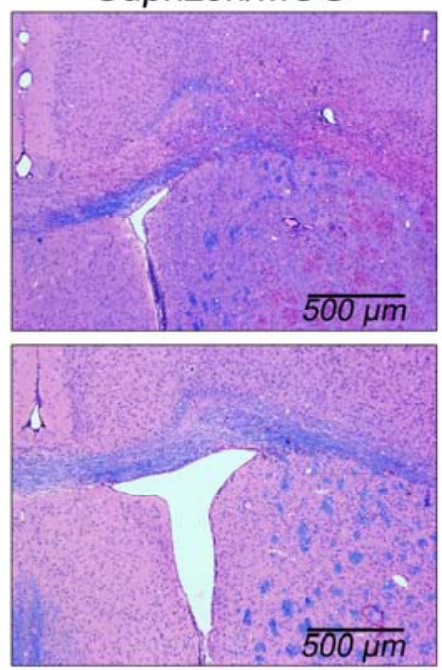

MBP
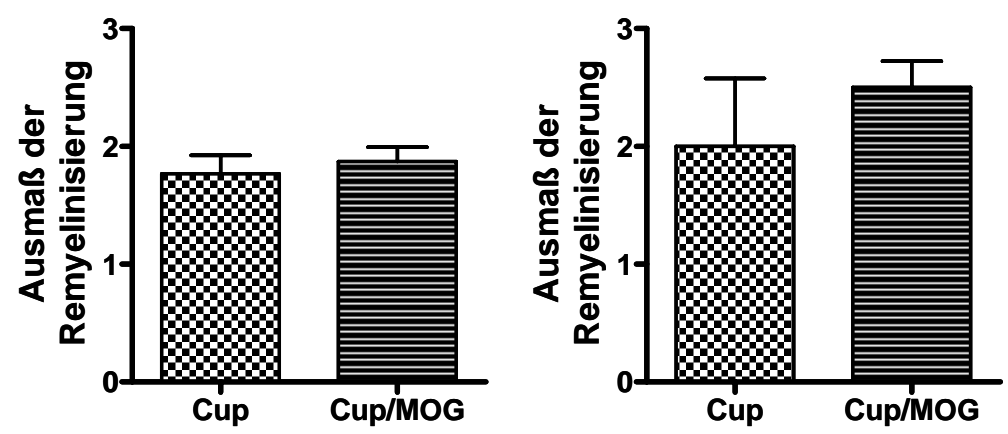

Abb. 4-10: Das Ausmaß der Remyelinisierung nach Beendigung der Cuprizon-Diät. (A) Die Abbildungen der LFB/PAS-Färbung zeigen, dass das Ausmaß der Entmarkung nach 4,5 Wochen Cuprizon-Diät zwischen den Versuchsgruppen Cuprizon und Cuprizon/MOG vergleichbar war. Die Effizienz der Remyelinisierung war in beiden untersuchen Gruppen ebenfalls vergleichbar. (B) Die semiquantitative Auswertung der Remyelinisierung anhand der LFB/PAS- und anti-MBP-Färbung verdeutlicht, dass keine Unterschiede zwischen den beiden Versuchsgruppen vorlagen (LFB/PAS: Cup: 1,8 \pm 0,9; Cup/MOG: 1,9 $\pm 0,8$; ungepaarter T-Test $P=0,594$ und MBP: Cup: 2,0 \pm 1 ; Cup/MOG: 2,5 \pm 1 ; ungepaarter T-Test $\mathrm{P}=0,351$ ).

\subsubsection{Expressionsanalyse von oligodendrogliaspezifischen Genen}

Der semiquantitative Score zur Bestimmung der myelinisierten Fläche anhand der Myelinfärbung erlaubt nur eine grobe Einschätzung. Des Weiteren sind unterschiedliche Proteinmengen immunhistochemisch nicht quantifizierbar. Mögliche geringe Unterschiede zwischen Cuprizon- und Cup/MOG-Tieren bei der Neubildung des Myelins sollten mittels quantitativer RT-PCR erfasst werden. Ein weiterer Vorteil dieser Methode war, dass die Expression weiterer oligodendrogliaspezifischer Gene untersucht werden konnte, deren Protein auf PFA-fixiertem Gewebe immunhistochemisch nicht nachgewiesen werden konnte. Die Expressionsanalyse erfolgte an drei repräsentativen Tieren pro Gruppe. 
Hierzu wurde der Balken nach 34 Tagen Demyelinisierung durch Cuprizon bzw. nach zwei oder fünf Tagen Remyelinisierung bei Normalfutter entnommen. Ein Teil der Tiere war wie in den vorangegangenen Versuchen mit $\mathrm{MOG}_{35-55}$ immunisiert worden. Das Expressionsniveau wurde als xfache Menge im Vergleich zu nicht-behandelten Mäusen angegeben.
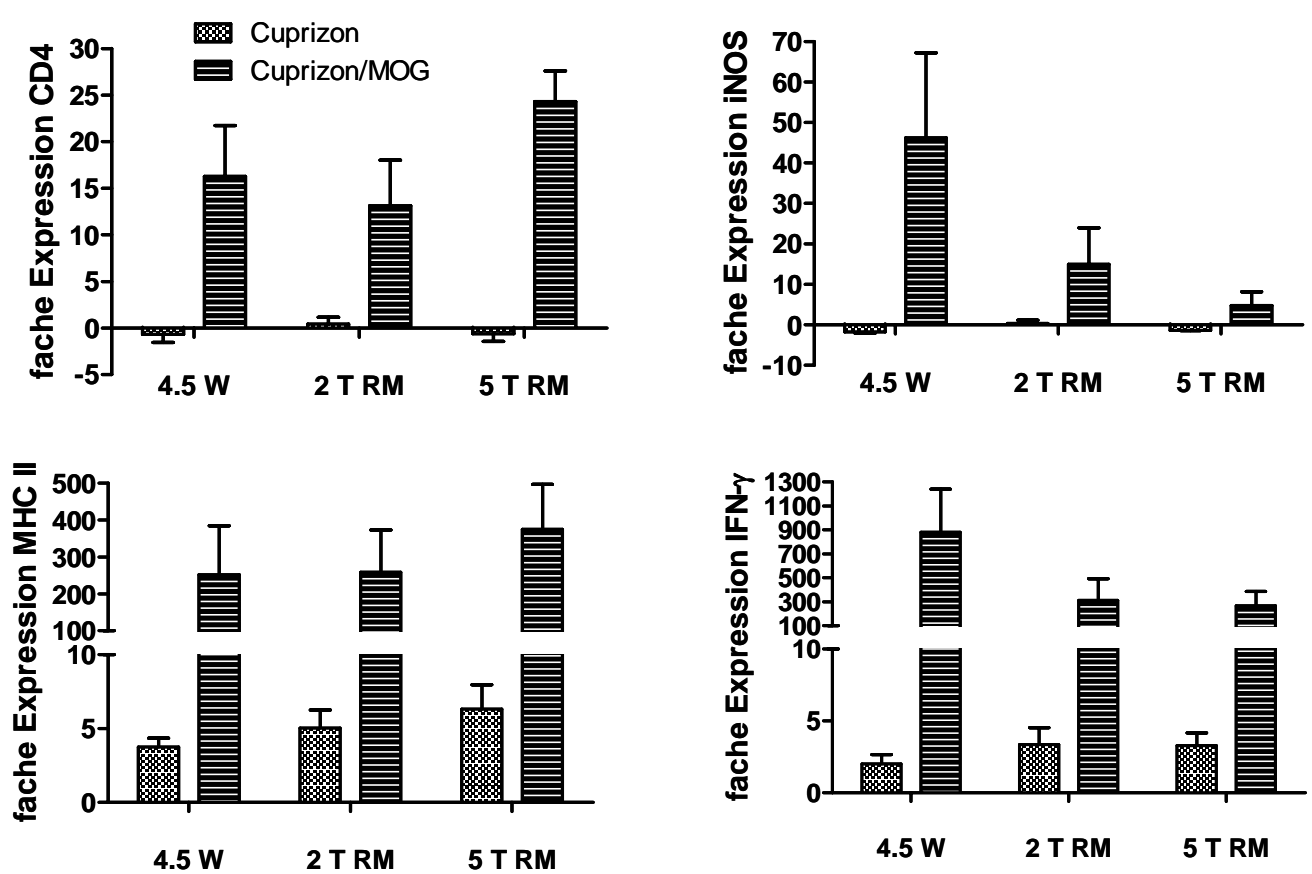

Abb. 4-11: Expression von entzündungsassoziierten Genen im Balken von Mäusen nach CuprizonGabe und zusätzlicher Immunisierung. Das Expressionsniveau von CD4 und iNOS im Balken von Cuprizon-behandelten Mäusen war mit nicht-behandelten Kontroll-Mäusen vergleichbar. Die Expression der Gene IFN- $\gamma$ und MHC II war im Balken von Cuprizon-behandelten Mäusen im Vergleich zu nicht-behandelten Kontrolltieren leicht erhöht. Im Gegensatz hierzu war in den Gehirnen von zusätzlich MOG $_{35-55}$-immunisierten Tieren deutlich mehr CD4, IFN- $\gamma$, MHC II und iNOS mRNA vorhanden. Die Expressionsanalyse der Entzündungsmarker diente als Nachweis, dass in immunisierten Tieren tatsächlich Entzündung im Balken vorhanden war. (4,5 W: 34 Tage Cuprizon-Diät, 2 T RM und 5 T RM: im Anschluss an die Cuprizon-Diät erhielten die Mäuse 2 bzw. 5 Tage Normalfutter zur Remyelinisierung)

Zunächst wurde durch die Menge an CD4 mRNA überprüft, ob alle immunisierten Tiere tatsächlich T-Zell-Infiltrate im Gehirn aufwiesen. Die Auswertung zeigte, dass Cuprizonbehandelte Mäuse und nicht-behandelte Kontrollen vergleichbare CD4 mRNA Mengen aufwiesen (4,5 W: $-1,7 \pm$ 1,5fach; 2 Tage RM: 0,4 \pm 1,3fach; 5 Tage RM: -0,61 \pm 1,4fach). Die zusätzliche Immunisierung führte hingegen zu einem deutlichen Anstieg der CD4Expression im Balken (4,5 W: 16,3 \pm 9,4fach; 2 Tage RM: 13,1 \pm 8,5fach; 5 Tage RM: $24,3 \pm 5,7$ fach). 
Ein weiterer Hinweis für einen entzündlichen Prozess war die Expression von IFN- $\gamma$, das bei ausschließlicher Cuprizon-Behandlung nur minimal vermehrt gebildet wurde (4,5 W: $2 \pm$ 1,1fach; 2 Tage RM: 3,4 \pm 2fach; 5 Tage RM: 3,3 \pm 1,6fach). Tiere mit deutlich nachweisbarer CD4 mRNA wiesen deutlich erhöhte Werte an IFN- $\gamma$ mRNA auf, wobei die maximale Menge unter demyelinisierenden Bedingungen (4,5 W) gemessen wurde (4,5 W: $879 \pm 624$ fach; 2 Tage RM: $310 \pm 312$ fach; 5 Tage RM: $264 \pm 211$ fach).

MHC II wird von antigenpräsentierenden Zellen, wie Makrophagen/Mikroglia, gebildet. Durch die 4,5 wöchige Verfütterung von Cuprizon kam es zu einem 3,8 \pm 1fachen Anstieg der MHC II mRNA. Die exprimierte Menge erhöhte sich bis zum Versuchsende nur leicht (4,5 W: $4 \pm 1$; 2 Tage RM: $5 \pm$ 2,1fach; 5 Tage RM: 6,3 \pm 2,9fach). Im Gegensatz hierzu wiesen Tiere mit T-Zellinfiltraten deutlich erhöhte MHC II Werte auf (4,5 W: $251 \pm 230 f a c h ; 2$ Tage RM: $258 \pm$ 199fach; 5 Tage RM: $375 \pm 210 f a c h)$.

Ein weiterer untersuchter Marker war das proinflammatorische Molekül iNOS. Dieses Gen wurde ausschließlich von den Tieren der Cuprizon/MOG-Gruppe gebildet, wobei die maximal gemessene Expression 17 Tage nach Immunisierung erreicht wurde $(=4,5$ Wochen Cuprizon) (Cuprizon: 4,5 W: $-1,7 \pm 0,6$ fach; 2 Tage RM: 0,4 \pm 1,4fach; 5 Tage RM: $-1,3 \pm$ 0,2fach; Cup/MOG: 4,5 W: 46,2 \pm 36,4fach; 2 Tage RM: $15 \pm$ 15fach; 5 Tage RM: $4,75 \pm 5,9$ fach) (Abb. 4-11).

Die Expression des Transkriptionsfaktors Olig2 war bei Cuprizon-Behandlung und in den Tagen der Remyelinisierung im Vergleich zu nicht-behandelten Kontrollen leicht vermindert. Ein Unterschied zwischen Tieren mit und ohne Entzündung war nicht vorhanden.

Ebenso konnte eine leicht verminderte Expression von Olig1 am Ende der Cuprizon-Diät gemessen werden. Während der ersten Tage der Remyelinisierung war diese mit der Expression in Kontrollmäusen vergleichbar.

Des Weiteren wurde die Expression von PDGF-R $\alpha$, Sox2 und MBP gemessen. Die Expression dieser Gene unterschied sich an allen drei untersuchten Zeitpunkten nur leicht von nicht-behandelten Kontrolltieren. Ein Unterschied zwischen Cuprizon-behandelten und Cup/MOG-Tieren war nicht vorhanden.

Deutlich reduziert war die Expression von PLP nach 4,5 Wochen Cuprizon-Diät. Zu diesem Zeitpunkt unterschied sich die Expressionsmenge zwischen den beiden Versuchsgruppen (Cup: $-21,2 \pm 6$ fach und Cup/MOG: $-12,8 \pm 4,8 f a c h$ ). Nach Beenden der Cuprizon-Verfütterung ( 2 und 5 Tage RM) war das Expressionsniveau mit nicht-behandelten Mäusen vergleichbar und kein Unterschied zwischen den beiden Versuchsgruppen vorhanden. Die einzelnen gemessenen Werte können der Tabelle 4-2 entnommen werden. 
Tabelle 4-2: Expression von oligodendrogliaspezifischen Genen im Balken von immunisierten und nicht immunisierten Mäusen. Die Expression der Transkriptionsfaktoren Olig1, Olig2 und Sox2, von PDGF-R $\alpha$ und der Myelinproteine PLP und MBP nach 4,5 Wochen Cuprizon-Gabe und 4,5 Wochen CuprizonDiät mit anschließender Remyelinisierung bei zwei bzw. fünf Tagen Normalfutter. Ein Teil der Mäuse war zusätzlich mit $\mathrm{MOG}_{35-55}$ immunisiert. Angegeben ist der mittlere xfache Unterschied der Genexpression von je drei repräsentativen Tieren pro Gruppe mit Standardabweichung im Vergleich zu nicht-behandelten Kontrollmäusen.

\begin{tabular}{l|cc|cc|cr}
\hline \hline & \multicolumn{2}{|c|}{4,5 Wochen Cup } & \multicolumn{2}{c|}{ 2 Tage RM } & \multicolumn{2}{c}{5 Tage RM } \\
\hline & Cup & Cup/MOG & Cup & Cup/MOG & Cup & Cup/MOG \\
\hline \hline Olig1 & $-2,2 \pm 0,3$ & $-0,9 \pm 1,7$ & $-0,1 \pm 2$ & $0,3 \pm 1,4$ & $0,7 \pm 2$ & $0,6 \pm 1,6$ \\
\hline Olig2 & $-1,3 \pm 0,2$ & $-0,7 \pm 1,6$ & $-0,6 \pm 1,5$ & $-1,2 \pm 0,2$ & $-0,9 \pm 2$ & $-0,7 \pm 1,6$ \\
\hline PDGF-R $\alpha$ & $-1,4 \pm 0,5$ & $0,3 \pm 1,5$ & $0 \pm 2$ & $0,8 \pm 2,5$ & $0,6 \pm 1,4$ & $0,6 \pm 1,5$ \\
\hline Sox2 & $-0,7 \pm 1,7$ & $0,45 \pm 1,5$ & $-0,5 \pm 1,3$ & $-0,4 \pm 1,2$ & $0,4 \pm 1,7$ & $1,2 \pm 0,2$ \\
\hline MBP & $-1,5 \pm 0,1$ & $-1,5 \pm 0,1$ & $-1,3 \pm 0.3$ & $-0,4 \pm 1,7$ & $0,4 \pm 1,4$ & $-0,5 \pm 1,4$ \\
\hline PLP & $-21,2 \pm 6$ & $-12,8 \pm 4,8$ & $-3,5 \pm 2,1$ & $-2,3 \pm 0,2$ & $-0,9 \pm 1,7$ & $-1,24 \pm 0,2$ \\
\hline \hline
\end{tabular}

\subsection{Magnetresonanztomographische Analyse von Entzündung und Entmar- kung im Modell der Cuprizon-EAE}

Bei der Maus-EAE kommt es im Gegensatz zur MS zu einem überwiegenden Befall des Rückenmarks. Allerdings ist eine spinale Bildgebung von lebenden Mäusen aufgrund technischer Schwierigkeiten nur schwer durchführbar und deshalb ist eine Korrelation zwischen histologischen Befunden und magnetresonanztomographischen (MRT)-Bildern kaum möglich (Nessler et al. 2007). Die Cuprizon-EAE erschien für derartige Korrelationsstudien ein geeigneteres Modell, da die Immunisierung von Cuprizon-behandelten Mäusen mit $\mathrm{MOG}_{35-55}$ zu reproduzierbaren Läsionen im Gehirn führte. Ein weiterer Vorteil dieses Versuchsansatzes war, dass magnetresonanztomographisch untersucht werden konnte, ob sich die Signale bei ausschließlicher Entmarkung mit äußerst geringem axonalen Schaden und Entmarkung mit Entzündung mit viel axonalem Schaden unterscheiden. 


\subsubsection{Verminderte Integrität der Blut-Hirn-Schranke nach Immunisierung}

Bei MS und EAE wandern Zellen des Immunsystems durch eine offene BHS in das zentrale Nervensystem ein (Kitz et al. 1984; Morrissey et al. 1996; Minagar und Alexander 2003). Im Gegensatz hierzu steht das Cuprizon-Modell, bei welchem die Toxin-induzierte Entmarkung bei geschlossener BHS abläuft (Bakker und Ludwin 1987; Kondo et al. 1987). Eine Störung der BHS kann in einer T1-gewichteten MRT-Messung in vivo durch eine Kontrastmittelanreicherung (Gadolinium (Gd) -DTPA) im Parenchym nachgewiesen werden.

Nach alleiniger Cuprizon-Diät war keine Öffnung der BHS nachweisbar. Ein Gadoliniuminduziertes, T1-hyperintenses Signal war lediglich in den Blutgefäßen vorhanden (Abb. 4-12 Cuprizon, Pfeilspitze). Im Gegensatz hierzu konnten in den Cuprizon/MOGTieren MS-ähnliche Gadoliniumanreicherungen im Balken, im Kleinhirn und in der Nähe der Basalganglien und der Seitenventrikel, nachgewiesen werden (Abb. 4-12; Cup/MOG, Pfeil).

Bei der wiederholten MRT-Messung an einer Maus konnte gezeigt werden, dass die Öffnung der BHS für mindestens drei Tage andauerte. Die Messung am Tag 16 nach Immunisierung zeigte nach Gd-Applikation kleine Gd-Anreicherungen um die Seitenventrikel, im Balken und im Kleinhirn. Diese Gd-induzierten Signalverstärkungen waren bei der Folgemessung 19 Tage nach Immunisierung erheblich vergrößert (Abb. 4-12 19dpi). Um auszuschließen, dass diese Signale durch das bei der ersten Messung applizierte Gd-DTPA zustande gekommen waren, erfolgte eine T1-gewichtete MRT-Messung vor der erneuten Gd-Applikation. Das Bild vor Kontrastmittelgabe wies jedoch keine hyperintensen Bereiche auf (Daten nicht gezeigt). 


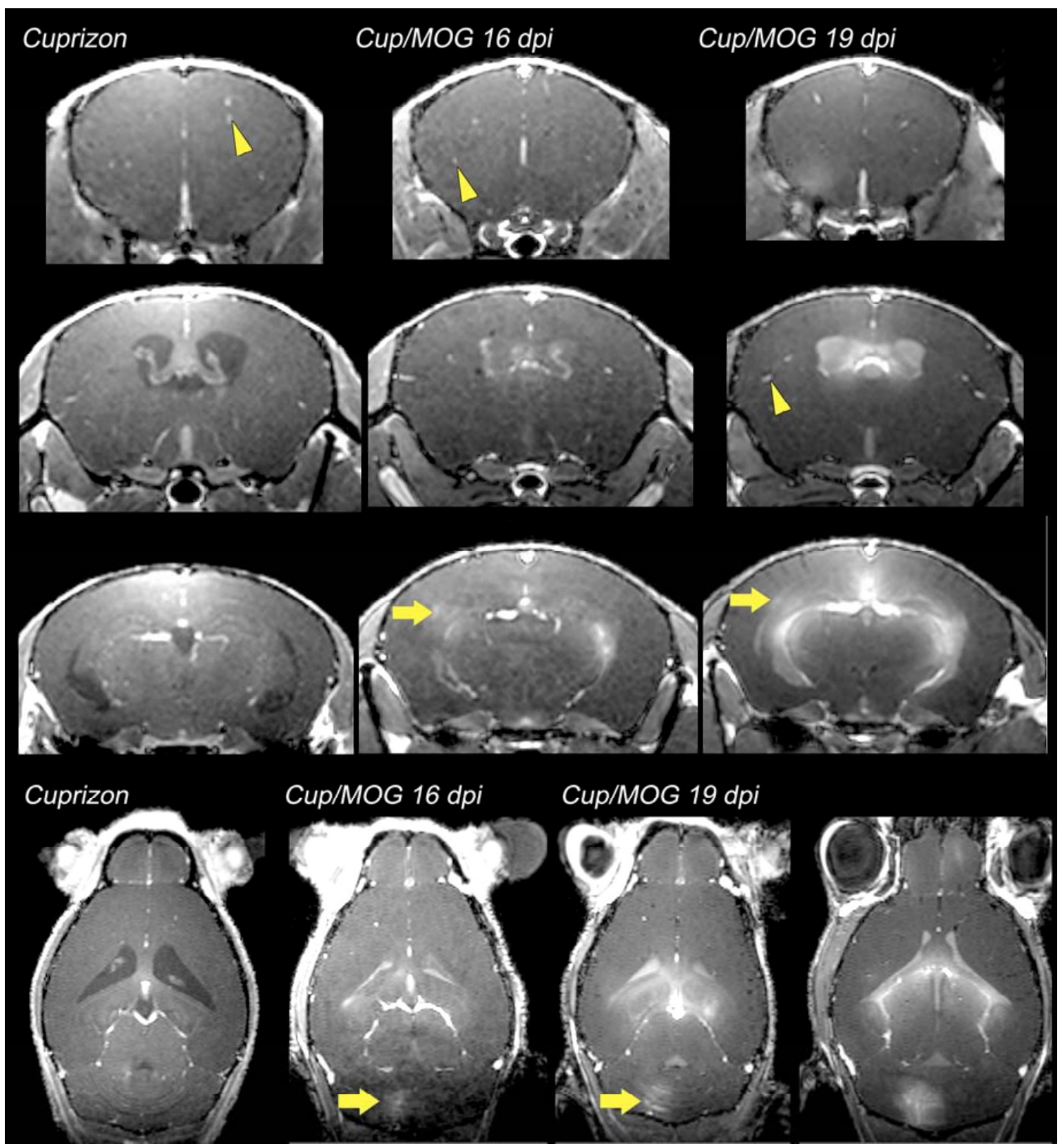

Abb. 4-12: Dauer der Blut-Hirn-Schranken Öffnung. Die BHS blieb nach alleiniger Verfütterung von Cuprizon intakt. Die Injektion von Gd-DTPA führte nur in den Gefäßen und Meningen zu einem hellen, hyperintensen Signal (Pfeilspitze). Durch die zusätzliche Immunisierung mit MOG $_{35-55}$ konnte das Gd-DTPA in das Parenchym eindringen (Pfeil) (16 dpi). Dies ist ein typisches Kennzeichen von akuten entzündlichen Läsionen. Bei der wiederholten MRT-Messung nach drei Tagen (19 dpi) waren diese weiterhin vorhanden und im Vergleich zum Vorbefund vergrößert. Alle Abbildungen entsprechen T1-gewichteten MRT-Sequenzen nach Gd-DTPA Injektion. dpi: Tage nach Immunisierung 
A T1 GTPA

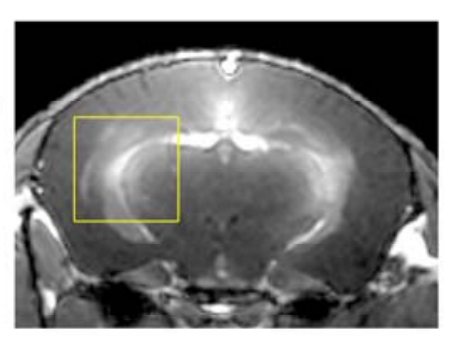

\section{T-Zellen $(C D 3)$}
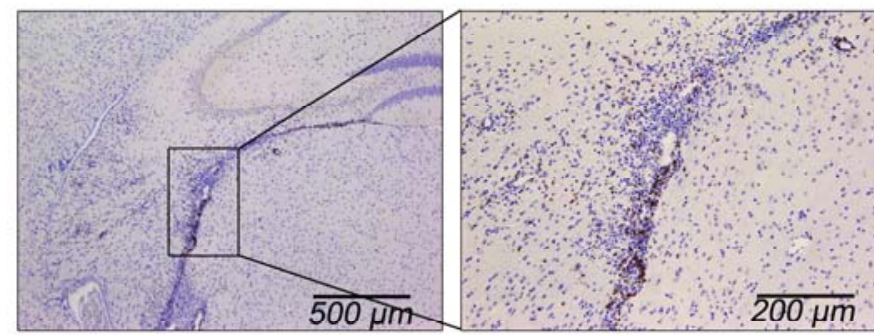

\section{Immun- globulin $(\lg G)$}

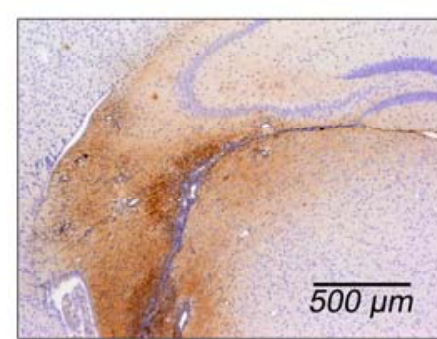

Fibrinogen
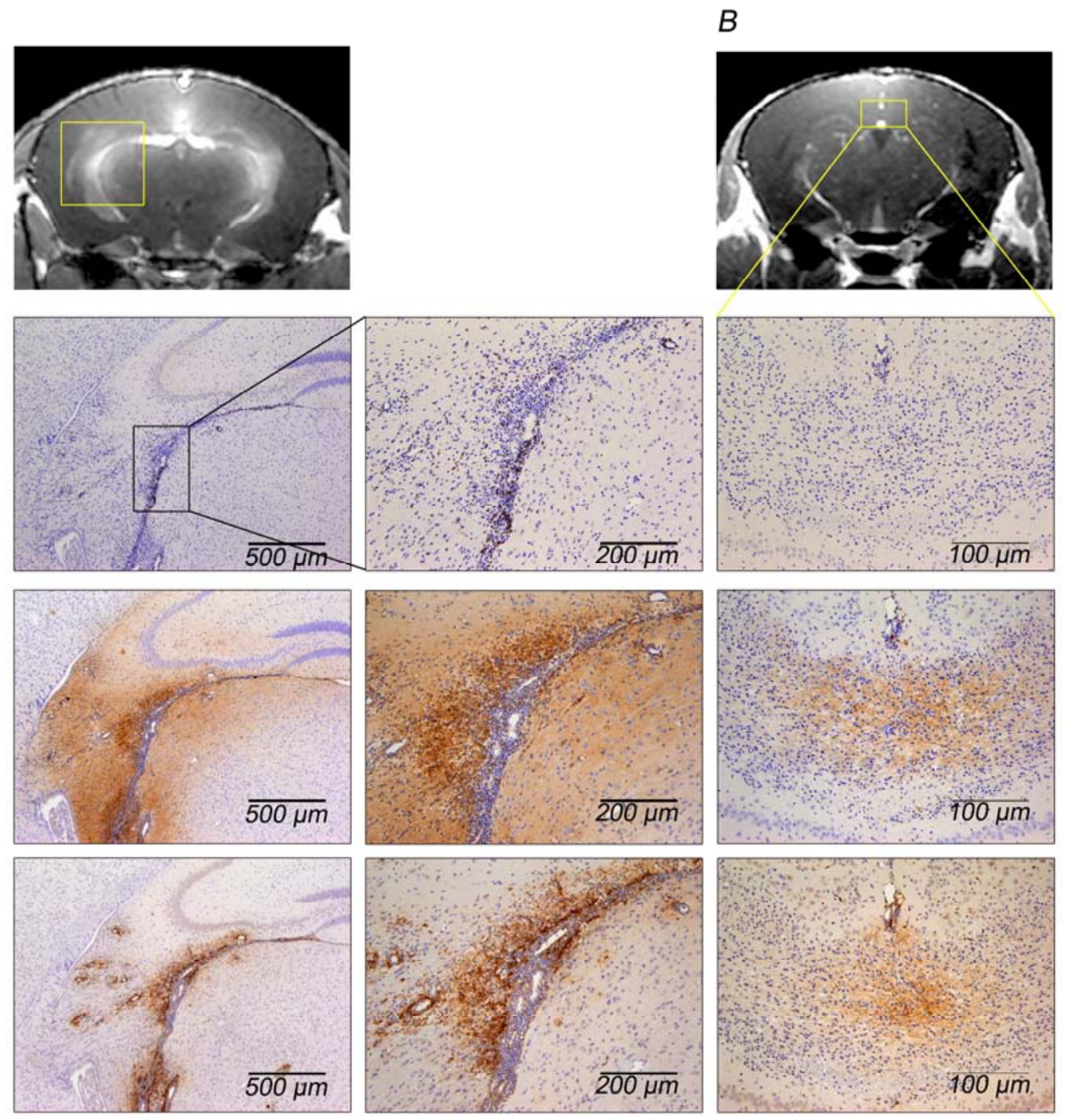

Abb. 4-13: Vergleich zwischen Gd-DTPA induzierten Signalen und histologisch nachweisbaren Ablagerungen von Fibrinogen und Immunglobulinen (IgG) sowie der Infiltration von T-Zellen. (A) Ein Teil der Gd-DTPA induzierten Signale entsprach den histologisch nachweisebaren Ablagerungen von Immunglobulin (IgG) und Fibriongen, sowie infiltrierten T-Zellen (CD3). (B) Des Weiteren gab es auch ausschließlich histologisch nachweisbare kleinere entzündliche Läsionen mit lgG-, und Fibrinogen-Ablagerungen sowie infiltrierten T-Zellen.

Histologisch kann eine offene Blut-Hirn-Schranke durch perivaskuläre Ablagerung von Immunglobulin (IgG) und Fibrinogen nachgewiesen werden.

Ein Vergleich zwischen den MRT-Bildern und den histologischen Präparaten zeigte, dass nicht in allen Bereichen mit Gd-DTPA-Anreicherung IgG- und Fibrinogenablagerungen vorhanden waren. Umgekehrt führten CD3-Zellinfiltrate nicht immer zu einem Gdinduzierten Signal. Histologisch war meistens eine Kolokalisation von CD3-positiven T-Zellen, Immunglobulin- und Fibrinogenablagerungen vorhanden (Abb. 4-13 und Daten nicht gezeigt). 


\subsubsection{Nachweis der axonalen Schädigung durch die Diffusions-Tensor-Bildgebung}

Die Magnetresonanztomographie (MRT) ist die wichtigste bildgebende Methode, um MS zu diagnostizieren und den Krankheitsverlauf bei MS-Patienten zu dokumentieren. Die Ergebnisse der konventionellen Messmethoden (T1 und T2 gewichtetes Signal) korrelieren nur schlecht mit dem Grad der Behinderung (Barkhof 2002). Des Weiteren kann aufgrund dieser konventionellen MRT-Messungen nicht immer unterschieden werden, welche Pathologie (Demyelinisierung, Remyelinisierung, Ausmaß der axonalen Schädigung) den klinischen Symptomen zu Grunde liegt (Bitsch et al. 2001; Song et al. 2005). Aus diesem Grund kommen neuerdings zusätzliche, verbesserte Verfahren, wie die Diffusions-Tensor-Bildgebung (DTI) und die Bestimmung der Magnetisierungstransferrate, zur Anwendung (Filippi 2002).

Dabei hat sich in letzten Jahren die DTI als einzigartige Möglichkeit erwiesen, die Mikrostruktur der weißen Substanz zu beurteilen (Boretius et al. 2007). DTI ist eine nichtinvasive Bildgebungsmethode, d. h. Kontrastmittel und potentiell schädliche ionisierende Strahlungen kommen nicht zum Einsatz. Diese Technik macht sich die anisotrope Natur der Wasserdiffusion in neuronalen und axonalen Strukturen zu nutze. Es wird davon ausgegangen, dass entlang der Axone (axiale Diffusivität) das Wasser besser fließen kann und eine höhere Fließgeschwindigkeit erreicht als Wasser, das quer zu den Axonen (radiale Diffusivität) fließt, wo hauptsächlich Myelin und Axone selbst, aber auch Zellen, die freie Fließgeschwindigkeit beeinträchtigen (Sun et al. 2006; Boretius et al. 2007). So bietet das Ausmaß der Diffusionsanisotropie Aufschluss über den Verlauf der Nervenfasern und die Gewebsstruktur (Filippi 2002). Speziell im Bereich der MS-Diagnostik ist es von Interesse, zwischen Entmarkung und axonalem Schaden zu unterscheiden. So wird versucht, mittels dieser Technik beide Parameter zu trennen.

Im experimentellen Modell der Cuprizon-induzierten Entmarkung konnte bereits gezeigt werden, dass durch Myelinverlust der Wert der radialen Diffusivität (RD) zunimmt. Die axiale Diffusivität (AD) war hingegen weitgehend unverändert. Lediglich nach dreiwöchiger Cuprizon-Diät zeigte sich eine verminderte axiale Diffusivität, die möglicherweise APP-positive Axone widerspiegelt (Song et al. 2005). Aufgrund der fehlenden entzündlichen Komponenten in diesem Modell konnte nicht untersucht werden, in wieweit dichte entzündliche Infiltrate und Gliose die Diffusion der Wassermoleküle beeinflussen. Durch die Verwendung des Cuprizon-EAE-Modells konnte nun erstmals untersucht werden, inwieweit sich die genannten Diffusivitäten sowie die fraktionale Anisotropie zwischen Entmarkung alleine und Entmarkung mit Entzündung unterscheiden. 

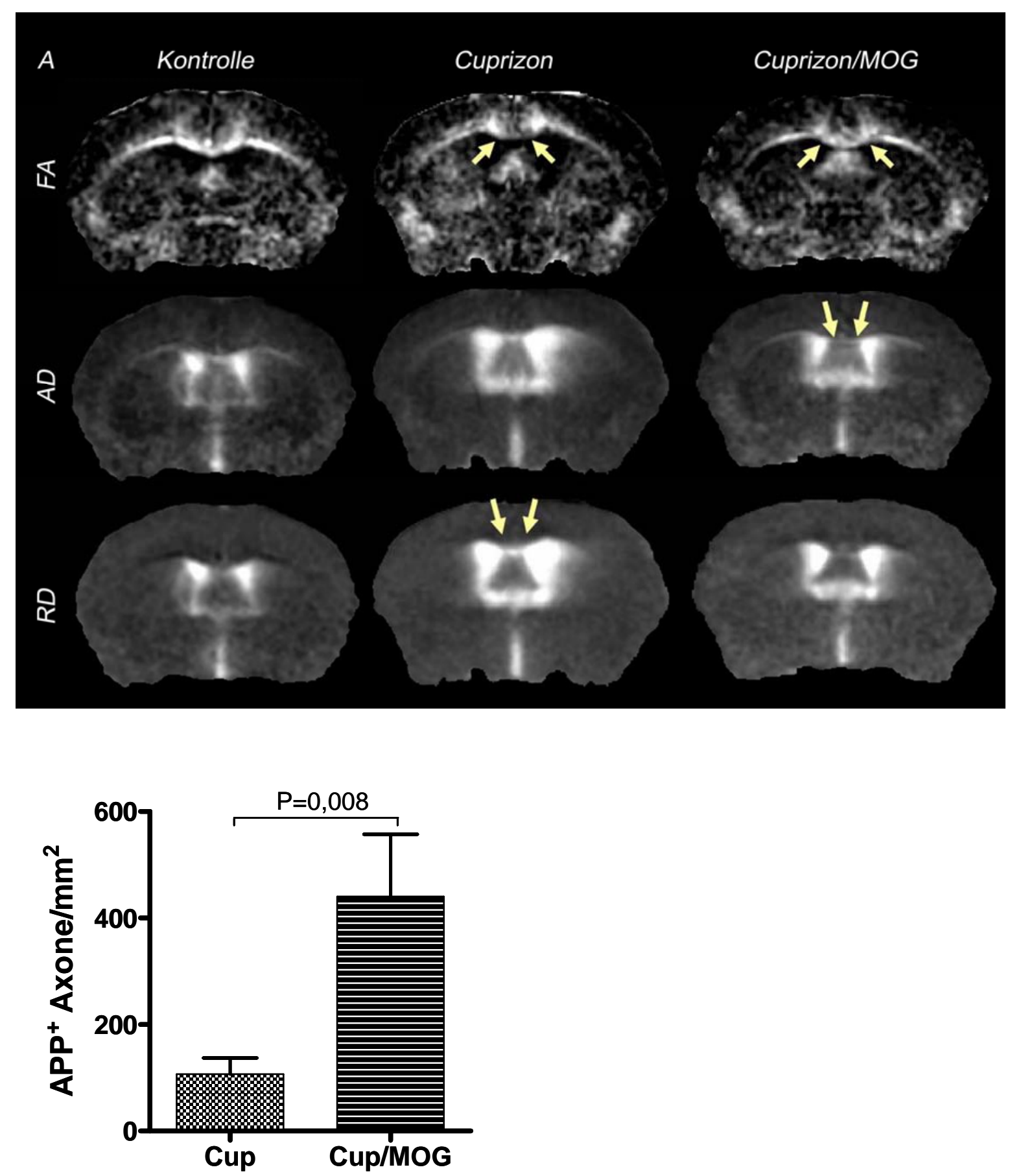

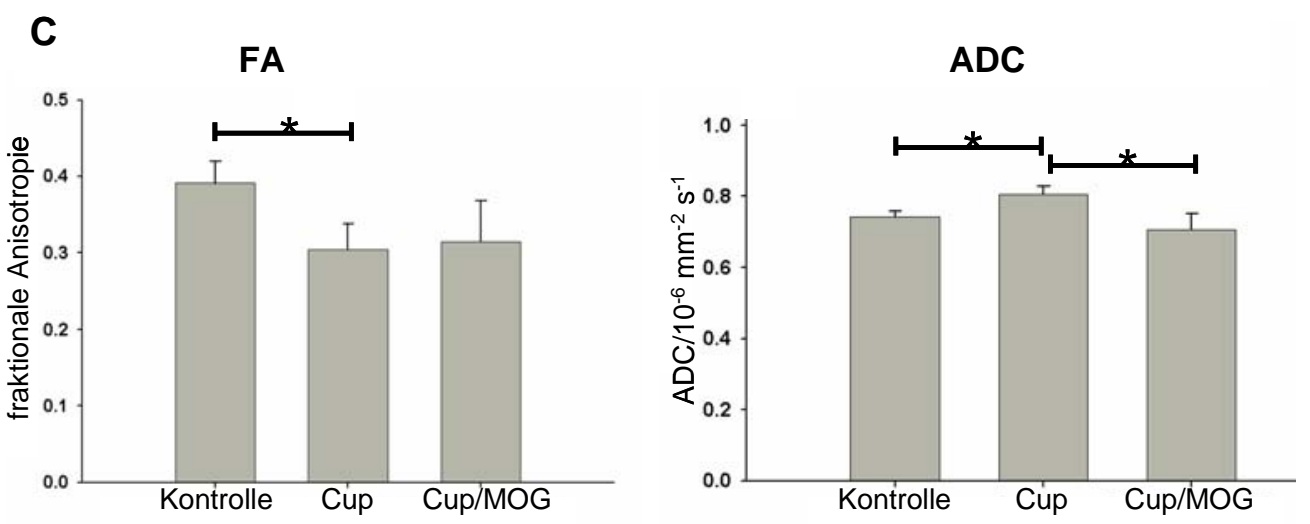

axiale Diffusivität

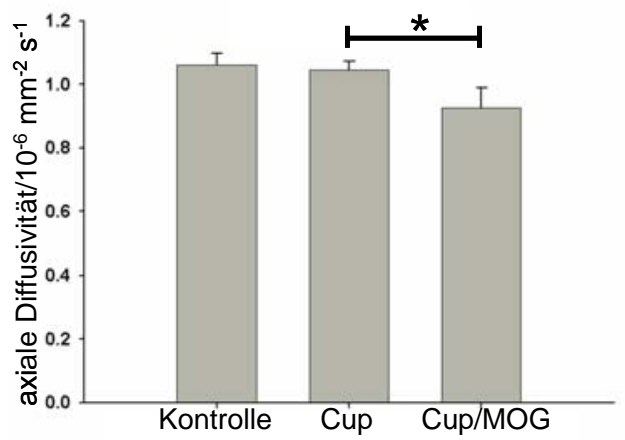

radiale Diffusivität

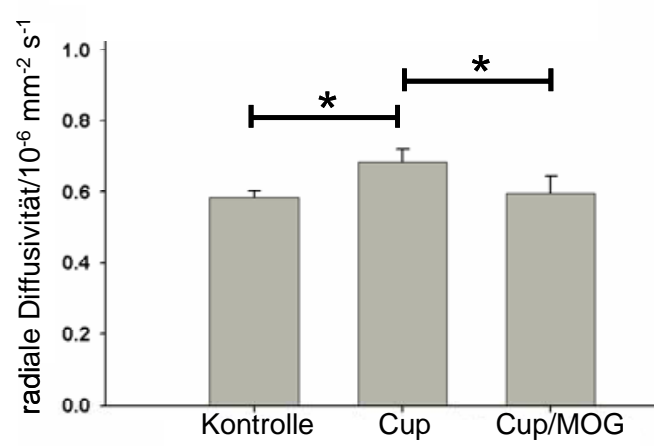

Abb. 4-14: Veränderung der Diffusivität bei der rein toxischen und der toxischen Entmarkung mit Entzündung $(A+C)$ Die Abbildungskarten der radialen Diffusivität $(R D)$ zeigten bei Cuprizon-behandelten Tieren eine Signalverstärkung im Bereich des Balkens und somit erhöhten RD-Werten (Kontrolle: 0,58 \pm 0,02; Cup: $0,68 \pm 0,04$; Kontrolle vs. Cup $P=0,08$ ). Bei Cup/MOG-Tieren war das erhaltene Signal mit nicht-behandelten Kontrollen vergleichbar und der Wert der RD zwischen beiden Gruppen nicht unterschiedlich (Cup und Cup/MOG) (Cup/MOG: 0,59 $\pm 0,05$; Kontrolle vs. Cup/MOG P=0,69; Cup vs. Cup/MOG P=0,016). Bei der axialen Diffusivität $(A D)$ zeigte sich nur bei Cup/MOG-Tieren ein deutlicher Signalverlust, welcher die reduzierte $A D$ wiedergab (Kontrolle: 1,06 $\pm 0,04$; Cup 1,05 $\pm 0,03$; Cup/MOG 0,92 $\pm 0,06$; Kontrolle vs. Cup $P=0,548$; Kontrolle vs. Cup/MOG $\mathrm{P}=0,008$; Cup vs. Cup/MOG $\mathrm{P}=0,008)$. Die fraktionale Anisotropie (FA) war bei beiden Versuchsgruppen im Vergleich zu nicht-behandelten Kontrollen in einem vergleichbaren Maße reduziert (Pfeile) (Kontrolle: 0,39 0,03; Cup: 0,3 \pm 0,03; Cup/MOG: 0,31 $\pm 0,05$; Kontrolle vs. Cup $P=0,008$; Kontrolle vs. Cup/MOG $\mathrm{P}=0,05$; Cup vs. Cup/MOG $\mathrm{P}=0,841$ ). Der scheinbare Diffusionskoeffizient (ADC) war durch die Cuprizon-Behandlung leicht erhöht (Kontrolle: 0,74 $\pm 0,02$; Cup: 0,8 $\pm 0,02$; Kontrolle vs. Cup P=0,008). Die zusätzliche Immunisierung mit $\mathrm{MOG}_{35-55}$ hatte einen leicht geringeren ADC-Wert im Vergleich zu nichtbehandelten Kontrollen zur Folge (Cup/MOG: 0,71 $\pm 0,05$; Kontolle vs. Cup/MOG P=0,22; Cup vs. Cup/MOG $\mathrm{P}=0,008)$. (B) Durch histologische Quantifizierung APP-positiver Axone wurde ein geringfügiger Axonschaden durch die Cuprizon-Behandlung nachgewiesen (Cup: $106 \mathrm{APP}^{+} \pm 68$ Axone $/ \mathrm{mm}^{2}$ ). Die zusätzliche Immunisierung erhöhte die Anzahl APP-positiver Axone deutlich (Cup/MOG: $444 \pm 263$ APP ${ }^{+}$Axone/mm²; MannWhitney Cup vs. Cup/MOG $P=0,008$ ) 
Durch die eigenen Arbeiten wurde gezeigt, dass bereits der Verlust der Markscheiden zu einer geringfügigen nicht signifikanten Reduktion der axialen Diffusivität führte (Kontrolle: 1,06 0 0,04; Cup: 1,05 $\pm 0,03$; Kontrolle vs. Cup $P=0,548$ ). Im Gegensatz hierzu hatte die zusätzliche Entzündung, welche durch Immunisierung mit $\mathrm{MOG}_{35-55}$ induziert wurde, einen deutlichen Rückgang der axialen Diffusivität zu Folge (Cup/MOG: 0,92 $\pm 0,06$; Kontrollen vs. Cup/MOG $\mathrm{P}=0,008$; Cup vs. Cup/MOG $\mathrm{P}=0,008)$. Dies stellte sich in den AD-Karten durch eine Reduzierung der Signalintensität im Balken dar (Pfeile) (Abb. 4-14).

Die histologische Quantifizierung APP-positiver Axone zeigte, dass Entmarkung alleine (Cuprizon) bereits eine Transportstörung in Axonen verursacht (Cuprizon: $106 \mathrm{APP}^{+} \pm 68$ Axone $/ \mathrm{mm}^{2}$ ). Diese Funktionsstörung der entmarkten Axone wurde allerdings durch Entzündungszellen und entzündliche Mediatoren deutlich erhöht (Cup/MOG: $444 \pm 263 \mathrm{APP}^{+}$Axone/mm²; Mann-Whitney Cup vs. Cup/MOG P=0,008) (Abb. 4-14 B).

Auf den Karten der radialen Diffusivität ergab der Balken nicht-behandelter Mäuse ein hypointenses Signal. Dieses war bei Cuprizon-behandelten Mäusen im Vergleich zu nicht -behandelten Kontrollen signifikant erhöht (hyperintense Darstellung des Balkens; Kontrollen: 0,58 \pm 0,02; Cup: 0,68 $\pm 0,04$; Kontrollen vs. Cup P=0,08). Im Gegensatz hierzu unterschieden sich Tiere mit zusätzlicher Entzündung hinsichtlich der radialen Diffusivität nicht von den Kontrolltieren $(0,59 \pm 0,05$; Kontrollen vs. Cup/MOG P=0,69; Cup vs. Cup/MOG $\mathrm{P}=0,016)$.

Für die fraktionale Anisotropie, welche das Ausmaß der Richtungsabhängigkeit wiedergibt, stellte sich das Corpus callosum auf den entsprechenden Karten als helle (hohe Anisotropie) deutlich abgegrenzte Struktur im Gegensatz zum dunkleren Kortex (niedrige Anisotropie) dar. Die Verfütterung von Cuprizon führte zu einer, im Vergleich zu Kontrolltieren, signifikanten Reduktion der FA-Werte (geringere Intensität auf der FA-Karte; Kontrollen: 0,39 $\pm 0,03$; Cup: 0,3 $\pm 0,03$; Kontrollen vs. Cup $P=0,008$ ). Entmarkung mit zusätzlicher Entzündung hatte im Vergleich zu Kontrollmäusen ebenfalls eine Reduktion der Anisotropie zur Folge, die mit der von Cuprizon-Mäusen vergleichbar war (Cup/MOG: $0,31 \pm 0,05$; Kontrolle vs. Cup/MOG $P=0,05$; Cup vs. Cup/MOG $P=0,841$ ).

Der scheinbare Diffusionskoeffizient (apparent diffusion coefficient ADC) gibt die mittlere Diffusion aus den drei bei der Messung erhalten Eigenwerten wieder. Der erhöhte ADC von Cuprizon-behandelten Mäusen ergibt sich aus der hier erhöhten radialen und der nur leicht reduzierten axialen Diffusivität (Kontrolle: 0,74 $\pm 0,02$ und Cup: 0,8 $\pm 0,02$; Kontrolle vs. Cup $\mathrm{P}=0,008$ ). Mäuse mit zusätzlicher Entzündung hatten im Vergleich zu Cuprizonbehandelten Tiere einen niedrigeren ADC-Wert, der mit dem Wert von Kontrolltieren ver- 
gleichbar war (Cup/MOG: 0,71 \pm 0,05; Kontolle vs. Cup/MOG $\mathrm{P}=0,22$ und Cup vs. Cup/MOG $P=0,008)$ (Abb. 4-14). 


\section{Diskussion}

\subsection{Pathogenese von Läsionen in der grauen Substanz}

Im Allgemeinen wird MS als eine Erkrankung der weißen Substanz erachtet. Entmarkte MS-Läsionen in der grauen Substanz konnten jedoch kürzlich durch die Verwendung von immunhistochemischen anti-Myelin-Färbungen und verbesserten Bildgebungsverfahren als wichtiger Bestandteil der MS-Pathologie identifiziert werden (Kidd et al. 1999; Bozzali et al. 2002). Sie tragen möglicherweise aufgrund der Schädigung von Dendriten und Neuronen zur neurologischen Behinderung und kognitiven Dysfunktion, wie Konzentrationsund Gedächtnisstörungen, bei (Brooks et al. 1984; Ghezzi et al. 1990; Thompson et al. 1993; Peterson et al. 2001). Allerdings standen bislang keine geeigneten Tiermodelle zur Verfügung, um diese krankhaften Veränderungen zu erforschen, da es bei den klassischen EAE-Modellen zu einem vorwiegenden Befall der weißen Substanz kommt. In der vorliegenden Arbeit konnte durch den selektiven Befall der grauen Substanz nach Immunisierung mit $\beta$-Synuklein ${ }_{93-111}$ erstmals untersucht werden, inwieweit die unmittelbare Nähe bzw. der direkte Kontakt von Entzündungszellen zu Neuronen diese schädigt und zwar unabhängig vom Befall der weißen Substanz.

Die Immunisierung von Mäusen und Ratten mit nicht Myelinproteinen, wie $\beta$-A4 (Furlan et al. 2003), Nogo-66 (Sicotte et al. 2003) und Neurofilament-light chain (Huizinga et al. 2007) führte bislang nur zu einer geringfügigen meningealen und / oder perivaskulären Entzündung (Berger et al. 1997). Die Immunisierung mit dem astoglialen Protein S100b verursachte ebenfalls ausschließlich perivaskuläre Infiltrate in der grauen und weißen Substanz des Rückenmarks (Kojima et al. 1994). Im Gegensatz hierzu führte die Immunisierung von Lewis-Ratten mit $\beta$-Synuklein ${ }_{93-111}$ (Mor et al. 2003) zu einer ausgeprägten, selektiven Entzündung in der grauen Substanz des Rückenmarks. $\beta$-Synuklein ist ein zytoplasmatisches, neuronenspezifisches Protein mit unbekannter Funktion und ist im Soma und in den präsynaptischen Nervenendigungen lokalisiert (Maroteaux et al. 1988; Jensen et al. 1999).

Neben einer Untersuchung der Schädigung der Nervenzellen durch die neuronenspezifische Immunantwort war es in der vorliegenden Studie von Interesse, das Ausmaß der Makrophagen/Mikrogliaaktivierung und des Axonschadens bei der rein entzündlichen $\beta$-Synuklein-EAE (ohne Myelinverlust) mit der entzündlich-entmarkenden Erkrankung nach anti-MOG-Antikörpertransfer zu vergleichen.

Aufgrund der hohen Homologie der immunogenen Domäne des $\beta$-Synukleinproteins zwischen Ratte und Mensch erscheint die $\beta$-Synuklein-EAE ein besonders geeignetes Modell 
zu sein, um neue Erkenntnisse über die pathologischen Auswirkungen von neuronenspezifischen T-Zellen und Antikörpern zu gewinnen. Hierduch soll ein besseres Verständnis der Pathogenese und Relevanz von Läsionen in der grauen Substanz bei der MS und anderen Autoimmunerkrankungen des ZNS erhalten werden.

\subsubsection{Läsionen in der grauen Substanz des Rückenmarks und des Gehirns nach Immunisierung mit $\beta$-Synuklein ${ }_{93-111}$}

Die Immunisierung mit $\beta$-Synuklein ${ }_{93-111}$ sowie der Transfer von synukleinspezifischen T-Zellen lösten EAE und Uveitis in Lewis-Ratten aus (Mor et al. 2003). Anhand eigener Untersuchungen konnte gezeigt werden, dass die so induzierte Enzephalomyelitis eine monophasische Erkrankung ist. In dem untersuchten Zeitraum von 32 Tagen wiesen die immunisierten Tiere nur einen Krankheitsschub auf. In der histologischen Auswertung zeigte sich ein selektiver Befall der grauen Substanz des Rückenmarks und des Hirnstamms. Einige Tiere wiesen zudem subpiale und perivaskuläre Läsionen im Großhirnkortex auf. Die Infiltrate bestanden, wie in anderen EAE-Modellen, aus Makrophagen/Mikroglia und T-Zellen. Insgesamt war dabei auffallend, dass die Entzündungszellen größtenteils in Regionen mit immunhistochemisch nachgewiesener $\beta$-Synukleinexpression lokalisiert waren. So konnte im Modell der $\beta$-Synuklein-EAE ebenfalls gezeigt werden, dass das verwendete Antigen den Ort der Entzündung beeinflusst (Berger et al. 1997). Die $\beta$-Synuklein-EAE ist eine rein entzündliche Enzephalomyelitis ohne Myelinverlust (3.1.1).

\subsubsection{Entmarkte Läsionen in der grauen Substanz nach anti-MOG-Antikörpertransfer}

Es wird davon ausgegangen, dass anti-MOG Antikörper bei der Entmarkung eine wesentliche Rolle spielen (Linington et al. 1988; van der Laan et al. 1996; Menon et al. 1997; Van der et al. 1999; Morris-Downes et al. 2002). So führte der Transfer des anti-MOGAntikörpers 8-18C5 bei der ebenfalls rein entzündlichen MBP-EAE zu perivaskulären Bereichen mit Myelinverlust in der weißen Substanz (Linington et al. 1988). Bei der $\beta$-Synuklein-EAE wurde eine größere Ähnlichkeit zur entmarkenden Pathologie der MS ebenfalls durch die zusätzliche Injektion des demyelinisierenden anti-MOG-Antikörpers 8-18C5 erzielt, welche die Ratten bei beginnender Erkrankung erhielten (3.2).

Im Gegensatz zu den beschriebenen MBP-EAE Kotransferversuchen, die zu entmarkten Läsionen in der weißen Substanz führten (Linington et al. 1988), konnte bei der $\beta$-Synuklein-EAE keine Verlängerung der Krankheitsphase und kein schwererer Krank- 
heitsverlauf als Folge des Myelinverlusts beobachtet werden. Die Entzündung löste sich unabhängig von der Entmarkung schnell und vollständig auf und führte zu keiner klinisch bemerkbaren dauerhaften Schädigung des Gewebes. Eine Erklärung hierfür sind womöglich die im Vergleich zum MBP-Modell kleineren Läsionen durch die verwendeten geringeren Antikörpermengen. Als Hauptgrund kann jedoch die Lokalisation der Entzündung in der grauen Substanz angesehen werden, da im Modell der $\beta$-Synuklein-EAE im Gegensatz zur MBP-EAE, kaum lange Nervenbahnen der weißen Substanz betroffen waren. Ein Befall der langen, insbesondere motorischen Bahnen macht sich klinisch viel stärker bemerkbar.

\subsubsection{Histologische Unterschiede zwischen der rein entzündlichen und der entzünd- lich-entmarkenden $\beta$-Synuklein-EAE}

In der vorliegenden Studie wurde bei der $\beta$-Synuklein-EAE Demyelinisierung durch den Transfer von anti-MOG Antikörpern induziert und deshalb konnte die Aktivierung von Makrophagen/Mikroglia sowie das Ausmaß an neuronaler und axonaler Schädigung mit und ohne Entmarkung vergleichend untersucht werden.

\subsubsection{Vermehrte Aktivierung der Makrophagen/Mikroglia in demyelinisierenden Läsionen}

In MS-Läsionen bilden schaumzellige, myelinphagozytierende Makrophagen/Mikroglia überwiegend antiinflammatorische und kaum proinflammatorische Zytokine. Deshalb wird davon ausgegangen, dass die Phagozytose von Myelin eine wichtige Rolle bei der Immunsuppression spielt (Boven et al. 2006). Welche Rolle die Myelinphagozytose für die Makrophagen/Mikrogliaaktivierung in sehr frühen Läsionsstadien (insbesondere 30 Std. nach Antikörpertransfer) spielt, wurde hier im Modell der $\beta$-Synuklein-EAE untersucht.

Die Expression von iNOS wird bei entzündlichen und neurodegenerativen Erkrankungen beschrieben und wird überwiegend als Marker für proinflammatorische, gewebsschädigende Prozesse gewertet (Smith und Lassmann 2002; Linares et al. 2006). In der vorliegenden Arbeit induzierte Entzündung alleine - im Gegensatz zur entzündlichen Entmarkung - nur in sehr wenigen Makrophagen/Mikroglia die Expression von iNOS (3.4.1). Die Phagozytose von Myelin scheint somit ein wichtiger Stimulus für die iNOS-Expression zu sein. CD163 vermittelt die Aufnahme des $\mathrm{Hb}-\mathrm{Hp}$ Komplexes in Zellen und HO-1 ist am intrazellulären Abbau des Häms beteiligt. Beide Moleküle gelten als antiinflammatorisch (Abraham und Drummond 2006). Die Expression von CD163 und HO-1 konnte in dieser 
Arbeit unabhängig von Entmarkung nachgewiesen werden, wobei in Ratten ohne Myelinverlust tendenziell mehr HO-1- und CD163-positive Zellen vorhanden waren (3.4.2 und 3.4.3). Möglicherweise wurde die Expression von HO-1 und CD163 bei Tieren mit Entmarkung durch proinflammatorische Mediatoren gehemmt. In den frühen, entzündlichen Läsionen der $\beta$-Synuklein-EAE wurde durch Myelinphagozytose die Expression von iNOS induziert und die der antiinflammatorischen Proteine HO-1 und CD163 gehemmt.

Im Modell der Cuprizon-EAE wurde die Expression dieser Aktivierungsmarker ebenfalls untersucht und deshalb wird deren mögliche Funktion bei Entzündung im nächsten $A b$ schnitt der Diskussion (5.2.5.1) näher erörtert.

Beim Vergleich der EAE-Läsionen in den seriellen Schnitten fiel auf, dass in Läsionen mit zahlreichen iNOS-positiven Zellen kaum HO-1- oder CD163-positive Zellen vorhanden waren. Deshalb soll in immunhistochemischen Doppelmarkierungen untersucht werden, ob sich eine Kolokalisation von iNOS und den beiden antiinflammatorischen Proteinen HO-1 und CD163 in einer Zelle ausschließen würde, oder ob Makrophagen/Mikroglia gleichzeitig pro- und antiinflammatorische Proteine exprimieren können. Zusätzlich soll in geplanten, weiterführenden Arbeiten mittels FACS-Analyse die Aktivierung der Makrophagen/Mikroglia weiter untersucht werden.

\subsubsection{CD8-defiziente Ratten zeigten nach Immunisierung mit ß-Synunklein ${ }_{93-111}$ einen vergleichbaren Krankheitsverlauf}

Früher wurde davon ausgegangen, dass MS eine Krankheit ist, welche hauptsächlich durch CD4-positive T-Zellen vermittelt wird (Friese und Fugger 2005). Heutzutage wird eine Beteiligung von zytotoxischen T-Zellen für sehr wahrscheinlich gehalten, obwohl die genaue Rolle der CD8-positiven Zellen bei MS noch nicht verstanden ist.

In den Rückenmarksquerschnitten der $\beta$-Synuklein ${ }_{93-111}$-immunisierten Ratten konnten zahlreiche CD8-positive Zellen nachgewiesen werden (30 Std. nach Transfer). Die Morphologie der CD8-positiven Zellen entsprach dabei teilweise (ca. 10\% der Makrophagen/Mikroglia) der von Phagozyten. Derartige CD8-positive Zellen mit Phagozytenmorphologie konnten bislang nur in nekrotischem Rattengewebe nachgewiesen werden (Kaffenberger et al. 1987; Jander et al. 1998; Weissenbock et al. 2000; Jander et al. 2001). Bei der rein entzündlichen MBP-EAE exprimierten hingegen nur T-Zellen das CD8Antigen (Schroeter et al. 2003). In der vorliegenden Arbeit wurde somit zum ersten Mal gezeigt, dass CD8-positive Phagozyten bei einer rein entzündlichen Erkrankung vorhanden sein können (3.2.1.2). 
Durch die Verwendung von CD8-defizienten Ratten sollte geklärt werden, inwieweit die CD8-positiven T-Zellen und Makrophagen/Mikroglia den Krankheitsprozess beeinflussen. Der Krankheitsverlauf, die mittlere maximale Krankheitsschwere und der Tag des Krankheitsbeginns waren bei CD8-defizienten und WT-Ratten sehr ähnlich. Die Rolle der zahlreichen CD8-positiven Zellen in den entzündlichen Läsionen der $\beta$-Synuklein ${ }_{93-111^{-}}$ immunisierten Ratten bleibt somit unklar und ist vermutlich in lokal-regulatorischen Funktionen zu suchen. Aufgrund der erhaltenen Ergebnisse wurde die Funktion der CD8positiven Zellen in der vorliegenden Arbeit nicht weiter untersucht. Gegen eine wichtige Funktion der CD8-positiven Zellen bei der Krankheitsinduktion spricht auch die verwende-

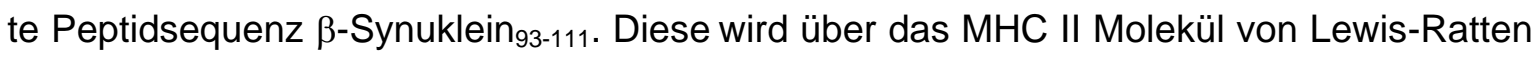
präsentiert (Reizis et al. 1996) und fördert gemeinsam mit der Verwendung von CFA einen CD4-mediierten Krankheitsprozess. Es kann allerdings nicht gänzlich ausgeschlossen werden, dass die Sequenz auch über MHC I präsentiert werden kann.

\subsubsection{Vermehrter axonaler Schaden durch Demyelinisierung}

Die Schädigung und der Verlust von Axonen sind typische Kennzeichen der MS-Läsionen (Ferguson et al. 1997; Bjartmar und Trapp 2001; Gold et al. 2006). Aktivierte Makrophagen/Mikroglia und T-Zellen bilden dabei toxische Mediatoren, welche die Axone schädigen können. Grundsätzlich werden zwei Phasen der axonalen Schädigung beschrieben. Die Axone sind in der ersten Phase von Myelin umgeben und somit besser vor Schädigungen geschützt. In der zweiten Phase, besonders in chronischen MS-Plaques, liegen entmarkte Axone vor, die zudem keinen trophischen Support von Oligodendrozyten mehr erhalten. Möglicherweise sind diese demyelinisierten Axone vulnerabler gegenüber toxischen, löslichen Komponenten und der zellulären Immunantwort (Bruck und Stadelmann 2003).

Die vorliegenden Ergebnisse der $\beta$-Synuklein-EAE unterstützen diese Hypothese. Entzündung alleine verursachte kaum eine Transportstörung in Axonen. Erst der Transfer des entmarkenden anti-MOG-Antikörpers und die daraus resultierende Demyelinisierung hatte zahlreiche APP-positive Axone zur Folge (3.3).

Der geringe Axonschaden in Tieren ohne Entmarkung kann einerseits durch die fehlende Entmarkung - wodurch die Axone besser vor Schädigung geschützt sind - und andererseits durch die äußerst geringe iNOS-Expression in Makrophagen/Mikroglia erklärt werden (Diaz-Sanchez et al. 2006). In den Tieren mit Entmarkung könnte u.a. iNOS, das ganz überwiegend in entmarkten Läsionen gebildet wurde, die axonale Transportstörung induziert haben (Sanders und De Keyser 2007). Die schädigende Wirkung von iNOS auf 
Axone in den entmarkten Läsionen beruht auf der Bildung von NO und NO-Produkten. Hohe NO-Konzentrationen im Gewebe führen zu einer Störung der mitochondrialen Atmungskette, wodurch ein Energiedefizit verursacht wird. Aufgrund dieses Energiemangels kommt es u. a. zu einem eingeschränkten axonalen Transport, der über die Akkumulation von APP nachgewiesen werden kann. Bei der humanen Erkrankung laießen sich APP-positive Axone ebenfalls hauptsächlich in aktiv entmarkenden MS-Läsionen nachweisen (Ferguson et al. 1997; Kornek et al. 2000). Eine axonschädigende Wirkung von iNOS konnte darüber hinaus im Tiermodell gezeigt werden (Aboul-Enein et al. 2006).

Die vorliegenden Ergebnisse zeigen, dass die Expression von iNOS eng mit Axonschaden in Verbindung steht. Allerdings können auch weitere Mechanismen, wie z.B. proteolytische Enzyme, Zytokine und freie Sauerstoffradikale zum Axonschaden beitragen. Die stetig fortschreitende Axonschädigung in inaktiven MS-Läsionen (Kornek et al. 2000) weist auf die Relevanz dieser zuletzt genannten Mechanismen hin.

\subsubsection{Neuronale cJun-Expression in der akuten Phase der $\beta$-Synuklein-EAE}

In diesem Abschnitt der Arbeit wurde durch den immunhistochemischen Nachweis der cJun-Expression, einem Mitglied der AP-1 Transkriptionsfaktorenfamilie, untersucht, ob die anti-neuronale Immunantwort zu einer Stressantwort der Neurone führt. Eine vermehrte cJun-Expression ist ein sensitiver und früh nachweisbarer neuronaler Stressmarker bei Axotomie, bei Ischämie, der Alzheimer Erkrankung und der MS (Herdegen et al. 1997). In Axotomiestudien konnte gezeigt werden, dass die Menge an gebildetem cJun mit der neuronalen Stressantwort korreliert (Hull und Bahr 1994).

Im Modell der hier untersuchten $\beta$-Synuklein-EAE führte bereits die alleinige Entzündung in der grauen Substanz zur gesteigerten neuronalen cJun-Expression, welche in Tieren mit zusätzlicher Entmarkung deutlich erhöht war (30 Std. nach Antikörpertransfer). Nach der Erholung der Tiere aus beiden Versuchsgruppen (20 Tage nach Antikörpertransfer) war die cJun-Expression in den Nervenzellen mit der in CFA-immunisierten Kontrollratten vergleichbar (3.5.1). Die zeitlich begrenzte cJun-Expression kann durch die entzündlich bedingte Zyto- und Chemokinexpression und die Bildung von reaktiven Sauerstoffmolekülen durch aktivierte Makrophagen/Mikroglia und T-Zellen erklärt werden. In Tieren mit Entmarkung bewirkten der Verlust von Myelin, die deutliche Schädigung der entmarkten Axone und die Expression von iNOS durch myelinphagozytierende Makrophagen/Mikroglia als zusätzliche Stressfaktoren eine nochmals vermehrte cJun-Expression in Nervenzellen. 
Nach bisherigen Erkenntnissen kann die cJun-Expression zum einen Regenerationsprozesse wie die Neuaussprossung von Axonen nach Axotomie (Robinson 1995) und Hypoglykämie (Gass et al. 1995) begleiten. Zum anderen kann sie ebenso den Zelltod zur Folge haben. Dabei kann im Einzelfall nicht vorhergesagt werden, ob die cJun-Expression Re- oder Degeneration zur Folge hat (Estus et al. 1994). Es wäre durchaus denkbar, dass die cJun-positiven Neurone in $\beta$-Synuklein ${ }_{93-111}$-immunisierten Tieren auf den Zelltod zugehen, da keine GAP-43-positiven Strukturen vorhanden waren (Daten nicht gezeigt). GAP-43 ist ein weiteres Protein, das bei neuronalen Regenerationsprozessen vermehrt gebildet wird (Benowitz et al. 1987; Benowitz und Routtenberg 1997). Ob diese „gestressten“ Nervenzellen im Modell der $\beta$-Synuklein-EAE tatsächlich zugrunde gehen wurde im nachfolgenden Arbeitsschritt durch die Quantifizierung der Nervenzellen überprüft.

\subsubsection{Kein Nervenzellverlust durch Entzündung in der grauen Substanz bei der $\beta$-Synuklein-EAE}

Ob die direkte anti-neuronale Immunantwort einen Untergang von Neuronen zur Folge hat, ist von Interesse, da es bei MS zur Schädigung und zum Verlust von Neuronen kommt. Obwohl der apoptotische Nervenzelltod im Großhirnkortex bei MS ein seltenes Ereignis zu sein scheint (1,4 TUNEL-positive Neurone/100 $\left.\mathrm{mm}^{2}\right)$ (Peterson et al. 2001), kann der neuronale Verlust im Verlauf der Krankheit 10 - 20\% betragen (Vercellino et al. 2005; Wegner et al. 2006). Zusätzlich werden bei einigen EAE-Modellen (Meyer et al. 2001; Diestel et al. 2003; Bannerman et al. 2005) und bei Ko-Kulturversuchen von Mausgehirnscheiben mit PLP- oder Ova-spezifischen T-Zellen (Nitsch et al. 2004) eine beeinträchtigte Funktion und ein Verlust von Nervenzellen beschrieben. Bisher wurde der Mechanismus, welcher die neuronale Stressreaktion bzw. den Untergang verursacht, noch nicht geklärt. Es können dafür drei Ursachen in Betracht gezogen werden. Zum einen könnten Nervenzellen durch die unmittelbare Nähe der Immunzellen und deren zelltoxische Produkte geschädigt werden. Zum anderen könnte die neuronale Apoptose sekundär durch den MS-typischen Verlust von Axonen induziert werden und die dritte Möglichkeit ist die Kombination aus beidem. Da die Immunisierung mit $\beta$-Synuklein ${ }_{93-111}$ zu einem selektiven Befall der grauen Substanz führte, konnte untersucht werden, ob bereits die unmittelbare Nähe von Entzündungszellen Neurone schädigen kann.

In den durchgeführten Experimenten konnte im akuten Krankheitsstadium (30 Std. nach Antikörpertransfer) ein Rückgang der Neuronendichte von ungefähr 30\% verzeichnet werden. Dies war unabhängig vom Transfer demyelinisierender Antikörper. Die Dichte der 
Neurone nahm jedoch mit beginnendem Rückgang der Entzündung (vier Tage nach Transfer) wieder zu und war 20 Tage nach Antikörpertransfer mit der Dichte von CFAimmunisierten Kontrollratten vergleichbar (3.5.2). Der fehlende Nachweis von apoptotischen Neuronen in der Hämalaun-Färbung und der transiente Verlust von NeuN-positiven Nervenzellen sprechen gegen einen programmierten Zelltod. Aktivierte Caspase-3, ein Protein des Apopotose-Effektorstadiums, konnte ebenfalls nicht nachgewiesen werden. Des Weiteren kamen in der TUNEL-Reaktion, die eine Fragmentierung der DNA anzeigt, nur apoptotische T-Zellen, aber keine Neurone zur Darstellung. In den Rückenmarksquerschnitten von $\beta$-Synuklein ${ }_{93-111}$-immunisierten Ratten gab es somit keine Anhaltspunkte für neuronalen Zelltod.

Eine Erklärung für den Rückgang der Neuronendichte im akuten Krankheitsstadium im Modell der $\beta$-Synuklein-EAE könnte eine veränderte Expression und / oder immunhistochemische Detektierbarkeit des neuronenspezifischen Proteins NeuN sein, da in den Rückenmarksquerschnitten auch NeuN-negative Nervenzellen vorhanden waren. Nach Ischämie konnte ebenfalls eine reduzierte Dichte NeuN-positiver Neurone gezeigt werden, obwohl bei der Kernfärbung ausschließlich intakte Zellkerne nachgewiesen werden konnten. Ebenso wiesen diese Nervenzellen in der HE-Färbung nicht die Morphologie apoptotischer Zellen auf und bildeten auch keine aktivierte Caspase-3 (Unal-Cevik et al. 2004). Zusätzlich wurde gezeigt, dass es nach Axotomie (McPhail et al. 2004) und im höheren Alter (Portiansky et al. 2006) bei Tieren zu einem Verlust des NeuN-Signals kommen kann. Alter (Smith und Hagen 2003) und Zellstress (Schirmer, Stadelmann unpublizierte Daten) können Änderungen im Phosphorylierungsstatus von neuronalen Proteinen verursachen. Ein möglicher Grund für NeuN-negative Nervenzellen könnte somit in einer fehlenden Phosphorylierung bzw. Dephosphorylierung von NeuN bestehen (Portiansky et al. 2006), da der NeuN-Antikörper nur phosphoryliertes NeuN erkennt (Lind et al. 2005). NeuN scheint unter inflammatorischen Bedingungen somit kein geeigneter Marker für die Quantifizierung von Neuronen zu sein. Aus diesem Grund wurde die Neuronendichte zusätzlich durch die Nissl-Färbung bestimmt. Da bei dieser Färbung die Dichte der Nervenzellen ebenso zunächst abnahm, kann nur ein Teil der reduzierten NeuN-positiven Neuronendichte durch die fehlende Detektierbarkeit von NeuN erklärt werden.

Die Entzündung führt zur Bildung eines Ödems, das in MS-Läsionen eine deutliche Volumenvergrößerung verursachen kann (Helms 2001). Ein Vergleich der Flächen der Rückenmarksquerschnitte in den eigenen Versuchen zeigte, dass die Fläche um ungefähr den prozentualen Wert zunahm, um welchen Faktor auch die Dichte der Neurone abnahm. Durch den Rückgang der Entzündung reduzierte sich die gemessene Fläche und 
die Dichte der Neuronen nahm wieder zu. Der gemessene Rückgang der Neuronendichte bei der $\beta$-Synuklein-EAE stellt also keinen absoluten Verlust an Neuronen dar, sondern kommt zum größten Teil durch die ödembedingte, transiente Flächenzunahme zustande.

Der fehlende Nachweis apoptotischer Neurone findet sich auch in anderen EAE-Modellen. Die histologische Auswertung von PLP-immunisierten SJL-Mäusen zeigte keine TUNELund aktivierte Caspase-3-positiven Neurone in Kortex, obwohl in diesem Modell ein enger Kontakt zwischen Immunzellen und Nervenzellen beschrieben wurde (Rasmussen et al. 2007). Die Immunisierung von C57BL/6-Mäusen mit MOG $_{35-55}$ verursachte ebenfalls keinen Neuronenverlust im Rückenmark, sondern lediglich eine Reduktion der Dendritendichte und eine Atrophie der Perikarien (Bannerman et al. 2005).

Neurone scheinen somit entzündliche Prozesse besser zu überleben als das sie umgebende Gewebe. Durch die konstitutive und IFN- $\gamma$ induzierte MHC I Expression können Neurone das Ziel von zytotoxischen T-Zellen werden (Neumann et al. 1995; Neumann et al. 1997). In in vitro Versuchen konnte allerdings gezeigt werden, dass Neurone, welche mit dem lymphozytären Choriomeningitis Virus (LCMV) infizierte sind, resistent gegenüber der Perforin-abhängigen Zelllyse sind (Medana et al. 2000). Ebenso hatte die Infektion von Mäusen mit LCMV, bei welcher eine antigen-spezifische Immunantwort gegen Neurone stattfindet, keinen wesentlichen Untergang der Nervenzellen zur Folge (Merkler, persönliche Mitteilung).

Neurone exprimieren FasL (CD95), einen Ligand des Apoptose-Signalwegs (French et al. 1996; Flugel et al. 2000). Dies könnte eine Art von Selbstschutz sein, da über die Bindung des Fas-Ligandens an den Fas-Rezeptor der Zelltod induziert werden kann (Abbas 1996) und auf diese Weise Apoptose in T-Zellen ausgelöst wird. Untermauert wird diese Hypothese durch nachfolgend beschriebenen Versuch: Die Immunisierung von Mäusen nach Fazialisaxotomie hatte die Infiltration von T-Zellen in den Hirnstammkern des durchtrennten Nervs zur Folge. Allerdings konnten auch bei diesem Versuch keine apoptotischen Nervenzellen, sondern nur apoptotische T-Zellen nachgewiesen werden. In weiteren in vitro Versuchen konnte gezeigt werden, dass neutralisierende anti-FasL-Antikörper TZellen vor dem programmierten Zelltod schützen und deshalb führten die Autoren die Apoptose der Lymphozyten auf die FasL-FasR Bindung zurück. Selbst der direkte Kontakt von T-Zellen und Nervenzellen scheint nicht zum Untergang von Neuronen zu führen (Flugel et al. 2000; Medana et al. 2001). In anderen Berichten wird sogar von einer trophischen Funktion aktivierter T-Zellen ausgegangen, da diese NGF und BDNF produzieren können (Ehrhard et al. 1993; Kerschensteiner et al. 1999; Flugel et al. 2000). Aktivierte 
Makrophagen/Mikroglia sezernieren zusätzlich trophische und antiinflammatorische Stoffe, die das Überleben von Neuronen begünstigen (Polazzi et al. 2001; Liao et al. 2005).

Eine stark gewebsdestruktive Entzündung bei der MOG-induzierten EAE in Ratten mag den Widerspruch zwischen dem fehlendem Verlust an Neuronen im Modell der $\beta$-Synuklein-EAE und dem Verlust von retinalen Ganglienzellen bei der MOG-EAE erklären (Meyer et al. 2001). So führte die MOG-EAE zu einem deutlichen Axonverlust, welcher möglicherweise über nachfolgende retrograde Chromatolyse den neuronalen Zelltod verursachen kann. Ein weiterer Unterschied zwischen beiden Modellen ist die Dauer der Erkrankung. Die MOG-induzierte EAE ist eine primär progredient fortschreitende Erkrankung. Im Gegensatz hierzu ist die $\beta$-Synuklein-EAE eine kurzzeitige, monophasische Erkrankung, bei welcher es zu keinem dauerhaften Parenchymschaden kommt. Bei MS wird ebenfalls der neuronale Verlust hauptsächlich in der chronischen Phase beschrieben. Daher scheinen wiederholte Krankheitsschübe und / oder ein Verlust der Axone der Nervenzellapoptose vorauszugehen (Peterson et al. 2001).

Abschließend lässt sich feststellen, dass die durch Entzündung in der grauen Substanz bedingte cJun-Expression bei der $\beta$-Synuklein-EAE eine transiente Stressantwort auf die Entzündungsreaktion darstellt, da keine apoptotischen Nervenzellen nachgewiesen werden konnten. Die zeitlich begrenzte Abnahme der Neuronendichte, konnte auf die ödembedingte Flächenzunahme zurückgeführt werden.

\subsubsection{Verlust Synaptophysin-positiver Strukturen}

Die Lähmung der Extremitäten von $\beta$-Synuklein ${ }_{93-111}$-immunisierten Ratten war von kurzer Dauer (3-4 Tage) und war gefolgt von einer vollständigen Erholung der Tiere. Vermutlich spielen Mediatoren, die während der transienten Entzündungsreaktion freigesetzt wurden, eine zentrale Rolle bei der Induktion der Lähmungserscheinungen. Ein vorübergehender Verlust von Synapsen kann ebenfalls zu neurologischer Dysfunktion führen (Zhu et al. 2003) und kann deshalb als weitere mögliche Ursache der Lähmungserscheinungen in Betracht gezogen werden.

In dicht infiltrierten Bereichen der Rückenmarksquerschnitte von Ratten mit $\beta$-SynukleinEAE war ein ausgeprägter Verlust des Synaptophysinsignals vorhanden. Der Verlust von synaptischen Strukturen war dabei auf die Tiere der akuten Krankheitsphase (30 Stunden) beschränkt (3.6). Es wäre durchaus denkbar, dass ein Verlust von Synapsen bei diesen Tieren eine zeitlich begrenzte Blockade der Erregungsübertragung verursachte, 
welche durch eine rasche Synapsenneubildung aufgehoben wurde (Jorgensen et al. 1997).

Bei der humanen Erkrankung kommt es ebenfalls zu einer Reduktion des Synaptophysinsignals um 47\% im demyelinisierten Kortex im Vergleich zum normal erscheinenden Neokortex der MS-Patienten (Wegner et al. 2006). Ein Zusammenhang zwischen der Infiltration von Entzündungszellen und dem Untergang von Synapsen scheint bei MS ebenso vorhanden zu sein, da dieser ebenfalls ausschließlich in dicht infiltrierten Bereichen und nicht in chronischen Entzündungsherden nachgewiesen wurde (Vercellino et al. 2005; Vercellino et al. 2007). Darüber hinaus wird bei der Alzheimerischen Erkrankung (Lue et al. 1996), bei HIV Enzephalomyelitis (Masliah et al. 1992) und in der akuten Phase der MBP-induzierten EAE bei Ratten (Zhu et al. 2003) ein Verlust von Synaptophysin beschrieben.

Einerseits wird es für möglich gehalten, dass eine direkte Immunantwort gegen Synapsen den Verlust verursachen kann, da MBP-spezifische T- und B-Zellen mit Synapsin-1, einem synaptischen Protein kreuzreagieren (Pedraza et al. 1988; De Santis et al. 1992). $\beta$-Synuklein ist ebenfalls in den synaptischen Nervenendigungen lokalisiert (Maroteaux et al. 1988; Jensen et al. 1999; Giasson et al. 2001), und die Immunisierung mit $\beta$-Synuklein ${ }_{93-111}$ führte zur Bildung von antigenspezifischen T-Zellen und Antikörpern. Es wäre also durchaus denkbar, dass die Immunreaktion gegen $\beta$-Synuklein den Verlust von Synapsen zur Folge hatte. Allerdings ist auf Grund der zytoplasmatischen Lokalisation des $\beta$-Synukleinproteins eine schädigende Wirkung von Antikörpern unwahrscheinlich, da diese nicht an ihr spezifisches Antigen binden können.

Andererseits wirken hohe extrazelluläre Glutamtkonzentrationen toxisch auf Synapsen und Dendriten (Zhu et al. 2003). Entzündungszellen setzten reichlich Glutamat frei (Piani und Fontana 1994) und verschiedene Entzündungsmediatoren hemmen die Wiederaufnahme von Glutamat in Zellen (Piani et al. 1993). So hängen Entzündung und toxische extrazelluläre Glutamatkonzentrationen eng zusammen.(Zhu et al. 2003) Die Relevanz dieses Schädigunsmechanismuses wird durch die folgende Beobachtung unterstützt: Bei MS liegen erhöhte Glutamatkonzentrationen vor (Srinivasan et al. 2005) und Substanzen, die die Glutamattransmission modulieren, können den Krankheitsverlauf bei MS und EAE verbessern, haben jedoch bei EAE keinen Einfluss auf das Ausmaß der Entzündung (Wallstrom et al. 1996; Killestein et al. 2005). Der Verlust von Synapsen aufgrund entzündlich bedingter hoher extrazellulärer Glutamatkonzentrationen ist somit eine plausible Erklärung für den Verlust des Synaptophysinsignals. 


\subsubsection{Zusammenfassung}

Die $\beta$-Synuklein-EAE ist eine Erkrankung der grauen Substanz und eignet sich daher als Modell für die Untersuchung der pathologischen Schädigungsmechanismen der grauen Substanz bei MS. Anhand dieses Modells wurde gezeigt, dass Demyelinisierung und daraus resultierende Myelinphagozytose die Expression von iNOS in Makrophagen/Mikroglia induziert. Die Expression der als antiinflammatorisch geltenden Proteine HO-1 und CD163 wurde unabhängig von Entmarkung nachgewiesen. Es konnte außerdem gezeigt werden, dass insbesondere der Verlust der Myelinscheiden Axonschaden begünstigt. Des Weiteren wurde nachgewiesen, dass die unmittelbare Nähe zwischen Entzündungszellen zwar neuronalen Zellstress, aber nicht Apoptose von Neuronen verursacht. 


\subsection{Cuprizon-EAE, ein neues Modell mit MS-ähnlichen Läsionen im Mausge- hirn}

Die gängigen Tiermodelle der MS spiegeln nicht alle typischen Kennzeichen der humanen Erkrankung wider. Speziell in Mäusen kommt es kaum zu primärer Entmarkung, und die pathologischen Prozesse verlaufen nahezu ausschließlich in der weißen Substanz des Rückenmarks. Deshalb war es das Ziel im folgenden Teil der Arbeit, ein neues Tiermodell mit reproduzierbaren, entzündlichen und entmarkten Läsionen im Mausgehirn zu entwickeln.

Die Verfütterung von Cuprizon, einem Kupferchelator, führt zum selektiven Verlust von Oligodendrozyten und Myelin und zur Aktivierung der Mikrogliazellen im Balken von Mäusen (Matsushima und Morell 2001). Die nachfolgende Immunisierung mit MOG $_{35-55}$-Peptid sollte eine gezielte Infiltration aktivierter T-Zellen in das vorgeschädigte Gehirngewebe induzieren und MS-ähnliche Entzündungsherde verursachen. Die Kombination dieser beiden experimentellen Modelle führte zu Entmarkung mit Entzündung und wird als Cuprizon-EAE bezeichnet.

Anhand des neu etablierten Modells konnte das Ausmaß der axonalen Schädigung sowie die Aktivierung der Makrophagen/Mikroglia bei reiner Entmarkung im Gegensatz zu Entmarkung mit Entzündung verglichen werden. In einem weiteren Schritt wurde die Effizienz der Remyelinisierung nach dem Beenden der Cuprizon-Diät zwischen der nicht entzündlichen Entmarkung durch Cuprizon und der Entmarkung mit Entzündung bei der CuprizonEAE vergleichend untersucht. Aufgrund der Lokalisation der Läsionen eignete sich das Modell der Cuprizon-EAE zudem für die Korrelation von Bildgebung (MRT) und Histopathologie.

\subsubsection{Infiltration von Entzündungszellen in vorgeschädigtes Gehirngewebe durch myelinspezifische T-Zellen}

Zunächst wurde der optimale Zeitpunkt für die Immunisierung Cuprizon-behandelter Mäuse untersucht und dabei festgestellt, dass eine Immunisierung nach 17 Tagen CuprizonDiät optimal war (4.2). Anschließend wurde anhand dieses Modells überprüft, ob ausschließlich aktivierte ZNS-spezifische T-Zellen die Infiltration von weiteren Entzündungszellen in das Corpus callosum induzieren können, oder ob aktivierte ZNS-unspezifische T-Zellen ebenfalls eine Entzündungsreaktion auslösen können.

In der vorliegenden Studie konnte durch die Cuprizon-bedingte Entmarkung und die zusätzliche Immunisierung mit $\mathrm{MOG}_{35-55}$ die Infiltration von T-Zellen und Makrophagen in 
das Corpus callosum von Mäusen erzielt werden. Bei einem Teil dieser MOG M5-55- $^{-}$ immunisierten Mäuse kam es sogar zu einer ausschließlichen Infiltration von Entzündungszellen in das Gehirn. Diese Tiere wiesen weder Lähmungserscheinungen noch histologisch nachweisbare EAE-Läsionen im Rückenmark auf. Im Gegensatz hierzu konnte durch die Immunisierung mit Ovalbumin, einem Bestandteil des Hühnereiweißes, keine vermehrte Einwanderung von Entzündungszellen in das Mausgehirn oder Rückenmark induziert werden (4.3.1).

Es müssen anscheinend zwei Bedingungen gegeben sein, um eine gezielte entzündliche Läsion im Mausgehirn zu induzieren: Erstens scheint die Infiltration von Entzündungszellen in „vorgeschädigtes“ Gehirngewebe erleichtert zu sein, da klassische EAE-Versuche nur selten zu Läsionen im Mausgehirn führen (Archambault et al. 2006) und zweitens können nur ZNS-spezifische, aktivierte T-Zellen eine weitergehende Entzündungsreaktion im Mausgehirn auslösen.

Die Ergebnisse der eigenen Studie sind in Übereinstimmung mit Untersuchungen nach traumatischen Läsionen, der Zyanidintoxikation und der Fazialisaxotomie. Bei diesen Modellen führte lokaler ZNS-Schaden ebenfalls zu einer gezielten Infiltration von T-Zellen in die geschädigte ZNS-Region (Levine 1960; Konno et al. 1990; Raivich et al. 1998; Bauer et al. 1998; Flugel et al. 2001b). In einem weiteren Modell, der fokalen, kortikalen EAE in Lewis-Ratten, konnte kürzlich gezeigt werden, dass die intrakortikale, atraumatische, stereotaktische Injektion von TNF- $\alpha$ und IFN- $\gamma$ in immunisierte Ratten eine Entzündungsreaktion mit Entmarkung im Kortex verursachen kann (Merkler et al. 2006b). Es wird angenommen, dass dabei die lokale Aufregulation von Adhäsionsmolekülen, sowie die lokale Sekretion von Zyto- und Chemokinen aktivierte T-Zellen von der Peripherie in geschädigtes ZNS-Gewebe „locken“ (Werner et al. 1998; Hofmann et al. 2002). Diese Voraussetzung für eine erleichterte Infiltration von T-Zellen wurde in der vorliegenden Arbeit durch die Cuprizon-Gabe erzielt. Eine vermehrte Expression von ICAM-1, MCP-1 und MIP-1 $\alpha$ konnte nach Cuprizon-Diät nachgewiesen werden (4.2.1).

Das in der vorliegenden Arbeit erzielte Ergebnis, dass nur nach Immunisierung mit einem ZNS-spezifischen Antigen ( $\mathrm{MOG}_{35-55}$ ) T-Zellen eine Entzündungsreaktion in geschädigtem Gehirnparenchym auslösen, ist ebenfalls in Übereinstimmung mit den Befunden aus der Literatur. In Studien wurde gezeigt, dass der adoptive Transfer von Ovalbuminspezifischen T-Zellen in Ratten und Mäuse mit lokal vorgeschädigtem ZNS keine weitere Rekrutierung von Entzündungszellen zur Folge hatte. Ausschließlich der gleichzeitige Transfer von Ova- und MBP-spezifischen T-Zellen induzierte eine vermehrte Infiltration von ZNS-unspezifischen T-Zellen (Bauer et al. 1998; Flugel et al. 2000; Archambault et al. 
2006). Für die Infiltration von ZNS-unspezifischen T-Zellen in das ZNS müssen scheinbar zwei Voraussetzungen gegeben sein: Erstens muss das ZNS durch enzephalitogene T-Zellen „konditioniert" sein und zweitens müssen die ZNS-unspezifischen T-Zellen ausreichend aktiviert sein, um die BHS passieren zu können (Flugel et al. 2001a). In einem weiteren Rattenmodell induzierte der Transfer von Ova-spezifischen T-Zellen eine geringfügig erhöhte T-Zelldichte in der Retina, eine Aktivierung der dortigen Makrophagen/Mikroglia und eine milde Schädigung der Blut-Retina-Schranke. Allerdings verursachte dies keine weitere Immunantwort. Im Gegensatz hierzu führte eine zuvor erfolgte intraokulare Injektion von Ovalbumin zu einer massiven Infiltration von Ova-spezifischen T-Zellen. Diese Versuche sind ein Hinweis darauf, dass aktivierte T-Zellen die geschlossene BHS zwar passieren können, aber nur nach Antigenerkennung eine Immunantwort ausgelöst wird (Hu et al. 2000).

Anhand der durchgeführten Versuche wurde gezeigt, dass nach MOG $_{35-55}$-Immunisierung eine massive Infiltration von Entzündungszellen in das Mausgehirn nur dann erfolgt, wenn zuvor eine lokale Aufregulation von Adhäsionsmolekülen und die Sezernierung von Zytound Chemokinen stattgefunden haben. Ohne diese „Vorschädigung“, wanderte der überwiegende Teil der T-Zellen in das Rückenmark der Mäuse ein.

\subsubsection{Infiltration von Entzündungszellen in das Mausgehirn über eine geöffnete Blut-Hirn-Schranke}

Bei MS und EAE erfolgt die Infiltration der Entzündungszellen über eine geöffnete BHS (Morrissey et al. 1996; Minagar und Alexander 2003). Bereiche mit einer nicht intakten BHS können magnetresonanztomographisch durch Kontrastmittelanreicherung (Gd-DTPA) im Parenchym nachgewiesen werden (Bruck et al. 1997). Gd-anreichernde MS-Läsionen gelten als akute Entzündungsherde, obwohl der Zeitverlauf der Gd-Anreicherung und die damit korrelierenden histopathologischen Befunde (Öffnung der BHS, Infiltration der Entzündungszellen, Dauer der Öffnung) noch ungenügend geklärt sind. Durch den Vergleich der Ergebnisse der MRT-Messungen und der histopathologischen Befunde wurde der Zeitverlauf der Läsionsbildung näher untersucht.

In der vorliegenden Arbeit wiesen die Mäuse, in Übereinstimmung mit der Literatur (McMahon et al. 2002) nach der Verfütterung von Cuprizon eine intakte BHS auf. Das Gd-DTPA ließ sich ausschließlich in den Blutgefäßen und Meningen nachweisen. Erst die Immunisierung von Cuprizon-behandelten Mäusen führte zu einer Öffnung der BHS im Bereich des Corpus callosum und entlang der Ventrikel. Dies wurde magnetresonanzto- 
mographisch durch eine parenchymale Anreicherung von Gd-DTPA in der T1-gewichteten MRT-Messung und histologisch durch Fibrinogen- und IgG-Ablagerungen nachgewiesen (4.6.1). Hinweise für eine geöffnete BHS wurden zusätzlich bei der FACS-Analyse erhalten. Die Gehirne der ausschließlich mit Cuprizon behandelten Tiere enthielten kaum $\mathrm{CD} 11 \mathrm{~b}^{+} / \mathrm{CD} 45^{\text {high }}$-Makrophagen, welche hingegen in den zusätzlich $\mathrm{MOG}_{35-55^{-}}$ immunisierten Tieren über die geöffnete BHS aus dem Blut zahlreich eingewandert waren (4.3.2).

Bei Maus-EAE-Versuchen kommt es im Balken und Kortex zu keiner BHS-Störung und Infiltration von Entzündungszellen (Rausch et al. 2003; Wuerfel et al. 2007). Die CuprizonEAE ist somit ein neues Mausmodell, welches besser mit der MS-Pathologie übereinstimmt und deshalb mögliche, MS-relevante Veränderungen im Mausgehirn besser untersucht werden können.

Die Lokalisation Gd-anreichernder Regionen stimmte nicht immer mit der Lokalisation der Fibrinogen- und IgG-Ablagerungen überein. Ein Teil der Bereiche mit Gd-DTPAinduzierter Signalverstärkung zeigte histologisch keine Fibrinogen- und IgGAblagerungen. Umgekehrt konnten die histologischen Marker der BHS-Störung nicht immer durch Gd-DTPA bestätigt werden. Allerdings führte eine deutlich erhöhte T-Zelldichte immer zu IgG- und Fibrinogenablagerungen.

Die Diskrepanz zwischen den erhaltenen MRT-Bildern und den histologisch nachweisbaren Markern kann teilweise durch die unterschiedliche Größe der Moleküle erklärt werden. Fibrinogen (340 kDa) und Immunglobuline (IgG; 150 kDa) weisen ein erheblich kleineres Molekulargewicht auf als Gd-DTPA (938 kDa, telefonische Auskunft bei Bayer-Schering). Es ist deshalb durchaus denkbar, dass IgG und Fibrinogen auf Grund ihrer Größe bereits vor Gd-DTPA in das Parenchym eindringen können und frühzeitig eine Öffnung der BHS markieren. Gd-DTPA diffundiert wahrscheinlich erst ins Parenchym, wenn die Entzündungsreaktion und BHS-Störung schon voll ausgebildet sind. Ein weiterer Grund dafür, dass Gd-DTPA-Signale nicht immer mit histologisch nachweisbaren Läsionen übereinstimmten, kann auch die unterschiedliche Dicke der untersuchten Gehirnscheiben sein. Das MRT-Signal (117 $\mu \mathrm{m}$ dicke Schnitte) wird im Vergleich zu den histologischen Präparaten (ca. $1 \mu \mathrm{m}$ dicke Schnitte) von erheblich dickeren Schnitten erhalten. Es ist durchaus möglich, dass die histologisch untersuchten Ebenen nicht immer exakt mit den Ebenen übereinstimmten, in denen eine Gd-DTPA-Anreicherung nachgewiesen werden konnte.

In einer MRT-Studie mit MS-Patienten erfolgte der Nachweis von entzündlichen Infiltraten durch so genannte ultra-kleine-Eisenoxidpartikel (USPIO). Diese werden von Makrophagen/Mikroglia phagozytiert und erzeugen bei einer T2-gewichteten MRT-Messung eine 
Signalverstärkung. Eine Kolokalisation der USPIO- und Gd-DTPA-induzierten Signale war bei dieser Studie ebenso nicht immer gegeben (Dousset et al. 2006). Vergleichbare Ergebnisse wurden bei der MBP-induzierten EAE in Lewis-Ratten erhalten (Rausch et al. 2003).

Ein direkter Vergleich der unterschiedlichen Marker einer BHS-Störung scheint nicht möglich zu sein, da diese wahrscheinlich geringfügig unterschiedliche Aspekte der Öffnung der BHS nachweisen.

\subsubsection{Axonale Schädigung im Mausgehirn nach T-Zell- und Makrophageninfiltration}

Die Degeneration von Axonen im ZNS ist ein größtenteils irreversibler Prozess und wird als Hauptgrund der bleibenden neurologischen Behinderung von MS-Patienten angesehen (Kornek et al. 2000; Lovas et al. 2000). Deshalb ist es von entscheidender Bedeutung die Mechanismen der axonalen Schädigung zu verstehen, um entsprechende Therapieansätze entwickeln zu können. Das Ausmaß an axonalem Schaden korreliert mit dem Ausmaß an Entzündung (Ferguson et al. 1997). In der vorliegenden Arbeit wurde das Ausmaß der axonalen Schädigung bei ausschließlicher Entmarkung durch Cuprizon und bei Entmarkung mit Entzündung untersucht.

Obwohl die Mikrogliazellen durch die Phagozytose von Myelin und apoptotischen Oligodendrozyten aktiviert und die Axone komplett entmarkt und deshalb vulnerabler gegenüber Schädigung waren, führte die Cuprizon-induzierte Entmarkung nur in vereinzelten Axonen zu einer akuten Transportstörung (4.4). Der in der eigenen Arbeit beobachtete verhältnismäßig geringe Axonschaden bei Cuprizon-induzierter Entmarkung entspricht den Ergebnissen der Literatur (Stidworthy et al. 2003). Im Gegensatz hierzu hatte die Aktivierung von Makrophagen/Mikroglia durch T-Zellen nach der Immunisierung mit MOG $_{35}$

55 und die Freisetzung entzündlicher Mediatioren wie z.B. IFN- $\gamma$ einen massiven Anstieg an APP-positiven Axonen zur Folge. Es scheint somit, dass die Art der Makrophagen/Mikrogliaaktivierung bei der erheblichen axonalen Schädigung eine entscheidende Rolle spielt und dass Komponenten der erworbenen Immunität den Axonschaden zusätzlich verstärken. Der Myelinverlust hingegen ist keine zwingende Voraussetzung für axonalen Schaden, da bei der nicht-entmarkenden MBP-EAE in Lewis-Ratten zahlreiche APPpositive Axone vorhanden waren (Aboul-Enein et al. 2006).

Alternativ zu T-Zellen können auch Serumkomponenten - wie Thrombin und Fibrinogen Makrophagen/Mikroglia aktivieren. Fibrinogen, bindet dabei über den Integrinrezeptor CD11b an Makrophagen/Mikroglia. Fibrinogenablagerungen können sowohl in MS- als 
auch in EAE-Läsionen nachgewiesen werden (Adams et al. 2007). Die Ablagerung von Fibrinogen korrelierte im Mausmodell mit vermehrtem axonalen Schaden (Akassoglou et al. 2000). Im Gegensatz hatte eine Hemmung der Integrin-Fibrinogen-Bindung eine abgeschwächte Makrophagen/Mikrogliaaktivierung mit einer reduzierten Dichte an iNOSpositiven Makrophagen/Mikroglia und einen milderen EAE-Verlauf zur Folge (Adams et al. 2007).

Durch die Immunisierung von Cuprizon-behandelten Mäusen waren sowohl T-Zellen als auch Ablagerungen von Immunglobulinen und Fibrinogen vorhanden. Die Frage, inwieweit durch Serumkomponenten aktivierte Makrophagen/Mikroglia Axone und Neurone schädigen können oder ob der größte Teil des Axonschadens durch eine Aktivierung von Makrophagen/Mikroglia durch autoreaktive T-Zellen vermittelt wird, könnte bei der Cuprizon-induzierten Entmarkung durch eine nicht-entzündliche Öffnung der BHS mit Alkylglycerolen untersucht werden (Erdlenbruch et al. 2003).

Zusammenfassend lässt sich sagen, dass Axonschaden durch Makrophagen/Mikroglia, $\mathrm{T}$ - und B-Zellen, aber ebenso durch sezernierte zytotoxische Entzündungsmediatoren vermittelt wird. Makrophagen/Mikroglia werden dabei häufig als Hauptverursacher angesehen, da sie zahlreiche zellschädigende Produkte wie Zyto- und Chemokine und reaktive Sauerstoffmoleküle, NO, Glutamat und Proteasen freisetzen können. Passend zur wichtigen Rolle der Makrophagen/Mikroglia ist auch die Beobachtung, dass eine Depletion von Makrophagen und Mikrogliazellen die Ausbildung von EAE-Symptomen verhindert (Huitinga et al. 1990).

\subsubsection{Expression von iNOS und S100A9 in monozytären Zellen nach Immunisierung mit MOG $_{35-55}$}

Die Expression von iNOS wird $u$. a. durch die proinflammatorischen Zytokine IFN- $\gamma$ und TNF- $\alpha$ induziert und wird bei MS mit akuter Entzündung und vermehrtem Axonschaden in Verbindung gebracht.

Im Modell der Cuprizon-EAE konnte ein Zusammenhang zwischen der Expression von iNOS und axonalem Schaden bestätigt werden. Ausschließlich die Gehirne von Cuprizonbehandelten und zusätzlich $\mathrm{MOG}_{35-55}$-immunisierten Tieren enthielten iNOS-positive Makrophagen/Mikroglia bei gleichzeitig vermehrter axonaler APP-Akkumulation (4.3.2 + 4.4). Dabei beschränkte sich die Lokalisation APP-positiver Axone nicht auf perivaskuläre Läsionen mit iNOS-positiven Makrophagen/Mikroglia, sondern ließen sich im ganzen Bal- 
ken vermehrt nachweisen. Allerdings traten APP-positive Axone verstärkt in den Läsionen mit S100A9- und iNOS-positiven Zellen auf.

Dieser Zusammenhang zeigte sich ebenfalls im Modell der $\beta$-Synuklein-EAE. Tiere ohne Entmarkung wiesen kaum iNOS-positive Makrophagen/Mikroglia und APP-positive Axone auf. Im Gegensatz hierzu waren in den entmarkten Läsionen nach anti-MOGAntikörpertransfer zahlreiche iNOS-exprimierende Makrophagen/Mikroglia und transportgestörte Axone vorhanden (3.3 und 3.4.1).

Die gewebsschädigende Wirkung von NO wurde bei weiteren Erkrankungen des zentralen Nervensystems beschrieben, wie z. B. der Alzheimerschen Erkrankung (Vodovotz et al. 1996); der Parkinson-Erkrankung (Knott et al. 2000), der amyotrophen Lateralsklerose (Sasaki et al. 2000), dem Hirninfarkt (Forster et al. 1999), der HIV-assoziierten Demenz (Adamson et al. 1996) und der MS (Bagasra et al. 1995). In einem Ratten-Modell konnte gezeigt werden, dass NO die Signalleitung entlang der peripheren Axone blockiert und entmarkte Nervenbahnen vulnerabler gegenüber NO sind (Redford et al. 1997). Bei der MBP-induzierten EAE korreliert der axonale Schaden weitgehend mit der Menge an gebildetem iNOS (Aboul-Enein et al. 2006). Des Weiteren konnte das Ausmaß an axonalem Schaden bei der Theiler-Virus Infektion durch pharmakologische Hemmung von iNOS mit Aminoguanidin reduziert werden (Rose et al. 1998). Zusätzlich wurden die Krankheitssymptome und die Entzündung bei EAE durch Aminoguanidin-Gabe vermindert (Cross et al. 1994; Brenner et al. 1997).

Der gezeigte Zusammenhang zwischen der iNOS-Expression und dem Ausmaß der axonalen Schädigung soll in geplanten, weiterführenden Experimenten untersucht werden. IFN- $\gamma$, das hauptsächlich von T-Zellen sezerniert wird, ist ein wesentlicher Induktor der iNOS-Expression (Jana et al. 2001). Ein Zusammenhang zwischen der IFN- $\gamma-$, CD4- und iNOS-Expression konnte in der eigenen Arbeit mittels quantitativer PCR gezeigt werden (4.5.2). In geplanten, weiterführenden Experimenten soll der Anteil des tatsächlich iNOSmediierte Axonschadens im Modell der Cuprizon-EAE indirekt durch die Verwendung von IFN- $\gamma$ R1/2-defizienten Mäusen untersucht werden. Wird der IFN- $\gamma$-Signalweg durch das Fehlen der Rezeptoren unterbrochen, so sollte die Menge an gebildetem iNOS und damit verbunden der axonale Schaden geringer sein. Allerdings sind neben NO auch Proteineasen, Zytokine, reaktive Sauerstoffmoleküle und womöglich aktivierte T-Zellen und Makrophagen/Mikroglia selbst an der Destruktion der Axone beteiligt.

Abschließend gilt anzumerken, dass sich eine pharmakologische Hemmung von iNOS nicht als alleinige MS-Therapie eignet, da NO zusätzlich entzündungshemmend wirkt. 
iNOS-defiziente Mäuse wiesen bei EAE-Versuchen im Vergleich zu WT-Mäusen einen schwereren Krankheitsverlauf, mit weniger apoptotischen T-Zellen und folglich erhöhten Mengen an IFN- $\gamma$ und TNF- $\alpha$ auf (Kahl et al. 2004; Dalton und Wittmer 2005). Es konnte gezeigt werden, dass NO die Proliferation von T-Zellen hemmt (Albina et al. 1991; Krenger et al. 1996). Eine Hemmung der iNOS-Expression bei Infektionsversuchen mit Viren (Karupiah et al. 1993; Wei et al. 1995), Bakterien (Stenger et al. 1994) und Protozoen (Nussler et al. 1993) verursachte ebenfalls einen schwereren Krankheitsverlauf bei Mäusen.

Als weiteres von Makrophagen produziertes proinflammatorisches Protein wurde in der vorliegenden Arbeit die Expression von S100A9 näher untersucht. Eine Expression konnte ausschließlich in den Gehirnen von Cuprizon-behandelten und zusätzlich MOG $_{35-55^{-}}$ immunisierten Tieren nachgewiesen werden. Sowohl die Cuprizon-induzierte Entmarkung, als auch die zusätzliche Immunisierung mit Ovalbumin führten zu keiner Expression von S100A9 in Monozyten (4.3.2).

S100A9 wird bei zahlreichen entzündlichen Erkrankungen vermehrt exprimiert. Es wird davon ausgegangen, dass S100A9 nur von akut aus dem Blut eingewanderten Makrophagen gebildet wird (Bruck et al. 1995; Foell et al. 2004). Die fehlende Expression bei Cuprizon-behandelten Mäusen könnte dies bestätigen, da diese bei geschlossener BHS verläuft (Bakker und Ludwin 1987; Kondo et al. 1987). Als weiterer Grund können fehlende proinflammatorische Signale angeführt werden, da die Expression von S100A9 durch proinflammatorische Zytokine wie TNF- $\alpha$ und IL-1 induziert werden kann (Yen et al. 1997).

In der vorliegenden Arbeit konnte gezeigt werden, dass S100A9-positive Zellen nur in Tieren mit T-Zellinfiltration vorhanden sind. Ob tatsächlich nur akut aus dem Blut eingewanderte Makrophagen S100A9 exprimieren soll in geplanten, weiterführenden Versuchen durch die Verwendung von kongenen Knochenmarkschimären (CD45.1 versus CD45.2) ermittelt werden. Die Expression der beiden Genvarianten ermöglicht eine Unterscheidung zwischen Blutzellen aus der Peripherie und den ortsständigen Mikrogliazellen.

\subsubsection{Proinflammatorische Zytokine hemmen die Expression von HO-1 und CD163}

HO-1 und CD163 sind zwei antiinflammatorische Proteine, deren Expression eng zusammen hängt (Willis et al. 1996). Frei vorliegendes Hämoglobin wird von Haptoglobin gebunden und dieser Komplex bindet an den Hämoglobin-Scavenger Rezeptor CD163 
(Kristiansen et al. 2001). Diese Bindung hat neben der Endozytose von HämoglobinHaptoglobin ( $\mathrm{Hb}-\mathrm{Hp})$ und der vermehrten HO-1-Expression auch die Freisetzung von $\mathrm{Zy}$ tokinen zur Folge. Eines der dadurch vermehrt exprimierten Zytokine ist IL-10, welches wiederum die Expression von HO-1 fördert (Philippidis et al. 2004).

In der vorliegenden Arbeit wurde CD163 bei der $\beta$-Synuklein ${ }_{93-111}$-induzierten EAE in Lewis-Ratten vermehrt exprimiert. Dabei enthielten die Rückenmarksquerschnitte von Tieren ohne entmarkte Läsionen tendenziell mehr CD163-positive Makrophagen als Ratten mit Entmarkung (3.4.2). Höhere Zahlen an HO-1-positiven Zellen konnten ebenfalls in Tieren mit ausschließlicher Entzündung im Vergleich zu Ratten mit Entmarkungsherden nachgewiesen werden (3.4.3).

Die Cuprizon-induzierte Entmarkung führte nicht zur HO-1-Expression in Makrophagen/Mikroglia. Hingegen wiesen zusätzlich $\mathrm{MOG}_{35-55}$-immunisierte Mäuse einige wenige HO-1-positive Zellen auf (4.3.2). Die niedrigen Zellzahlen können möglicherweise dadurch erklärt werden, dass die Entzündung einerseits die HO-1 Expression induziert und andererseits IFN- $\gamma$ die HO-1 Expression hemmt (Hegazi et al. 2005). Insgesamt war auffallend, dass im Gewebe von $\beta$-Synuklein / 8-18C5-Ratten und Cuprizon / MOG-Mäusen eine vergleichbare Dichte an HO-1-positiven Zellen vorlag. Dies spricht für ähnliche pathologische Vorgänge in beiden Modellen.

Die Expression von CD163 wird unter anderem durch die Zytokine IL-10 und IL-6 induziert (Van Den Heuvel et al. 1999; Buechler et al. 2000). Allerdings scheinen Glukokortikoide, welche als Reaktion auf entzündliche Bedingungen wie LPS-Stimulation oder EAE gebildet werden (Huitinga et al. 2000), der Hauptinduktor zu sein (Hogger et al. 1998; Van Den Heuvel et al. 1999). Inflammatorische Zytokine und entzündliche Bedingungen hingegen fördern die Abspaltung von CD163 von der Oberfläche. Dies führt zu einem Anstieg an löslichem CD163 (sCD163), welches anschließend im Plasma nachweisbar ist (Fabriek et al. 2007).

Die vorliegenden Ergebnisse weisen darauf hin, dass die antikörperinduzierte Entmarkung im $\beta$-Synuklein-Modell u.a. durch die erhöhte iNOS-Expression ein stark proinflammatorisches Milieu schafft, durch welches eine vermehrte CD163-Abspaltung von der Zelloberfläche erfolgte. Deshalb konnten vermutlich in diesen Ratten weniger CD163-positive Makrophagen nachgewiesen werden als in Ratten mit ausschließlicher Entzündung. Eine erhöhte SCD163-Konzentration lässt sich bei diversen akut-entzündlichen sowie chronischen Erkrankungen (Matsushita et al. 2002; Moller et al. 2004; Roberts et al. 2004), unter anderem auch bei MS, nachweisen. MS-Patienten haben hierzu passend weniger 
CD163-positive Zellen im Gewebe (Fabriek et al. 2007). Bei der humanen Erkrankung exprimieren nicht nur perivaskuläre Makrophagen CD163, sondern auch schaumzellige Makrophagen/Mikroglia in akuten MS-Läsionen (Fabriek et al. 2005b). Im Modell der $\beta$-Synuklein-EAE konnten in der vorliegenden Arbeit ebenfalls CD163-positive Zellen im Parenchym nachgewiesen werden.

Als mögliche Funktion von sCD163 wird die Hemmung der T-Zellproliferation diskutiert, was anhand der Phorbolester induzierten Proliferation von T-Zellen belegt werden konnte (Hogger und Sorg 2001; Frings et al. 2002). Auf diese Weise trägt SCD163 zu einer Verminderung der Entzündungsantwort bei (Hintz et al. 2002). In den eigenen Versuchen wiesen die Rückenmarksquerschnitte von Tieren mit Entmarkung weniger T-Zellen auf (3.2.1.1). Dies könnte durch die proliferationshemmende Wirkung von sCD163 erklärt werden.

Eine antiinflammatorische Wirkung von HO-1 wurde bei Sepsis, bei der LPS-Stimulation von Milzzellen und bei EAE-Versuchen beschrieben (Kapturczak et al. 2004; Chora et al. 2007). Im Gegenzug führt die HO-1-Depletion zu einer Verschiebung des $T_{H} 1-T_{H} 2-$ Zytokingleichgewichts, wobei vermehrt $\mathrm{T}_{\mathrm{H}^{-1}}$ Zytokine gebildete wurden (Kapturczak et al. 2004).

Die postulierte antiinflammatorische Wirkung des membrangebundenen CD163 beruht zum Teil auf der proteolytischen Spaltung von Häm in den Zellen durch HO-1. Dabei werden Bilirubin, Biliverdin und vor allem $\mathrm{CO}$ freigesetzt. Biliverdin und Bilirubin sind beides antioxidativ wirkende Moleküle, welche durch Bindung von reaktiven Sauerstoffmolekülen und NO-Produkten das Gewebe vor Schädigung schützen. Des Weiteren wird ein direkter immunregulatorischer Effekt von Biliverdin beschrieben, das die NF-кB Aktivierung hemmt und folglich die Expression von iNOS, IL-6 und IFN- $\gamma$ unterdrückt (Gibbs und Maines 2007; Kim et al. 2008). CO hemmt die Expression von proinflammatorischen Zytokinen in LPS stimulierten Makrophagen (Otterbein et al. 2000; Hegazi et al. 2005). Allerdings ist bislang nicht verstanden, welchen Anteil die einzelnen Komponenten an der antiinflammatorischen Wirkung von CD163 haben.

Die HO-1-Expression kann deshalb als anti-entzündliche Gegenregulation verstanden werden (Chora et al. 2007), welche in Abwesenheit von Entmarkung (Synuklein/lgG1) stärker ausgeprägt war. Sie schützt das Gewebe, indem die Expression von iNOS, TNF- $\alpha$ und der Matrixmetalloproteinase-9 (MMP-9) gehemmt wird und antiinflammatorische $\mathrm{T}_{\mathrm{H}}$ 2-Zytokine gebildet werden (Lee und Chau 2002; Xia et al. 2007). MMP-9 wird mit der Schädigung von Axonen in Verbindung gebracht (Newman et al. 2001). Die schützende 
Wirkung von HO-1 konnte in den eigenen Versuchen belegt werden, da Ratten ohne Entmarkung kaum iNOS bildeten und nur sehr wenige APP-positive Axone aufwiesen.

Die Wirkung von HO-1 scheint - wie schon zuvor der Effekt von iNOS - von der exprimierten Menge abzuhängen, da eine übermäßige Bildung zu Eisenablagerungen in Zellen führt und zur Bildung von freien Radikalen in den Mitochondrien auf Grund hoher Mengen an CO (Zhang und Piantadosi 1992). Des Weiteren wirken hohe Mengen an Bilirubin ebenfalls toxisch und induzieren die Expression von proinflammatorischen Zytokinen (Mehindate et al. 2001).

Zusammenfassend kann eine Klassifizierung der Makrophagen/Mikroglia in "gute“ und „böse" aufgrund der Expression von iNOS, HO-1 und CD163 nicht vorgenommen werden, da je nach exprimierten Proteinmengen zellschädigende oder protektive Eigenschaften überwiegen.

\subsubsection{Entzündung hat keinen Einfluss auf Geschwindigkeit und Ausmaß der Remyelinisierung}

In akut entzündlichen MS-Läsionen werden die Oligodendrozytenrekrutierung und Oligodendrozytenaktivierung sowie eine erhöhte Synthese von Myelinproteinen oft mit dem Vorhandensein von T- und B-Zellen und Makrophagen in Verbindung gebracht. Ein Hinweis auf die Bedeutung der Entzündung für die Remyelinisierung ist das weitgehende Fehlen einer Neubildung der Markscheiden in chronischen MS-Läsionen, welche nur noch wenige Entzündungszellen aufweisen. Eine verzögerte Remyelinisierung konnte nach Toxin-induziertem Myelinverlust in TNF- $\alpha$-, IL-1 $\beta$-, MHC II- und T- und B-Zell-defizienten Mäusen nachgewiesen werden (Arnett et al. 2001; Mason et al. 2001; Arnett et al. 2003; Bieber et al. 2003). Die Depletion von Makrophagen oder Mikrogliazellen hemmte ebenfalls die Neubildung der Markscheiden im Tiermodell (Kotter et al. 2005; Li et al. 2005). Der Einfluss von Entzündung auf die Remyelinisierung wurde in der vorliegenden Arbeit histologisch und durch die Expressionsanalyse von oligodendrozytenspezifischen Genen untersucht.

Die exprimierte mRNA-Menge der untersuchten Transkriptionsfaktoren Olig1, Olig2 und Sox2 sowie von PDGF-R $\alpha$ und MBP unterschied sich zu den gemessenen Zeitpunkten (4,5 Wochen Cuprizon, zwei und fünf Tage Remyelinisierung) nicht wesentlich von nichtbehandelten Kontrollmäusen. Ein Unterschied zwischen Tieren mit ausschließlicher Entmarkung und Entmarkung mit Entzündung war ebenfalls nicht vorhanden. Die PLP mRNA-Menge war nach 4,5 Wochen Cuprizon-Diät stark reduziert, und nur zu die- 
sem Zeitpunkt war das Expressionsniveau in Tieren mit Entmarkung und zusätzlicher Entzündung deutlich höher (Faktor 8) (4.5.2). Der Anteil der bemarkten Fläche und die Dichte der NogoA-positiven Oligodendrozyten, der NogoA/Olig2-doppeltpositiven und Olig2-positiven Oligodendrozytenvorläuferzellen war zwischen den beiden Gruppen nicht unterschiedlich (4.5.1). Im Modell der Cuprizon-EAE konnte somit eine effizientere Remyelinisierung durch Entzündung nicht nachgewiesen werden.

Im normalen adulten ZNS bilden Oligodendrozytenvorläuferzellen (OPCs) eine stabile Zellpopulation, welche sich nur sehr selten teilt. Nach Entmarkung werden diese OPCs aktiviert, wobei eine erhöhte Transkription von Olig1, Olig2, Nkx2.2, Sox2 und PDGF-R $\alpha$ erfolgt. Die Expression dieser Gene wird mit der entwicklungsbedingten Myelinisierung in Verbindung gebracht. Die Expression dieser Gene wurde im Detail bislang nur nach Ethidiumbromid-induzierter Entmarkung untersucht und eine vermehrte Expression beschrieben (Fancy et al. 2004). Möglicherweise konnte beim Cuprizon-induzierten Myelinverlust aufgrund der gleichzeitig stattfindenden De- und Remyelinisierungsvorgänge keine wesentliche veränderte Expression nachgewiesen werden. Aus diesem Grund soll EAE in Kombination mit der Ethidiumbromid-induzierten Entmarkung in geplanten Versuchen etabliert werden. Bei diesem Modell wird die entmarkende Läsion durch eine einmalige Injektion von Ethidiumbromid ausgelöst. Bereits fünf Tage nach Entmarkungsinduktion wird die maximale Expression von Olig1, Olig2 und PDGF-R $\alpha$ und Nkx2.2 gemessen.

Die Studien in allen oben erwähnten Modellen (Cuprizon-, Lysolezithin- und Ethidiumbromid-induzierter Entmarkung), in denen eine verbesserte Remyelinisierung durch Entzündung beschrieben wurde, beruhen auf dem Vergleich von immundefizienten, makrophagen- oder mikrogliadepletierten im Vergleich zu WT-Mäusen. Möglicherweise beruht die verzögerte Neubildung der Markscheiden in diesen immundefizienten Tieren hauptsächlich auf einer reduzierten Aktivierung der Mikrogliazellen und damit verbundenen geringeren Myelinphagozytose. Die Phagozytose von Myelinbruchstücken ist eine wichtige Voraussetzung für die Neubemarkung der Axone, da Myelinreste diesen Vorgang hemmen (Kotter et al. 2006). Unterstützt wird diese Annahme durch die beobachtete verzögerte Remyelinisierung in alten Ratten nach Beenden der Cuprizone-Gabe, was die Autoren dieser Studie auf eine geringere Aktivierung der Mikrogliazellen zurückführten (Zhao et al. 2006).

Ein weiterer Unterschied der oben genannten Modelle zur Cuprizon-EAE ist das weitgehende Fehlen einer adaptiven Immunantwort mit deutlicher T-Zellinfiltration. In der Literatur wird beschrieben, dass IFN- $\gamma$, das hauptsächlich von aktivierten T-Zellen gebildet wird, die Remyelinisierung nach Beenden der Cuprizon-Diät verzögert. Dies wird zum einen 
durch die erhöhte Vulnerabilität von myelinisierenden Oligodendrozyten gegenüber IFN- $\gamma$ und zum anderen durch die IFN- $\gamma$ induzierte Expression von Zyto- und Chemokinen erklärt (Lin et al. 2006). Im Modell der Cuprizon-EAE konnte ebenfalls eine deutlich erhöhte IFN- $\gamma$ Expression nachgewiesen werden (4.5.2). Eine weitere mögliche Erklärung für die vergleichbare Remyelinisierungseffizienz in beiden Versuchsgruppen in der vorliegenden Studie könnte sein, dass Entzündung zwar die Proliferation von Oligodendrozytenvorläuferzellen fördert - in den eigenen Experimenten waren in den beiden Versuchsgruppen eine vergleichbare Dichte an Oligodendrozyten und Oligodendrozytenvorläuferzellen vorhanden - aber IFN- $\gamma$ gleichzeitig die Apoptose in myelinisierenden Oligodendrozyten induziert und somit die Neubildung des Myelins verhindert. Zusätzlich könnten nach dem Beenden der Cuprizon-Gabe in $\mathrm{MOG}_{35-55}$-immunisierten Tieren aufgrund der fortwährenden Entzündung neue Myelinbruchstücke entstehen, welche die Differenzierung der Oligodendrozytenvorläuferzellen in myelinbildende Oligodendrozyten verhindern (Kotter et al. 2006).

Die Remyelinisierungseffizienz war somit während einer akuten adaptiven Entzündungsantwort in der vorliegenden Studie nicht verbessert. Die vorliegenden Ergebnisse sind neue wichtige Erkenntnisse, da die Cuprizon-EAE - aufgrund der beteiligten adaptiven Immunantwort - deutlich besser der humanen Erkrankung MS entspricht, bei welcher entmarkte Läsion nur teilweise remyelinisieren (Chang et al. 2002).

\subsubsection{Entzündung und Entmarkung verändern die Anisotropie bei der Diffusions- Tensor-Bildgebung}

Mit herkömmlichen magnetresonanztomographischen Messmethoden (T1 und T2 gewichtetes Signal) kann die den Signalveränderungen zugrunde liegende Gewebspathologie z.B. Demyelinisierung, Remyelinisierung, Entzündung und axonale Schädigung nicht immer zuverlässig bestimmt werden. In den letzten Jahren wurde die Diffusions-TensorBildgebung (DTI) als neuartige Methode entwickelt, um die Gewebsstruktur und den Verlauf von Nervenfasern in vivo zu untersuchen (Filippi 2002). Mit Hilfe dieser Technik wird versucht, bei MS zwischen Entmarkung und axonalem Schaden zu unterscheiden.

In der eigenen Arbeit wiesen Cuprizon-behandelte Tiere nur wenige geschädigte, APPpositive Axone und eine leicht reduzierte axiale Diffusivität (AD) auf. Im Gegensatz hierzu hatten zusätzlich immunisierte Tiere zahlreiche transportgeschädigte Axone und eine signifikant niedrigere AD. Die Hypothese, dass der Wert der AD das Ausmaß an axonaler Schädigung wiedergibt, scheint sich somit zu bestätigen. So spiegelt möglicherweise die 
leichtgradige Reduktion der AD bei der Cuprizon-bedingten Entmarkung, den geringfügigen histologisch nachweisbaren axonalen Schaden in Form vereinzelter APP-positiver Axone wider.

In der Veröffentlichung von Song et. al. 2006 wurde nach einer vergleichbaren Dauer der Cuprizon-Diät von vier Wochen ebenfalls eine geringere $A D$ und vereinzelte geschädigte Axone nachgewiesen. Ein Zusammenhang zwischen der AD und dem axonalen Schaden wurde auch bei der Wallerschen Degeneration von peripheren und zentralnervösen Nervenfasern gezeigt (Beaulieu et al. 1996; Thomalla et al. 2004). Des Weiteren wiesen Patienten nach traumatischen Läsionen eine verminderte AD auf, was mit einer diffusen axonalen Schädigung in Verbindung zu stehen scheint (Arfanakis et al. 2002). Der Zusammenbruch axonaler Strukturen und die daraus resultierenden Zelltrümmer sowie die Aggregation von Filamenten und Organellen sind mögliche Gründe für eine eingeschränkte Diffusion der Wassermoleküle entlang der Axone (Beaulieu et al. 1996; Arfanakis et al. 2002; Sun et al. 2006). Ebenso könnten Wasseransammlungen in geschädigten Axonen zu einer Auftreibung führen und auf diese Weise die AD reduzieren. Des Weiteren kann ein verlangsamter axonaler Transport ebenso als Ursache angeführt werden. Über einen möglichen Einfluss dieser Mechanismen auf die radiale Diffusivität (RD) kann nur spekuliert werden (Sun et al. 2006).

In der eigenen Arbeit wurde bei Tieren mit ausschließlichem Myelinverlust nach 4,5 Wochen Cuprizon-Diät eine signifikant erhöhte RD gemessen.

Dieses Ergebnis ist im Gegensatz zu den von Song publizierten Ergebnissen, bei welchen nach vier Wochen Cuprizon nur eine minimal erhöhte RD vorhanden war. Eine signifikant erhöhte RD und ein deutlicher Myelinverlust wurden erst nach sechs Wochen Versuchsdauer gemessen (Sun et al. 2006). Diese Diskrepanz kann am ehesten durch das unterschiedliche Ausmaß an Myelinverlust erklärt werden. Die Tiere in den eigenen Versuchen wiesen nach 4,5 Wochen Cuprizon-Diät einen stärkeren Myelinverlust auf. Im Gegensatz hierzu wird in einer weiteren Publikation - in Übereinstimmung mit den eigenen Ergebnissen - nach vier Wochen Cuprizon-Diät ein deutlicher Myelinverlust mit leicht geringerer $A D$ und erhöhter RD beschrieben (Wu et al. 2008). Des Weiteren haben magnetresonanztomographische Messungen an so genannten „Shiverer“-Mäusen, bei welchen es durch eine homozygote, autosomal-rezessive Mutation des MBP-Gens zu einer nicht vollständigen Ausbildung des Myelins kommt (Privat et al. 1979; Inoue et al. 1981; Shine et al. 1992), gezeigt, dass der Myelinverlust in Kombination mit geringem axonalen Schaden die RD erhöhen (Nair et al. 2005). 
Es scheint, dass eine erhöhte RD erst nach einem gewissen Myelinverlust gemessen werden kann, da lokal proliferierende Mikrogliazellen die Diffusion quer zu den Axonen behindern können. Einen Einfluss der Zellmembranen auf die Wasserdiffusion wurde nach traumatischen Läsionen angenommen. Die Autoren dieser Studie gehen davon aus, dass vor allem der Membranverlust durch sterbende Neurone die RD erhöhte (Arfanakis et al. 2002). Der Einfluss von Zellen auf die RD wurde ebenfalls in der eigenen Arbeit anhand Cuprizon-behandelter und zusätzlich $\mathrm{MOG}_{35-55}$-immunisierter Tiere gezeigt. Die RD von Tieren mit dichten zellulären, entzündlichen Infiltraten unterschied sich nicht von nicht-behandelten Kontrolltieren. Aufgrund des histologisch vergleichbaren Myelinverlusts zwischen Cuprizon-behandelten und Cuprizon/MOG-immunisierten Mäusen ist davon auszugehen, dass der Wert der RD bei beiden Gruppen in gleichem Maße erhöht sein müsste. Es scheint, dass dichte, zelluläre Infiltrate die Diffusion der Wassermoleküle quer zu den Axonen in einem ähnlichen Maße beeinflussten wie Myelin.

Die in der Literatur postulierte Unterscheidung zwischen Axonschaden und Myelinverlust mit Hilfe der DTI war im Modell der Cuprizon-EAE nicht möglich. Dies ist womöglich auf die fehlende Entzündung bei der Cuprizon-induzierten Entmarkung zurückzuführen. Bei der reinen Cuprizon-induzierten Entmarkung zeigten der Vergleich der LFB/PASFärbungen und DTI-Messungen eine enge Korrelation zwischen dem Myelinverlust und dem Anstieg der RD im Verlauf der Zeit. Des Weiteren war die AD nahezu unverändert und es waren kaum geschädigte Axone vorhanden (Song et al. 2005). Dieser Zusammenhang

zwischen

Axonschaden / AD und Myelinverlust / RD wurde darüber hinaus bei der Retinaischämie in der Ratte gezeigt. In diesem Modell wurde der anfängliche geringe Axonschaden durch eine geringere $A D$ und unveränderte RD wiedergegeben. Zu einem späteren Zeitpunkt kam es zur Entmarkung und einer erhöhten RD (Song et al. 2003).

Aus den eigenen Ergebnissen kann geschlossen werden, dass entzündliche Infiltrate die Diffusion entlang der Axone erheblich beeinflussen. Obwohl das Ausmaß der Entmarkung in beiden Versuchsgruppen vergleichbar war (Daten nicht gezeigt), war lediglich in der Gruppe der Cuprizon-behandelten Mäuse die radiale Diffusivität erhöht. Es scheint also, dass dieser Messwert nicht nur von den Markscheiden, sondern auch durch dichte, zelluläre Infiltrate und Gliose beeinflusst wird.

Pathologische ZNS-Veränderungen wie z. B. Trauma- und MS-Läsionen werden bei Menschen anhand des scheinbaren Diffusionskoeffizienten (ADC) untersucht, welcher die mittlere Diffusivität aus den drei bei der Messung erhaltenen Eigenwerten wiedergibt. 
Der ADC war bei Mäusen mit Toxin-induzierter Entmarkung - aufgrund der erhöhten RD und kaum verminderten $A D$ - leicht erhöht. Tiere mit zusätzlicher Entzündung hatten einen leicht reduzierten ADC - aufgrund der unveränderten RD und reduzierten AD - im Vergleich zu Kontrolltieren.

Ein veränderter ADC wurde bei der MS (Castriota et al. 2000; Filippi et al. 2001), dem Hirninfarkt (Werring et al. 2000; Ito et al. 2001), der Adrenoleukodystrophie (Jones et al. 1999) und im Alter (Nusbaum et al. 2001) gezeigt. MS-Patienten mit schubförmigem Krankheitsverlauf wiesen dabei einen leicht erhöhten ADC auf, während dieser bei Patienten mit sekundär progredienter MS signifikant erhöht war (Castriota et al. 2000; Filippi et al. 2001). Die längere Krankheitsdauer der MS und die damit verbundene stärkere Gewebsschädigung könnte die Unterschiede im Vergleich zu den untersuchten Mäusen erklären.

Die fraktionale Anisotropie (FA), ein weiterer bei der DTI erhaltener Parameter, gibt das Ausmaß der Richtungsabhängigkeit wieder. Je weniger die Diffusion der Wassermoleküle von der Richtung abhängt, desto weiter geht dieser Wert gegen Null. Bei den eigenen Untersuchungen hatten Entmarkung und Entmarkung mit Entzündung eine vergleichbare Reduktion der FA im Vergleich zu nicht-behandelten Kontrollen zur Folge.

Bei MS-Patienten wiesen Läsionen mit dichter Infiltration den niedrigsten FA-Wert auf (Filippi et al. 2001), was durch den Gewebsschaden und die Ausbildung eines Ödems erklärt wird. Aus diesen Ergebnissen lässt sich schließen, dass schon die alleinige Gabe von Cuprizon das Gewebe strukturell so verändert, dass die in gesunden, myelinisierten Nervenfasern nachweisbare gerichtete Bewegung der Wassermoleküle hier deutlich reduziert ist. Eine zusätzliche Infiltration von Entzündungszellen führte jedoch zu keiner weiteren Reduktion der Richtungsabhängigkeit der Diffusion.

In weiteren, geplanten Versuchen sollen T1- und T2-gewichtete Messungen durchgeführt werden. Mit Hilfe der Diskriminanzanalyse wird eine Unterscheidung zwischen reiner Entmarkung und Entmarkung mit Entzündung angestrebt. Des Weiteren soll bei diesen geplanten Experimenten die Magnetisierungstransferrate von Tieren nach Cuprizoninduzierter Entmarkung und Tieren mit zusätzlicher Entzündung verglichen werden.

\subsubsection{Zusammenfassung}

Durch die Kombination der Toxin-induzierten Entmarkung mittels Cuprizon und der Immunisierung mit $\mathrm{MOG}_{35-55}$ konnten im Mausgehirn reproduzierbare Entmarkungsherde induziert werden, welche eine große Ähnlichkeit zu MS-Läsionen aufweisen. Die Infiltration 
von Entzündungszellen erfolgte über eine geöffnete BHS, welche histologisch durch Immunglobulin- und Fibrinogenablagerungen und magnetresonanztomographisch durch Gd-DTPA-Anreicherung nachgewiesen wurde. Des Weiteren wurde gezeigt, dass Makrophagen/Mikroglia nur nach entzündlicher Entmarkung die proinflammatorischen Proteine iNOS und S100A9 exprimieren und dass diese vermehrten Axonschaden verursachen. Die vermehrte axonale Schädigung wurde neben der Histologie auch mittels DTI durch eine reduzierte axonale Diffusivität in Cuprizon-behandelten und zusätzlich MOG $_{35-55}$ immunisierten Mäusen ebenfalls nachgewiesen. Die radiale Diffusivität in Mäusen mit Entmarkungsherden unterschied sich hingegen nicht von nicht-behandelten Kontrollen, vermutlich da dichte Infiltrate die Diffusion der Wassermoleküle in einem vergleichbaren Maße beeinflussen wie Myelin. Obwohl postuliert wurde, dass die Entzündung die Neubildung der Markscheiden fördert, konnte dies im Modell der Cuprizon-EAE nicht nachgewiesen werden. In den untersuchten Gruppen war kein Unterschied zwischen dem Anteil der bemarkten Fläche, der Anzahl der Oligodendrozyten und der Expression von oligodendrogliaspezifischen Genen vorhanden. 


\section{Literaturverzeichnis}

1. Abbas AK. Die and let live: eliminating dangerous lymphocytes. Cell 1996; 84: 655-657.

2. Aboul-Enein $F$, Weiser $P$, Hoftberger $R$, Lassmann $H$, Bradl M. Transient axonal injury in the absence of demyelination: a correlate of clinical disease in acute experimental autoimmune encephalomyelitis. Acta Neuropathol. 2006; 111: 539-547.

3. Abraham NG, Drummond G. CD163-Mediated hemoglobin-heme uptake activates macrophage HO-1, providing an antiinflammatory function. Circ.Res. 2006; 99: 911-914.

4. Adams RA, Bauer J, Flick MJ et al. The fibrin-derived gamma377-395 peptide inhibits microglia activation and suppresses relapsing paralysis in central nervous system autoimmune disease. J.Exp.Med. 2007; 204: 571-582.

5. Adamson DC, Wildemann B, Sasaki M et al. Immunologic NO synthase: elevation in severe AIDS dementia and induction by HIV-1 gp41. Science 1996; 274: 1917-1921.

6. Adelmann M, Wood J, Benzel I et al. The N-terminal domain of the myelin oligodendrocyte glycoprotein (MOG) induces acute demyelinating experimental autoimmune encephalomyelitis in the Lewis rat. J.Neuroimmunol. 1995; 63: 17-27.

7. Akassoglou K, Kombrinck KW, Degen JL, Strickland S. Tissue plasminogen activatormediated fibrinolysis protects against axonal degeneration and demyelination after sciatic nerve injury. J.Cell Biol. 2000; 149: 1157-1166.

8. Albina JE, Abate JA, Henry WL, Jr. Nitric oxide production is required for murine resident peritoneal macrophages to suppress mitogen-stimulated $T$ cell proliferation. Role of IFN-gamma in the induction of the nitric oxide-synthesizing pathway. J.Immunol. 1991; 147: 144-148.

9. Albina JE, Henry WL, Jr. Suppression of lymphocyte proliferation through the nitric oxide synthesizing pathway. J.Surg.Res. 1991; 50: 403-409.

10. Archambault AS, Sim J, McCandless EE, Klein RS, Russell JH. Region-specific regulation of inflammation and pathogenesis in experimental autoimmune encephalomyelitis 
1. J.Neuroimmunol. 2006; 181: 122-132.

11. Arfanakis K, Haughton VM, Carew JD, Rogers BP, Dempsey RJ, Meyerand ME. Diffusion tensor MR imaging in diffuse axonal injury. AJNR Am.J.Neuroradiol. 2002; 23: 794802.

12. Arnett HA, Mason J, Marino M, Suzuki K, Matsushima GK, Ting JP. TNF alpha promotes proliferation of oligodendrocyte progenitors and remyelination. Nat.Neurosci. 2001; 4: $1116-1122$.

13. Arnett HA, Wang Y, Matsushima GK, Suzuki K, Ting JP. Functional genomic analysis of remyelination reveals importance of inflammation in oligodendrocyte regeneration. J.Neurosci. 2003; 23: 9824-9832.

14. Babbe H, Roers A, Waisman A et al. Clonal expansions of CD8(+) T cells dominate the $T$ cell infiltrate in active multiple sclerosis lesions as shown by micromanipulation and single cell polymerase chain reaction. J.Exp.Med. 2000; 192: 393-404.

15. Bagasra O, Michaels $\mathrm{FH}$, Zheng YM et al. Activation of the inducible form of nitric oxide synthase in the brains of patients with multiple sclerosis. Proc.Natl.Acad.Sci.U.S.A 1995; 92: 12041-12045.

16. Bakker DA, Ludwin SK. Blood-brain barrier permeability during Cuprizone-induced demyelination. Implications for the pathogenesis of immune-mediated demyelinating diseases. J.Neurol.Sci. 1987; 78: 125-137.

17. Bala S, Failla ML. Copper deficiency reversibly impairs DNA synthesis in activated T lymphocytes by limiting interleukin 2 activity. Proc.Natl.Acad.Sci.U.S.A 1992; 89: 67946797.

18. Bannerman PG, Hahn A, Ramirez S et al. Motor neuron pathology in experimental autoimmune encephalomyelitis: studies in THY1-YFP transgenic mice. Brain 2005; 128 : 1877-1886.

19. Baranano DE, Snyder SH. Neural roles for heme oxygenase: contrasts to nitric oxide synthase. Proc.Natl.Acad.Sci.U.S.A 2001; 98: 10996-11002. 
20. Barkhof F. The clinico-radiological paradox in multiple sclerosis revisited. Curr.Opin.Neurol. 2002; 15: 239-245.

21. Barron KD. The microglial cell. A historical review. J.Neurol.Sci. 1995; 134 Suppl: 5768.

22. Bauer J, Bradl M, Hickley WF et al. T-cell apoptosis in inflammatory brain lesions: destruction of T cells does not depend on antigen recognition. Am.J.Pathol. 1998; 153: 715724.

23. Bauer J, Rauschka $H$, Lassmann $H$. Inflammation in the nervous system: the human perspective. Glia 2001; 36: 235-243.

24. Baxter AG. The origin and application of experimental autoimmune encephalomyelitis. Nat.Rev.Immunol. 2007; 7: 904-912.

25. Beaulieu C, Does MD, Snyder RE, Allen PS. Changes in water diffusion due to Wallerian degeneration in peripheral nerve. Magn Reson.Med. 1996; 36: 627-631.

26. Ben Nun A, Wekerle $H$, Cohen IR. The rapid isolation of clonable antigen-specific $T$ lymphocyte lines capable of mediating autoimmune encephalomyelitis. Eur.J.Immunol. 1981; 11: 195-199.

27. Benowitz LI, Perrone-Bizzozero NI, Finklestein SP. Molecular properties of the growthassociated protein GAP-43 (B-50). J.Neurochem. 1987; 48: 1640-1647.

28. Benowitz LI, Routtenberg A. GAP-43: an intrinsic determinant of neuronal development and plasticity. Trends Neurosci. 1997; 20: 84-91.

29. Berger T, Weerth S, Kojima K, Linington C, Wekerle H, Lassmann H. Experimental autoimmune encephalomyelitis: the antigen specificity of $\mathrm{T}$ lymphocytes determines the topography of lesions in the central and peripheral nervous system. Lab Invest 1997; 76: 355-364.

30. Bieber AJ, Kerr S, Rodriguez M. Efficient central nervous system remyelination requires T cells. Ann.Neurol. 2003; 53: 680-684. 
31. Bitsch A, Kuhlmann T, Stadelmann C, Lassmann H, Lucchinetti C, Bruck W. A longitudinal MRI study of histopathologically defined hypointense multiple sclerosis lesions. Ann.Neurol. 2001; 49: 793-796.

32. Bitsch A, Schuchardt J, Bunkowski S, Kuhlmann T, Bruck W. Acute axonal injury in multiple sclerosis. Correlation with demyelination and inflammation. Brain 2000; 123 ( Pt 6): $1174-1183$.

33. Bjartmar C, Trapp BD. Axonal and neuronal degeneration in multiple sclerosis: mechanisms and functional consequences. Curr.Opin.Neurol. 2001; 14: 271-278.

34. Bo L, Vedeler CA, Nyland H, Trapp BD, Mork SJ. Intracortical multiple sclerosis lesions are not associated with increased lymphocyte infiltration. Mult.Scler. 2003a; 9: 323331.

35. Bo L, Vedeler CA, Nyland HI, Trapp BD, Mork SJ. Subpial demyelination in the cerebral cortex of multiple sclerosis patients. J.Neuropathol.Exp.Neurol. 2003b; 62: 723-732.

36. Bogdan C, Vodovotz Y, Nathan C. Macrophage deactivation by interleukin 10. J.Exp.Med. 1991; 174: 1549-1555.

37. Bogdan C, Vodovotz Y, Paik J, Xie QW, Nathan C. Mechanism of suppression of nitric oxide synthase expression by interleukin-4 in primary mouse macrophages. J.Leukoc.Biol. 1994; 55: 227-233.

38. Boretius S, Wurfel J, Zipp F, Frahm J, Michaelis T. High-field diffusion tensor imaging of mouse brain in vivo using single-shot STEAM MRI. J.Neurosci.Methods 2007; 161: 112-117.

39. Boven LA, Van Meurs M, Van Zwam M et al. Myelin-laden macrophages are antiinflammatory, consistent with foam cells in multiple sclerosis. Brain 2006; 129: 517-526.

40. Bozzali M, Cercignani M, Sormani MP, Comi G, Filippi M. Quantification of brain gray matter damage in different MS phenotypes by use of diffusion tensor MR imaging. AJNR Am.J.Neuroradiol. 2002; 23: 985-988. 
41. Brenner T, Brocke S, Szafer F et al. Inhibition of nitric oxide synthase for treatment of experimental autoimmune encephalomyelitis. J.Immunol. 1997; 158: 2940-2946.

42. Brink BP, Veerhuis R, Breij EC, Van D, V, Dijkstra CD, Bo L. The pathology of multiple sclerosis is location-dependent: no significant complement activation is detected in purely cortical lesions. J.Neuropathol.Exp.Neurol. 2005; 64: 147-155.

43. Brooks DJ, Leenders KL, Head G, Marshall J, Legg NJ, Jones T. Studies on regional cerebral oxygen utilisation and cognitive function in multiple sclerosis. J.Neurol.Neurosurg.Psychiatry 1984; 47: 1182-1191.

44. Brown GC. Mechanisms of inflammatory neurodegeneration: iNOS and NADPH oxidase. Biochem.Soc.Trans. 2007; 35: 1119-1121.

45. Bruck W, Bitsch A, Kolenda H, Bruck Y, Stiefel M, Lassmann H. Inflammatory central nervous system demyelination: correlation of magnetic resonance imaging findings with lesion pathology. Ann.Neurol. 1997; 42: 783-793.

46. Bruck W, Porada P, Poser S et al. Monocyte/macrophage differentiation in early multiple sclerosis lesions. Ann.Neurol. 1995; 38: 788-796.

47. Bruck W, Stadelmann C. Inflammation and degeneration in multiple sclerosis. Neurol.Sci. 2003; 24 Suppl 5: S265-S267.

48. Buechler C, Ritter M, Orso E, Langmann T, Klucken J, Schmitz G. Regulation of scavenger receptor CD163 expression in human monocytes and macrophages by pro- and antiinflammatory stimuli. J.Leukoc.Biol. 2000; 67: 97-103.

49. Castriota SA, Tomaiuolo F, Sabatini U, Nocentini U, Grasso MG, Caltagirone C. Demyelinating plaques in relapsing-remitting and secondary-progressive multiple sclerosis: assessment with diffusion MR imaging. AJNR Am.J.Neuroradiol. 2000; 21: 862-868.

50. Chakrabarty A, Emerson MR, LeVine SM. Heme oxygenase-1 in SJL mice with experimental allergic encephalomyelitis. Mult.Scler. 2003; 9: 372-381. 
51. Chang A, Tourtellotte WW, Rudick R, Trapp BD. Premyelinating oligodendrocytes in chronic lesions of multiple sclerosis. N.Engl.J.Med. 2002; 346: 165-173.

52. Chora AA, Fontoura $P$, Cunha A et al. Heme oxygenase-1 and carbon monoxide suppress autoimmune neuroinflammation

1. J.Clin.Invest 2007; 117: 438-447.

53. Cross AH, Misko TP, Lin RF, Hickey WF, Trotter JL, Tilton RG. Aminoguanidine, an inhibitor of inducible nitric oxide synthase, ameliorates experimental autoimmune encephalomyelitis in SJL mice. J.Clin.Invest 1994; 93: 2684-2690.

54. Dalton DK, Wittmer S. Nitric-oxide-dependent and independent mechanisms of protection from CNS inflammation during Th1-mediated autoimmunity: evidence from EAE in iNOS KO mice. J.Neuroimmunol. 2005; 160: 110-121.

55. Davie CA, Barker GJ, Webb S et al. Persistent functional deficit in multiple sclerosis and autosomal dominant cerebellar ataxia is associated with axon loss. Brain 1995; 118 ( Pt 6): 1583-1592.

56. De Santis ML, Roth GA, Cumar FA. Cellular immune crossreactivity between myelin basic protein and synapsin in rats with experimental allergic encephalomyelitis. J.Neurosci.Res. 1992; 31: 46-51.

57. De Stefano N, Matthews PM, Fu L et al. Axonal damage correlates with disability in patients with relapsing-remitting multiple sclerosis. Results of a longitudinal magnetic resonance spectroscopy study. Brain 1998; 121 ( Pt 8): 1469-1477.

58. De Stefano N, Narayanan S, Matthews PM, Francis GS, Antel JP, Arnold DL. In vivo evidence for axonal dysfunction remote from focal cerebral demyelination of the type seen in multiple sclerosis. Brain 1999; 122 ( Pt 10): 1933-1939.

59. Diaz-Sanchez M, Williams K, DeLuca GC, Esiri MM. Protein co-expression with axonal injury in multiple sclerosis plaques

1. Acta Neuropathol.(Berl) 2006; 111: 289-299. 
60. Diestel A, Aktas O, Hackel $D$ et al. Activation of microglial poly(ADP-ribose)polymerase-1 by cholesterol breakdown products during neuroinflammation: a link between demyelination and neuronal damage. J.Exp.Med. 2003; 198: 1729-1740.

61. Dong Z, Lavrovsky Y, Venkatachalam MA, Roy AK. Heme oxygenase-1 in tissue pathology: the Yin and Yang. Am.J.Pathol. 2000; 156: 1485-1488.

62. Dousset $\mathrm{V}$, Brochet $\mathrm{B}$, Deloire MS et al. MR imaging of relapsing multiple sclerosis patients using ultra-small-particle iron oxide and compared with gadolinium. AJNR Am.J.Neuroradiol. 2006; 27: 1000-1005.

63. Droste A, Sorg C, Hogger P. Shedding of CD163, a novel regulatory mechanism for a member of the scavenger receptor cysteine-rich family. Biochem.Biophys.Res.Commun. 1999; 256: 110-113.

64. Ehrhard PB, Erb P, Graumann U, Otten U. Expression of nerve growth factor and nerve growth factor receptor tyrosine kinase Trk in activated CD4-positive T-cell clones. Proc.Natl.Acad.Sci.U.S.A 1993; 90: 10984-10988.

65. Emerson MR, Biswas S, LeVine SM. Cuprizone and piperonyl butoxide, proposed inhibitors of T-cell function, attenuate experimental allergic encephalomyelitis in SJL mice. J.Neuroimmunol. 2001; 119: 205-213.

66. Erdlenbruch B, Alipour M, Fricker G et al. Alkylglycerol opening of the blood-brain barrier to small and large fluorescence markers in normal and C6 glioma-bearing rats and isolated rat brain capillaries. Br.J.Pharmacol. 2003; 140: 1201-1210.

67. Estus S, Zaks WJ, Freeman RS, Gruda M, Bravo R, Johnson EM, Jr. Altered gene expression in neurons during programmed cell death: identification of c-jun as necessary for neuronal apoptosis. J.Cell Biol. 1994; 127: 1717-1727.

68. Fabriek BO, Dijkstra CD, van den Berg TK. The macrophage scavenger receptor CD163. Immunobiology 2005a; 210: 153-160.

69. Fabriek BO, Moller HJ, Vloet RP et al. Proteolytic shedding of the macrophage scavenger receptor CD163 in multiple sclerosis. J.Neuroimmunol. 2007; 187: 179-186. 
70. Fabriek BO, Van Haastert ES, Galea I et al. CD163-positive perivascular macrophages in the human CNS express molecules for antigen recognition and presentation. Glia 2005b; 51: 297-305.

71. Fancy SP, Zhao C, Franklin RJ. Increased expression of Nkx2.2 and Olig2 identifies reactive oligodendrocyte progenitor cells responding to demyelination in the adult CNS. Mol.Cell Neurosci. 2004; 27: 247-254.

72. Ferguson B, Matyszak MK, Esiri MM, Perry VH. Axonal damage in acute multiple sclerosis lesions. Brain 1997; 120 ( Pt 3): 393-399.

73. Filippi M, Cercignani M, Inglese M, Horsfield MA, Comi G. Diffusion tensor magnetic resonance imaging in multiple sclerosis. Neurology 2001; 56: 304-311.

74. Flugel A, Berkowicz T, Ritter T et al. Migratory activity and functional changes of green fluorescent effector cells before and during experimental autoimmune encephalomyelitis 1. Immunity. 2001a; 14: 547-560.

75. Flugel A, Bradl M, Kreutzberg GW, Graeber MB. Transformation of donor-derived bone marrow precursors into host microglia during autoimmune CNS inflammation and during the retrograde response to axotomy

1. J.Neurosci.Res. 2001b; 66: 74-82.

76. Flugel A, Schwaiger FW, Neumann $\mathrm{H}$ et al. Neuronal FasL induces cell death of encephalitogenic T lymphocytes. Brain Pathol. 2000; 10: 353-364.

77. Foell D, Hernandez-Rodriguez J, Sanchez M, Vogl T, Cid MC, Roth J. Early recruitment of phagocytes contributes to the vascular inflammation of giant cell arteritis. J.Pathol. 2004; 204: 311-316.

78. Foell D, Wittkowski H, Vogl T, Roth J. S100 proteins expressed in phagocytes: a novel group of damage-associated molecular pattern molecules. J.Leukoc.Biol. 2007; 81: 28-37.

79. Fogdell A, Hillert J, Sachs C, Olerup O. The multiple sclerosis- and narcolepsyassociated HLA class II haplotype includes the DRB5*0101 allele. Tissue Antigens 1995; 46: 333-336. 
80. Ford AL, Goodsall AL, Hickey WF, Sedgwick JD. Normal adult ramified microglia separated from other central nervous system macrophages by flow cytometric sorting. Phenotypic differences defined and direct ex vivo antigen presentation to myelin basic protein-reactive CD4+ T cells compared. J.Immunol. 1995; 154: 4309-4321.

81. Ford ML, Evavold BD. Specificity, magnitude, and kinetics of MOG-specific CD8+ T cell responses during experimental autoimmune encephalomyelitis. Eur.J.Immunol. 2005; 35: 76-85.

82. Forster C, Clark HB, Ross ME, Iadecola C. Inducible nitric oxide synthase expression in human cerebral infarcts. Acta Neuropathol. 1999; 97: 215-220.

83. Frankel D, Mehindate K, Schipper HM. Role of heme oxygenase-1 in the regulation of manganese superoxide dismutase gene expression in oxidatively-challenged astroglia. J.Cell Physiol 2000; 185: 80-86.

84. French LE, Hahne M, Viard I et al. Fas and Fas ligand in embryos and adult mice: ligand expression in several immune-privileged tissues and coexpression in adult tissues characterized by apoptotic cell turnover. J.Cell Biol. 1996; 133: 335-343.

85. Friese MA, Fugger L. Autoreactive CD8+ T cells in multiple sclerosis: a new target for therapy?

1. Brain 2005; 128: 1747-1763.

86. Frings W, Dreier J, Sorg C. Only the soluble form of the scavenger receptor CD163 acts inhibitory on phorbol ester-activated T-lymphocytes, whereas membrane-bound protein has no effect. FEBS Lett. 2002; 526: 93-96.

87. Frosch M, Strey A, Vogl T et al. Myeloid-related proteins 8 and 14 are specifically secreted during interaction of phagocytes and activated endothelium and are useful markers for monitoring disease activity in pauciarticular-onset juvenile rheumatoid arthritis. Arthritis Rheum. 2000; 43: 628-637.

88. Furlan R, Brambilla E, Sanvito $\mathrm{F}$ et al. Vaccination with amyloid-beta peptide induces autoimmune encephalomyelitis in C57/BL6 mice. Brain 2003; 126: 285-291. 
89. Gass P, Katsura K, Zuschratter W, Siesjo B, Kiessling M. Hypoglycemia-elicited immediate early gene expression in neurons and glia of the hippocampus: novel patterns of FOS, JUN, and KROX expression following excitotoxic injury. J.Cereb.Blood Flow Metab 1995; 15: 989-1001.

90. Gebhardt C, Nemeth J, Angel P, Hess J. S100A8 and S100A9 in inflammation and cancer. Biochem.Pharmacol. 2006; 72: 1622-1631.

91. Gentleman SM, Nash MJ, Sweeting CJ, Graham DI, Roberts GW. Beta-amyloid precursor protein (beta APP) as a marker for axonal injury after head injury. Neurosci.Lett. 1993; 160: 139-144.

92. Ghezzi A, Montanini R, Basso PF, Zaffaroni M, Massimo E, Cazzullo CL. Epilepsy in multiple sclerosis. Eur.Neurol. 1990; 30: 218-223.

93. Giasson BI, Duda JE, Forman MS, Lee VM, Trojanowski JQ. Prominent perikaryal expression of alpha- and beta-synuclein in neurons of dorsal root ganglion and in medullary neurons. Exp.Neurol. 2001; 172: 354-362.

94. Gibbs PE, Maines MD. Biliverdin inhibits activation of NF-kappaB: reversal of inhibition by human biliverdin reductase. Int.J.Cancer 2007; 121: 2567-2574.

95. Gilmore CP, Bo L, Owens T, Lowe J, Esiri MM, Evangelou N. Spinal cord gray matter demyelination in multiple sclerosis-a novel pattern of residual plaque morphology. Brain Pathol. 2006; 16: 202-208.

96. Giovannoni G. Cerebrospinal fluid and serum nitric oxide metabolites in patients with multiple sclerosis. Mult.Scler. 1998; 4: 27-30.

97. Giovannoni G, Heales SJ, Silver NC et al. Raised serum nitrate and nitrite levels in patients with multiple sclerosis. J.Neurol.Sci. 1997; 145: 77-81.

98. Giovannoni G, Silver NC, O'Riordan J et al. Increased urinary nitric oxide metabolites in patients with multiple sclerosis correlates with early and relapsing disease. Mult.Scler. 1999; 5: 335-341. 
99. Gold R, Linington C, Lassmann H. Understanding pathogenesis and therapy of multiple sclerosis via animal models: 70 years of merits and culprits in experimental autoimmune encephalomyelitis research

1. Brain 2006; 129: 1953-1971.

100. Gordon S. Alternative activation of macrophages. Nat.Rev.Immunol. 2003; 3: 23-35.

101. Graversen JH, Madsen M, Moestrup SK. CD163: a signal receptor scavenging haptoglobin-hemoglobin complexes from plasma. Int.J.Biochem.Cell Biol. 2002; 34: 309-314.

102. Griscavage JM, Rogers NE, Sherman MP, Ignarro LJ. Inducible nitric oxide synthase from a rat alveolar macrophage cell line is inhibited by nitric oxide. J.Immunol. 1993; 151: 6329-6337.

103. Hegazi RA, Rao KN, Mayle A, Sepulveda AR, Otterbein LE, Plevy SE. Carbon monoxide ameliorates chronic murine colitis through a heme oxygenase 1-dependent pathway. J.Exp.Med. 2005; 202: 1703-1713.

104. Helms G. Volume correction for edema in single-volume proton MR spectroscopy of contrast-enhancing multiple sclerosis lesions. Magn Reson.Med. 2001; 46: 256-263.

105. Hendriks JJ, Teunissen CE, de Vries HE, Dijkstra CD. Macrophages and neurodegeneration. Brain Res.Brain Res.Rev. 2005; 48: 185-195.

106. Heppner FL, Greter M, Marino D et al. Experimental autoimmune encephalomyelitis repressed by microglial paralysis. Nat.Med. 2005; 11: 146-152.

107. Herdegen $\mathrm{T}$, Skene $\mathrm{P}$, Bahr M. The c-Jun transcription factor--bipotential mediator of neuronal death, survival and regeneration. Trends Neurosci. 1997; 20: 227-231.

108. Hewett SJ, Corbett JA, McDaniel ML, Choi DW. Interferon-gamma and interleukin-1 beta induce nitric oxide formation from primary mouse astrocytes. Neurosci.Lett. 1993; 164: 229-232. 
109. Hintz KA, Rassias AJ, Wardwell K et al. Endotoxin induces rapid metalloproteinasemediated shedding followed by up-regulation of the monocyte hemoglobin scavenger receptor CD163. J.Leukoc.Biol. 2002; 72: 711-717.

110. Hiremath MM, Saito Y, Knapp GW, Ting JP, Suzuki K, Matsushima GK. Micro$\mathrm{glial} /$ macrophage accumulation during cuprizone-induced demyelination in C57BL/6 mice. J.Neuroimmunol. 1998; 92: 38-49.

111. Hofmann N, Lachnit N, Streppel M et al. Increased expression of ICAM-1, VCAM-1, MCP-1, and MIP-1 alpha by spinal perivascular macrophages during experimental allergic encephalomyelitis in rats. BMC.Immunol. 2002; 3: 11.

112. Hoftberger R, Aboul-Enein F, Brueck $W$ et al. Expression of major histocompatibility complex class I molecules on the different cell types in multiple sclerosis lesions. Brain Pathol. 2004; 14: 43-50.

113. Hogger P, Dreier J, Droste A, Buck F, Sorg C. Identification of the integral membrane protein RM3/1 on human monocytes as a glucocorticoid-inducible member of the scavenger receptor cysteine-rich family (CD163). J.Immunol. 1998; 161: 1883-1890.

114. Hogger P, Sorg C. Soluble CD163 inhibits phorbol ester-induced lymphocyte proliferation. Biochem.Biophys.Res.Commun. 2001; 288: 841-843.

115. Hu P, Pollard JD, Chan-Ling T. Breakdown of the blood-retinal barrier induced by activated T cells of nonneural specificity. Am.J.Pathol. 2000; 156: 1139-1149.

116. Huitinga I, Schmidt ED, van der Cammen MJ, Binnekade R, Tilders FJ. Priming with interleukin-1beta suppresses experimental allergic encephalomyelitis in the Lewis rat. J.Neuroendocrinol. 2000; 12: 1186-1193.

117. Huitinga I, van Rooijen N, de Groot CJ, Uitdehaag BM, Dijkstra CD. Suppression of experimental allergic encephalomyelitis in Lewis rats after elimination of macrophages. J.Exp.Med. 1990; 172: 1025-1033. 
118. Huizinga R, Heijmans N, Schubert $P$ et al. Immunization with neurofilament light protein induces spastic paresis and axonal degeneration in Biozzi $A B H$ mice. J.Neuropathol.Exp.Neurol. 2007; 66: 295-304.

119. Huizinga R, Linington $C$, Amor S. Resistance is futile: antineuronal autoimmunity in multiple sclerosis. Trends Immunol. 2008.

120. Hull M, Bahr M. Differential regulation of $\mathrm{C}-\mathrm{JUN}$ expression in rat retinal ganglion cells after proximal and distal optic nerve transection. Neurosci.Lett. 1994; 178: 39-42.

121. Huseby ES, Liggitt D, Brabb T, Schnabel B, Ohlen C, Goverman J. A pathogenic role for myelin-specific CD8(+) T cells in a model for multiple sclerosis. J.Exp.Med. 2001; 194: 669-676.

122. Inoue $Y$, Nakamura R, Mikoshiba K, Tsukada Y. Fine structure of the central myelin sheath in the myelin deficient mutant Shiverer mouse, with special reference to the pattern of myelin formation by oligodendroglia. Brain Res. 1981; 219: 85-94.

123. Ito R, Melhem ER, Mori S, Eichler FS, Raymond GV, Moser HW. Diffusion tensor brain MR imaging in X-linked cerebral adrenoleukodystrophy. Neurology 2001; 56: 544547.

124. Jana M, Liu X, Koka S, Ghosh S, Petro TM, Pahan K. Ligation of CD40 stimulates the induction of nitric-oxide synthase in microglial cells. J.Biol.Chem. 2001; 276: 4452744533.

125. Jander S, Lausberg F, Stoll G. Differential recruitment of CD8+ macrophages during Wallerian degeneration in the peripheral and central nervous system. Brain Pathol. 2001; 11: 27-38.

126. Jander S, Schroeter M, D'Urso D, Gillen C, Witte OW, Stoll G. Focal ischaemia of the rat brain elicits an unusual inflammatory response: early appearance of CD8+ macrophages/microglia. Eur.J.Neurosci. 1998; 10: 680-688.

127. Jensen PH, Li JY, Dahlstrom A, Dotti CG. Axonal transport of synucleins is mediated by all rate components. Eur.J.Neurosci. 1999; 11: 3369-3376. 
128. Jones DK, Lythgoe D, Horsfield MA, Simmons A, Williams SC, Markus HS. Characterization of white matter damage in ischemic leukoaraiosis with diffusion tensor MRI. Stroke 1999; 30: 393-397.

129. Jorgensen OS, Hansen LI, Hoffman SW, Fulop Z, Stein DG. Synaptic remodeling and free radical formation after brain contusion injury in the rat. Exp.Neurol. 1997; 144: 326-338.

130. Kaffenberger W, Gruber DF, MacVittie TJ. Rat monocytes in a model of combined injury express the OX8 antigen. J.Leukoc.Biol. 1987; 42: 181-187.

131. Kahl KG, Schmidt HH, Jung S, Sherman P, Toyka KV, Zielasek J. Experimental autoimmune encephalomyelitis in mice with a targeted deletion of the inducible nitric oxide synthase gene: increased T-helper 1 response. Neurosci.Lett. 2004; 358: 58-62.

132. Kapturczak MH, Wasserfall C, Brusko $\mathrm{T}$ et al. Heme oxygenase-1 modulates early inflammatory responses: evidence from the heme oxygenase-1-deficient mouse. Am.J.Pathol. 2004; 165: 1045-1053.

133. Karupiah G, Xie QW, Buller RM, Nathan C, Duarte C, MacMicking JD. Inhibition of viral replication by interferon-gamma-induced nitric oxide synthase. Science 1993; 261 : 1445-1448.

134. Kerkhoff C, Eue I, Sorg C. The regulatory role of MRP8 (S100A8) and MRP14 (S100A9) in the transendothelial migration of human leukocytes

2. Pathobiology 1999; 67: 230-232.

135. Kerschensteiner M, Gallmeier E, Behrens $L$ et al. Activated human T cells, B cells, and monocytes produce brain-derived neurotrophic factor in vitro and in inflammatory brain lesions: a neuroprotective role of inflammation? J.Exp.Med. 1999; 189: 865-870.

136. Kidd D, Barkhof F, McConnell R, Algra PR, Allen IV, Revesz T. Cortical lesions in multiple sclerosis. Brain 1999; 122 ( Pt 1): 17-26.

137. Killestein J, Kalkers NF, Polman CH. Glutamate inhibition in MS: the neuroprotective properties of riluzole. J.Neurol.Sci. 2005; 233: 113-115. 
138. Kim KM, Pae HO, Zhung M et al. Involvement of anti-inflammatory heme oxygenase1 in the inhibitory effect of curcumin on the expression of pro-inflammatory inducible nitric oxide synthase in RAW264.7 macrophages. Biomed.Pharmacother. 2008.

139. Kim SH, Shin YK, Lee KM, Lee JS, Yun JH, Lee SM. An improved protocol of biotinylated tyramine-based immunohistochemistry minimizing nonspecific background staining

1. J.Histochem.Cytochem. 2003; 51: 129-132.

140. Kitz K, Lassmann H, Karcher D, Lowenthal A. Blood-brain barrier in chronic relapsing experimental allergic encephalomyelitis: a correlative study between cerebrospinal fluid protein concentrations and tracer leakage in the central nervous system. Acta Neuropathol. 1984; 63: 41-50.

141. Knott C, Stern G, Wilkin GP. Inflammatory regulators in Parkinson's disease: iNOS, lipocortin-1, and cyclooxygenases-1 and -2. Mol.Cell Neurosci. 2000; 16: 724-739.

142. Kojima K, Berger T, Lassmann $\mathrm{H}$ et al. Experimental autoimmune panencephalitis and uveoretinitis transferred to the Lewis rat by T Iymphocytes specific for the S100 beta molecule, a calcium binding protein of astroglia. J.Exp.Med. 1994; 180: 817-829.

143. Kondo A, Nakano T, Suzuki K. Blood-brain barrier permeability to horseradish peroxidase in twitcher and cuprizone-intoxicated mice. Brain Res. 1987; 425: 186-190.

144. Konno H, Yamamoto $\mathrm{T}$, Suzuki $\mathrm{H}$ et al. Targeting of adoptively transferred experimental allergic encephalitis lesion at the sites of wallerian degeneration. Acta Neuropathol. 1990; 80: 521-526.

145. Koo EH, Sisodia SS, Archer DR et al. Precursor of amyloid protein in Alzheimer disease undergoes fast anterograde axonal transport. Proc.Natl.Acad.Sci.U.S.A 1990; 87: 1561-1565.

146. Koprowski $\mathrm{H}$, Zheng $\mathrm{YM}$, Heber-Katz $\mathrm{E}$ et al. In vivo expression of inducible nitric oxide synthase in experimentally induced neurologic diseases. Proc.Natl.Acad.Sci.U.S.A 1993; 90: 3024-3027. 
147. Kornek B, Storch MK, Weissert R et al. Multiple sclerosis and chronic autoimmune encephalomyelitis: a comparative quantitative study of axonal injury in active, inactive, and remyelinated lesions. Am.J.Pathol. 2000; 157: 267-276.

148. Kotter MR, Li WW, Zhao C, Franklin RJ. Myelin impairs CNS remyelination by inhibiting oligodendrocyte precursor cell differentiation. J.Neurosci. 2006; 26: 328-332.

149. Kotter MR, Zhao C, van Rooijen N, Franklin RJ. Macrophage-depletion induced impairment of experimental CNS remyelination is associated with a reduced oligodendrocyte progenitor cell response and altered growth factor expression. Neurobiol.Dis. 2005; 18 : 166-175.

150. Krenger W, Falzarano G, Delmonte J, Jr., Snyder KM, Byon JC, Ferrara JL. Interferon-gamma suppresses T-cell proliferation to mitogen via the nitric oxide pathway during experimental acute graft-versus-host disease. Blood 1996; 88: 1113-1121.

151. Kristiansen M, Graversen $\mathrm{JH}$, Jacobsen $\mathrm{C}$ et al. Identification of the haemoglobin scavenger receptor. Nature 2001; 409: 198-201.

152. Kubes P, Suzuki M, Granger DN. Nitric oxide: an endogenous modulator of leukocyte adhesion. Proc.Natl.Acad.Sci.U.S.A 1991; 88: 4651-4655.

153. Kuhlmann T, Remington L, Maruschak B, Owens T, Bruck W. Nogo-A is a reliable oligodendroglial marker in adult human and mouse CNS and in demyelinated lesions. J.Neuropathol.Exp.Neurol. 2007; 66: 238-246.

154. Kunz D, Walker G, Eberhardt W, Pfeilschifter J. Molecular mechanisms of dexamethasone inhibition of nitric oxide synthase expression in interleukin 1 beta-stimulated mesangial cells: evidence for the involvement of transcriptional and posttranscriptional regulation. Proc.Natl.Acad.Sci.U.S.A 1996; 93: 255-259.

155. Kutzelnigg A, Lassmann $\mathrm{H}$. Cortical lesions and brain atrophy in MS. J.Neurol.Sci. 2005; 233: 55-59.

156. Lassmann $\mathrm{H}$, Bruck W, Lucchinetti C. Heterogeneity of multiple sclerosis pathogenesis: implications for diagnosis and therapy. Trends Mol.Med. 2001; 7: 115-121. 
157. Lassmann H, Bruck W, Lucchinetti CF. The immunopathology of multiple sclerosis: an overview. Brain Pathol. 2007; 17: 210-218.

158. Law SK, Micklem KJ, Shaw JM et al. A new macrophage differentiation antigen which is a member of the scavenger receptor superfamily. Eur.J.Immunol. 1993; 23: 23202325.

159. Lee TS, Chau LY. Heme oxygenase-1 mediates the anti-inflammatory effect of interleukin-10 in mice. Nat.Med. 2002; 8: 240-246.

160. Levine S. Localization of allergic encephalomyelitis in lesions of cyanide encephalopathy. J.Neuropathol.Exp.Neurol. 1960; 19: 238-247.

161. Li JY, Henning JP, Dahlstrom A. Differential localization of alpha-, beta- and gammasynucleins in the rat CNS. Neuroscience 2002; 113: 463-478.

162. Li WW, Setzu A, Zhao C, Franklin RJ. Minocycline-mediated inhibition of microglia activation impairs oligodendrocyte progenitor cell responses and remyelination in a nonimmune model of demyelination. J.Neuroimmunol. 2005; 158: 58-66.

163. Liao H, Bu WY, Wang TH, Ahmed S, Xiao ZC. Tenascin-R plays a role in neuroprotection via its distinct domains that coordinate to modulate the microglia function. J.Biol.Chem. 2005; 280: 8316-8323.

164. Lin W, Kemper A, Dupree JL, Harding HP, Ron D, Popko B. Interferon-gamma inhibits central nervous system remyelination through a process modulated by endoplasmic reticulum stress. Brain 2006; 129: 1306-1318.

165. Linares D, Taconis M, Mana $\mathrm{P}$ et al. Neuronal nitric oxide synthase plays a key role in CNS demyelination

1. J.Neurosci. 2006; 26: 12672-12681.

166. Lind D, Franken S, Kappler J, Jankowski J, Schilling K. Characterization of the neuronal marker NeuN as a multiply phosphorylated antigen with discrete subcellular localization

1. J.Neurosci.Res. 2005; 79: 295-302. 
167. Linington C, Bradl M, Lassmann H, Brunner C, Vass K. Augmentation of demyelination in rat acute allergic encephalomyelitis by circulating mouse monoclonal antibodies directed against a myelin/oligodendrocyte glycoprotein. Am.J.Pathol. 1988; 130: 443-454.

168. Linnington C, Webb M, Woodhams PL. A novel myelin-associated glycoprotein defined by a mouse monoclonal antibody. J.Neuroimmunol. 1984; 6: 387-396.

169. Lovas G, Szilagyi N, Majtenyi K, Palkovits M, Komoly S. Axonal changes in chronic demyelinated cervical spinal cord plaques. Brain 2000; 123 ( Pt 2): 308-317.

170. Lublin FD, Reingold SC. Defining the clinical course of multiple sclerosis: results of an international survey. National Multiple Sclerosis Society (USA) Advisory Committee on Clinical Trials of New Agents in Multiple Sclerosis. Neurology 1996; 46: 907-911.

171. Lue LF, Brachova L, Civin WH, Rogers J. Inflammation, A beta deposition, and neurofibrillary tangle formation as correlates of Alzheimer's disease neurodegeneration. J.Neuropathol.Exp.Neurol. 1996; 55: 1083-1088.

172. MacMicking J, Xie QW, Nathan C. Nitric oxide and macrophage function. Annu.Rev.Immunol. 1997; 15: 323-350.

173. Maines MD. Heme oxygenase: function, multiplicity, regulatory mechanisms, and clinical applications. FASEB J. 1988; 2: 2557-2568.

174. Mancuso C. Heme oxygenase and its products in the nervous system. Antioxid.Redox.Signal. 2004; 6: 878-887.

175. Mancuso C, Perluigi M, Cini C, De Marco C, Giuffrida Stella AM, Calabrese V. Heme oxygenase and cyclooxygenase in the central nervous system: a functional interplay. J.Neurosci.Res. 2006; 84: 1385-1391.

176. Maroteaux L, Campanelli JT, Scheller RH. Synuclein: a neuron-specific protein localized to the nucleus and presynaptic nerve terminal. J.Neurosci. 1988; 8: 2804-2815.

177. Masliah E, Achim CL, Ge N, DeTeresa R, Terry RD, Wiley CA. Spectrum of human immunodeficiency virus-associated neocortical damage. Ann.Neurol. 1992; 32: 321-329. 
178. Mason JL, Jones JJ, Taniike M, Morell P, Suzuki K, Matsushima GK. Mature oligodendrocyte apoptosis precedes IGF-1 production and oligodendrocyte progenitor accumulation and differentiation during demyelination/remyelination. J.Neurosci.Res. 2000; 61: 251-262.

179. Mason JL, Suzuki K, Chaplin DD, Matsushima GK. Interleukin-1beta promotes repair of the CNS. J.Neurosci. 2001; 21: 7046-7052.

180. Matsushima GK, Morell P. The neurotoxicant, cuprizone, as a model to study demyelination and remyelination in the central nervous system. Brain Pathol. 2001; 11: 107-116.

181. Matsushita N, Kashiwagi M, Wait R et al. Elevated levels of soluble CD163 in sera and fluids from rheumatoid arthritis patients and inhibition of the shedding of CD163 by TIMP-3. Clin.Exp.Immunol. 2002; 130: 156-161.

182. McMahon EJ, Suzuki K, Matsushima GK. Peripheral macrophage recruitment in cuprizone-induced CNS demyelination despite an intact blood-brain barrier. J.Neuroimmunol. 2002; 130: 32-45.

183. McPhail LT, McBride CB, McGraw J, Steeves JD, Tetzlaff W. Axotomy abolishes NeuN expression in facial but not rubrospinal neurons. Exp.Neurol. 2004; 185: 182-190.

184. Medana I, Li Z, Flugel A, Tschopp J, Wekerle H, Neumann H. Fas ligand (CD95L) protects neurons against perforin-mediated T Iymphocyte cytotoxicity. J.Immunol. 2001; 167: 674-681.

185. Medana IM, Gallimore A, Oxenius A, Martinic MM, Wekerle H, Neumann H. MHC class I-restricted killing of neurons by virus-specific CD8+ T lymphocytes is effected through the Fas/FasL, but not the perforin pathway. Eur.J.Immunol. 2000; 30: 3623-3633.

186. Mehindate K, Sahlas DJ, Frankel D et al. Proinflammatory cytokines promote glial heme oxygenase-1 expression and mitochondrial iron deposition: implications for multiple sclerosis. J.Neurochem. 2001; 77: 1386-1395. 
187. Menon KK, Piddlesden SJ, Bernard CC. Demyelinating antibodies to myelin oligodendrocyte glycoprotein and galactocerebroside induce degradation of myelin basic protein in isolated human myelin. J.Neurochem. 1997; 69: 214-222.

188. Merkler D, Boscke R, Schmelting B et al. Differential macrophage/microglia activation in neocortical EAE lesions in the marmoset monkey. Brain Pathol. 2006a; 16: 117123.

189. Merkler D, Ernsting T, Kerschensteiner M, Bruck W, Stadelmann C. A new focal EAE model of cortical demyelination: multiple sclerosis-like lesions with rapid resolution of inflammation and extensive remyelination. Brain 2006b; 129: 1972-1983.

190. Merrill JE, Murphy SP, Mitrovic B et al. Inducible nitric oxide synthase and nitric oxide production by oligodendrocytes. J.Neurosci.Res. 1997; 48: 372-384.

191. Meyer R, Weissert R, Diem R et al. Acute neuronal apoptosis in a rat model of multiple sclerosis. J.Neurosci. 2001; 21: 6214-6220.

192. Minagar A, Alexander JS. Blood-brain barrier disruption in multiple sclerosis. Mult.Scler. 2003; 9: 540-549.

193. Moestrup SK, Moller HJ. CD163: a regulated hemoglobin scavenger receptor with a role in the anti-inflammatory response. Ann.Med. 2004; 36: 347-354.

194. Moller HJ, de Fost M, Aerts H, Hollak C, Moestrup SK. Plasma level of the macrophage-derived soluble CD163 is increased and positively correlates with severity in Gaucher's disease. Eur.J.Haematol. 2004; 72: 135-139.

195. Mor F, Quintana F, Mimran A, Cohen IR. Autoimmune encephalomyelitis and uveitis induced by $T$ cell immunity to self beta-synuclein. J.Immunol. 2003; 170: 628-634.

196. Morell P, Barrett CV, Mason JL et al. Gene expression in brain during cuprizoneinduced demyelination and remyelination. Mol.Cell Neurosci. 1998; 12: 220-227. 
197. Mori F, Tanji K, Yoshimoto M, Takahashi H, Wakabayashi K. Immunohistochemical comparison of alpha- and beta-synuclein in adult rat central nervous system. Brain Res. 2002; 941: 118-126.

198. Morris-Downes MM, Smith PA, Rundle JL et al. Pathological and regulatory effects of anti-myelin antibodies in experimental allergic encephalomyelitis in mice. J.Neuroimmunol. 2002; 125: 114-124.

199. Morrissey SP, Stodal H, Zettl U et al. In vivo MRI and its histological correlates in acute adoptive transfer experimental allergic encephalomyelitis. Quantification of inflammation and oedema. Brain 1996; 119 ( Pt 1): 239-248.

200. Murphy AN, Fiskum G, Beal MF. Mitochondria in neurodegeneration: bioenergetic function in cell life and death. J.Cereb.Blood Flow Metab 1999; 19: 231-245.

201. Nacken W, Sopalla C, Propper C, Sorg C, Kerkhoff C. Biochemical characterization of the murine S100A9 (MRP14) protein suggests that it is functionally equivalent to its human counterpart despite its low degree of sequence homology. Eur.J.Biochem. 2000; 267: 560-565.

202. Nair G, Tanahashi Y, Low HP, Billings-Gagliardi S, Schwartz WJ, Duong TQ. Myelination and long diffusion times alter diffusion-tensor-imaging contrast in myelin-deficient shiverer mice. Neuroimage. 2005; 28: 165-174.

203. Naito S, Namerow N, Mickey MR, Terasaki PI. Multiple sclerosis: association with HL-A3. Tissue Antigens 1972; 2: 1-4.

204. Nessler S, Boretius S, Stadelmann C et al. Early MRI changes in a mouse model of multiple sclerosis are predictive of severe inflammatory tissue damage. Brain 2007; 130: 2186-2198.

205. Neumann H, Cavalie A, Jenne DE, Wekerle $\mathrm{H}$. Induction of MHC class I genes in neurons. Science 1995; 269: 549-552.

206. Neumann H, Medana IM, Bauer J, Lassmann H. Cytotoxic T lymphocytes in autoimmune and degenerative CNS diseases. Trends Neurosci. 2002; 25: 313-319. 
207. Neumann H, Schmidt H, Cavalie A, Jenne D, Wekerle H. Major histocompatibility complex (MHC) class I gene expression in single neurons of the central nervous system: differential regulation by interferon (IFN)-gamma and tumor necrosis factor (TNF)-alpha. J.Exp.Med. 1997; 185: 305-316.

208. Newman TA, Woolley ST, Hughes PM, Sibson NR, Anthony DC, Perry VH. T-celland macrophage-mediated axon damage in the absence of a CNS-specific immune response: involvement of metalloproteinases. Brain 2001; 124: 2203-2214.

209. Nimmerjahn A, Kirchhoff F, Helmchen F. Resting microglial cells are highly dynamic surveillants of brain parenchyma in vivo. Science 2005; 308: 1314-1318.

210. Nitsch R, Pohl EE, Smorodchenko A, Infante-Duarte C, Aktas O, Zipp F. Direct impact of $T$ cells on neurons revealed by two-photon microscopy in living brain tissue. J.Neurosci. 2004; 24: 2458-2464.

211. Nusbaum AO, Tang CY, Buchsbaum MS, Wei TC, Atlas SW. Regional and global changes in cerebral diffusion with normal aging. AJNR Am.J.Neuroradiol. 2001; 22: 136142.

212. Nussler AK, Renia L, Pasquetto V, Miltgen $F$, Matile $H$, Mazier D. In vivo induction of the nitric oxide pathway in hepatocytes after injection with irradiated malaria sporozoites, malaria blood parasites or adjuvants. Eur.J.Immunol. 1993; 23: 882-887.

213. Oertle $T$, van der Haar ME, Bandtlow CE et al. Nogo-A inhibits neurite outgrowth and cell spreading with three discrete regions. J.Neurosci. 2003; 23: 5393-5406.

214. Oleszak EL, Chang JR, Friedman H, Katsetos CD, Platsoucas CD. Theiler's virus infection: a model for multiple sclerosis. Clin.Microbiol.Rev. 2004; 17: 174-207.

215. Otterbein LE, Bach FH, Alam J et al. Carbon monoxide has anti-inflammatory effects involving the mitogen-activated protein kinase pathway. Nat.Med. 2000; 6: 422-428.

216. Pedraza LT, Roth GA, Cumar FA. Identification as synapsin of a synaptosomal protein immunoreacting with anti-myelin basic protein antiserum. J.Neurochem. 1988; 51: 413-420. 
217. Peterson JW, Bo L, Mork S, Chang A, Trapp BD. Transected neurites, apoptotic neurons, and reduced inflammation in cortical multiple sclerosis lesions. Ann.Neurol. 2001; 50: $389-400$.

218. Pfaffl MW. A new mathematical model for relative quantification in real-time RT-PCR. Nucleic Acids Res. 2001; 29: e45.

219. Philippidis P, Mason JC, Evans BJ et al. Hemoglobin scavenger receptor CD163 mediates interleukin-10 release and heme oxygenase-1 synthesis: antiinflammatory monocyte-macrophage responses in vitro, in resolving skin blisters in vivo, and after cardiopulmonary bypass surgery. Circ.Res. 2004; 94: 119-126.

220. Piani D, Fontana A. Involvement of the cystine transport system xc- in the macrophage-induced glutamate-dependent cytotoxicity to neurons. J.Immunol. 1994; 152: 35783585.

221. Piani D, Frei K, Pfister HW, Fontana A. Glutamate uptake by astrocytes is inhibited by reactive oxygen intermediates but not by other macrophage-derived molecules including cytokines, leukotrienes or platelet-activating factor. J.Neuroimmunol. 1993; 48: 99104.

222. Polazzi E, Gianni T, Contestabile A. Microglial cells protect cerebellar granule neurons from apoptosis: evidence for reciprocal signaling. Glia 2001; 36: 271-280.

223. Polfliet MM, Fabriek BO, Daniels WP, Dijkstra CD, van den Berg TK. The rat macrophage scavenger receptor CD163: expression, regulation and role in inflammatory mediator production

2. Immunobiology 2006; 211: 419-425.

224. Portiansky EL, Barbeito CG, Gimeno EJ, Zuccolilli GO, Goya RG. Loss of NeuN immunoreactivity in rat spinal cord neurons during aging

2. Exp.Neurol. 2006; 202: 519-521.

225. Prineas JW, Barnard RO, Kwon EE, Sharer LR, Cho ES. Multiple sclerosis: remyelination of nascent lesions. Ann.Neurol. 1993; 33: 137-151. 
226. Privat A, Jacque C, Bourre JM, Dupouey P, Baumann N. Absence of the major dense line in myelin of the mutant mouse "shiverer". Neurosci.Lett. 1979; 12: 107-112.

227. Raivich G, Banati R. Brain microglia and blood-derived macrophages: molecular profiles and functional roles in multiple sclerosis and animal models of autoimmune demyelinating disease. Brain Res.Brain Res.Rev. 2004; 46: 261-281.

228. Raivich G, Jones LL, Kloss CU, Werner A, Neumann H, Kreutzberg GW. Immune surveillance in the injured nervous system: T-lymphocytes invade the axotomized mouse facial motor nucleus and aggregate around sites of neuronal degeneration. J.Neurosci. 1998; 18: 5804-5816.

229. Rasmussen S, Wang $Y$, Kivisakk $P$ et al. Persistent activation of microglia is associated with neuronal dysfunction of callosal projecting pathways and multiple sclerosis-like lesions in relapsing--remitting experimental autoimmune encephalomyelitis. Brain 2007; 130: 2816-2829.

230. Rausch M, Hiestand P, Baumann D, Cannet C, Rudin M. MRI-based monitoring of inflammation and tissue damage in acute and chronic relapsing EAE. Magn Reson.Med. 2003; 50: 309-314.

231. Redford EJ, Kapoor R, Smith KJ. Nitric oxide donors reversibly block axonal conduction: demyelinated axons are especially susceptible. Brain 1997; 120 ( Pt 12): 2149-2157.

232. Reizis $B$, Mor $F$, Eisenstein $M$ et al. The peptide binding specificity of the MHC class II I-A molecule of the Lewis rat, RT1.BI. Int.Immunol. 1996; 8: 1825-1832.

233. Ritter M, Buechler C, Kapinsky M, Schmitz G. Interaction of CD163 with the regulatory subunit of casein kinase II (CKII) and dependence of CD163 signaling on CKII and protein kinase C. Eur.J.Immunol. 2001; 31: 999-1009.

234. Ritter M, Buechler C, Langmann T, Orso E, Klucken J, Schmitz G. The scavenger receptor CD163: regulation, promoter structure and genomic organization. Pathobiology 1999; 67: 257-261. 
235. Roberts ES, Masliah E, Fox HS. CD163 identifies a unique population of ramified microglia in HIV encephalitis (HIVE). J.Neuropathol.Exp.Neurol. 2004; 63: 1255-1264.

236. Robinson GA. Axotomy-induced regulation of c-Jun expression in regenerating rat retinal ganglion cells. Brain Res.Mol.Brain Res. 1995; 30: 61-69.

237. Rose JW, Hill KE, Wada $Y$ et al. Nitric oxide synthase inhibitor, aminoguanidine, reduces inflammation and demyelination produced by Theiler's virus infection. J.Neuroimmunol. 1998; 81: 82-89.

238. Roth J, Vogl T, Sorg C, Sunderkotter C. Phagocyte-specific S100 proteins: a novel group of proinflammatory molecules. Trends Immunol. 2003; 24: 155-158.

239. Ryter SW, Kim HP, Hoetzel A et al. Mechanisms of cell death in oxidative stress. Antioxid.Redox.Signal. 2007; 9: 49-89.

240. Sanders P, De Keyser J. Janus faces of microglia in multiple sclerosis. Brain Res.Rev. 2007; 54: 274-285.

241. Sasaki S, Shibata N, Komori T, Iwata M. iNOS and nitrotyrosine immunoreactivity in amyotrophic lateral sclerosis. Neurosci.Lett. 2000; 291: 44-48.

242. Scapagnini G, D'Agata V, Calabrese $\vee$ et al. Gene expression profiles of heme oxygenase isoforms in the rat brain. Brain Res. 2002; 954: 51-59.

243. Schaer DJ, Alayash AI, Buehler PW. Gating the radical hemoglobin to macrophages: the anti-inflammatory role of CD163, a scavenger receptor. Antioxid.Redox.Signal. 2007; 9: 991-999.

244. Schaer DJ, Boretti FS, Hongegger A et al. Molecular cloning and characterization of the mouse CD163 homologue, a highly glucocorticoid-inducible member of the scavenger receptor cysteine-rich family. Immunogenetics 2001; 53: 170-177.

245. Schipper HM. Heme oxygenase expression in human central nervous system disorders. Free Radic.Biol.Med. 2004; 37: 1995-2011. 
246. Schroeter M, Stoll G, Weissert R, Hartung HP, Lassmann H, Jander S. CD8+ phagocyte recruitment in rat experimental autoimmune encephalomyelitis: association with inflammatory tissue destruction

1. Am.J.Pathol. 2003; 163: 1517-1524.

247. Sedgwick JD, Schwender S, Imrich H, Dorries R, Butcher GW, ter M, V. Isolation and direct characterization of resident microglial cells from the normal and inflamed central nervous system. Proc.Natl.Acad.Sci.U.S.A 1991; 88: 7438-7442.

248. Shine HD, Readhead C, Popko B, Hood L, Sidman RL. Morphometric analysis of normal, mutant, and transgenic CNS: correlation of myelin basic protein expression to myelinogenesis. J.Neurochem. 1992; 58: 342-349.

249. Sicher SC, Vazquez MA, Lu CY. Inhibition of macrophage la expression by nitric oxide. J.Immunol. 1994; 153: 1293-1300.

250. Sicotte M, Tsatas O, Jeong SY, Cai CQ, He Z, David S. Immunization with myelin or recombinant Nogo-66/MAG in alum promotes axon regeneration and sprouting after corticospinal tract lesions in the spinal cord. Mol.Cell Neurosci. 2003; 23: 251-263.

251. Skulina C, Schmidt S, Dornmair K et al. Multiple sclerosis: brain-infiltrating CD8+ T cells persist as clonal expansions in the cerebrospinal fluid and blood. Proc.Natl.Acad.Sci.U.S.A 2004; 101: 2428-2433.

252. Smith AR, Hagen TM. Vascular endothelial dysfunction in aging: loss of Aktdependent endothelial nitric oxide synthase phosphorylation and partial restoration by $(R)$ alpha-lipoic acid. Biochem.Soc.Trans. 2003; 31: 1447-1449.

253. Smith KJ, Lassmann $\mathrm{H}$. The role of nitric oxide in multiple sclerosis. Lancet Neurol. 2002; 1: 232-241.

254. Song SK, Sun SW, Ju WK, Lin SJ, Cross AH, Neufeld AH. Diffusion tensor imaging detects and differentiates axon and myelin degeneration in mouse optic nerve after retinal ischemia. Neuroimage. 2003; 20: 1714-1722. 
255. Song SK, Yoshino J, Le TQ et al. Demyelination increases radial diffusivity in corpus callosum of mouse brain. Neuroimage. 2005; 26: 132-140.

256. Sospedra M, Martin R. Immunology of multiple sclerosis. Annu.Rev.Immunol. 2005; 23: $683-747$.

257. Srinivasan R, Sailasuta N, Hurd R, Nelson S, Pelletier D. Evidence of elevated glutamate in multiple sclerosis using magnetic resonance spectroscopy at $3 \mathrm{~T}$. Brain 2005; 128: 1016-1025.

258. Stenger S, Thuring $\mathrm{H}$, Rollinghoff $\mathrm{M}$, Bogdan $\mathrm{C}$. Tissue expression of inducible nitric oxide synthase is closely associated with resistance to Leishmania major. J.Exp.Med. 1994; 180: 783-793.

259. Sternberger LA, Sternberger NH. Monoclonal antibodies distinguish phosphorylated and nonphosphorylated forms of neurofilaments in situ. Proc.Natl.Acad.Sci.U.S.A 1983; 80: 6126-6130.

260. Stidworthy MF, Genoud S, Suter U, Mantei N, Franklin RJ. Quantifying the early stages of remyelination following cuprizone-induced demyelination. Brain Pathol. 2003; 13: 329-339.

261. Stocker R, Yamamoto Y, McDonagh AF, Glazer AN, Ames BN. Bilirubin is an antioxidant of possible physiological importance. Science 1987; 235: 1043-1046.

262. Sun D, Whitaker JN, Huang $Z$ et al. Myelin antigen-specific CD8+ T cells are encephalitogenic and produce severe disease in C57BL/6 mice. J.Immunol. 2001; 166: 7579-7587.

263. Sun SW, Liang HF, Trinkaus K, Cross AH, Armstrong RC, Song SK. Noninvasive detection of cuprizone induced axonal damage and demyelination in the mouse corpus callosum. Magn Reson.Med. 2006; 55: 302-308.

264. Suttner DM, Dennery PA. Reversal of HO-1 related cytoprotection with increased expression is due to reactive iron. FASEB J. 1999; 13: 1800-1809. 
265. Suzuki K, Kikkawa Y. Status spongiosus of CNS and hepatic changes induced by cuprizone (biscyclohexanone oxalyldihydrazone). Am.J.Pathol. 1969; 54: 307-325.

266. Tenhunen R, Marver HS, Schmid R. Microsomal heme oxygenase. Characterization of the enzyme. J.Biol.Chem. 1969; 244: 6388-6394.

267. Thomalla G, Glauche V, Koch MA, Beaulieu C, Weiller C, Rother J. Diffusion tensor imaging detects early Wallerian degeneration of the pyramidal tract after ischemic stroke. Neuroimage. 2004; 22: 1767-1774.

268. Thompson AJ, Kermode AG, Moseley IF, MacManus DG, McDonald WI. Seizures due to multiple sclerosis: seven patients with MRI correlations. J.Neurol.Neurosurg.Psychiatry 1993; 56: 1317-1320.

269. Touil T, Deloire-Grassin MS, Vital C, Petry KG, Brochet B. In vivo damage of CNS myelin and axons induced by peroxynitrite. Neuroreport 2001; 12: 3637-3644.

270. Unal-Cevik I, Kilinc M, Gursoy-Ozdemir Y, Gurer G, Dalkara T. Loss of NeuN immunoreactivity after cerebral ischemia does not indicate neuronal cell loss: a cautionary note 1. Brain Res. 2004; 1015: 169-174.

271. Van Dam AM, Bauer J, Man AHW, Marquette C, Tilders FJ, Berkenbosch F. Appearance of inducible nitric oxide synthase in the rat central nervous system after rabies virus infection and during experimental allergic encephalomyelitis but not after peripheral administration of endotoxin. J.Neurosci.Res. 1995; 40: 251-260.

272. Van Den Heuvel MM, Tensen CP, van As JH et al. Regulation of CD 163 on human macrophages: cross-linking of CD163 induces signaling and activation. J.Leukoc.Biol. 1999; 66: 858-866.

273. van der Laan LJ, Ruuls SR, Weber KS, Lodder IJ, Dopp EA, Dijkstra CD. Macrophage phagocytosis of myelin in vitro determined by flow cytometry: phagocytosis is mediated by CR3 and induces production of tumor necrosis factor-alpha and nitric oxide 1. J.Neuroimmunol. 1996; 70: 145-152. 
274. van der Veen RC. Nitric oxide and T helper cell immunity. Int.Immunopharmacol. 2001; 1: 1491-1500.

275. van der Veen RC, Hinton DR, Incardonna F, Hofman FM. Extensive peroxynitrite activity during progressive stages of central nervous system inflammation. J.Neuroimmunol. 1997; 77: 1-7.

276. Van der GA, Kortekaas M, Hoekstra K, Dijkstra CD, Amor S. The role of anti-myelin (auto)-antibodies in the phagocytosis of myelin by macrophages. J.Neuroimmunol. 1999; 101: 61-67.

277. Vercellino M, Merola A, Piacentino $C$ et al. Altered glutamate reuptake in relapsingremitting and secondary progressive multiple sclerosis cortex: correlation with microglia infiltration, demyelination, and neuronal and synaptic damage. J.Neuropathol.Exp.Neurol. 2007; 66: 732-739.

278. Vercellino M, Plano F, Votta B, Mutani R, Giordana MT, Cavalla P. Grey matter pathology in multiple sclerosis. J.Neuropathol.Exp.Neurol. 2005; 64: 1101-1107.

279. Vodovotz Y, Bogdan C. Control of nitric oxide synthase expression by transforming growth factor-beta: implications for homeostasis. Prog.Growth Factor Res. 1994; 5: 341351.

280. Vodovotz $\mathrm{Y}$, Lucia MS, Flanders $\mathrm{KC}$ et al. Inducible nitric oxide synthase in tanglebearing neurons of patients with Alzheimer's disease. J.Exp.Med. 1996; 184: 1425-1433.

281. Vogl T, Ludwig S, Goebeler M et al. MRP8 and MRP14 control microtubule reorganization during transendothelial migration of phagocytes. Blood 2004; 104: 4260-4268.

282. Wallstrom E, Diener P, Ljungdahl A, Khademi M, Nilsson CG, Olsson T. Memantine abrogates neurological deficits, but not CNS inflammation, in Lewis rat experimental autoimmune encephalomyelitis. J.Neurol.Sci. 1996; 137: 89-96.

283. Weaver LK, Hintz-Goldstein KA, Pioli PA et al. Pivotal advance: activation of cell surface Toll-like receptors causes shedding of the hemoglobin scavenger receptor CD163. J.Leukoc.Biol. 2006; 80: 26-35. 
284. Wegner C, Esiri MM, Chance SA, Palace J, Matthews PM. Neocortical neuronal, synaptic, and glial loss in multiple sclerosis. Neurology 2006; 67: 960-967.

285. Wei XQ, Charles IG, Smith A et al. Altered immune responses in mice lacking inducible nitric oxide synthase. Nature 1995; 375: 408-411.

286. Weiss HA, Millward JM, Owens T. CD8+ T cells in inflammatory demyelinating disease. J.Neuroimmunol. 2007; 191: 79-85.

287. Weissenbock H, Hornig M, Hickey WF, Lipkin WI. Microglial activation and neuronal apoptosis in Bornavirus infected neonatal Lewis rats. Brain Pathol. 2000; 10: 260-272.

288. Werner A, Kloss CU, Walter J, Kreutzberg GW, Raivich G. Intercellular adhesion molecule-1 (ICAM-1) in the mouse facial motor nucleus after axonal injury and during regeneration. J.Neurocytol. 1998; 27: 219-232.

289. Werring DJ, Toosy AT, Clark CA et al. Diffusion tensor imaging can detect and quantify corticospinal tract degeneration after stroke. J.Neurol.Neurosurg.Psychiatry 2000; 69: 269-272.

290. Willis D, Moore AR, Frederick R, Willoughby DA. Heme oxygenase: a novel target for the modulation of the inflammatory response. Nat.Med. 1996; 2: 87-90.

291. Wu QZ, Yang Q, Cate HS et al. MRI identification of the rostral-caudal pattern of pathology within the corpus callosum in the cuprizone mouse model. J.Magn Reson.Imaging 2008; 27: 446-453.

292. Wuerfel J, Tysiak E, Prozorovski T et al. Mouse model mimics multiple sclerosis in the clinico-radiological paradox. Eur.J.Neurosci. 2007; 26: 190-198.

293. Xia ZW, Xu LQ, Zhong WW et al. Heme oxygenase-1 attenuates ovalbumin-induced airway inflammation by up-regulation of foxp3 T-regulatory cells, interleukin-10, and membrane-bound transforming growth factor- 1. Am.J.Pathol. 2007; 171: 1904-1914. 
294. Yen T, Harrison CA, Devery JM et al. Induction of the S100 chemotactic protein, CP10, in murine microvascular endothelial cells by proinflammatory stimuli. Blood 1997; 90: 4812-4821.

295. Zhang J, Piantadosi CA. Mitochondrial oxidative stress after carbon monoxide hypoxia in the rat brain. J.Clin.Invest 1992; 90: 1193-1199.

296. Zhao C, Fancy SP, Kotter MR, Li WW, Franklin RJ. Mechanisms of CNS remyelination--the key to therapeutic advances. J.Neurol.Sci. 2005; 233: 87-91.

297. Zhao C, Li WW, Franklin RJ. Differences in the early inflammatory responses to toxin-induced demyelination are associated with the age-related decline in CNS remyelination

3. Neurobiol.Aging 2006; 27: 1298-1307.

298. Zhu B, Luo L, Moore GR, Paty DW, Cynader MS. Dendritic and synaptic pathology in experimental autoimmune encephalomyelitis. Am.J.Pathol. 2003; 162: 1639-1650.

299. Zwadlo-Klarwasser G, Neubert R, Stahlmann R, Schmutzler W. Influence of dexamethasone on the RM 3/1-positive macrophages in the peripheral blood and tissues of a New World monkey (the marmoset Callithrix jacchus). Int.Arch.Allergy Immunol. 1992; 97: 178-180. 


\section{Anhang}

\subsection{Danksagung}

Mein besonderer Dank gilt

Christine Stadelmann für ihre guten und hilfreichen Ratschläge, die ausgezeichnete Betreuung und Unterstützung meiner Arbeit, für ihre Geduld und ihr Verständnis besonders in den Zeiten als nicht alles rund lief.

Herrn Prof. Dr. D. Doenecke für die Betreuung seitens der biologischen Fakultät und für sein wissenschaftliches Interesse an meiner Arbeit.

Herrn Prof. Dr. T. Pieler für die Bereitschaft das Korreferat zu übernehmen.

Herrn Prof. W. Brück für sein Interesse an meiner Arbeit, den wissenschaftlichen Ratschlägen und Ideen.

Angela, Brigitte, Heidi, Katja und Uta für die Unterstützung bei den Experimenten, vor allem bei den scheinbar nie enden wollenden immunhistochemischen Färbungen, so dass meine Arbeit am Mikroskop nie ausging.

Enrique und Tobias, meinen beiden „Leidensgenossen“ sowie Doron und Christiane für die konstruktiven Diskussionen und Hilfen,

auch allen anderen Kollegen für die gemeinsame Zeit in der Neuropathologie, an die ich mich gerne zurückerinnern werde,

sowie unseren Kooperationspartnern Susann Boretius, Patrik Vollmar und Fred Lühder, durch deren Hilfe manche Ideen erst verwirklicht werden konnten.

Meinen Eltern, die mich immer unterstützt und entscheidend dazu beigetragen haben, dass ich soweit kommen konnte

natürlich auch Marc dafür, dass er so ist, wie er ist. 


\subsection{Veröffentlichungen}

1. Escher A., Merkler D., Brück D., Diem R., Nessler R. and Stadelmann C. Neuronal damage in a rat model of selective autoimmune grey matter inflammation and demyelination (Manuskript in Vorbereitung)

2. Escher A., Nessler S., Merkler D., Boretius S., Brück W., Lühder F., Vollmar P. and Stadelmann C. Combination of Cuprizone-induced demyelination and autoimmune inflammation mimic MS lesion pathology in the mouse corpus callosum (Manuskript in Vorbereitung)

3. Escher A., Boretius S., Nessler S., Merkler D., Brück W., Frahm J. and Stadelmann C. MRI assessment of axonal damage in a model of inflammation and demyelination in the mouse cerebrum (Manuskript in Vorbeibreitung) 


\subsection{Lebenslauf}

persönliche Daten

Angelika Escher

Rastenburger Weg 11

37083 Göttingen

geboren am 22.07.1977

in Augsburg

Schul- und Berufsausbildung

1983 - $1992 \quad$ Grund- und Hauptschule in Affing

$1992-1994$

Ausbildung zur staatlich geprüften Kinderpflegerin

$1994-1995$

Berufsaufbauschule, Erlangung der Fachschulreife

$1995-1997$

Berufsoberschule, Erlangung der

fachgebundenen Hochschulreife

Hochschulstudium

1997 - 05/2002 Biologiestudium an der Universität Bayreuth

1999 Vordiplom

2002

Diplomhauptprüfung: Genetik, Mikrobiologie und Biochemie Titel der Diplomarbeit: „Analyse der Regulation des $h t p G$ -

Gens von Bacillus subtilis“

10/2002 - 06/2003 Wissenschaftliche Mitarbeiterin am Max Delbrück Centrum für molekulare Medizin in Berlin-Buch

10/2003 Wissenschaftliche Mitarbeiterin am Institut für Neuropathologie, der Georg-August-Universität Göttingen 
seit 2007

Dissertation am Institut für Neuropathologie mit dem Titel: Neuroaxonale Schädigung in experimentellen Modellen der multiplen Sklerose

Göttingen, den 26.06.2008 